BNL-107265-2015-IR

\title{
Conversion Preliminary Safety Analysis Report for the NIST Research Reactor
}

\author{
D.J. Diamond, J.S. Baek, A.L. Hanson, L-Y. Cheng, \\ N. Brown, and A. Cuadra
}

December 2014

\begin{abstract}
Nuclear Science and Technology Department
Brookhaven National Laboratory
\end{abstract}

\begin{abstract}
U.S. Department of Energy
National Nuclear Security Administration National Institute of Standards and Technology
\end{abstract}

Notice: This manuscript has been authored by employees of Brookhaven Science Associates, LLC under Contract No. DE-AC02-98CH10886 with the U.S. Department of Energy. The publisher by accepting the manuscript for publication acknowledges that the United States Government retains a non-exclusive, paid-up, irrevocable, world-wide license to publish or reproduce the published form of this manuscript, or allow others to do so, for United States Government purposes. 


\section{DISCLAIMER}

This report was prepared as an account of work sponsored by an agency of the United States Government. Neither the United States Government nor any agency thereof, nor any of their employees, nor any of their contractors, subcontractors, or their employees, makes any warranty, express or implied, or assumes any legal liability or responsibility for the accuracy, completeness, or any third party's use or the results of such use of any information, apparatus, product, or process disclosed, or represents that its use would not infringe privately owned rights. Reference herein to any specific commercial product, process, or service by trade name, trademark, manufacturer, or otherwise, does not necessarily constitute or imply its endorsement, recommendation, or favoring by the United States Government or any agency thereof or its contractors or subcontractors. The views and opinions of authors expressed herein do not necessarily state or reflect those of the United States Government or any agency thereof. 


\section{Conversion Preliminary Safety Analysis Report for the NIST Research Reactor}

Manuscript Completed

December 30, 2014

Prepared by

D.J. Diamond, J.S. Baek, A.L. Hanson, L-Y. Cheng, N. Brown, and A. Cuadra

Nuclear Science \& Technology Department

Brookhaven National Laboratory

Upton, NY 11973

Prepared for:

National Nuclear Security Administration

National Institute of Standards and Technology 



\section{PREFACE}

The NIST Center for Neutron Research (NCNR) is a reactor-laboratory complex providing the National Institute of Standards and Technology (NIST) and the nation with a world-class facility for the performance of neutron-based research. The heart of this facility is the NIST research reactor (aka NBSR); a heavy water moderated and cooled reactor operating at $20 \mathrm{MW}$. It is fueled with high-enriched uranium (HEU) fuel elements. A Global Threat Reduction Initiative (GTRI) program is underway to convert the reactor to low-enriched uranium (LEU) fuel. This program includes the qualification of the proposed fuel, uranium and molybdenum alloy foil clad in an aluminum alloy, and the development of the fabrication techniques.

This report is a preliminary version of the Safety Analysis Report (SAR) that would be submitted to the U.S. Nuclear Regulatory Commission (NRC) for approval prior to conversion. The report follows the recommended format and content from the NRC codified in NUREG-1537, "Guidelines for Preparing and Reviewing Applications for the Licensing of Non-power Reactors," Chapter 18, "Highly Enriched to Low-Enriched Uranium Conversions.” The emphasis in any conversion SAR is to explain the differences between the LEU and HEU cores and to show the acceptability of the new design; there is no need to repeat information regarding the current reactor that will not change upon conversion. Hence, as seen in the report, the bulk of the SAR is devoted to Chapter 4, Reactor Description, and Chapter 13, Safety Analysis.

Although the authors are from Brookhaven National Laboratory, the report could not have been written without the close support of the staff at the NCNR. We thank Sean O'Kelly, Michael Rowe, and Robert Williams for their close collaboration. The authors appreciate the financial support of the National Nuclear Security Administration and the project management of John Stevens and Erik Wilson at Argonne National Laboratory. Thanks also to Lynda Fitz who ably performed all the administrative work for this report. 


\section{TABLE OF CONTENTS}

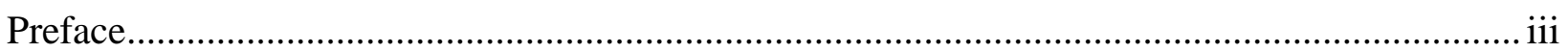

1. GENERAL DESCRIPTION OF THE FACILITY ……………................................. 1

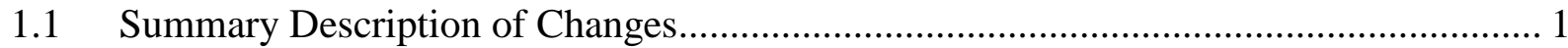

1.1.1 Fuel Element Changes ......................................................................................... 3

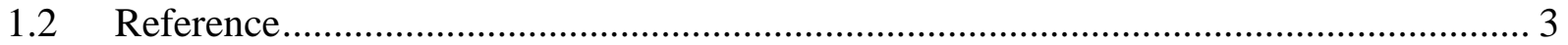

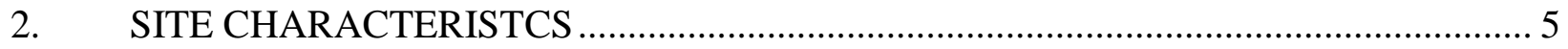

3. DESIGN OF STRUCTURES, SYSTEMS, AND COMPONENTS ………..................... 5

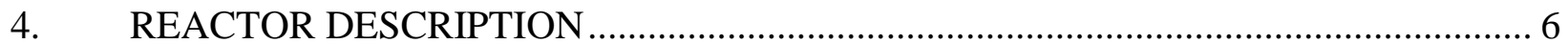

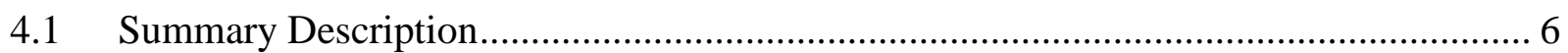

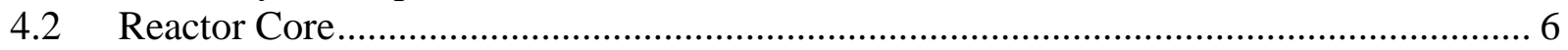

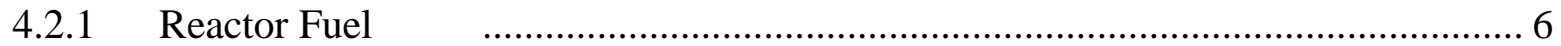

4.2.2 Control Elements ..................................................................................... 11

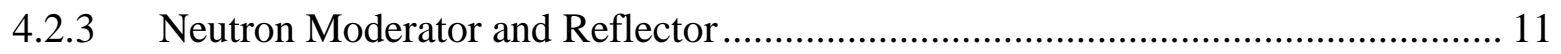

4.2.4 Neutron Startup Source .................................................................................. 11

4.2.5 Core Support Structure …………………........................................................... 12

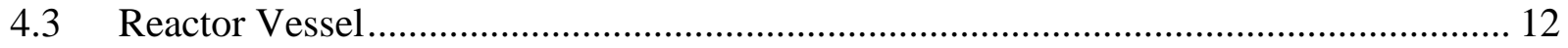

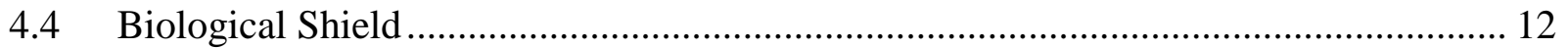

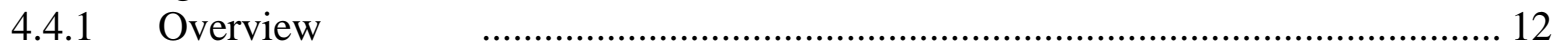

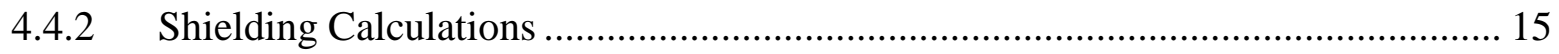

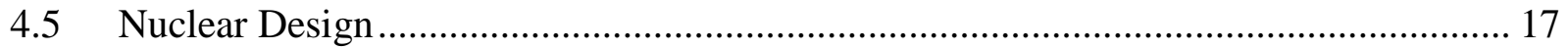

4.5.1 Neutronic and Burn-up Model of the NBSR ........................................................ 18

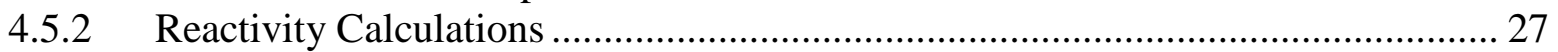

4.5.3 Power Distribution and Energy Spectra Calculations........................................... 35

4.5.4 Reactor Kinetics Parameters ................................................................................. 43

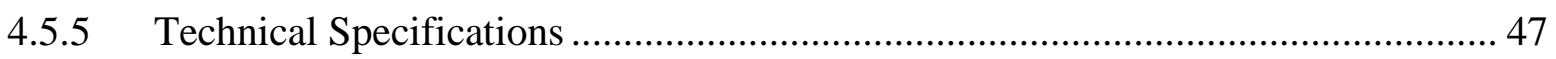

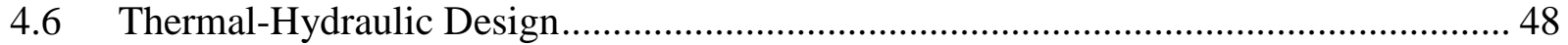

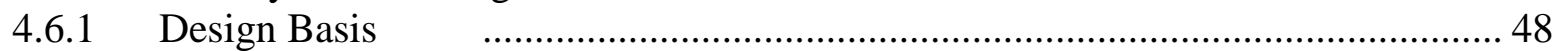

4.6.2 Determination of Limiting Conditions............................................................ 49

4.6.3 Shutdown Cooling .......................................................................................... 54

4.6.4 Operation with Natural Convection ......................................................................... 54

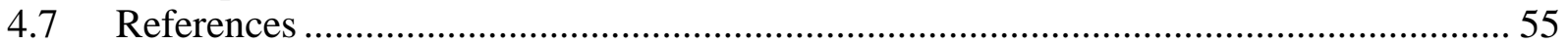

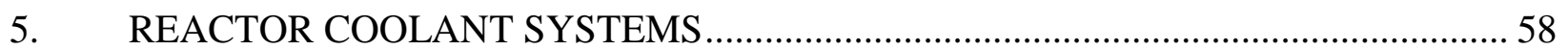

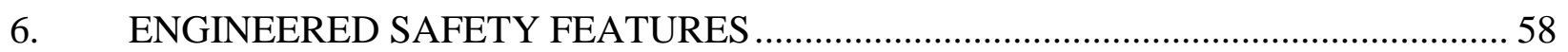

7. INSTRUMENTATION AND CONTROL SYSTEMS .............................................. 58

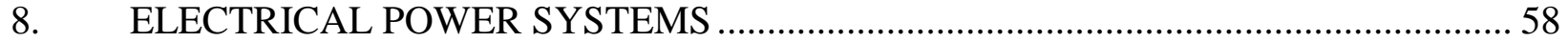

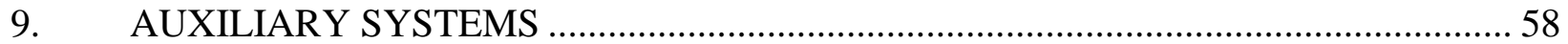

10. EXPERIMENTAL FACILITIES AND UTILIZATION ................................................... 58

11. RADIATION PROTECTION AND RADIOACTIVE WASTE ....................................... 59

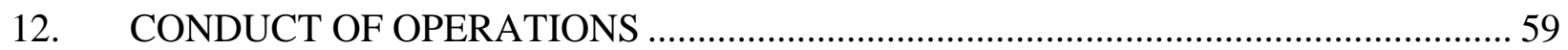

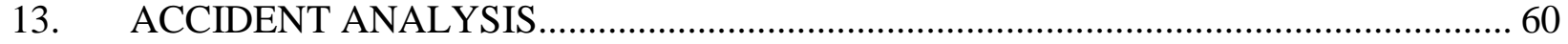

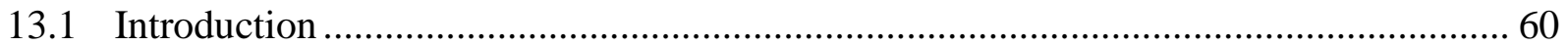

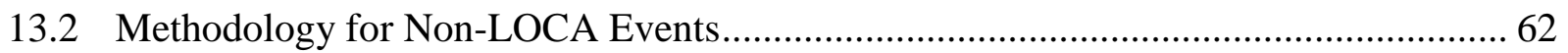

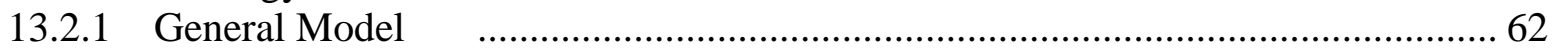

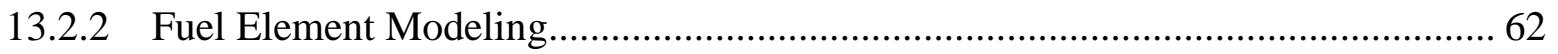




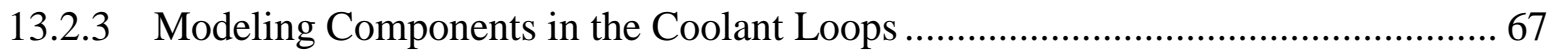

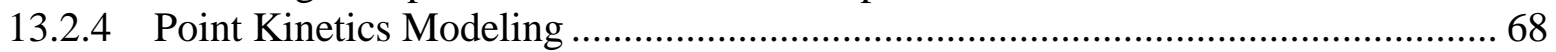

13.2.5 Control Variables and Trips........................................................................... 70

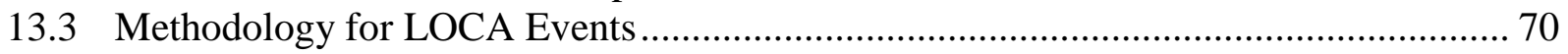

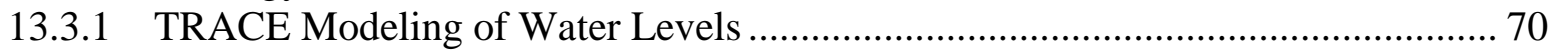

13.3.2 HEATING7.3 Modeling of Heat Conduction........................................................ 74

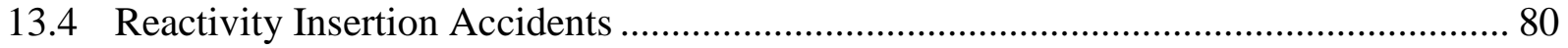

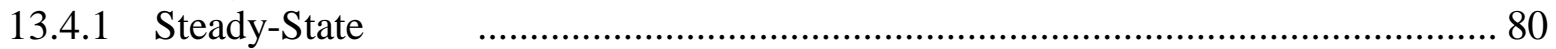

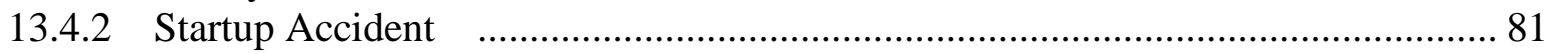

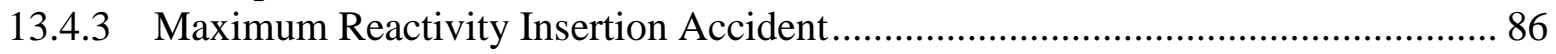

13.4.4 Other Reactivity Insertion Accidents.................................................................... 91

13.4.5 Summary of Reactivity Insertion Accidents ........................................................ 91

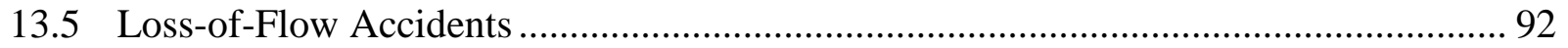

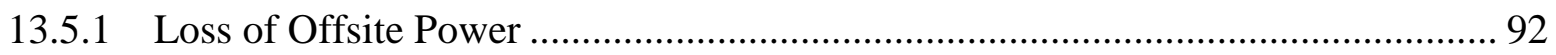

13.5.2 Seizure of One Primary Pump …………….......................................................... 98

13.5.3 Throttling of Coolant Flow to Outer Plenum............................................................. 103

13.5.4 Throttling of Coolant Flow to Inner Plenum ...................................................... 110

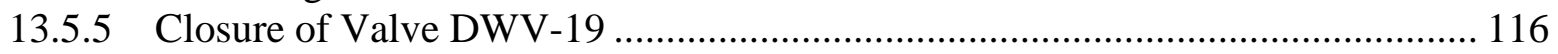

13.5.6 Summary of Loss-of-Flow Accidents .................................................................... 119

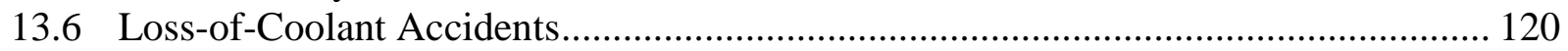

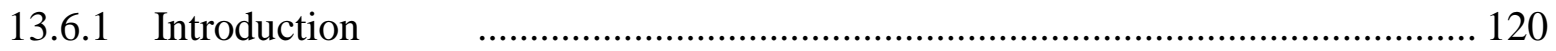

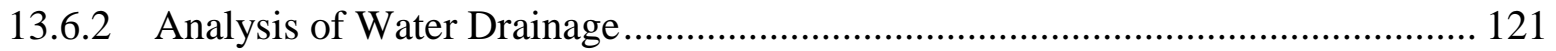

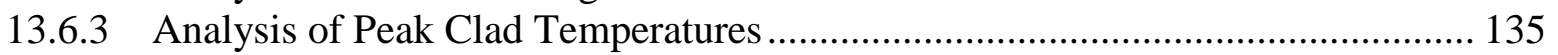

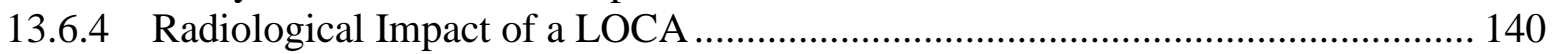

13.6.5 Summary for LOCA Events.................................................................................. 142

13.7 Natural Circulation Cooling at Low Power Operation................................................. 142

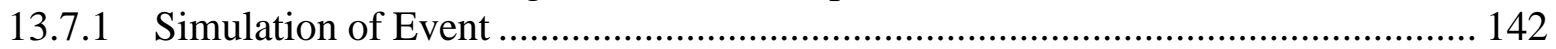

13.7.2 Limiting Parameters .............................................................................................. 143

13.7.3 Natural Circulation Cooling Under Different Conditions ..................................... 145

13.8 Maximum Hypothetical Accident .......................................................................... 146

13.9 Mishandling, Malfunction, or Misloading of Fuel .................................................... 149

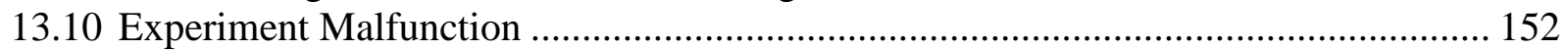

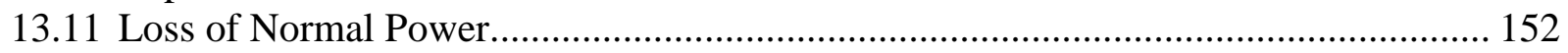

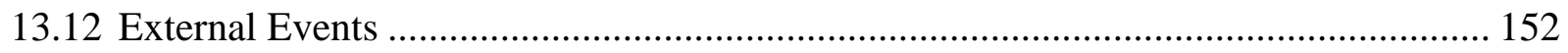

13.13 Summary and Conclusions..................................................................................... 153

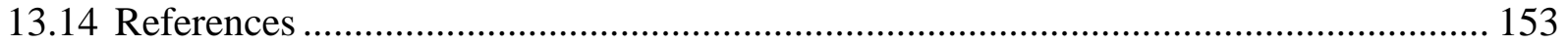

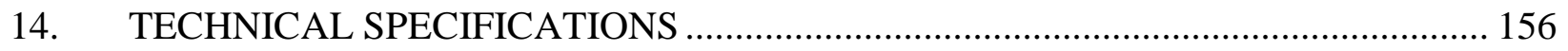

14.1 Fuel Element Design ................................................................................................. 156

14.2 Safety Limits and Limiting Conditions for Operation .................................................. 156

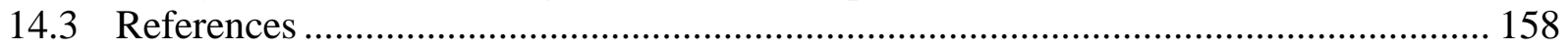

15. OTHER LICENSING CONSIDERATIONS …………................................................ 159 


\section{LIST OF FIGURES}

Figure 1.1 NBSR Vessel Internals and Reactor Core ……........................................................ 2

Figure 4.1 Two Views of NBSR Fuel Element .............................................................. 7

Figure 4.2 Cross Sectional View of Fuel Element....................................................................... 7

Figure 4.3 Fuel Element Position Designation ...................................................................... 10

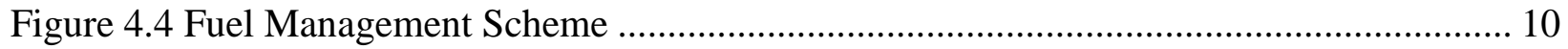

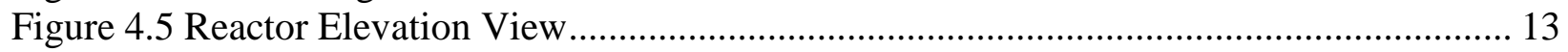

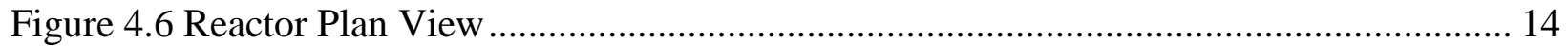

Figure 4.7 Illustration of Mesh Geometry, z-Direction is Out of the Page .................................. 16

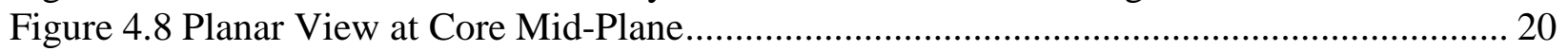

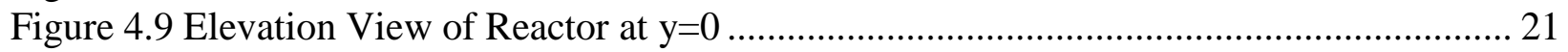

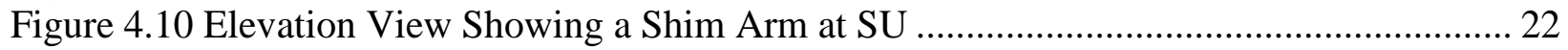

Figure 4.11 Elevation View at y=0 Showing Fuel Elements....................................................... 23

Figure 4.12 Inventory Calculation Flow-Chart........................................................................... 26

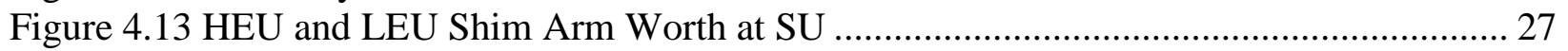

Figure 4.14 HEU and LEU Shim Arm Worth at EOC ................................................................ 27

Figure 4.15 Regulating Rod Worth at SU for HEU and LEU Fuel ............................................... 29

Figure 4.16 Regulating Rod Worth at EOC for HEU and LEU Fuels......................................... 29

Figure 4.17 Elevation View with the Moderator at the Dump Level ............................................ 31

Figure 4.18 Effect of Light Water Ingress on the Value of $k_{\text {eff }}$ at SU ........................................ 34

Figure 4.19 Effect of Light Water Ingress on the Value of $\mathrm{k}_{\mathrm{eff}}$ at EOC ......................................... 34

Figure 4.20 Radial Power Distribution for the HEU Core at SU.................................................... 36

Figure 4.21 Radial Power Distribution for the LEU Core at SU ................................................... 36

Figure 4.22 Radial Power Distribution for the HEU Core at EOC................................................. 37

Figure 4.23 Radial Power Distribution for the LEU Core at EOC ………....................................... 37

Figure 4.24 Plate-Wise Relative Power for FE A-4 at SU ............................................................ 39

Figure 4.25 Plate-Wise Relative Power for FE A-4 at EOC.......................................................... 39

Figure 4.26 Axial Power Distribution for FE A-4 at SU ........................................................ 40

Figure 4.27 Axial Power Distribution for FE A-4 at EOC ………................................................... 40

Figure 4.28 Thermal Neutron Energy Spectra in Gap .................................................................... 41

Figure 4.29 Change (\%) in Thermal Flux within the Gap, LEU vs. HEU...................................... 42

Figure 4.30 Change (\%) in Fast Flux within the Gap, LEU vs. HEU ............................................ 43

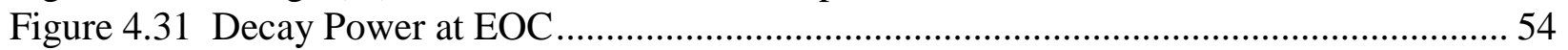

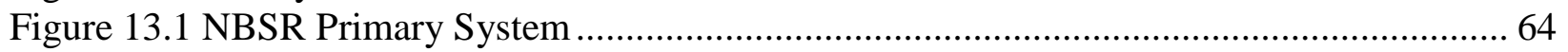

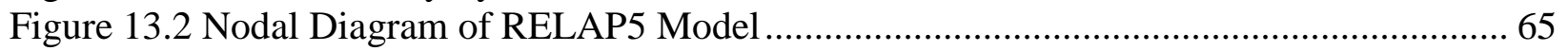

Figure 13.3 Schematic of Coolant Channels of Fuel Elements ...................................................... 66

Figure 13.4 Top-View of Single Coolant Channel with Fuel Plates .............................................. 66

Figure 13.5 Reactivity Worth of Shim Arms at SU with HEU and LEU Fuels .............................69

Figure 13.6 Reactivity Worth of Shim Arms at EOC with HEU and LEU Fuels ........................ 69

Figure 13.7 Nodal Diagram of TRACE Model ................................................................... 71

Figure 13.8 Inner Reserve Tank, Emergency Distribution Pan, and Upper Plenum ..................... 72

Figure 13.9 Emergency Distribution Pan and IRT Water Streams............................................... 73

Figure 13.10 Water Impingement in Mockup Test with Upper Part of Fuel Element ................. 74

Figure 13.11 Fuel Plate (Grey Regions with Fuel Meat Darker Grey) and Side Plates in

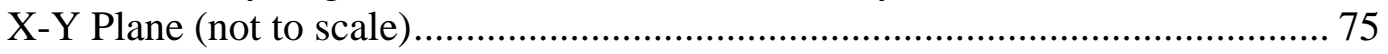


Figure 13.12 Regions of Fuel Plate and Side Plates of Upper Fuel Element in X-Z Plane (not to scale)............................................................................................ 76

Figure 13.13 Regions of Nine Fuel Plates, Side Plates and Outside Plate in X-Y Plane

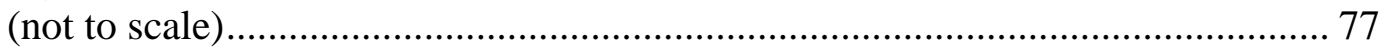

Figure 13.14 Heat Flux as Boundary Condition Applied to Outer Surface of Side Plate .......... 79

Figure 13.15 Reactor Power in Startup Accident .......................................................... 82

Figure 13.16 Clad Temperature in Startup Accident ........................................................ 83

Figure 13.17 Critical-Heat-Flux Ratios in Startup Accident .............................................. 84

Figure 13.18 Onset-of-Flow-Instability Ratio in Startup Accident ....................................... 85

Figure 13.19 Reactor Power in Maximum Reactivity Insertion Accident................................ 87

Figure 13.20 Clad Temperature in Maximum Reactivity Insertion Accident ............................ 88

Figure 13.21 Critical-Heat-Flux Ratio in Maximum Reactivity Insertion Accident ................... 89

Figure 13.22 Onset-of-Flow-Instability Ratio in Maximum Reactivity Insertion Accident ....... 90

Figure 13.23 Primary System Flow after Loss of Offsite Power with LEU Fuel at SU............. 93

Figure 13.24 Reactor Power after Loss of Offsite Power....................................................... 94

Figure 13.25 Clad Temperature after Loss of Offsite Power................................................ 95

Figure 13.26 Critical-Heat-Flux Ratio after Loss of Offsite Power ....................................... 95

Figure 13.27 Onset-of-Flow-Instability Ratio after Loss of Offsite Power............................... 97

Figure 13.28 Primary System Flows after Seizure of One Primary Pump; LEU Fuel at SU ...... 99

Figure 13.29 Reactor Power after Seizure of One Primary Pump ........................................... 99

Figure 13.30 Clad Temperature after Seizure of One Primary Pump...................................... 100

Figure 13.31 Critical Heat Flux Ratio after Seizure of One Primary Pump........................... 101

Figure 13.32 Onset-of-Flow-Instability Ratio after Seizure of One Primary Pump................. 102

Figure 13.33 Primary System Flows after Throttling of Coolant Flow to Outer Plenum;

LEU Fuel at SU........................................................................................ 104

Figure 13.34 Reactor Power after Throttling of Coolant Flow to Outer Plenum .................... 105

Figure 13.35 Clad Temperature after Throttling of Coolant Flow to Outer Plenum ................. 106

Figure 13.36 Mass Flow Rate in Hottest Channel after Throttling of Coolant Flow to Outer Plenum; LEU Fuel at SU ........................................................................ 107

Figure 13.37 Critical Heat Flux Ratio after Throttling of Coolant Flow to Outer Plenum ....... 108

Figure 13.38 Onset-of-Flow-Instability Ratio after Throttling of Coolant Flow to Outer Plenum 109

Figure 13.39 Primary System Flows after Throttling of Coolant Flow to Inner Plenum with LEU Fuel at SU................................................................................ 111

Figure 13.40 Reactor Power after Throttling of Coolant Flow to Inner Plenum..................... 112

Figure 13.41 Clad Temperature after Throttling of Coolant Flow to Inner Plenum................. 112

Figure 13.42 Critical Heat Flux Ratio after Throttling of Coolant Flow to Inner Plenum ........ 114

Figure 13.43 Onset-of-Flow-Instability Ratio after Throttling of Coolant Flow to Inner

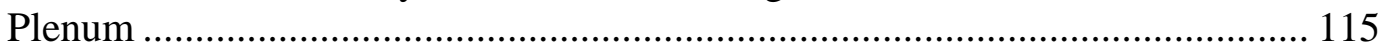

Figure 13.44 Coolant Flowrate at Outlet of Primary Pumps ................................................. 116

Figure 13.45 Reactor Power after Closure of DWV-19 ................................................... 117

Figure 13.46 Clad Temperature after Closure of DMW-19 ................................................. 118

Figure 13.47 CHFR after Closure of DWV-19................................................................ 118

Figure 13.48 OFIR after Closure of DWV-19 ................................................................ 119

Figure 13.49 Mass Flowrate at Guillotine Break Between Vessel Outlet and Control Valve

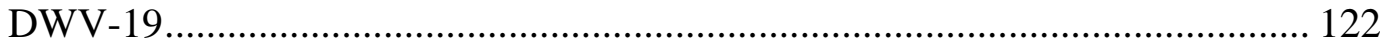


Figure 13.50 Vessel Water Level after GBLOCA Between Vessel Outlet and Control

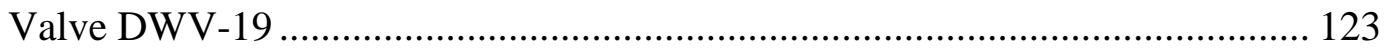

Figure 13.51 End-state of Coolant Inside Vessel after Break at Vessel Outlet ....................... 125

Figure 13.52 Mass Flowrate at Guillotine Break Between Outer Plenum and Control Valve

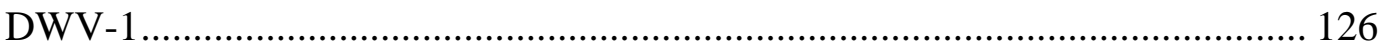

Figure 13.53 Vessel Water Level after Guillotine Break Between Outer Plenum and Control Valve DWV-1

Figure 13.54 Water Level in Fuel Elements after Guillotine Break Between Outer Plenum and Control Valve DWV-1 .................................................................... 128

Figure 13.55 End-state of Coolant after GBLOCA at Inlet Pipes to Outer or Inner Plenums... 130

Figure 13.56 Mass Flowrate at Guillotine Break Between Inner Plenum and Control Valve DWV-2

Figure 13.57 Vessel Water Level after Guillotine Break Between Inner Plenum and Control Valve DWV-2

Figure 13.58 Water Level in Fuel Elements after Guillotine Break Between Inner Plenum and Control Valve DWV-2 ........................................................................ 132

Figure 13.59 End-State of Coolant after SBLOCA at Inlet Pipe to Outer Plenum .................. 134

Figure 13.60 End-State of Coolant after SBLOCA at Inlet Pipe to Inner Plenum .................... 135

Figure 13.61 Peak Clad Temperature with Uniform Film Thickness $(0.1 \mathrm{~cm})$ after

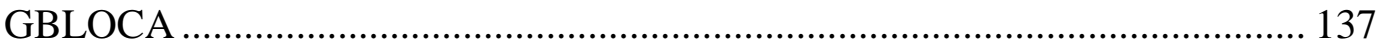

Figure 13.62 LEU Clad Temperature at Film after GBLOCA …......................................... 138

Figure 13.63 Peak Clad Temperature with Reduced Film $(0.04 \mathrm{~cm})$ on Side Plate and Partial Cooling of $9^{\text {th }}$ Plate 140

Figure 13.64 Natural Circulation Coolant Velocities inside Core at Low Power .................... 143

Figure 13.65 Clad Temperature for Natural Circulation Cooling at Low Power Operation ..... 144

Figure 13.66 CHFR for Natural Circulation Cooling at Low Power..................................... 145

Figure 13.67 Radial Power Distribution with Fresh HEU FE in the F3 Position...................... 151

Figure 13.68 Radial Power Distribution with Fresh LEU FE in the H3 Position..................... 151 


\section{LIST OF TABLES}

Table 1.1 Fuel Element Changes ................................................................................. 4

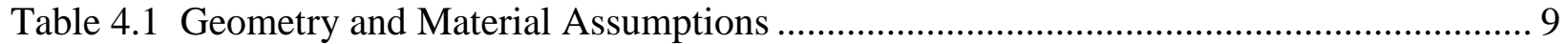

Table 4.2 Fast Neutron Flux Ratio (LEU/HEU) at Startup .................................................... 17

Table 4.3 Fast Neutron Flux Ratio (LEU/HEU) at End-of-Cycle ........................................... 17

Table 4.4 Summary of Core Nuclear Parameters ................................................................. 18

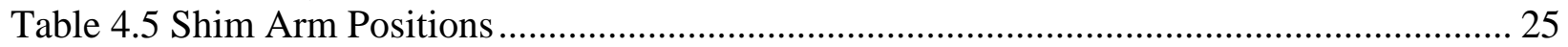

Table 4.6 Total Shim Arm Worth $(\% \Delta \mathrm{k} / \mathrm{k})$ Calculated for the HEU and LEU Fuels ................. 28

Table 4.7 Total Regulating Rod Worth $(\% \Delta \mathrm{k} / \mathrm{k})$ Calculated for the HEU and LEU Fuels.......... 28

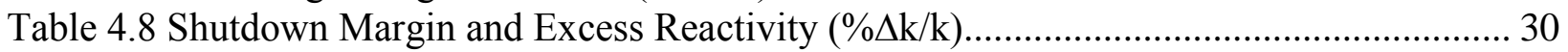

Table 4.9 Value of $\mathrm{k}_{\mathrm{eff}}$ with Moderator at the Dump Level................................................... 31

Table 4.10 Moderator Temperature Coefficient $\left(\% \Delta \mathrm{k} / \mathrm{k} /{ }^{\circ} \mathrm{C}\right)$............................................... 32

Table 4.11 Void Coefficient ( $\% \Delta \mathrm{k} / \mathrm{k} /$ liter) for Voiding Specific Areas in the Core .................... 33

Table 4.12 Reactivity Insertion $(\% \Delta \mathrm{k} / \mathrm{k})$ from Flooding the Beam Tubes ................................ 33

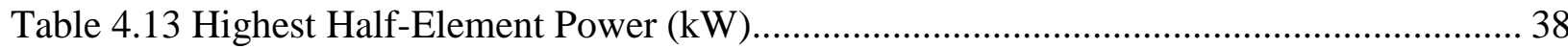

Table 4.14 Power (MW) Generated by the Inner Plenum FEs vs. the Outer Plenum FEs ........... 38

Table 4.15 Percent of Fissions as Calculated by MCNPX .................................................... 44

Table 4.16 Recommended Delayed Neutron Parameters for the HEU and LEU Cores............... 45

Table 4.17 Delayed Neutrons from the ${ }^{2} \mathrm{H}(\gamma, \mathrm{n})^{1} \mathrm{H}$ Nuclear Reaction ........................................ 46

Table 4.18 Prompt Neutron Lifetime for the HEU and LEU Cores ........................................ 47

Table 4.19 Hot Channel Factors and References to Underlying Tolerances ............................ 51

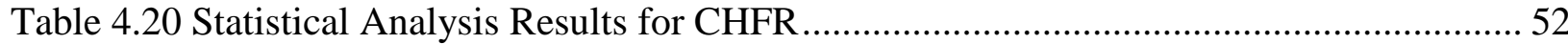

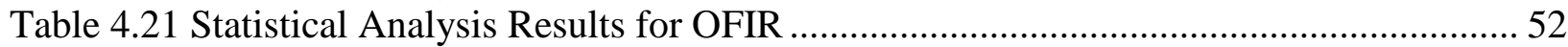

Table 4.22 Steady State Thermal-Hydraulic Parameters ........................................................ 52

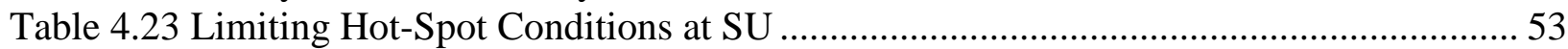

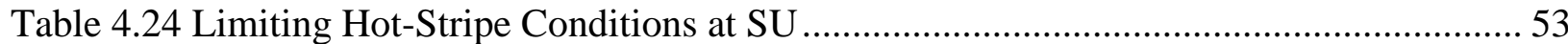

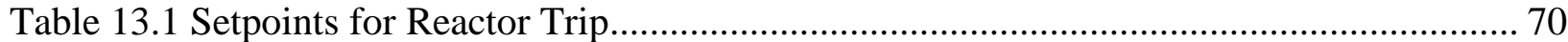

Table 13.2 Regions in X-Y and X-Z Planes for Thin (and Thick) Liquid Film ........................ 75

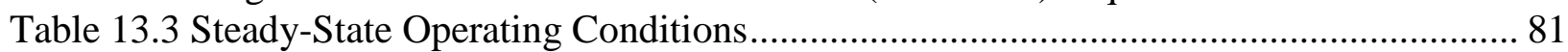

Table 13.4 Reactor Peak Power in Startup Accident ................................................................ 83

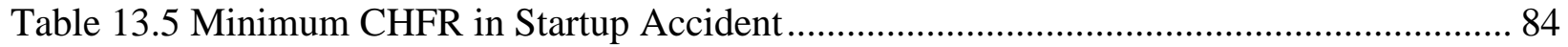

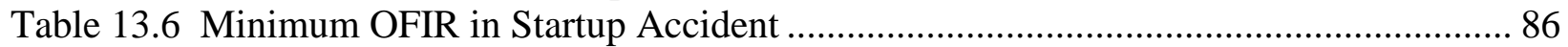

Table 13.7 Minimum CHFR in Maximum Reactivity Insertion Accident ................................. 89

Table 13.8 Minimum OFIR in Maximum Reactivity Insertion Accident ................................. 90

Table 13.9 Minimum CHFR after Loss of Offsite Power ................................................... 96

Table 13.10 Minimum OFIRs after Loss of Offsite Power ................................................... 97

Table 13.11 Minimum CHFR after Seizure of One Primary Pump ......................................... 101

Table 13.12 Minimum OFIR after Seizure of One Primary Pump........................................... 103

Table 13.13 Minimum CHFR after Throttling of Coolant Flow to Outer Plenum.................... 108

Table 13.14 Minimum OFIR after Throttling of Coolant Flow to Outer Plenum ..................... 110

Table 13.15 Minimum CHFR after Throttling of Coolant Flow to Inner Plenum .................... 114

Table 13.16 Minimum OFIR after Throttling of Coolant Flow to Inner Plenum..................... 115

Table 13.17 Break Locations and Sizes................................................................................ 121

Table 13.18 Sequence of Events after Guillotine Break Between Vessel Outlet and

DWV-19 
Table 13.19 Sequence of Events after Guillotine Break Between Outer Plenum and Control

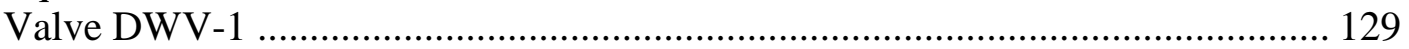

Table 13.20 Sequence of Events After Guillotine Break Between Inner Plenum and Control

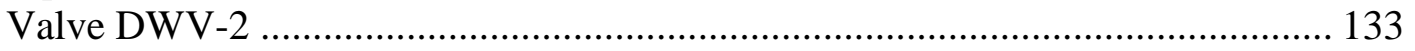

Table 13.24 Activity of I, Kr, and Xe Isotopes in Half-Element.............................................. 147

Table 13.25 Leak Rates to Confinement and Release Rates to Stack ……………....................... 148

Table 13.26 Ten-Minute Dose (TEDE) to NBSR Staff after MHA .......................................... 148

Table 13.27 Dose (TEDE) to an Individual at $400 \mathrm{~m}$ Exclusion Zone after MHA .................... 149

Table 13.28 Maximum Relative Power (RP) for a Misloaded FE .............................................. 150 


\section{GENERAL DESCRIPTION OF THE FACILITY}

\subsection{Summary Description of Changes}

The NBSR is located at the NIST Center for Neutron Research (NCNR) in Gaithersburg, MD on the campus of the National Institute of Standards and Technology (NIST). It is a heavy water $\left(\mathrm{D}_{2} \mathrm{O}\right)$ cooled, moderated, and reflected, tank-type reactor that operates at a design power of 20 MWth. The NBSR is cooled by forced circulation upward through two concentric plenums within the reactor core. There is no pulsing capability in the NBSR. There are thirty fuel elements in the core on a triangular pitch. The fuel elements are split axially into two sections with a gap located between the two at the vertical mid-plane of the core. This gap allows beam tubes to be pointed directly at the mid-plane of the core so that thermal neutrons can escape for use in thermal and cold neutron scattering research while minimizing contamination from fast neutrons and gamma rays. Each half-element encapsulates seventeen curved fuel plates in the materials test reactor (MTR) geometry. The control elements within the NBSR consist of four semaphore-type shim safety arms and a single automatic regulating rod. Figure 1.1 shows a drawing of the vessel internals including the reactor core.

The NBSR is operated for 38.5-day cycles. At the end of each cycle four fuel elements are removed from the core. The remaining 26 fuel elements are moved to new positions and four fresh, unirradiated fuel elements are inserted into the core. Fourteen of the thirty fuel elements are in the core for seven cycles and sixteen fuel elements remain for eight cycles.

The large volume and spacing within the core provides very flexible capabilities for thermal neutron irradiation. Insertion of eight radial beam tubes and two cold neutron sources into the plane of the fuel gap (see Items 4 and 15 in Figure 1.1) allows high intensity, low energy beams of neutrons to be extracted. A pneumatic rabbit system provides researchers with the ability to automatically inject samples into the core region of the reactor while thimbles provide for manual sample loading.

In normal operation the NBSR is cooled by forced convection of the $\mathrm{D}_{2} \mathrm{O}$ coolant; for accidents, there are emergency cooling sources. A large $\mathrm{D}_{2} \mathrm{O}$ hold-up tank and a $\mathrm{D}_{2} \mathrm{O}$ hold-up pan ensure adequate coolant supply in the event of a piping rupture. The inner reserve tank (Item 11 in Figure 1.1) is located in the top reflector and is drained through two non-isolable pipes at the bottom of the tank. These pipes feed a flow distributor that routes emergency cooling to the individual fuel elements. A secondary hold up pan (Item 20 in Figure 1.1) keeps the bottom half of the individual fuel elements immersed in coolant and collects water from the inner reserve tank that splashes out of the distributor pan or runs down the outside of the fuel elements.

There are several $\mathrm{D}_{2} \mathrm{O}$ reflectors in the NBSR. During refueling the top reflector is drained to slightly above the top of the active core. This level is maintained by the low-level overflow pipe that is concentric with the overflow pipe. During abnormal operation, a third overflow pipe, concentric with the fuel transfer chute, serves as a moderator dump to drop the $\mathrm{D}_{2} \mathrm{O}$ level to just above the active core for emergency shutdown. 


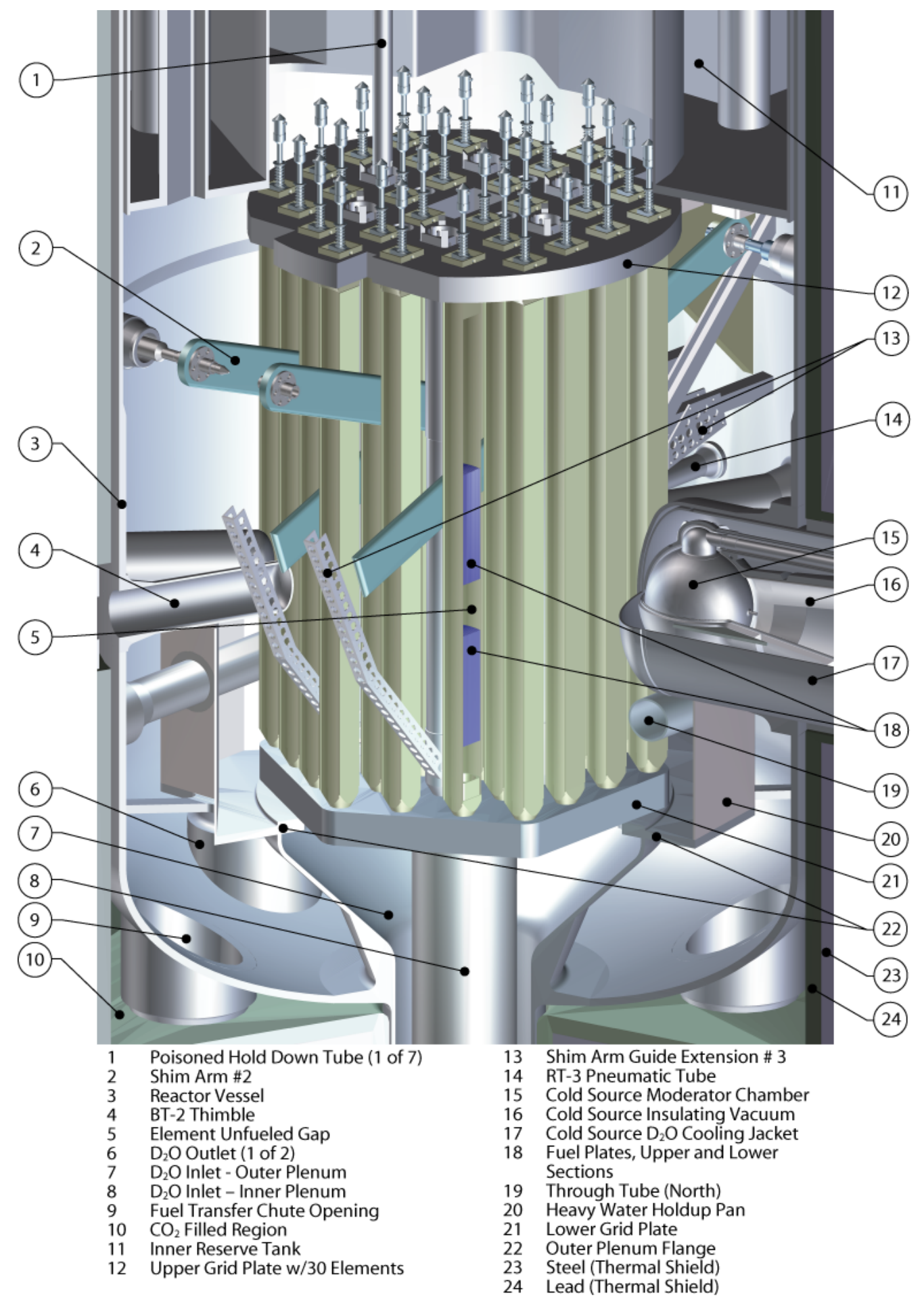

Figure 1.1 NBSR Vessel Internals and Reactor Core 
A complete description of the NBSR reactor and support facility is provided in the current Safety Analysis Report (SAR) (NIST, 2010). The only changes that will be made in the NBSR reactor because of the conversion are the change in the fuel meat composition within the fuel plates, the thickness of the fuel meat and the aluminum cladding, and the introduction of a zirconium layer between the clad and the foil. The external dimensions of the fuel plates remain the same as does the design of the fuel elements and other structures within the vessel. A description of the change in the fuel elements is given below.

\subsubsection{Fuel Element Changes}

Presently the NBSR is fueled with high-enriched uranium (HEU) with a nominal ${ }^{235} \mathrm{U}$ enrichment of $93 \%$. The fuel is $\mathrm{U}_{3} \mathrm{O}_{8}$ in an aluminum powder dispersion that is clad in aluminum alloy. Each fuel element is constructed of 17 plates in each upper and lower half (34 plates per fuel element) and is constructed in the MTR curved plate geometry.

The fuel meat for the low-enriched uranium (LEU) conversion of the NBSR is U10Mo metal alloy foils with aluminum alloy cladding and a $\mathrm{Zr}$ interlayer between the foil and clad. The geometry for the LEU fuel element is identical to the geometry presently used for the HEU fuel with the exception of the thickness of the fuel meat and the clad. Data for the U10Mo fuel are given in Table 1.1 along with data for the existing HEU fuel (Hanson, 2011). The ${ }^{235} \mathrm{U}$ content of each fuel element increases from $350 \mathrm{~g}$ for HEU to $383 \mathrm{~g}$ for LEU. The thickness of the aluminum cladding for the LEU fuel is 0.0208 in $(0.0528 \mathrm{~cm})$ (half the difference between plate thickness and fuel thickness in the table) on each side. This includes the $\mathrm{Zr}$ interlayer which is expected to be 0.001 in $(0.00254 \mathrm{~cm})$ thick.

\subsection{Reference}

Hanson, A.L. and Diamond, D.J., "Calculation of Design Parameters for an Equilibrium LEU Core in the NBSR,” Technical Report, Brookhaven National Laboratory, Upton, NY, September 29, 2011.

NIST, "Safety Analysis Report (SAR) for License Renewal for the National Institute of Standards and Technology Reactor - NBSR; NBSR 14, Rev 4," National Institute of Standards and Technology (NIST), Gaithersburg, MD, 2010. 
Table 1.1 Fuel Element Changes

\begin{tabular}{|l|c|c|}
\hline Property & HEU & LEU \\
\hline${ }^{235}$ U, grams & 350 & 383 \\
\hline${ }^{238}$ U, grams & 26 & 1556 \\
\hline O, grams & 68 & 0 \\
\hline Al, grams & 625 & 0 \\
\hline Mo, grams & 0 & 215 \\
\hline Total grams & 1069 & 2154 \\
\hline & 3.61 & \\
\hline Fuel meat density, g/cm ${ }^{3}$ & $0.020(0.0508)$ & $0.0085(0.0216)$ \\
\hline Fuel thickness, in $\left(\mathrm{cm}^{3}\right.$ & $2.415(6.134)$ & $2.415(6.134)$ \\
\hline Fuel width, in $(\mathrm{cm})$ & $11(27.94)$ & $11(27.94)$ \\
\hline Fuel length, in (cm) & 296.0 & 125.9 \\
\hline Total fuel volume (cm $\left.{ }^{3}\right)$ & & \\
\hline & $13(33.2)$ & $13(33.2)$ \\
\hline Fuel plate length, in (cm) & $2.68(6.8)$ & $2.68(6.8)$ \\
\hline Fuel plate width, in (cm) & $0.0501(0.127)$ & $0.0501(0.127)$ \\
\hline Fuel plate thickness, in (cm) & $5.5(13.97)$ & $5.5(13.97)$ \\
\hline Fuel plate radius of curvature, in (cm) & & \\
\hline & 70 & 60 \\
\hline Average U-235 burnup, \% & & \\
\hline
\end{tabular}




\section{SITE CHARACTERISTCS}

There are no changes to the site characteristics as a result of conversion; information on this subject can be found in the current Safety Analysis Report.

\section{DESIGN OF STRUCTURES, SYSTEMS, AND COMPONENTS}

It is not expected that there will be any changes to principal architectural and engineering design bases for the structures, systems and components of the NBSR as a result of conversion; information on this subject cab be found in the current Safety Analysis Report. 


\section{REACTOR DESCRIPTION}

\subsection{Summary Description}

The NBSR is a heavy water $\left(\mathrm{D}_{2} \mathrm{O}\right)$ cooled, moderated, and reflected, tank-type reactor that operates at a design power of $20 \mathrm{MWth}$. The NBSR is cooled by forced circulation upward through two concentric plenums within the reactor core. There is no pulsing capability in the NBSR. There are thirty fuel elements in the core on a triangular pitch. The fuel elements are split axially into two sections with a mid-plane gap located between the two halves. This midplane gap allows thermal neutrons to be extracted for use in thermal and cold neutron scattering research while minimizing contamination from fast neutrons and gamma rays. Each halfelement encapsulates seventeen curved fuel plates. The control elements within the NBSR consist of four semaphore-type shim safety arms and a single automatic regulating rod. Figure 1.1 shows the vessel internals including the reactor core.

The large volume and spacing within the core provides very flexible capabilities for thermal neutron irradiation. Insertion of eight radial beam tubes and two cold neutron sources into the plane of the fuel gap allows high intensity, low energy beams of neutrons to be extracted. A pneumatic rabbit system provides researchers with the ability to automatically inject samples into the core region of the reactor while thimbles provide for manual sample loading.

A complete description of the NBSR reactor and support facility is provided in the previous Safety Analysis Report (SAR) (NIST, 2010a). The only changes that will be made in the NBSR reactor because of the conversion are: the fuel meat composition within the fuel plates, the thickness of the fuel meat and the aluminum cladding, and the introduction of a zirconium layer between the clad and the fuel meat. The external dimensions of the fuel plates remain the same as does the design of the complete fuel element.

\subsection{Reactor Core}

\subsubsection{Reactor Fuel}

\subsubsection{Fuel Element Description}

Presently, the NBSR is fueled with high-enriched uranium (HEU) with a nominal ${ }^{235} \mathrm{U}$ enrichment of $93 \%$. The fuel meat is $\mathrm{U}_{3} \mathrm{O}_{8}$ in an aluminum powder dispersion that is clad in aluminum alloy. Each fuel element (FE) is constructed of 17 plates in each upper and lower half (34 plates per fuel element) and is constructed in the MTR curved plate geometry. The proposed fuel meat for the low-enriched uranium (LEU) conversion of the NBSR is U10Mo metal foils (10\% Mo by weight) with aluminum alloy cladding. The LEU fuel will have an enrichment of $19.75 \%$. The fuel element geometry for the LEU fuel is identical to the geometry presently used for the HEU fuel with the exception of the thickness of the fuel meat and the clad. Nominal fuel characteristics are given in Table 1.1. Cut-away drawings of the fuel element are in Figure 4.1 and a cross sectional view at the elevation of the fuel plates is given in Figure 4.2. 

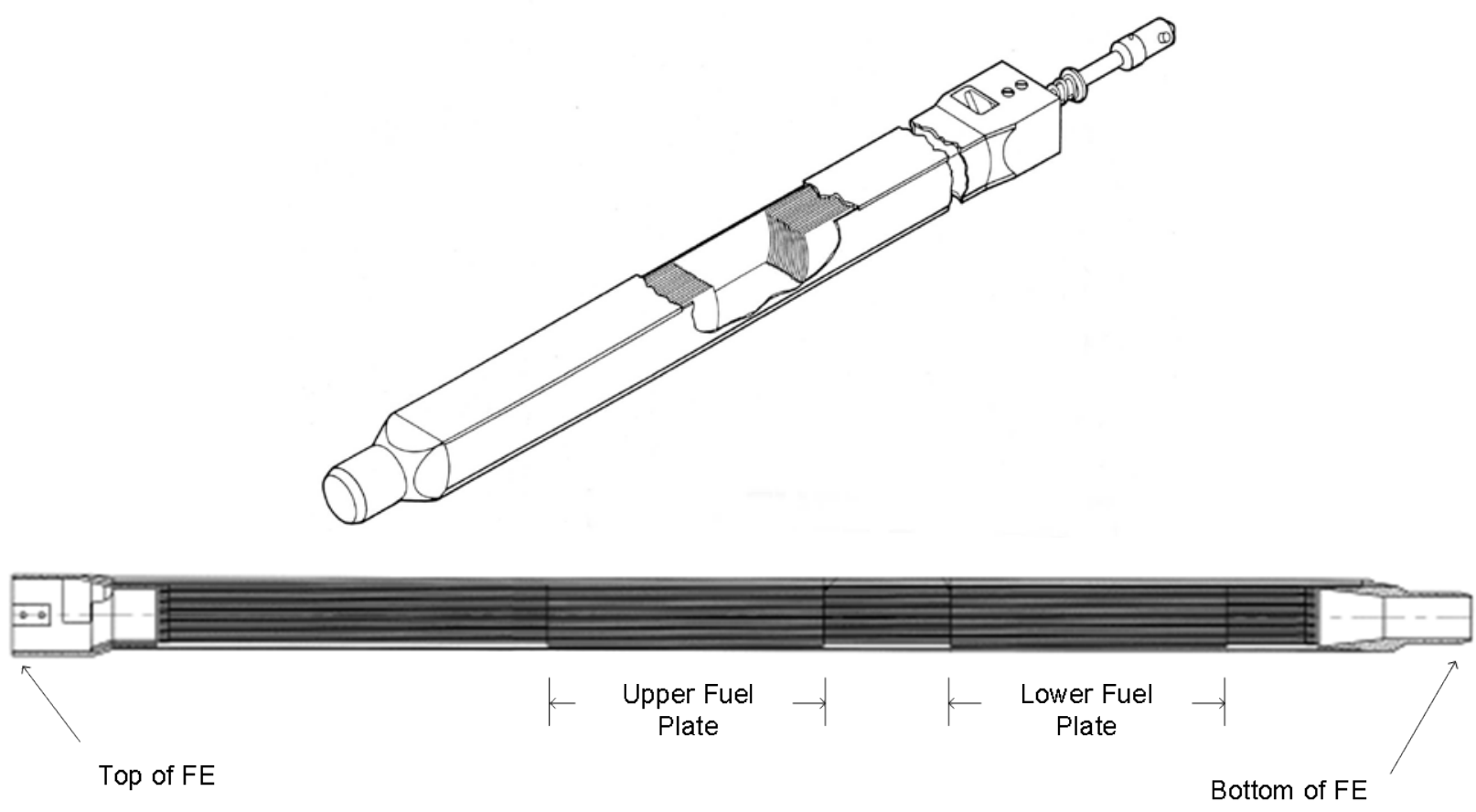

Figure 4.1 Two Views of NBSR Fuel Element

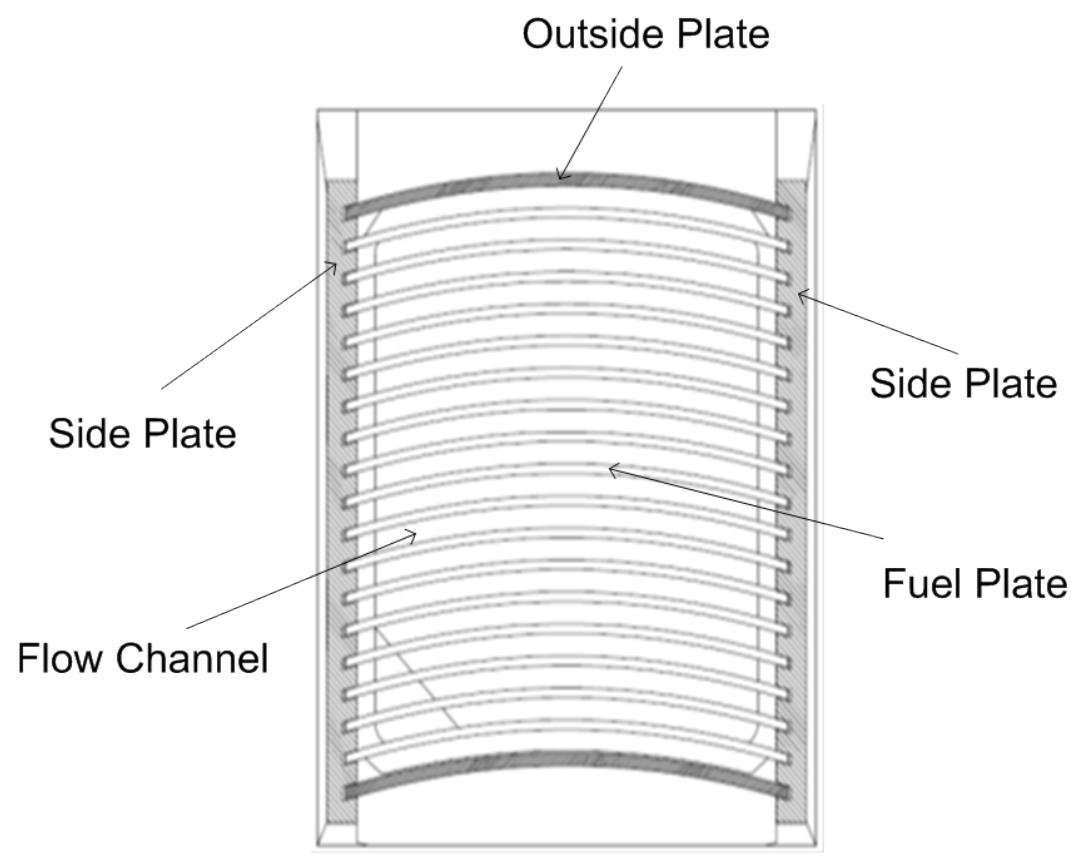

Figure 4.2 Cross Sectional View of Fuel Element 
Table 4.1 shows the fuel element geometry and material assumptions utilized in the safety analysis (SA) for both the HEU and the LEU cores. The source of the information is also given. Tolerances in the table are limiting values. The tolerances or uncertainties in properties come from several sources. The rolling tolerance of the fuel foils is $\pm 0.001 \mathrm{in}$, so the fuel thickness is specified as $0.0085 \pm 0.001 \mathrm{in}$. The ${ }^{235} \mathrm{U}$ content of each LEU fuel plate has an uncertainty based on the uncertainty in the molybdenum content of the LEU fuel--the $10 \%$ weight specification for molybdenum has an uncertainty of $\pm 1 \%$--and the uncertainty in enrichment. There is also an uncertainty in ${ }^{235} \mathrm{U}$ content due to uncertainty in total weight of the foil. Tolerances or uncertainties in geometric quantities for LEU fuel can be assumed to be the same as for the HEU fuel. For material quantities, for example, local fuel loading, the tolerance is expected to be as good as for HEU. However, these are subjective evaluations and may be modified when more is known about fuel fabrication.

There are 30 fuel elements in the core. Six elements are located in the inner core (cooled by flow from the inner plenum) and twenty-four elements in the outer core (cooled by flow from the outer plenum). Figure 4.3 shows the labeling of fuel element positions. The 3.5-inch in-core irradiation thimbles are identified with brackets $(<>)$ and the regulating rod is identified as $<\mathrm{RR}>$. The large cold neutron source (CNS) is also identified on the figure.

In Figure 4.4 each fuel position is identified with two numbers and one letter. The letters are either $\mathrm{E}$ or $\mathrm{W}$ for the east or west side of the core noting that a fuel element always stays in the east side or in the west side of the core. The fuel management scheme allows for 16 fuel elements to stay in the core for eight cycles and 14 to stay in the core for seven cycles. The first number denotes how many cycles the element will be in the core (either eight or seven) and the second number denotes the cycle in which the fuel element resides. Therefore at the beginning of a cycle, the 8-1 and 7-1 fuel elements are unirradiated fuel elements, whereas 8-8 and 7-7 are in their final cycles and will be removed after the cycle is over. After a cycle is finished the 8-8 and 7-7 fuel elements are removed and the 8-7 elements are moved into the 8-8 positions, the 7-6 elements are moved into the 7-7 positions, etc. The process proceeds with unirradiated fuel placed in the 8-1 and 7-1 positions. 
Table 4.1 Geometry and Material Assumptions

\begin{tabular}{|c|c|c|}
\hline Parameter & HEU Specification & LEU Analysis Assumes \\
\hline $\begin{array}{c}\text { Maximum channel } \\
\text { width (at plate center) }\end{array}$ & $116 \pm 7$ mil [1] & $\begin{array}{c}116 \pm 7 \mathrm{mil} \\
\text { (same as HEU) }\end{array}$ \\
\hline Average channel width & 114 mil [2] & $114 \mathrm{mil}$ [2] \\
\hline $\begin{array}{l}\text { Minimum channel } \\
\text { width for SA }\end{array}$ & 107.5 mil [2] & $107.5 \mathrm{mil}[2]$ \\
\hline Plate thickness & $50 \mathrm{mil}[1]$ & 50 mil [3] \\
\hline Clad thickness & 15 mil [1] & $\begin{array}{c}20.8 \mathrm{mil}^{3} \text { (including } 1.0 \pm 0.5 \mathrm{mil} \\
\text { Zr layer [4]) }\end{array}$ \\
\hline $\begin{array}{l}\text { Minimum clad } \\
\text { thickness }\end{array}$ & 10.5 mil, not used in SA [1] & 10.5 mil, not used in SA [5] \\
\hline $\begin{array}{c}\text { Clad scratch maximum } \\
\text { depth }\end{array}$ & $\begin{array}{l}<5 \text { mil (over fuel meat), not } \\
\text { used in SA }\end{array}$ & $\begin{array}{l}<5 \text { mil (over fuel meat), not used } \\
\text { in SA [5] }\end{array}$ \\
\hline $\begin{array}{l}\text { Clad dent maximum } \\
\text { depth }\end{array}$ & $<6$ mil, not used in SA & $<6$ mil, not used in SA [5] \\
\hline Fuel meat & $\mathrm{U}_{3} \mathrm{O}_{8}$ dispersion in $\mathrm{Al}$ & $\begin{array}{l}\text { U10Mo alloy with Mo } 10 \pm 1 \text { w/o } \\
\text { [4] }\end{array}$ \\
\hline Fuel meat thickness & $20 \mathrm{mil}$ & $8.5 \pm 1 \mathrm{mil} \mathrm{[3]}$ \\
\hline U-235 enrichment & $93 \pm 1 \mathrm{w} / \mathrm{o}[1]$ & $19.75 \pm 0.20 \mathrm{w} / \mathrm{o}[4]$ \\
\hline $\begin{array}{l}\text { Average U-235 fuel } \\
\text { loading (plate) }\end{array}$ & $10.294 \pm 0.2 \mathrm{~g}[1]$ & $\begin{array}{c}11.265 \pm 0.24 \mathrm{~g} \text {, based on Mo and } \\
\text { enrichment uncertainties [4] }\end{array}$ \\
\hline Bonding integrity & $\begin{array}{l}\text { Fuel is subjected to blister test at } \\
482 \pm 11^{\circ} \mathrm{C} \text { for at least one hour. }\end{array}$ & $\begin{array}{l}\text { Debond characterization and } \\
\text { tolerances to be determined }\end{array}$ \\
\hline $\begin{array}{l}\text { Local fuel homo- } \\
\text { geneity }\end{array}$ & $112 \%$ of nominal [1] & $112 \%$ of nominal \\
\hline Fission density limit & $\begin{array}{c}<3.1 \mathrm{E} 21 \text { fission/cc } \\
\text { (100\% U-235 burnup) }\end{array}$ & 7.2E21 fission/cc [6] \\
\hline $\begin{array}{l}\text { U-10Mo specific heat; } \\
\text { U10Mo thermal } \\
\text { conductivity }\end{array}$ & Not applicable & $\begin{array}{l}\text { Values provided in [7] and [8]. } \\
\text { Uncertainties are not available or } \\
\text { used in the safety analysis. }\end{array}$ \\
\hline 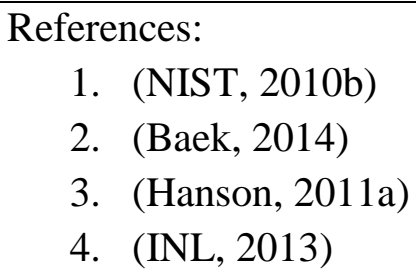 & \multicolumn{2}{|c|}{$\begin{array}{ll}\text { 5. } & \text { (Woolstenhulme, 2012) } \\
\text { 6. } & \text { (Brown, 2014a) } \\
\text { 7. } & \text { (Rest, 2006) } \\
\text { 8. } & \text { (Burkes, 2010) }\end{array}$} \\
\hline
\end{tabular}




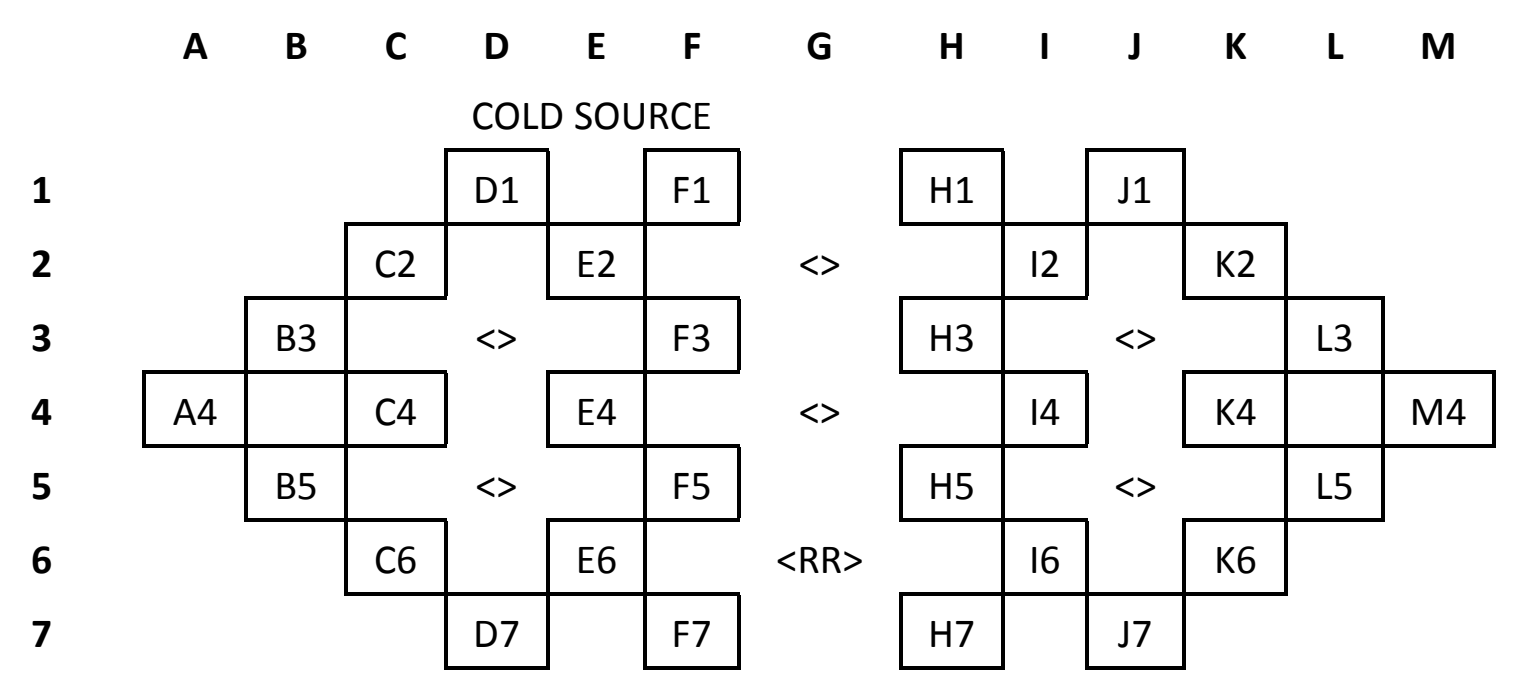

Figure 4.3 Fuel Element Position Designation

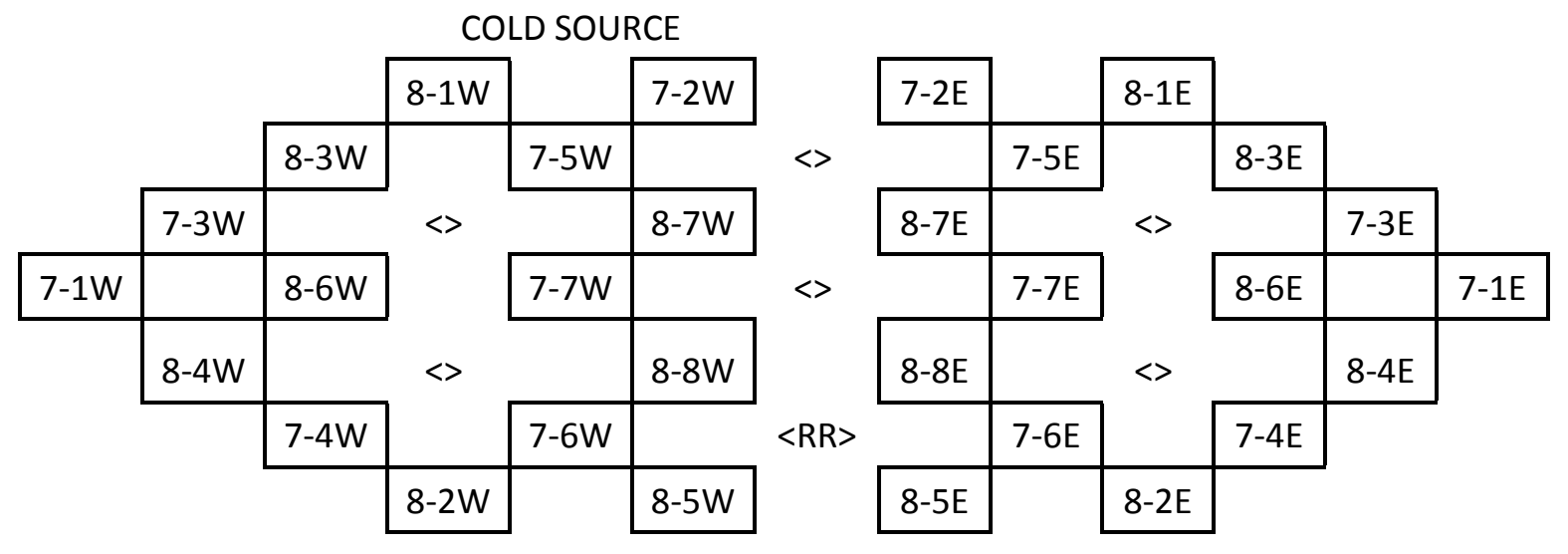

Figure 4.4 Fuel Management Scheme

\subsubsection{Technical Specifications}

There is one technical specification (NIST, 2009) concerning the fuel element design (as opposed to being related to operation). It is given below with the modifications (underlined or with strikeout) necessary to accommodate the LEU fuel. Note that the expectation is that the fuel will be qualified.

Technical Specification 5.3, Reactor Core and Fuel:

1. The $20 \mathrm{MW}$ reactor core may consist of $303.0 \times 3.3$ inch $(7.6 \times 8.4 \mathrm{~cm})$ MTR curved plate-type fuel elements. The NBSR MTR-type fuel elements shall be such that the central 7 inches of the fuel element contains no fuel. The middle 6 inches of the aluminum in the unfueled region of each plate shall have been removed.

2. The side plates, unfueled outer plates, and end adaptor castings of the fuel element shall be aluminum alloy. 
3. The fuel plates shall be $\mathrm{U}_{3} \Theta_{8}$ dispersed in a matrix of aluminum uranium-molybdenum alloy foils clad with aluminum alloy with a zirconium interlayer between foil and clad.

Basis:

1. The neutronic and thermal hydraulic analysis was based on the use of 30 NBSR MTRtype thirty-four (34) plate fuel elements. The NBSR fuel element has a 7 inch centrally located unfueled area, in the open lattice array. The middle 6 inches of aluminum in the unfueled region has been removed. The analysis requires that the fuel be loaded in a specific pattern. Significant changes in core loading patterns would require a recalculation of the power distribution to ensure that the CHFR would be within acceptable limits.

2. and 3. The fuel element with aluminum alloy clad dispersion fuels used in the MTR fuel elements have a 50 year record of reliability at many research reactors. and uraniummolybdenum alloy foils have been qualified for use in the NBSR.

\subsubsection{Fabrication}

LEU fuel fabrication studies are presently underway as part of the GTRI fuel fabrication pillar. Information on LEU fuel fabrication is not yet available.

\subsubsection{Control Elements}

The reactivity control mechanism for the LEU-fueled NBSR will not be changed from the HEUfueled NBSR. The specifications and operating principles of the shim safety arms, regulating rod, and moderator dump will not be changed. The reactivity worth of the shim safety arms, regulating rod, and emergency moderator dump are discussed in Section 0.

\subsubsection{Neutron Moderator and Reflector}

The $\mathrm{D}_{2} \mathrm{O}$ moderator and reflector for the LEU-fueled NBSR will not be changed from the HEUfueled NBSR. There are several $\mathrm{D}_{2} \mathrm{O}$ regions that act as reflectors. The side reflector is $50.8 \mathrm{~cm}$ (20 in) thick and the top reflector is $300 \mathrm{~cm}$ (118 in) thick. During refueling the top reflector is drained to slightly above the top of the active core. This level is maintained by the low-level overflow pipe that is concentric with the overflow pipe. During abnormal operation, a third overflow pipe, concentric with the fuel transfer chute, serves as a moderator dump to drop the $\mathrm{D}_{2} \mathrm{O}$ level to $2.5 \mathrm{~cm}$ ( 1 in) above the active core for emergency shutdown.

\subsubsection{Neutron Startup Source}

The startup source is rarely utilized in the NSBR. In the event that the startup source is used in the LEU core, no changes will be made to the startup source or the startup source insertion procedure used for the HEU core. 


\subsubsection{Core Support Structure}

The core support structure for the LEU-fueled NBSR will not be changed from the HEU-fueled NBSR. The specifications and operating principles of the core support structure will not be changed. The fuel elements are held in place within an upper and lower grid plate. They are locked down against the upper grid plate with a spring loaded pin. When the forced flow is initiated, the force is enough that the fuel elements will lift from the lower grid plate and allow $\sim 4 \%$ of the coolant to bypass the fuel element. This had been verified for HEU fuel and will in the future be verified via testing at Oregon State University for LEU fuel.

\subsection{Reactor Vessel}

The reactor vessel for the LEU-fueled NBSR will not be changed from that for the HEU-fueled NBSR. The specifications and operating principles of the reactor vessel will not be changed.

\subsection{Biological Shield}

The shielding surrounding the NBSR is an integral part of the confinement building, installed during the construction of the building. It was designed originally for 10-MW operation but experience has demonstrated the adequacy of the design for 20 MW. Chapter 10 of (NBS, 1980) contains a description of the design considerations for the construction of the biological shield. The biological shield of the NBSR will not be altered for the conversion to LEU fuel. This section is a summary of its description and an analysis of the potential change, after conversion, of the radiation field that it is designed to protect against.

\subsubsection{Overview}

The biological or bulk shield of heavy concrete surrounds the thermal shield and reduces the radiation that penetrates the thermal shield to insignificant levels, on the order of instrument background, at accessible areas on the shield's face. This requirement is more stringent than that set by personnel exposure limitations.

Figure 4.5 is an elevation view of the reactor showing the biological shield. At the core elevation, the thermal shield, consisting of 2 in $(5 \mathrm{~cm})$ of lead and 8 in $(20 \mathrm{~cm})$ of steel, nearly surrounds the reactor vessel with the exception of penetrations for the beam tubes and the thermal column. This can be seen in the plan view shown in Figure 4.6. A large $\mathrm{D}_{2} \mathrm{O}$ tank on the south side of the core, shown in Figure 4.5 and Figure 4.6 fills an opening in the thermal shield, allowing thermal neutrons entry into the thermal column. The shield, which extends to the top of the vessel and underneath it, is light water cooled. At full power, about $350 \mathrm{~kW}$ is deposited in the thermal shield, preventing the concrete in the biological shield from excessive heating. Calculations (NBS, 1980) of the gamma-ray energy deposition versus depth in the thermal shield show that energy absorption decreases from about $0.6 \mathrm{~W} / \mathrm{cm}^{3}$, in the lead adjacent to the vessel, to $0.03 \mathrm{~W} / \mathrm{cm}^{3}$, at the steel-concrete interface. A major component of the gammaray heating in the biological shield is from high-energy capture gamma rays from neutrons absorbed in the iron. 


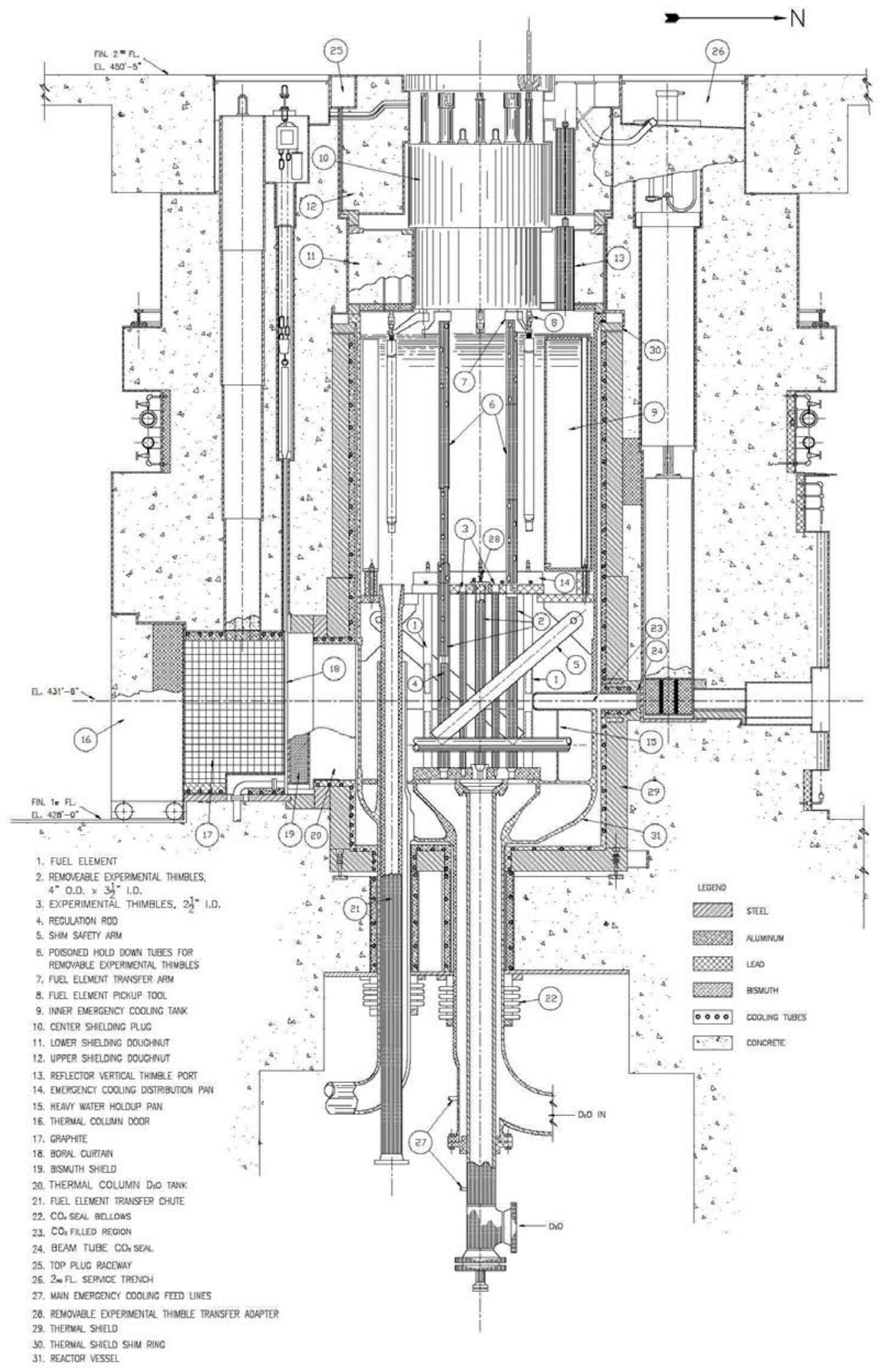

Figure 4.5 Reactor Elevation View 


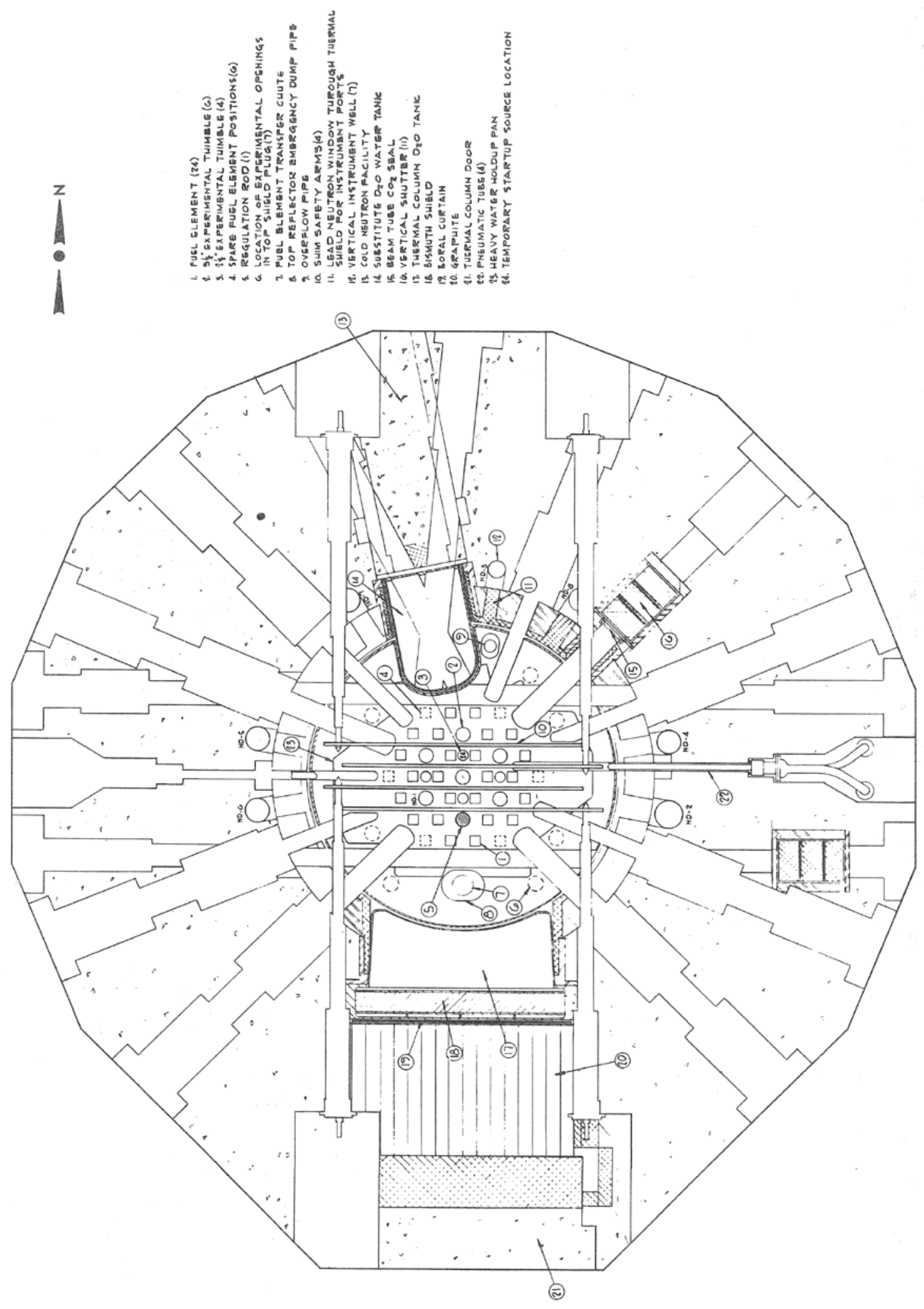

Figure 4.6 Reactor Plan View 
The bulk reactor shield is made of magnetite concrete with a minimum dry density of $240 \mathrm{lb} / \mathrm{ft}^{3}$ $\left(3,844 \mathrm{~kg} / \mathrm{m}^{3}\right)$. Its minimum thickness in the reactor's high-flux central plane region is 74 in $(188 \mathrm{~cm})$. The concrete was formed directly against the thermal shield on the inside and has 0.5 in $(1.3 \mathrm{~cm})$ thick steel faceplates on the outside. The three top plugs are made of stainless steel and filled with 3 in $(7.6 \mathrm{~cm})$ of lead on the bottom in turn covered by magnetite concrete.

\subsubsection{Shielding Calculations}

The HEU-to-LEU conversion of the NBSR requires evaluation of the existing magnetite concrete biological shield surrounding the vessel. The total core power $(20 \mathrm{MW})$ is the same for both the LEU and the HEU core. The power in the core shifts inward for the LEU compared to the HEU core (details are given in Section 4.5.3), so the present shield is not expected to receive as much radiation after conversion to LEU. The entire biological shield is not present in the neutronics model (discussed in Section 4.5.1) of the NBSR, so it is not possible to perform shielding calculations using that model directly. However, a suitable analog exists to evaluate the existing shielding.

The biological shield is required to reduce both neutron and gamma radiation to safe working levels within the reactor building. Almost all of the gamma flux within the biological shield is a direct product of neutron capture within the steel of the thermal shield or the iron in the magnetite concrete. Thus, the gamma ray flux is a secondary source that is proportional to the strength of the primary (neutron) source. Iron has a significant gamma production cross section in the fast energy range. In total, approximately $75 \%$ of the gamma flux in the biological shield is the result of neutron capture in the thermal shield and $25 \%$ of the gamma flux in the biological shield is the result of neutron capture in the biological shield itself (NIST, 2010a). The most significant shielding-related quantity that can be extracted from the existing neutronics model is the fast $(>0.1 \mathrm{MeV})$ neutron flux leaving the NBSR core.

The shielding calculations in the previous SAR (NIST, 2010a) show that the radiation fields exiting the biological shield radially and the top plug, axially, are acceptable for the HEU core. In order to see if this conclusion still holds for the LEU core, the neutron flux on the periphery (outer reflector boundary) of the NBSR core was calculated using a detailed MCNP (LANL, 2008) model of the NBSR for both LEU and HEU fuel. This model is explained in Section 4.5.1. A cylindrical mesh was overlaid on the entire NBSR core with radial mesh points every $10 \mathrm{~cm}$ out to $100 \mathrm{~cm}$, azimuthal mesh points every $36^{\circ}$, and axial meshpoints every $16 \mathrm{~cm}$ from $60 \mathrm{~cm}$ to $100 \mathrm{~cm}$. The volume contained within the radial mesh is shown shaded in Figure 4.7, which shows the origin for the $(r, \theta, z)$ geometry used. (The multiple mesh elements in the r-, $\theta$-, and z-direction do not appear on this figure.) 


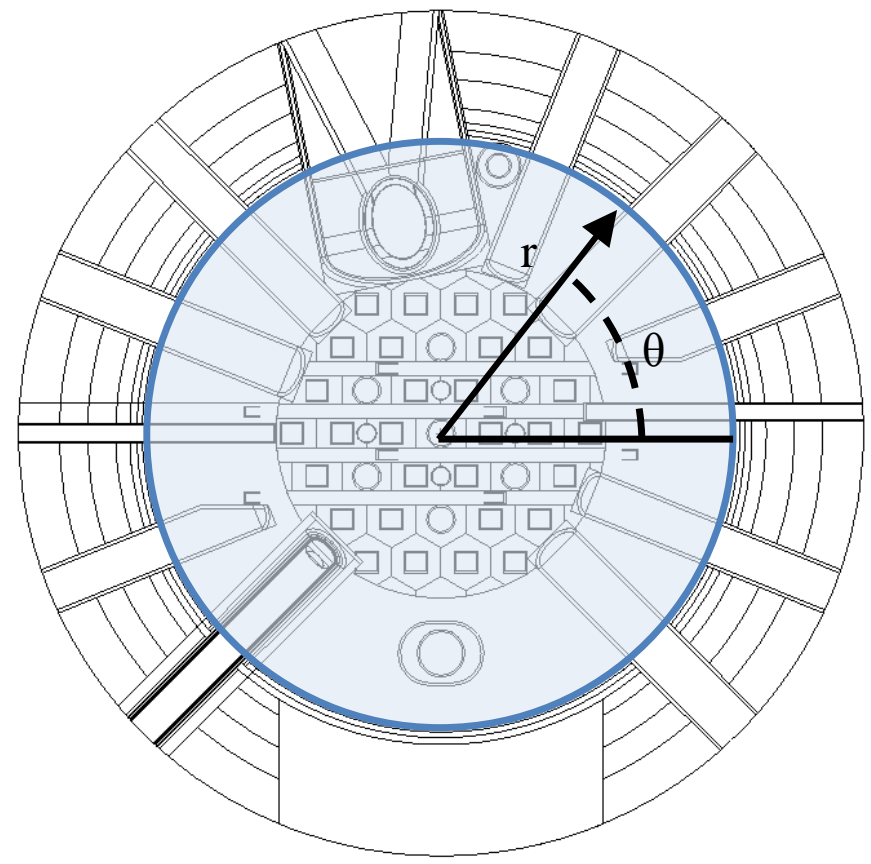

Figure 4.7 Illustration of Mesh Geometry, z-Direction is Out of the Page

Table 4.2 and Table 4.3 show the results of calculations of the ratio of the fast neutron flux in the LEU NBSR to the fast neutron flux in the HEU NBSR at start-up (SU, at the beginning-of-cycle before the buildup of fission products like ${ }^{135} \mathrm{Xe}$ ) and end-of-cycle (EOC) around the periphery of the core. This neutron flux is indicative of the neutron flux entering the biological shield. These tables show the relative flux as a function of the height on the outside surface of the core as well as the azimuthal angle. The coloring indicates whether there is a decrease (green shades) or increase (red shades) in the flux.

The fast flux from the LEU NBSR is almost always lower than the fast flux from the HEU NBSR. In the few mesh elements where the fast flux from the LEU core is higher than the HEU core, the difference is only several percent. This is consistent with the results in Section 4.5.3 that show that the fission distribution (the primary source of fast neutrons) shifts inward in the LEU core. The average decrease, relative to the HEU core, in the fast neutron flux on the periphery of the LEU core is approximately $7 \%$ at both SU and EOC. The gamma ray flux at the outer edge of the biological shield is the result of neutron capture reactions in the thermal shield or within the biological shield itself. Thus, a separate calculation of the gamma ray flux is not warranted since a decrease in the fast neutron flux after conversion will result in a similar decrease in the gamma flux.

From this analysis, the conversion from HEU to LEU should not impact the operability of the biological shield and the radiation fields around the reactor should be similar if not less after conversion than before conversion. 
Table 4.2 Fast Neutron Flux Ratio (LEU/HEU) at Startup

Angle (degrees)

\begin{tabular}{l|llllllllllll|} 
z-cm & 5.0 & 25.9 & 57.7 & 89.5 & 121.4 & 153.2 & 185.0 & 216.8 & 248.6 & 280.5 & 312.3 & 344.1 \\
\hline 63.6 & 0.96 & 0.93 & 0.83 & 0.92 & 0.90 & 0.85 & 0.92 & 0.94 & 1.00 & 0.97 & 1.01 & 0.85 \\
49.1 & 0.95 & 0.91 & 0.83 & 0.93 & 0.93 & 0.93 & 0.96 & 0.96 & 0.97 & 0.99 & 0.93 & 0.91 \\
34.5 & 0.94 & 0.90 & 0.86 & 0.92 & 0.90 & 0.89 & 0.93 & 0.95 & 0.97 & 0.99 & 0.95 & 0.93 \\
20.0 & 0.94 & 0.93 & 0.93 & 0.90 & 0.92 & 0.92 & 0.90 & 0.96 & 0.95 & 1.03 & 0.95 & 0.94 \\
5.5 & 0.91 & 0.92 & 0.91 & 0.91 & 0.91 & 0.93 & 0.93 & 0.96 & 0.98 & 0.97 & 0.96 & 0.96 \\
-9.1 & 0.95 & 0.93 & 0.90 & 0.90 & 0.92 & 0.93 & 0.92 & 0.96 & 0.93 & 0.96 & 0.97 & 0.95 \\
-23.6 & 0.93 & 0.91 & 0.92 & 0.90 & 0.89 & 0.94 & 0.93 & 0.95 & 0.95 & 0.98 & 0.95 & 0.94 \\
-38.2 & 0.90 & 0.90 & 0.90 & 0.91 & 0.90 & 0.93 & 0.92 & 0.95 & 0.96 & 0.96 & 0.97 & 0.92 \\
-52.7 & 1.00 & 0.93 & 0.90 & 0.90 & 0.91 & 0.95 & 0.95 & 0.97 & 0.96 & 0.97 & 0.96 & 0.89 \\
\hline
\end{tabular}

Table 4.3 Fast Neutron Flux Ratio (LEU/HEU) at End-of-Cycle

Angle (degrees)

\begin{tabular}{l|llllllllllll|} 
Z-cm & 5.0 & 25.9 & 57.7 & 89.5 & 121.4 & 153.2 & 185.0 & 216.8 & 248.6 & 280.5 & 312.3 & \multicolumn{2}{l}{344.1} \\
\cline { 2 - 11 } 63.6 & 0.93 & 1.10 & 0.92 & 0.94 & 0.94 & 0.89 & 0.94 & 0.85 & 0.86 & 0.85 & 0.95 & 0.90 \\
49.1 & 1.03 & 0.95 & 0.93 & 0.92 & 0.91 & 0.94 & 0.90 & 0.92 & 0.91 & 0.93 & 0.97 & 0.93 \\
34.5 & 0.89 & 0.88 & 0.90 & 0.91 & 0.90 & 0.93 & 0.95 & 0.98 & 0.93 & 0.96 & 0.94 & 0.94 \\
20.0 & 0.90 & 0.91 & 0.92 & 0.90 & 0.89 & 0.93 & 0.94 & 0.98 & 0.95 & 0.98 & 0.95 & 0.93 \\
5.5 & 0.95 & 0.92 & 0.92 & 0.90 & 0.93 & 0.94 & 0.92 & 0.95 & 0.96 & 0.95 & 0.96 & 0.94 \\
-9.1 & 0.93 & 0.92 & 0.91 & 0.90 & 0.93 & 0.93 & 0.93 & 0.96 & 0.96 & 0.96 & 0.96 & 0.95 \\
-23.6 & 0.91 & 0.92 & 0.87 & 0.91 & 0.91 & 0.92 & 0.94 & 0.94 & 0.94 & 0.98 & 0.94 & 0.93 \\
-38.2 & 0.94 & 0.92 & 0.89 & 0.91 & 0.91 & 0.89 & 0.94 & 0.95 & 0.98 & 0.94 & 0.96 & 0.94 \\
-52.7 & 0.96 & 0.90 & 0.92 & 0.90 & 0.90 & 0.91 & 0.94 & 0.98 & 0.97 & 0.93 & 0.98 & 0.93 \\
\hline
\end{tabular}

\subsection{Nuclear Design}

This section provides a summary description of the methodology used for the nuclear design as well as results for significant parameters. Results are provided for both the HEU and LEU cores to evaluate the effect of conversion. The results are primarily at the SU condition since this is the most reactive point in the cycle and hence, bounding for most analyses. For some parameters results are given for both SU and EOC conditions. The latter state point is bounding in transients for which the rate at which the reactor shuts down is important, since differential shim arm worth 
is lowest when the shim arms are withdrawn at EOC. A summary of the significant parameters, which are explained in this section, is given in Table 4.4 for both the HEU and LEU cores.

Table 4.4 Summary of Core Nuclear Parameters

\begin{tabular}{|c|c|c|}
\hline Parameter & HEU Core & LEU Core \\
\hline Excess reactivity $(\% \Delta \mathrm{k} / \mathrm{k})$ & 6.7 & 6.3 \\
\hline $\begin{array}{l}\text { Shutdown margin with highest worth shim arm (No. 3) } \\
\text { out }(\% \Delta \mathrm{k} / \mathrm{k})\end{array}$ & -10.1 & -10.8 \\
\hline $\mathrm{k}_{\mathrm{eff}}$ with moderator at dump level, SU & 0.9857 & 0.9849 \\
\hline $\mathrm{k}_{\mathrm{eff}}$ with moderator at dump level, EOC & 0.9124 & 0.9215 \\
\hline Shim arm worth, SU $(\% \Delta \mathrm{k} / \mathrm{k})$ & 24.9 & 24.2 \\
\hline Shim arm worth,EOC $(\% \Delta \mathrm{k} / \mathrm{k})$ & 27.2 & 26.0 \\
\hline Regulating rod worth, SU (\% $\Delta \mathrm{k} / \mathrm{k})$ & 0.50 & 0.53 \\
\hline Regulating rod worth, EOC (\% $\% \mathrm{k} / \mathrm{k})$ & 0.45 & 0.43 \\
\hline Moderator temperature coefficient, SU $\left(\% \Delta \mathrm{k} / \mathrm{k} /{ }^{\circ} \mathrm{C}\right)$ & -0.0297 & -0.0280 \\
\hline Moderator temperature coefficient, EOC $\left(\% \Delta \mathrm{k} / \mathrm{k} /{ }^{\circ} \mathrm{C}\right)$ & -0.0275 & -0.0228 \\
\hline Void coefficient, all thimbles voided, SU $(\% \Delta \mathrm{k} / \mathrm{k} / \mathrm{liter})$ & -0.038 & -0.039 \\
\hline Void coefficient, all thimbles voided, EOC $(\% \Delta \mathrm{k} / \mathrm{k} / \mathrm{liter})$ & -0.031 & -0.032 \\
\hline Void coefficient, all FEs voided, SU (\% $\% \mathrm{k} / \mathrm{k} / \mathrm{liter})$ & -0.019 & -0.018 \\
\hline Void coefficient, all FEs voided, EOC $(\% \Delta \mathrm{k} / \mathrm{k} / \mathrm{liter})$ & -0.022 & -0.022 \\
\hline Reactivity insertion for CNS flooded, SU (\% $\Delta \mathrm{k} / \mathrm{k})$ & 0.24 & 0.15 \\
\hline Reactivity insertion for CNS flooded, EOC $(\% \Delta \mathrm{k} / \mathrm{k})$ & 0.25 & 0.15 \\
\hline $\begin{array}{l}\text { Reactivity insertion flooding one tangential BT, SU } \\
(\% \Delta \mathrm{k} / \mathrm{k})\end{array}$ & 0.27 & 0.26 \\
\hline $\begin{array}{l}\text { Reactivity insertion flooding one tangential BT, EOC } \\
(\% \Delta \mathrm{k} / \mathrm{k})\end{array}$ & 0.20 & 0.26 \\
\hline Peak half-element relative power, SU & 1.28 & 1.35 \\
\hline Peak half-element relative power, EOC & 1.18 & 1.15 \\
\hline Peak half-element relative power with misloaded FE & 1.93 & 1.83 \\
\hline Delayed neutron fraction, SU & 0.00665 & 0.00649 \\
\hline Delayed neutron fraction, EOC & 0.00662 & 0.00649 \\
\hline Recommended prompt neutron lifetime, SU ( $\mu$ s) & 650 & 600 \\
\hline Recommended prompt neutron lifetime, EOC $(\mu \mathrm{s})$ & 750 & 700 \\
\hline
\end{tabular}

\subsubsection{Neutronic and Burn-up Model of the NBSR}

The following two sections summarize the neutronics model using Monte Carlo and the burnup algorithm. More information on the methodology is found in (Hanson, 2005a) and (Hanson, 2011b). 


\subsubsection{NBSR Modeling with MCNP}

To assess the safety consequences of the conversion from HEU fuel to LEU fuel a state-of-theart MCNP $^{\mathrm{a}}$ (LANL, 2008) model of the NBSR core has been developed. An earlier version of this model was used with MCNP as the primary reactor physics modeling tool for the NBSR SAR (NIST, 2010a) and was the basic tool to determine the performance of the cold neutron sources in the NBSR. The well-established code MCNPX v.2.7.0 (Pelowitz, 2011) was utilized both to determine the core inventory and to analyze the core neutronics of the NBSR for the current report. The neutronics calculations were used to quantify the impact of the LEU conversion under normal, off-normal, and accident conditions.

MCNPX, which is based on the source code of MCNP4C, is a generalized transport code that extends the capabilities of MCNP to particles other than neutrons and photons. Therefore, MCNPX utilizes many of the features of MCNP, including the capability to define complex heterogeneous problem geometries utilizing nested universes. MCNPX has integrated burn-up calculation capability, so inventories can be calculated directly. The ENDF/B-VII cross section library was used for the analysis.

The three-dimensional (3-D) MCNPX model of the NBSR incorporates the important physical features of the NBSR core. The analyses performed have been shown to be valid by satisfying the constraints imposed, namely, that with the initial and final (fully withdrawn) measured shim arm positions the code gives a multiplication constant $\left(\mathrm{k}_{\mathrm{eff}}\right)$ of unity, within an acceptable uncertainty. In addition, the shim arm worth (see also Section 4.5.2.1) at SU and EOC is (conservatively) calculated to be $\$ 24.9$ and $\$ 27.2$, respectively, whereas the measured value obtained from data over many cycles is $\$ 33.3$ (Williams, 2012) with an estimated uncertainty of $\pm 10 \%$.

A horizontal cross-section of the NBSR core at the mid-plane is shown in Figure 4.8. A vertical cross section (x-z plane using a coordinate system with the same origin as in Figure 4.7) is shown in Figure 4.9 . Elevation views showing a single shim arm and the individual fuel elements, respectively, are shown in Figure 4.10 and Figure 4.11. The major geometric features incorporated in the model include:

- a triangular-pitch array of 30 fuel elements, six vertical thimbles, the moderator dump line, and the fuel transfer chute

- all 1020 fuel plates with explicit cladding, and $\mathrm{D}_{2} \mathrm{O}$-filled coolant channels, positioned in hexahedral repeated structures for the upper and lower halves of the core

- sixty fuel material specifications that represent the upper- and lower-half of each individual fuel element

- the four shim arms and the regulating rod, which can be positioned anywhere between the fully withdrawn and fully inserted (SCRAM) positions

- nine radial beam tubes, two tangential beam tubes, the vertical beam tube, and the four in-core pneumatic 'rabbit' tubes

\footnotetext{
${ }^{a}$ MCNP is the generic name for a series of radiation transport computer codes which has been developed at Los Alamos National Laboratory over the past few decades. Major releases have a single modifier after MCNP and minor releases have a second modifier after it.
} 
- the large cryogenic beam port, the large liquid hydrogen cold source, and the small cold source located in beam tube 9

- the reactor vessel, $\mathrm{D}_{2} \mathrm{O}$ moderator, and the core reflector

- layers of lead and iron outside of the vessel, comprising the thermal shield, and a layer of concrete, for part of the biological shield

- a portion of the $\mathrm{D}_{2} \mathrm{O}$ tank, providing neutronic coupling with the graphite in the thermal column.

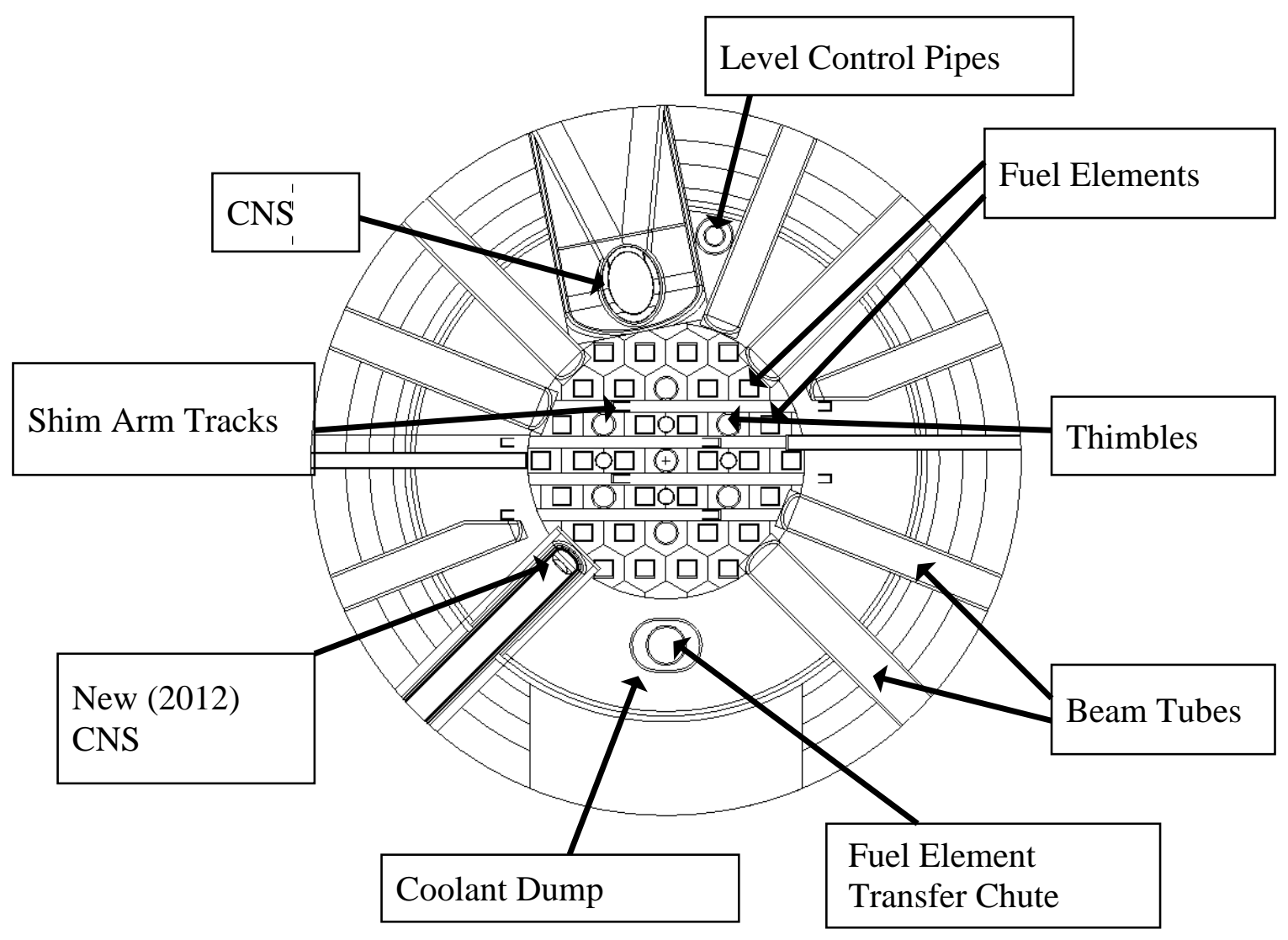

Figure 4.8 Planar View at Core Mid-Plane 


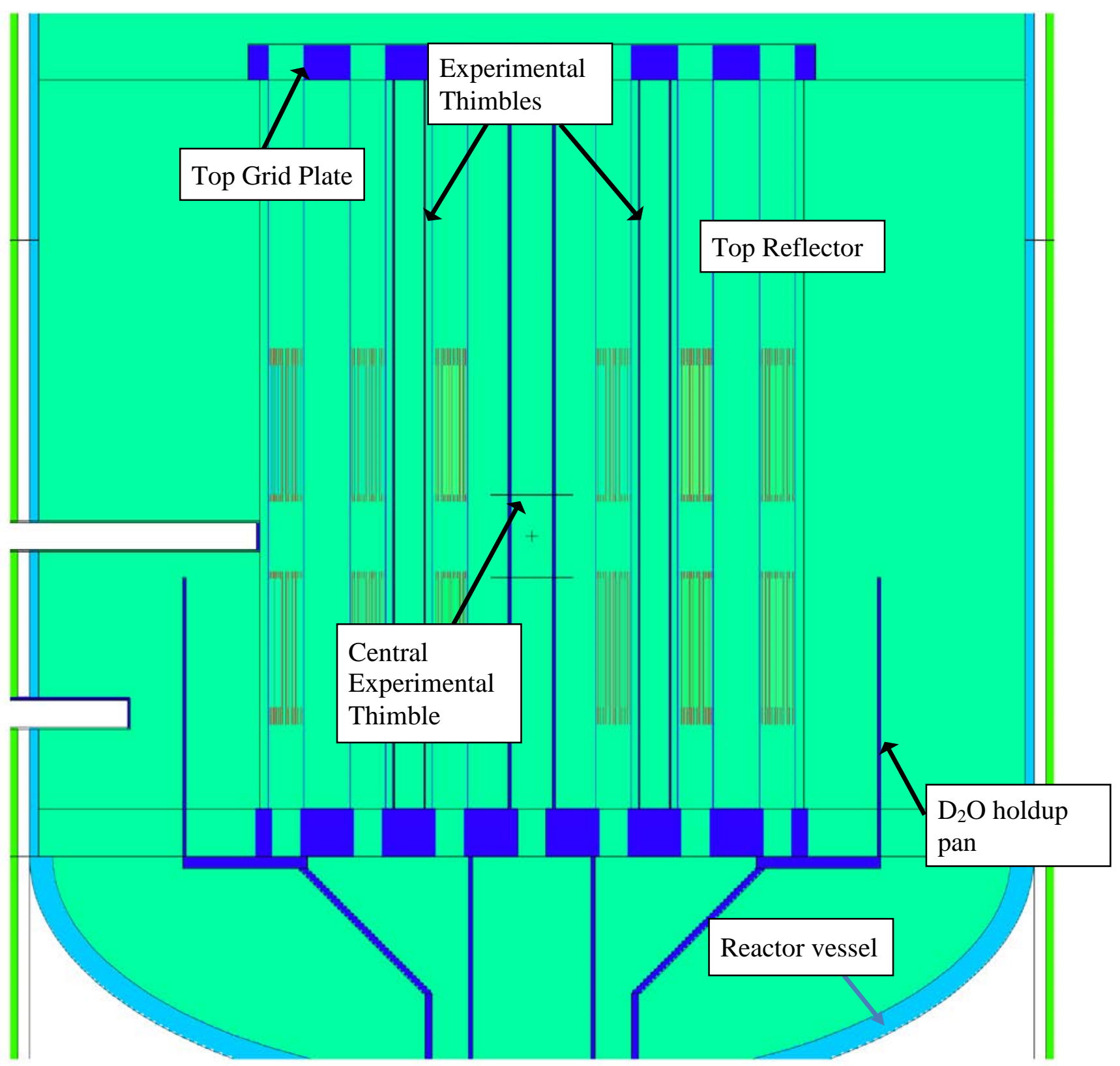

Figure 4.9 Elevation View of Reactor at $y=0$ 


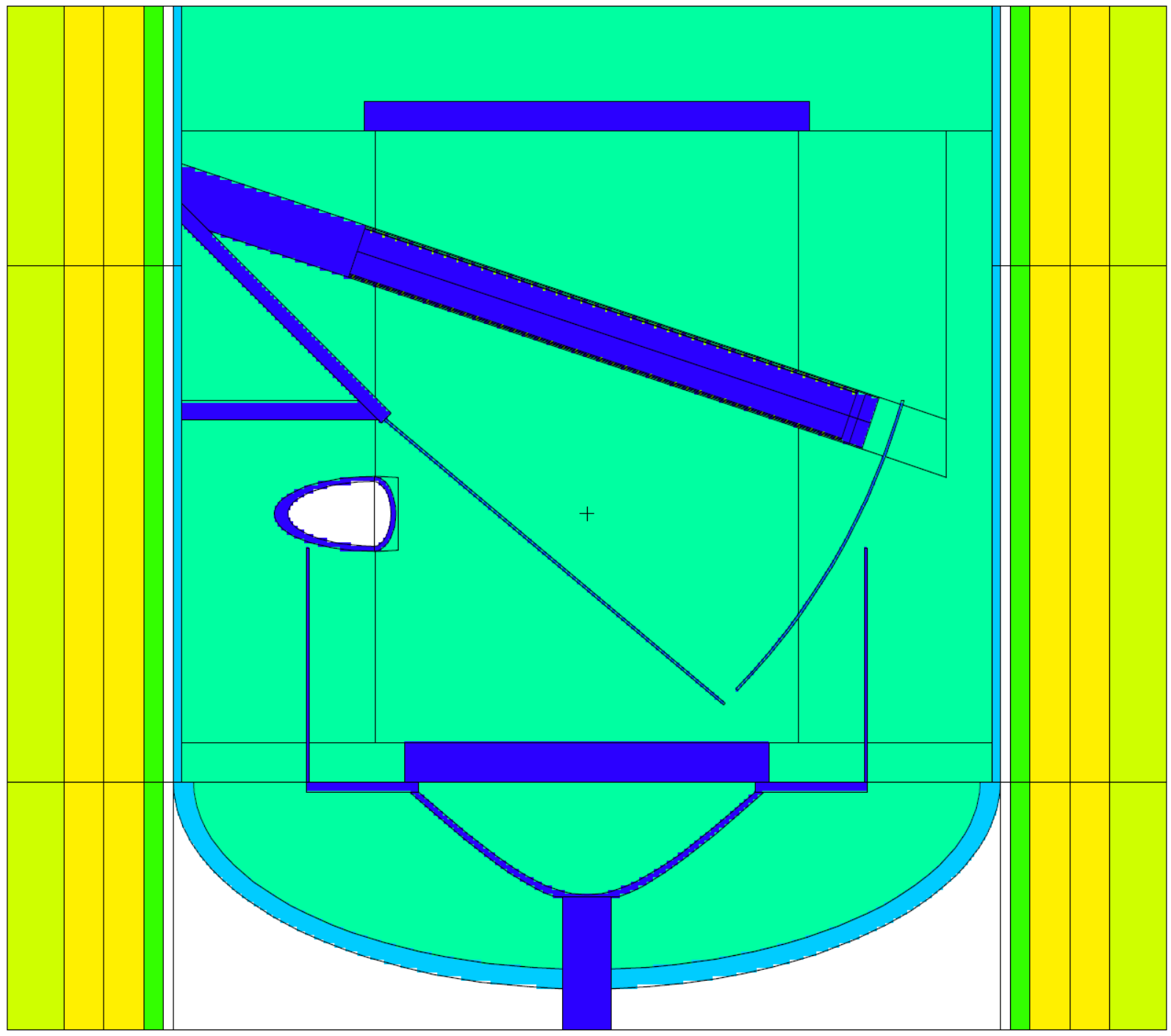

Figure 4.10 Elevation View Showing a Shim Arm at SU 


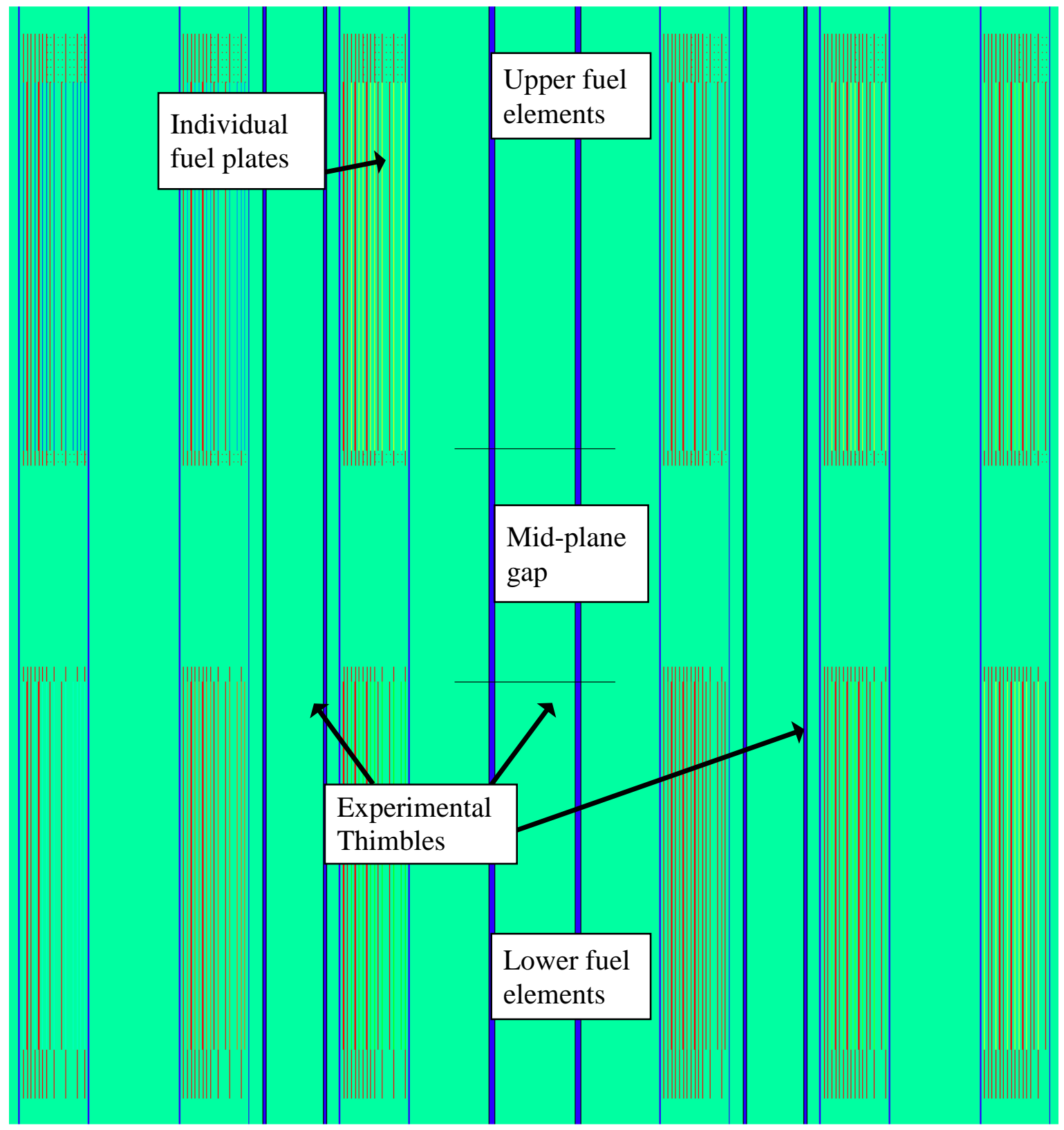

Figure 4.11 Elevation View at $y=0$ Showing Fuel Elements

\subsubsection{Burn-up Model of the NBSR}

MCNPX was utilized for the generation of inventories in the burn-up calculation. MCNPX has incorporated the CINDER'90 code (Wilson, 2008) for solution of the burn-up equations.

Although the burn-up analysis is very sophisticated, several simplifications were necessary. The most significant simplification is that the number of compositions that can be used is limited.

Hence, each upper and lower section of a fuel element was assumed to be a unique homogenized composition resulting in only 60 compositions to track. 
Another limitation is that not every fission product can be included in the inventory. Any isotope that is not present in the library of isotopes is ignored by MCNPX. Additionally, MCNPX does not include any representative (or "lumped") fission product to make up the difference in the fission product mass that is "ignored." MCNPX handles this issue by reducing the mass (and hence the fuel density since the volume is maintained) that is tracked in each material when CINDER'90 returns an isotope that MCNPX does not recognize. When the inventories are generated for subsequent MCNP or MCNPX calculations, the mass of each isotope in each material is extracted and the "missing mass" is calculated. That mass is added to the mass of ${ }^{133} \mathrm{Cs}$, as the "representative fission product" in order to return the total mass of each material back to its original value. The isotope ${ }^{133} \mathrm{Cs}$ was selected since it is a stable fission product that is produced by the fission of all fissionable atoms so it is always present in the inventories of fission products.

The ENDF/B-VII cross section libraries were utilized for the present analysis. The ENDF/B-VII libraries contain more cross section files for fission products than the ENDF/B-VI cross section libraries, which were utilized in the previous SAR (NIST, 2010a). In that SAR, the unaccounted mass was reported to be $\sim 1.2 \%$ per cycle per fuel material. In the present analysis the unaccounted mass is $\sim 0.13 \%$ per cycle per fuel material. The greatest number of fission products that were generated for the inventories in the previous SAR was 54. In the present analysis 181 fission products were generated.

The first step of the burn-up calculation is to calculate inventories with the NBSR model using MCNPX with 60 materials, each material representing one half of a fuel element, and a 38.5-day cycle. This cycle length has been determined to be the most desirable from the point of view of both operations staff and experimentalists. The burn-up analyses were performed to obtain inventories at four different state points at fixed times during a single cycle. Each state point was represented by the same standard NBSR model with two minor modifications: (1) the shim arms are in different positions from the previous state point and, (2) the initial inventory is extracted from the previous burnup interval.

The four state points used for the analysis were start-up (SU), beginning-of-cycle (BOC), middle-of-cycle (MID), and end-of-cycle (EOC). The SU core has fresh fuel in four locations and the short-lived fission product poisons, such as ${ }^{135} \mathrm{Xe}$, in the previously irradiated fuel have decayed away during the refueling period since the end of the previous cycle. In the BOC core, all the short-lived fission products, including ${ }^{135} \mathrm{Xe}$, are at equilibrium concentrations. BOC occurs approximately 1.5 days into a new cycle. During that initial 1.5-day period, the shim arms move $\sim 5^{\circ}$. EOC is the point at which the shim arms are completely removed and the MID point is halfway between BOC and EOC. The shim arm angles for each of the state points are shown in Table 4.5. For the generation of the inventories, three models are used with the shim arms placed halfway between those four positions (also shown in Table 4.5). After each step the inventory is extracted, adjusted for the unaccounted mass, normalized to unity weight fraction, and inserted into the subsequent model. In all cases the regulating rod is placed at 50\% withdrawn.

The flow chart for the methodology to calculate the inventories is shown in Figure 4.12. The determination of the SU inventory is different from the other inventories. At the end of the 
cycle, the fuel is allowed to decay for 10.5 days, the typical refueling period. The inventories for the 7-7 and 8-8 fuel elements are deleted. The other fuel elements are shifted according to the fuel management scheme shown in Figure 4.4, and fresh, unirradiated fuel elements are inserted into the 7-1 and 8-1 positions.

Table 4.5 Shim Arm Positions

\begin{tabular}{|l|c|c|c|}
\hline & $\begin{array}{c}\text { Days into } \\
\text { Cycle }\end{array}$ & $\begin{array}{c}\text { Angle from } \\
\text { Horizontal } \\
\text { (degrees) }\end{array}$ & $\begin{array}{c}\text { Angle Set for } \\
\text { BURN } \\
\text { (degrees) }\end{array}$ \\
\hline SU & 0 & -19.7 & -17.0 \\
\hline BOC & 1.5 & -14.6 & -11.9 \\
\hline MID & 19 & -9.2 & -4.6 \\
\hline EOC & 38.5 & 0 & \\
\hline
\end{tabular}

To obtain the inventories for each of the points in the equilibrium fuel cycle, a first guess was made for the inventories and then calculations were carried out over multiple cycles to achieve the (converged) equilibrium values. Several iterations were performed in order to determine that equilibrium was reached in the inventories for both the HEU and LEU fuels. For the HEU fuel more than 30 cycles were calculated and for the LEU fuel more than 20 cycles were calculated to achieve the equilibrium compositions. Once a set of inventories was developed, the $\mathrm{k}_{\mathrm{eff}}$ was calculated for the EOC equilibrium condition. This condition was the "base case" for the subsequent analyses since it represents the only core configuration that is known to be identical for the HEU and LEU cores, i.e. the shim arms and regulating rod are withdrawn and there is no longer enough excess reactivity in the core to maintain criticality. At this point the NBSR is assumed to shut down. By definition, the value of $\mathrm{k}_{\mathrm{eff}}$ is unity just before the reactor shuts down.

Because models of operating nuclear reactors are not perfect, it is not unusual for the calculated value of $k_{\text {eff }}$ to exhibit a bias (Bess, 2011), that is, a consistent deviation from the actual value of $\mathrm{k}_{\mathrm{eff}}$. For the NBSR the bias from the model is determined by knowing the constituents of the fresh HEU fuel elements, and calculating equilibrium inventories at EOC. EOC occurs after 38.5 days $^{\mathrm{b}}$ of full $20 \mathrm{MW}$ operation and at that point in time there is usually not enough excess reactivity to maintain operation and the reactor is shut down. The bias is then determined by calculating the value of $\mathrm{k}_{\mathrm{eff}}$ at EOC, noting that the true value should be unity. The value of $\mathrm{k}_{\mathrm{eff}}$ at EOC for the HEU core then establishes the bias for the calculations for the LEU core. The bias for the present analysis is approximately $0.6 \% \Delta \mathrm{k} / \mathrm{k}$.

\footnotetext{
${ }^{\mathrm{b}}$ Cycles are not always terminated exactly after 38.5 days and hence, calculations mimic the ideal rather than the exact equilibrium cycle.
} 


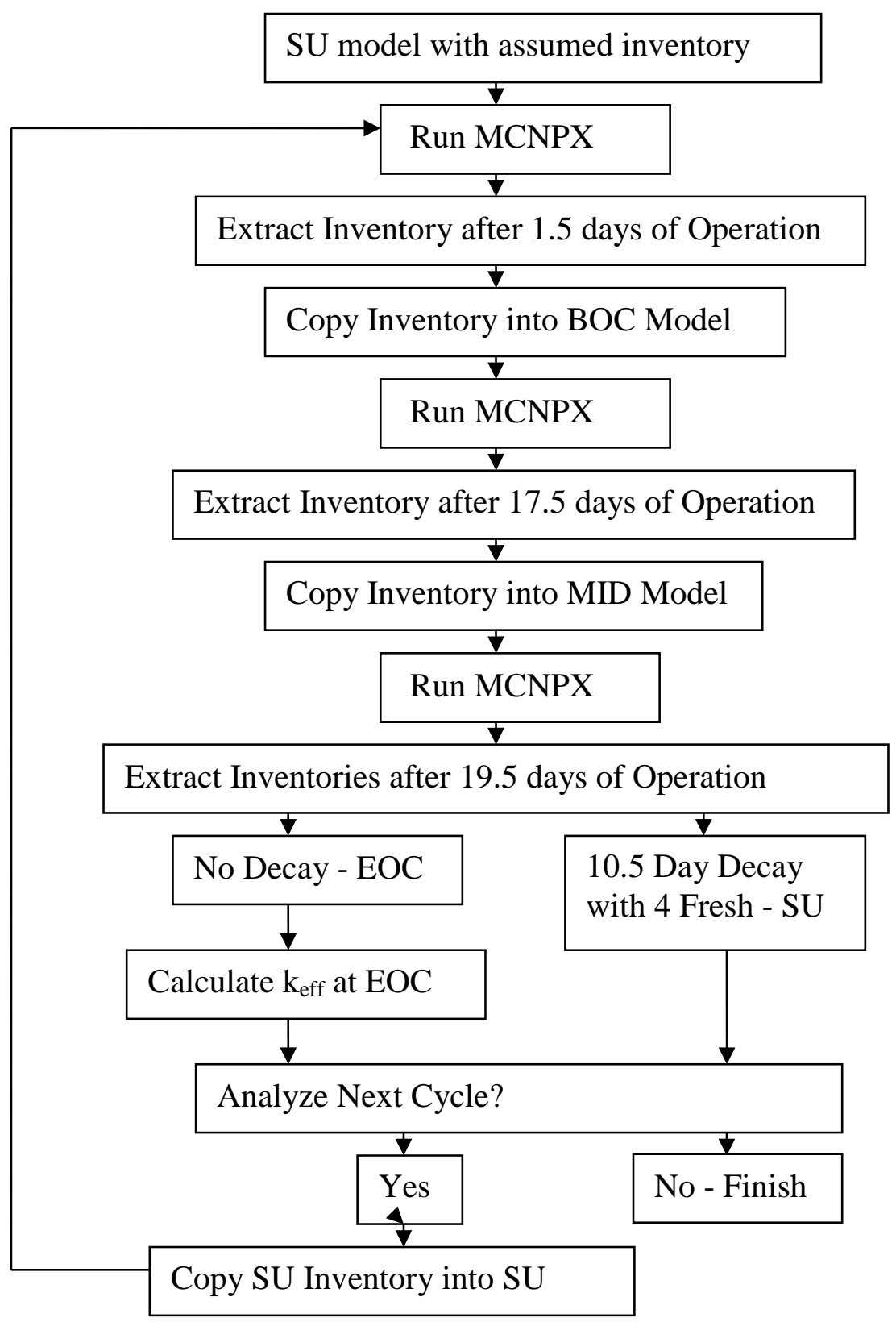

Figure 4.12 Inventory Calculation Flow-Chart 


\subsubsection{Reactivity Calculations}

\subsubsection{Reactivity Worth of the Shim Safety Arms and Regulating Rod}

The reactivity of the NBSR is controlled with four cadmium shim arms that are rotated through the core in a semaphore fashion. The worth of fresh (assuming no burn-up of the cadmium in the shim arms) shim arms was calculated using the fuel inventories at SU and EOC and calculating $\mathrm{k}_{\mathrm{eff}}$ as a function of shim arm position (moving all four of the shim arms together). The shim arm worth curves for the HEU and LEU cores are shown at SU in Figure 4.13 and at EOC in Figure 4.14. The shim arms with the LEU fuel have slightly less total worth than the shim arms with the HEU fuel. The total shim arm worth for the two fuels is shown in Table 4.6. The decrease in the calculated total worth was $1.2 \%$ for SU and $4.4 \%$ for EOC.

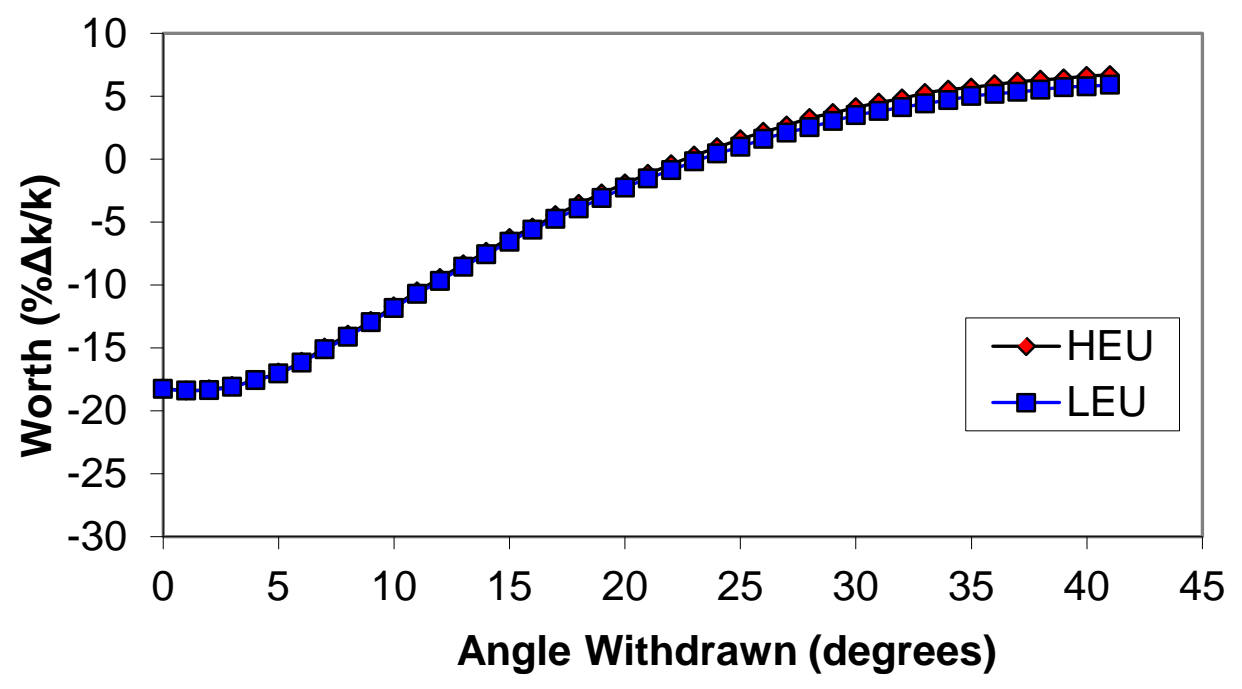

Figure 4.13 HEU and LEU Shim Arm Worth at SU

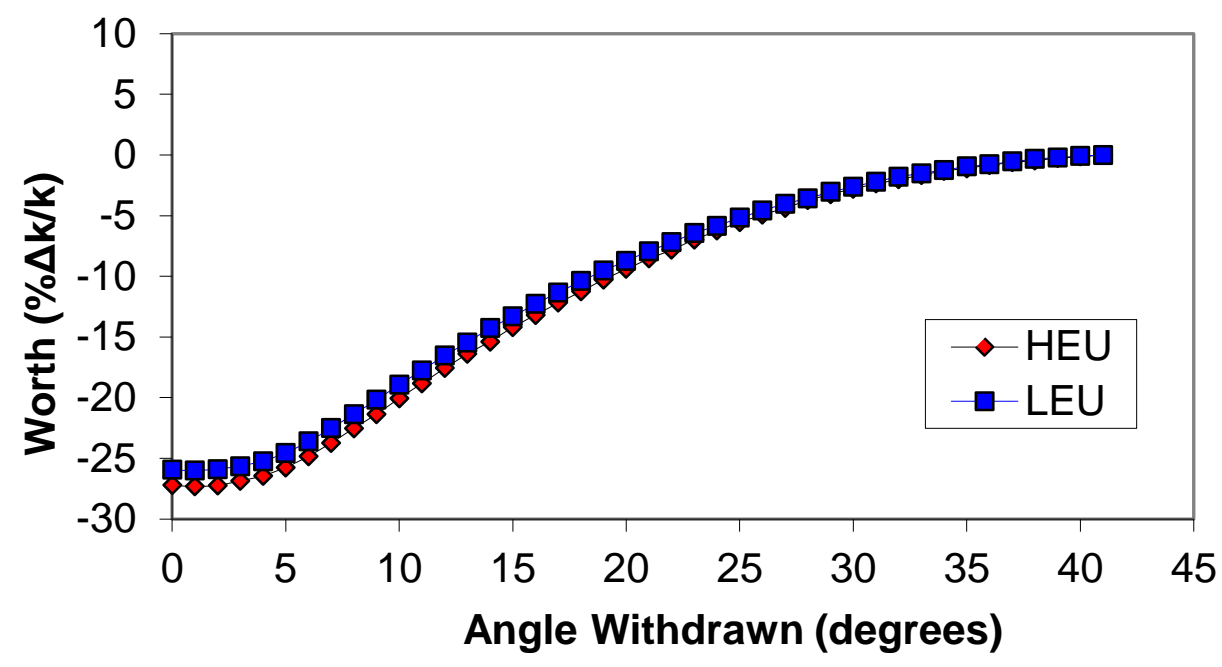

Figure 4.14 HEU and LEU Shim Arm Worth at EOC 
Table 4.6 Total Shim Arm Worth $(\% \Delta \mathrm{k} / \mathrm{k})$ Calculated for the HEU and LEU Fuels

\begin{tabular}{|l|c|c|}
\hline & HEU & LEU \\
\hline SU & 24.9 & 24.2 \\
\hline EOC & 27.2 & 26.0 \\
\hline
\end{tabular}

These calculations are for fresh (or with no significant burn-up) cadmium shim arms. Analysis and measurements have shown that the burnup of the cadmium reduces the worth of the shim arms to the extent that they need to be replaced with fresh blades after 25 cycles. Analysis has shown (Hanson, 2013) that the worth of the rods is reduced by approximately 22\% after 25 cycles. This varies only slightly depending on whether HEU or LEU fuel is present and the time in the cycle. The $22 \%$ deficiency is taken into account in the transient analysis presented in Chapter 13. Hence, at SU, the calculations are done with a total shim arm worth of $19.4 \% \Delta \mathrm{k} / \mathrm{k}$ for the HEU core and $19.2 \% \Delta \mathrm{k} / \mathrm{k}$ for the LEU core.

The regulating rod is an aluminum rod located in the G6 position. It performs the automatic fine control of the reactivity between larger reactivity insertions when the shim arms are moved. As the uranium in the core fissions, excess reactivity is lost and that loss is compensated by a slow and continuous withdrawal of the regulating rod. When the regulating rod is nearly fully withdrawn the shims arms are moved outward and the regulating rod is re-inserted. The regulating rod works by adding a large volume of a weak absorber and displacing the $\mathrm{D}_{2} \mathrm{O}$ moderator from the G6 position in the core when it is fully inserted. The total worth is shown in Table 4.7 for the two fuels and for the SU and EOC conditions. The worth curves (HEU and LEU) for the regulating rod are shown at SU in Figure 4.15 and at EOC in Figure 4.16. The regulating rod worth is generally slightly higher for the LEU fuel than for the HEU fuel.

Table 4.7 Total Regulating Rod Worth $(\% \Delta \mathrm{k} / \mathrm{k})$ Calculated for the HEU and LEU Fuels

\begin{tabular}{|l|c|c|}
\hline & HEU & LEU \\
\hline SU & 0.50 & 0.53 \\
\hline EOC & 0.45 & 0.43 \\
\hline
\end{tabular}




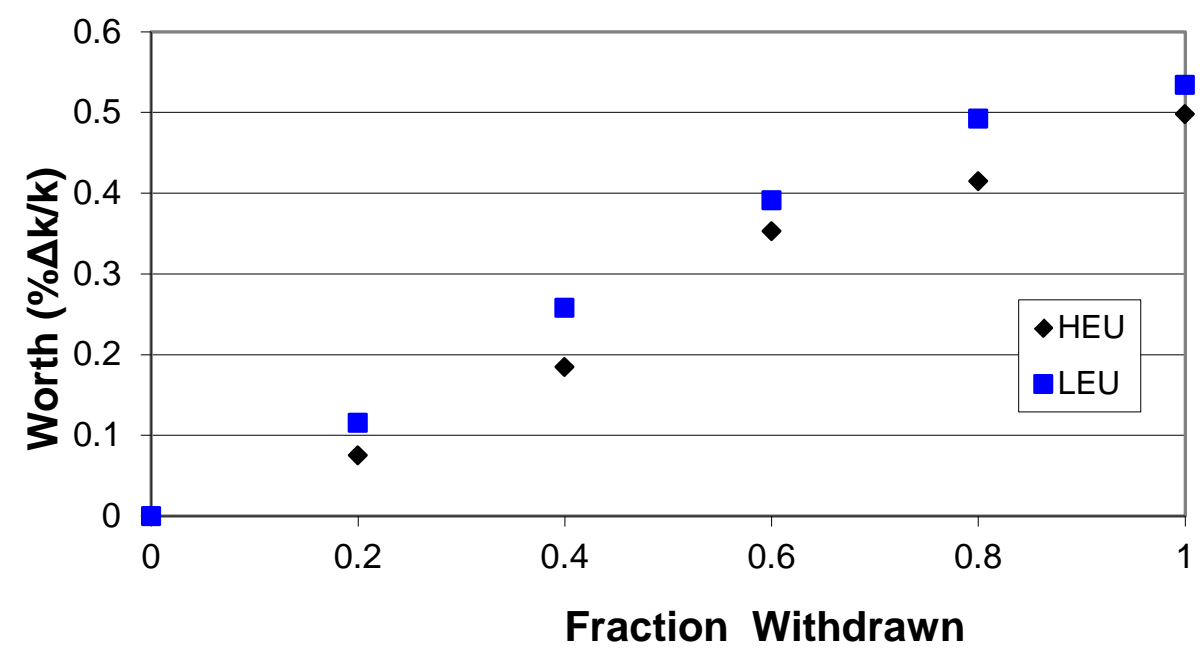

Figure 4.15 Regulating Rod Worth at SU for HEU and LEU Fuel

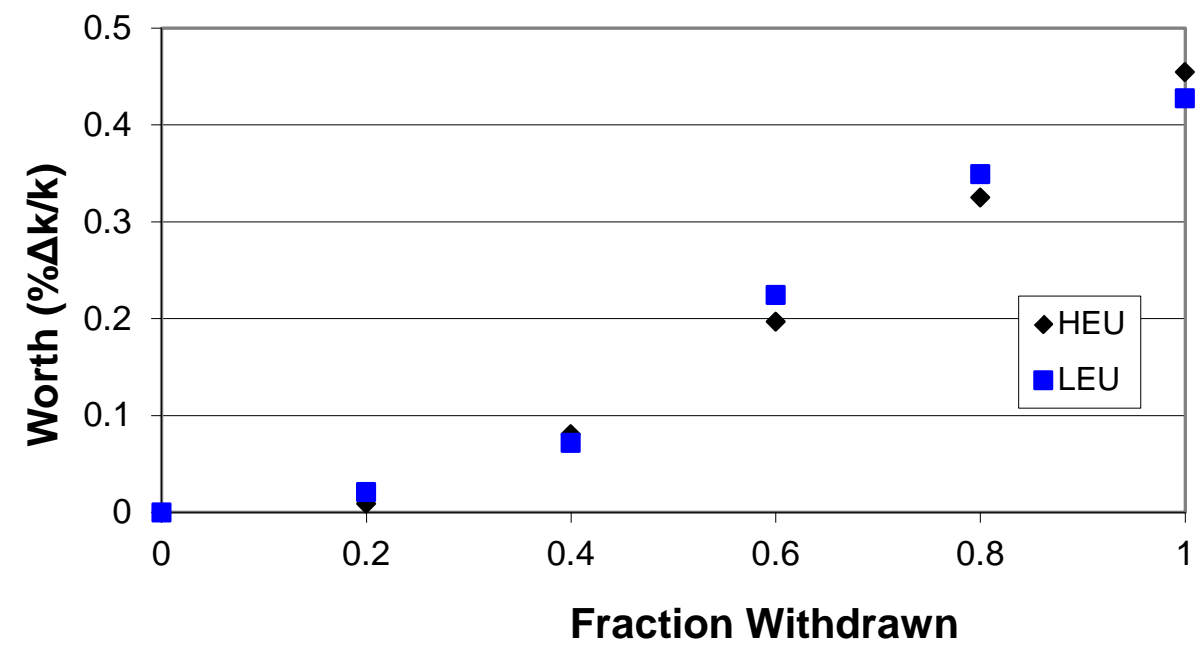

Figure 4.16 Regulating Rod Worth at EOC for HEU and LEU Fuels

\subsubsection{Excess Reactivity and Shutdown Margin}

NBSR Technical Specification 3.1.2, Reactivity Limitations, states that the core cannot be loaded such that the excess reactivity will exceed $15 \% \Delta \mathrm{k} / \mathrm{k}$ and it also states that the NBSR shall not be operated if it cannot be kept shutdown with the most reactive shim arm fully retracted. To determine if these conditions are met, $\mathrm{k}_{\text {eff }}$ was calculated under the following conditions: all shims inserted (shutdown reactivity), all shim arms withdrawn (excess reactivity), and three of the four shim arms inserted with the other withdrawn (shutdown margin, SDM). The calculations were performed at the most reactive state point in the cycle, which is SU with four fresh fuel elements and no ${ }^{135}$ Xe poison. 
The results for the calculations are shown in Table 4.8. These results demonstrate that neither the HEU nor the LEU equilibrium cores exceed the excess reactivity limit of $15 \% \Delta \mathrm{k} / \mathrm{k}$. This table also shows that for both the HEU and LEU fuels the core can be maintained in a shutdown condition with the most reactive shim arm withdrawn; shim arm \#3. This conclusion is not changed when the shim arms are depleted as explained in Section 4.5.2.1.

Table 4.8 Shutdown Margin and Excess Reactivity $(\% \Delta \mathbf{k} / \mathbf{k})$

\begin{tabular}{|l|l|c|c|}
\hline \multicolumn{2}{|l|}{} & HEU & LEU \\
\hline Shutdown reactivity (all shim arms in) & -18.2 & -18.3 \\
\hline SDM & Shim 1 out & -12.1 & -12.2 \\
\hline SDM & Shim 2 out & -11.1 & -11.2 \\
\hline SDM & Shim 3 out & -10.1 & -10.8 \\
\hline SDM & Shim 4 out & -11.6 & -11.9 \\
\hline Excess reactivity (all shim arms out) & 6.7 & 6.3 \\
\hline
\end{tabular}

\subsubsection{Moderator Dump}

The NBSR has a pipe, referred to as the moderator dump, whose entrance is just above the fueled portion of the core. If an emergency situation requires it, the pipe can be used to drain the coolant to that dump level leaving the core with no upper reflector. The lack of an upper reflector results in the reactor becoming subcritical. The NBSR model was modified so that the coolant above the core could be changed as is shown in Figure 4.17. In this figure the area above the fueled portion of the core is devoid of coolant.

Calculations of $k_{\text {eff }}$ when the coolant is lowered to the dump level were performed with the shim arms and regulating rod fully withdrawn. The calculations were done for the two state points of most concern, SU and EOC. The results are shown in Table 4.9 and demonstrate that the NBSR can be kept subcritical under all conditions if the coolant were to be lowered to the dump level. 


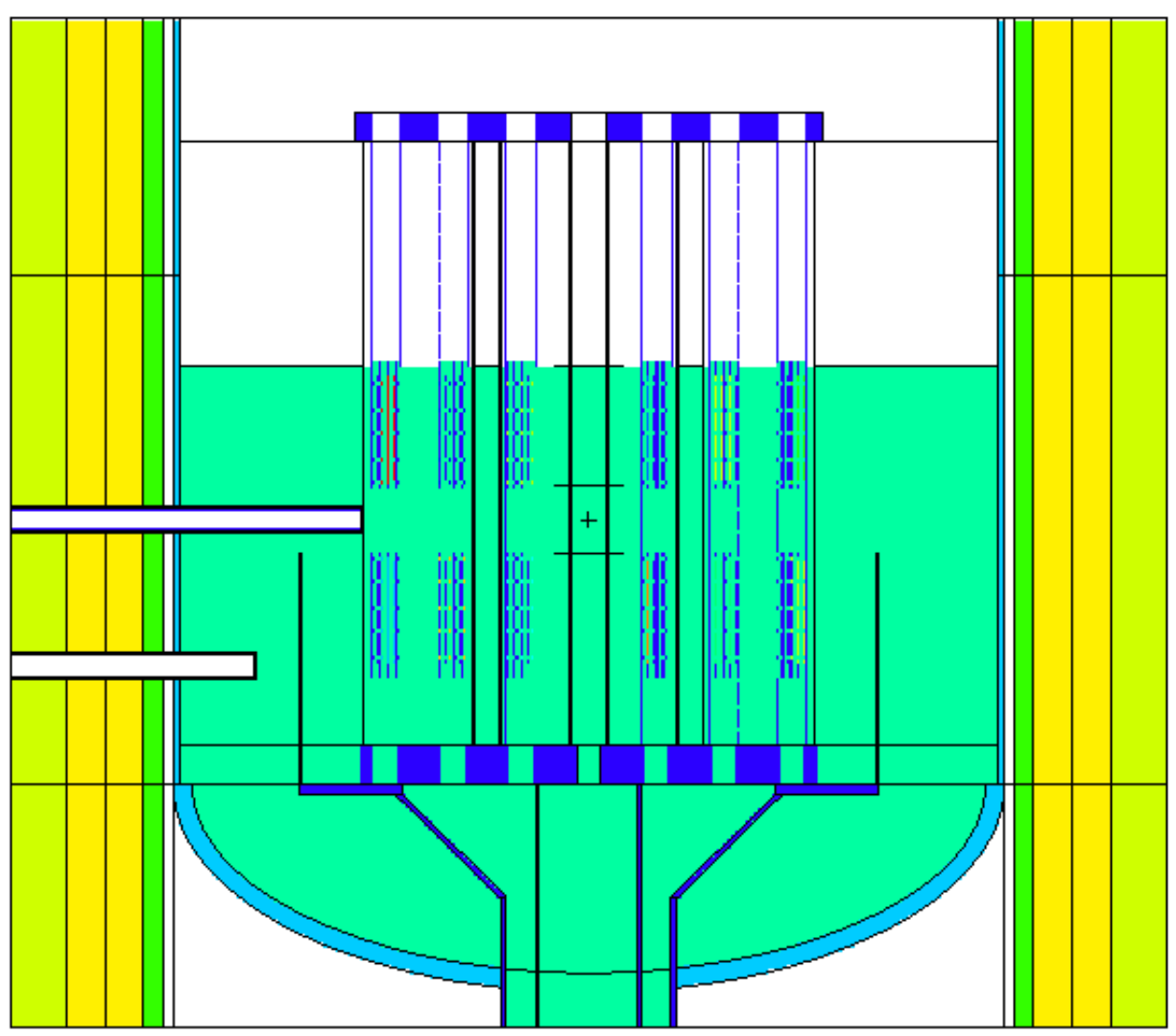

Figure 4.17 Elevation View with the Moderator at the Dump Level

Table 4.9 Value of $\mathbf{k}_{\text {eff }}$ with Moderator at the Dump Level

\begin{tabular}{|c|c|c|}
\hline & HEU & LEU \\
\hline SU & $0.98572 \pm 0.00044$ & $0.98491 \pm 0.00029$ \\
\hline EOC & $0.91241 \pm 0.00029$ & $0.92150 \pm 0.00028$ \\
\hline
\end{tabular}

\subsubsection{Moderator Temperature Reactivity Coefficient}

The moderator temperature reactivity coefficient (MTC) is defined for an increase in temperature in the $\mathrm{D}_{2} \mathrm{O}$ moderator, coolant, and reflector. It has been calculated for the HEU and LEU cores at SU and EOC. The MTC is negative so if there is an inadvertent power rise, and hence a heating of the moderator, there will be a negative feedback causing a reduction in power.

MCNPX handles temperature of the moderator in two ways. The first is by specifying the density of the moderator and the second is through the cross section file which provides a scattering kernel. The density of the $\mathrm{D}_{2} \mathrm{O}$ is a user input and can be changed in a continuous manner in order to study the effects of moderator temperature on the performance of the NBSR. For the model of the NBSR the density of the $\mathrm{D}_{2} \mathrm{O}$ is $1.0977 \mathrm{~g} / \mathrm{cm}^{3}$, the density at $46^{\circ} \mathrm{C}\left(115^{\circ} \mathrm{F}\right)$. 
The scattering kernel of the deuterium was selected to be at $20^{\circ} \mathrm{C}$. In the ENDF/B-VII cross section files the scattering kernels are in $50^{\circ} \mathrm{C}$ increments, so the next highest available scattering kernel for deuterium is for a temperature of $77^{\circ} \mathrm{C}$. The $20^{\circ} \mathrm{C}$ scattering kernel was selected since it is closest to the actual nominal operating temperature of the NBSR.

The MTC was calculated using the two ways of representing temperature change. First the scattering kernel was changed from $20^{\circ} \mathrm{C}$ to $77^{\circ} \mathrm{C}$. The value of $\mathrm{k}_{\text {eff }}$ (and $\Delta \mathrm{k} / \mathrm{k}$ ) was calculated and then divided by the temperature change. Second, the density was changed from that at $46^{\circ} \mathrm{C}$ to $96^{\circ} \mathrm{C}$ in $10^{\circ} \mathrm{C}$ increments maintaining the $20^{\circ} \mathrm{C}$ scattering kernel. For each temperature step the value of $\mathrm{k}_{\text {eff }}$ was calculated and $\Delta \mathrm{k} / \mathrm{k}$ was divided by the temperature change. The values of $\Delta \mathrm{k} / \mathrm{k} /{ }^{\circ} \mathrm{C}$ were then averaged. The values of reactivity change per degree from the scattering kernel change are added to the values calculated with the density change. The results of the calculations for the HEU and LEU fuel at SU and EOC are presented in Table 4.10. The MTC results are similar for the HEU and LEU cores.

Table 4.10 Moderator Temperature Coefficient $\left(\% \Delta \mathrm{k} / \mathrm{k} /{ }^{\circ} \mathrm{C}\right)$

\begin{tabular}{|l|c|c|c|c|}
\hline & \multicolumn{2}{|c|}{ SU } & \multicolumn{2}{c|}{ EOC } \\
\hline & HEU & LEU & HEU & LEU \\
\hline By Scattering Kernel & -0.0087 & -0.0063 & -0.0074 & -0.0045 \\
\hline By Density Change & -0.0225 & -0.0218 & -0.0201 & -0.0183 \\
\hline Total & -0.0397 & -0.0280 & -0.0275 & -0.0228 \\
\hline
\end{tabular}

\subsubsection{Void Reactivity Coefficient}

The NBSR is an under-moderated reactor and is sensitive to the presence of $\mathrm{D}_{2} \mathrm{O}$ throughout the core and reflector. Any decrease in $\mathrm{D}_{2} \mathrm{O}$ density within the NBSR will result in a negative reactivity insertion. This holds true for both the HEU and LEU cores. The void feedback coefficients were calculated as a function of $\mathrm{D}_{2} \mathrm{O}$ voiding within various locations in the NBSR core. The voiding process was modeled as a change in the density of the coolant and moderator. In the discussion of the MTC in Section 0, lowering the density of the moderator was shown to result in negative feedback so any process that results in moderator density reduction will likewise have negative feedback.

Voiding within a fuel element or irradiation thimble was calculated for the following cases:

- $\quad$ void all 2.5-in irradiation thimbles

- void all 3.5-in irradiation thimbles

- void all irradiation thimbles

- void the 7-in gap in the fuel elements

- void all of the fuel elements within the upper and lower bounds of the fueled regions

A void in an irradiation thimble could theoretically be created by placing an experiment in the thimble, but there is no credible method to create any void in the fuel elements other than boiling due to local flow blockage. The methodology for this analysis was similar to the methodology 
for calculating the MTC. The region was first voided, the reactivity change $(\Delta \mathrm{k} / \mathrm{k})$ calculated, and the reactivity change divided by the volume of the void. The results are presented in Table 4.11 for the HEU and LEU cores at SU and EOC. The results demonstrate that a void forming anywhere within the NBSR will provide negative reactivity feedback. The magnitude of the feedback is similar for the HEU and LEU cores.

Table 4.11 Void Coefficient ( $\% \Delta \mathrm{k} / \mathrm{k} / \mathrm{liter})$ for Voiding Specific Areas in the Core

\begin{tabular}{|l|l|l|}
\hline \multicolumn{1}{|c|}{ SU } & HEU & LEU \\
\hline Four 2.5-in thimbles voided & & \\
\hline Six 3.5-in thimbles voided & -0.045 & -0.044 \\
\hline All thimbles voided & -0.036 & -0.037 \\
\hline All FE gaps voided & -0.038 & -0.039 \\
\hline All FEs voided & -0.027 & -0.031 \\
\hline \multicolumn{1}{|c|}{ EOC } & -0.019 & -0.018 \\
\hline Four 2.5-in thimbles voided & & \\
\hline Six 3.5-in thimbles voided & -0.034 & -0.035 \\
\hline All thimbles voided & -0.030 & -0.032 \\
\hline All FE gaps voided & -0.031 & -0.032 \\
\hline All FEs voided & -0.022 & -0.023 \\
\hline
\end{tabular}

\subsubsection{Beam Tube Flooding}

Beam tube flooding was hypothesized to occur if a $\mathrm{D}_{2} \mathrm{O}$-cooled experiment in a beam tube were to leak, or a crack were to occur in a beam tube, or the cold neutron source. Such an event would allow $\mathrm{D}_{2} \mathrm{O}$ to enter areas that are normally filled with air or vacuum and introduce positive reactivity. Results for the three situations of interest are given in Table 4.12. As can be seen from the table, the reactivity added is less than the $0.5 \% \Delta \mathrm{k} / \mathrm{k}$ used to analyze the maximum reactivity insertion accident (Chapter 13). These calculations assumed a complete flooding of the beam tubes.

Table 4.12 Reactivity Insertion (\% $\% \mathrm{k} / \mathrm{k})$ from Flooding the Beam Tubes

\begin{tabular}{|l|c|c|c|c|}
\hline \multirow{2}{*}{} & \multicolumn{2}{|c|}{ SU } & \multicolumn{2}{c|}{ EOC } \\
\cline { 2 - 5 } & HEU & LEU & HEU & LEU \\
\hline CNS Flooded & 0.24 & 0.15 & 0.25 & 0.15 \\
\hline Average Radial Beam Tube & 0.17 & 0.17 & 0.18 & 0.17 \\
\hline One Tangential Beam Tube & 0.27 & 0.26 & 0.20 & 0.21 \\
\hline
\end{tabular}




\subsubsection{Light Water Ingress}

The NBSR is a $\mathrm{D}_{2} \mathrm{O}$ cooled and moderated system. The $\mathrm{D}_{2} \mathrm{O}$ used in the NBSR is $99.97 \%$ pure with $0.03 \% \mathrm{H}_{2} \mathrm{O}$. Any additional light water contamination would have a negative effect on the reactivity of the NBSR. This is shown in terms of $\mathrm{k}_{\text {eff }}$ vs the amount of $\mathrm{H}_{2} \mathrm{O}$ impurity, at SU in Figure 4.18 and at EOC in Figure 4.19.

Figure 4.18 Effect of Light Water Ingress on the Value of $k_{\text {eff }}$ at SU

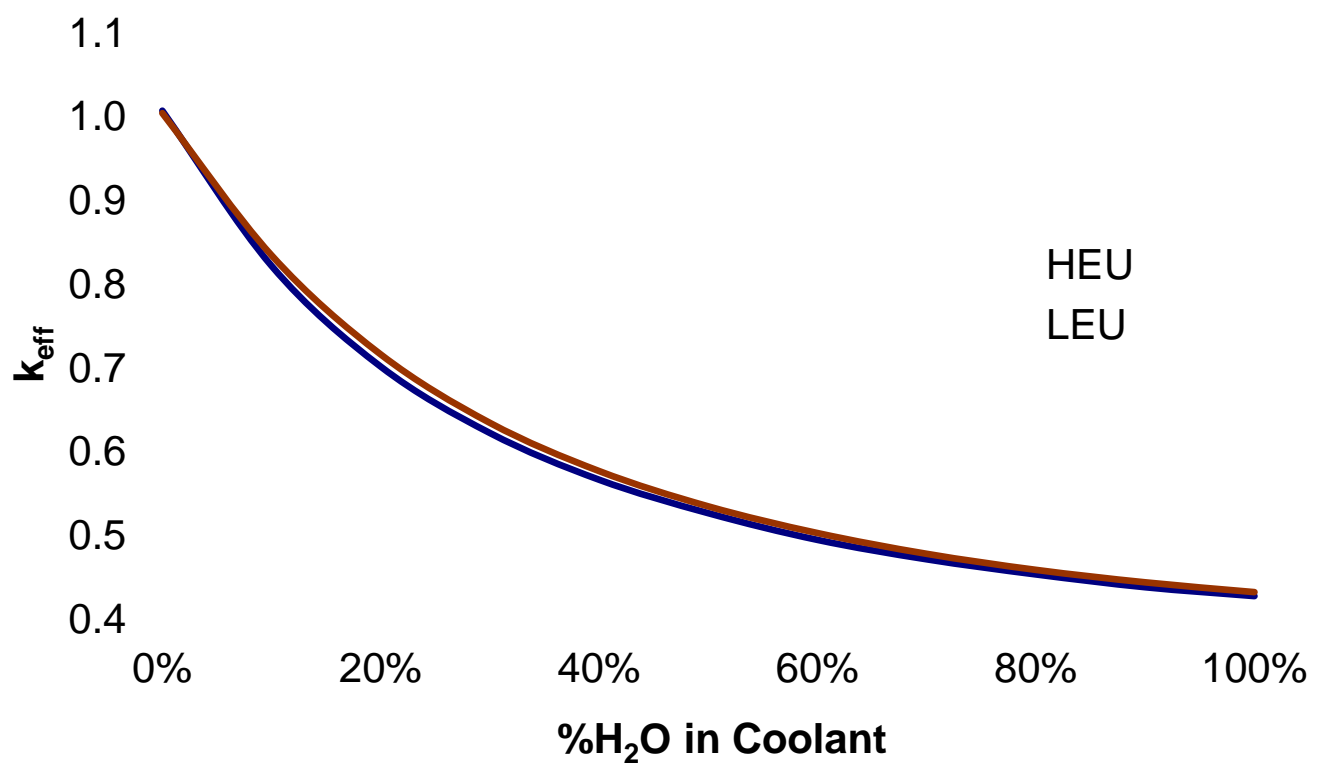

Figure 4.19 Effect of Light Water Ingress on the Value of $\mathbf{k}_{\text {eff }}$ at EOC 


\subsubsection{Power Distribution and Energy Spectra Calculations}

\subsubsection{Radial Power Distribution}

The radial power distributions show the average power generated in each half fuel element. Figure 4.20 shows the radial relative power distribution for the upper and lower half cores for the HEU core at SU. The relative power is normalized so that unity represents the average power in a half fuel element, i.e., $1 / 60$ of the total core power (=1/3 MW). Red shades are used for relative powers above unity and green shades for those below unity. Figure 4.21shows the radial power distribution for the upper and lower half cores for the LEU core at SU, which can be compared to the results in Figure 4.20. Figure 4.22 and Figure 4.23 show the power distributions at EOC for the HEU and LEU cores, respectively.

The radial power distributions demonstrate differences between the HEU and LEU cores. As shown in Table 4.13, the maximum half-element power at SU increases from $427 \mathrm{~kW}$ to $449 \mathrm{~kW}$ when going from HEU to LEU fuel (0.33 MW times the relative powers in Figure 4.20 and Figure 4.21). At EOC there is a decrease in the maximum half-element power. The location of the maximum power is also given in Table 4.13 .

There are two plenums in the NBSR dividing the coolant flow between the six innermost fuel elements and the other 24 fuel elements. As is shown in Table 4.14, there is an 8.4\% increase in the power in the innermost six fuel elements (FEs) at SU when going from HEU to LEU fuel and at EOC there is an $11 \%$ increase, though the total power generated by the inner six FEs is smaller at EOC than at SU. This indicates that when converting from HEU to LEU fuel, there is a net power shift from the perimeter of the core towards the inner portion of the core. This is also clear from looking at the more detailed radial power distributions shown in Figure 4.20 and Figure 4.21. The effect of this increase, on key thermal-hydraulic parameters, is given in Section 4.6.2.

The power shift is due primarily to the additional amount of ${ }^{238} \mathrm{U}$, in the LEU core relative to the HEU core. The isotope acts as an absorber, reducing the leakage out of the core. The consequence of the reduced leakage from the core into the beam tubes and CNS is a penalty to the users of the NBSR.

At SU there is more power generated in the lower half of the core than there is in the upper half of the core. This is due to the shim arms suppressing the power in the upper half of the core at SU. Because there is more power generated in the lower half of the core than there is in the upper half of the core starting at SU, the burn-up is initially reduced in the upper half of the core. By the time the shim arms are swung out of the core and EOC is approached, the power is shifted to the upper half of the core. 


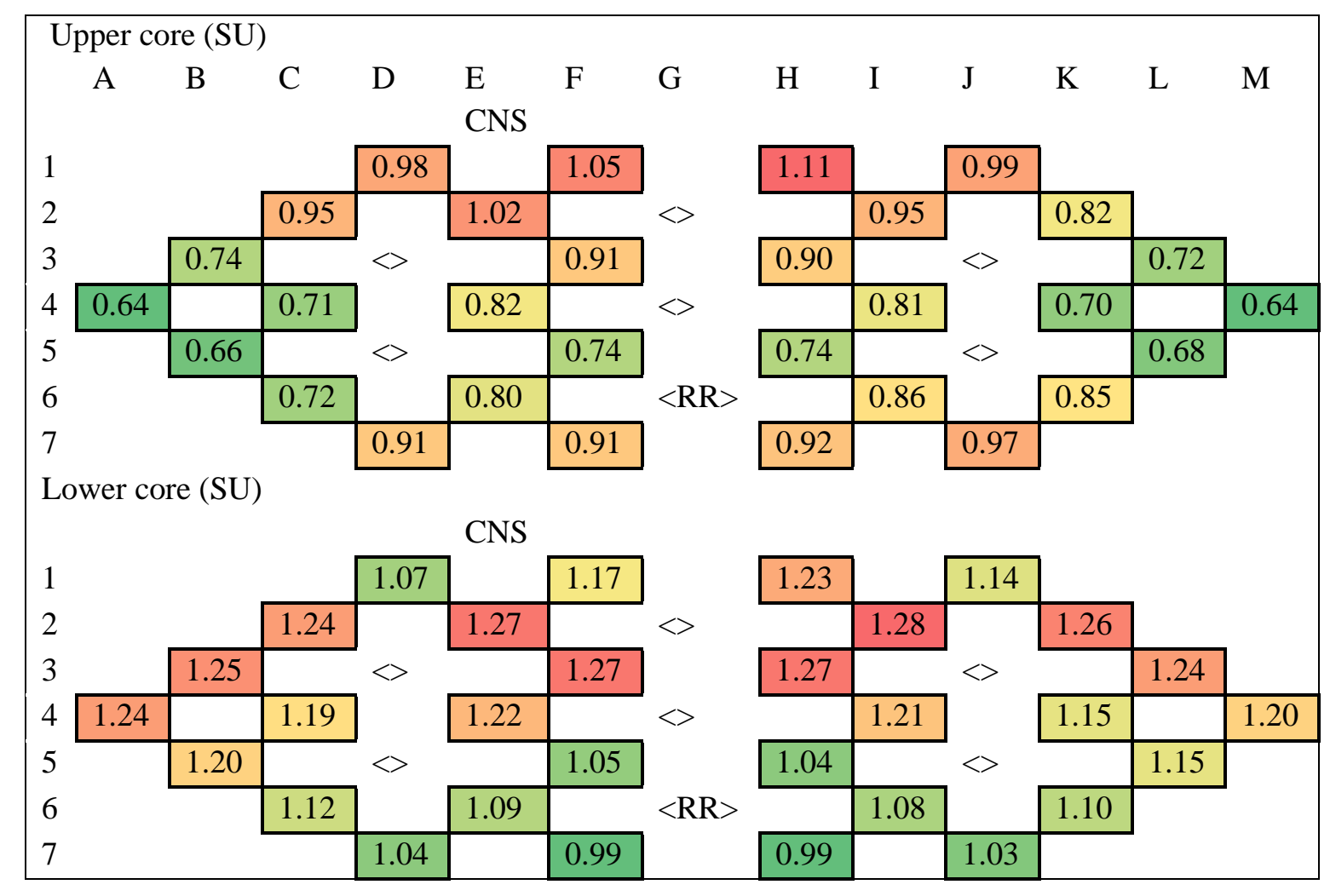

Figure 4.20 Radial Power Distribution for the HEU Core at SU

\begin{tabular}{|c|c|c|c|c|c|c|c|c|c|c|c|c|c|}
\hline \multicolumn{14}{|c|}{ Upper core (SU) } \\
\hline & A & B & $\mathrm{C}$ & $\mathrm{D}$ & $\begin{array}{l}\text { E } \\
\text { CNS }\end{array}$ & $\mathrm{F}$ & G & $\mathrm{H}$ & I & $\mathrm{J}$ & K & $\mathrm{L}$ & M \\
\hline 1 & & & & 0.90 & & 1.01 & & 1.05 & & 0.93 & & & \\
\hline 2 & & & 0.91 & & 1.01 & & $<>$ & & 0.94 & & 0.78 & & \\
\hline 3 & & 0.71 & & $<>$ & & 0.97 & & 0.96 & & $<>$ & & 0.69 & \\
\hline 4 & 0.61 & & 0.73 & & 0.89 & & $<>$ & & 0.89 & & 0.74 & & 0.62 \\
\hline 5 & & 0.66 & & $<>$ & & 0.84 & & 0.85 & & $<>$ & & 0.69 & \\
\hline 6 & & & 0.72 & & 0.84 & & $<\mathrm{RR}>$ & & 0.91 & & 0.87 & & \\
\hline 7 & & & & 0.89 & & 0.91 & & 0.94 & & 0.96 & & & \\
\hline \multicolumn{14}{|c|}{ Lower core (SU) } \\
\hline & & & & & CNS & & & & & & & & \\
\hline 1 & & & & 0.98 & & 1.09 & & 1.15 & & 1.05 & & & \\
\hline 2 & & & 1.18 & & 1.25 & & $<>$ & & 1.27 & & 1.19 & & \\
\hline 3 & & 1.20 & & $<>$ & & 1.35 & & 1.34 & & $<>$ & & 1.19 & \\
\hline 4 & 1.15 & & 1.21 & & 1.30 & & $<>$ & & 1.30 & & 1.18 & & 1.13 \\
\hline 5 & & 1.16 & & $<>$ & & 1.17 & & 1.16 & & $<>$ & & 1.12 & \\
\hline 6 & & & 1.10 & & 1.13 & & $<\mathrm{RR}>$ & & 1.12 & & 1.10 & & \\
\hline 7 & & & 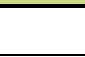 & 1.00 & & 1.01 & & 1.00 & & 1.01 & & & \\
\hline
\end{tabular}

Figure 4.21 Radial Power Distribution for the LEU Core at SU 


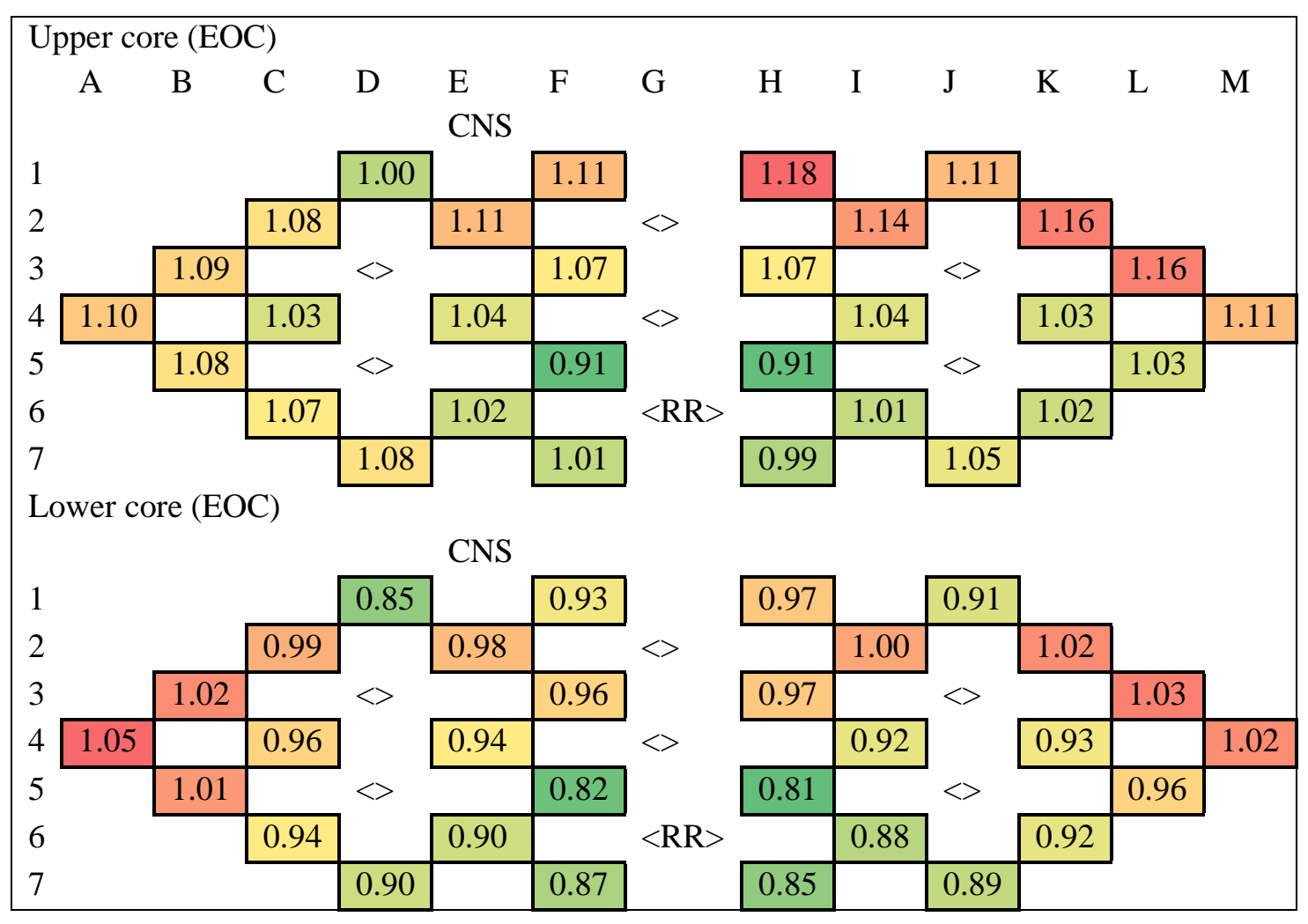

Figure 4.22 Radial Power Distribution for the HEU Core at EOC

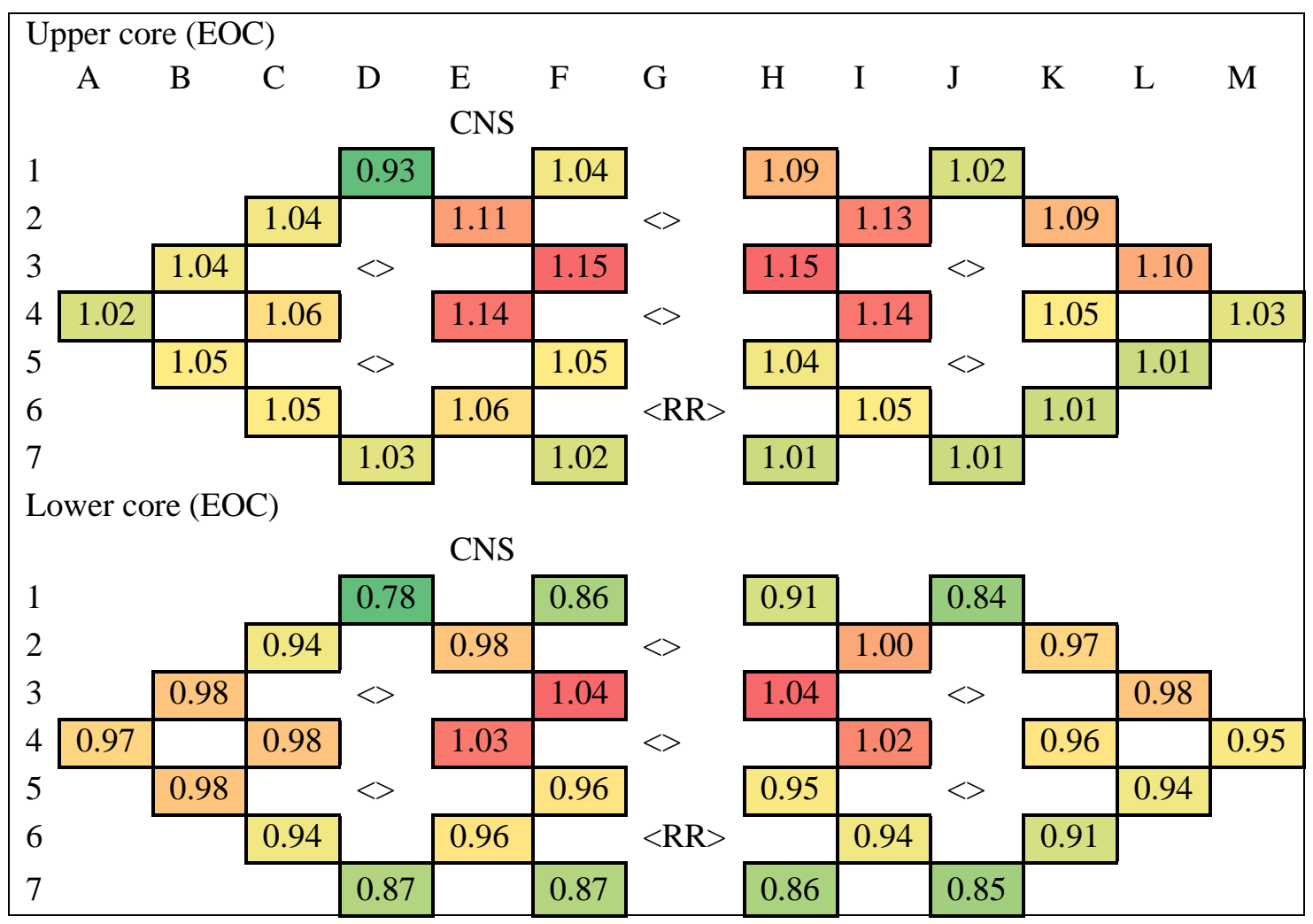

Figure 4.23 Radial Power Distribution for the LEU Core at EOC 
Table 4.13 Highest Half-Element Power (kW)

\begin{tabular}{|l|c|c|c|c|}
\hline & \multicolumn{2}{|c|}{ HEU } & \multicolumn{2}{c|}{ LEU } \\
\hline SU & I2 Lower & 427 & F3 Lower & 449 \\
\hline EOC & H1 Upper & 393 & H3 Upper & 385 \\
\hline
\end{tabular}

Table 4.14 Power (MW) Generated by the Inner Plenum FEs vs. the Outer Plenum FEs

\begin{tabular}{|l|c|c|c|c|c|c|}
\hline & \multicolumn{3}{|c|}{ SU } & \multicolumn{3}{c|}{ EOC } \\
\hline & HEU & LEU & $\boldsymbol{\Delta ( \% )}$ & HEU & LEU & $\boldsymbol{\Delta ( \% )}$ \\
\hline Outer 24 & 16.00 & 15.64 & -2.1 & 16.18 & 15.76 & -2.6 \\
\hline Inner 6 & 4.00 & 4.34 & 8.4 & 3.82 & 4.24 & 11.1 \\
\hline
\end{tabular}

\subsubsection{Axial and Plate-wise Power Distributions}

To obtain more detailed power distributions, a model was developed in which each fuel plate was divided into $2 \times 2 \mathrm{~cm}$ (nominal) squares. The number of fissions, which is proportional to the local power density, was calculated for each square. Thermal-hydraulic analyses are performed using these three-dimensional power distributions to ensure the reactor can be safely operated with the LEU fuel at all points in the fuel cycle.

The choice of mesh size for the MCNPX calculations is based on the observation that heat conduction in a fuel plate will result in a lateral heat flux profile (i.e. across the width of a fuel plate that is flatter than the profile of the energy deposition due to fission, primarily due to the effect of conduction to the $\mathrm{Al}$ alloy at the ends of the plate. The lateral heat conduction problem was analyzed both analytically (Rowe, 2008) and numerically (Cheng, 2010). The results show that the average energy deposition per unit surface area of a mesh cell for a $2 \times 2 \mathrm{~cm}$ mesh conservatively captures the maximum wall heat flux determined by solving the detailed heat conduction problem for a fuel plate. The acceptable mesh translates into three mesh intervals in the lateral direction and 14 mesh intervals in the axial direction for each fuel plate.

Figure 4.24 shows the plate-wise power in fuel element A-4, a fresh FE, at SU, for both the HEU and LEU equilibrium cores. The relative power is normalized to the total power in the FE so the difference between top and bottom plates is evident. As can be seen, the distribution among plates is not very different for the HEU and LEU cores. The distribution is always peaked at the end plates where there is additional moderation available. This is also true at EOC as can be seen in Figure 4.25. The latter figure also shows how the axial power shifts to the upper half of the fuel at EOC in contrast to the higher power in the lower half seen in Figure 4.24. This is the result of shim arm movement during the cycle.

Figure 4.26 shows the axial power distribution for the entire FE A-4 at SU for both the HEU and LEU equilibrium cores. The curves are normalized to total FE power. Similar curves for EOC are shown in Figure 4.27. Both sets of curves show insignificant differences between HEU and LEU cores. Peaking occurs at the ends of the fuel plates due to the effect of additional moderator in that region. The highest peaking occurs close to the midplane and is in the bottom 
half of the FE at SU and the top half at EOC. Axial distributions like these, for a hot plate rather than for an entire FE, are used in the thermal-hydraulic analyses.

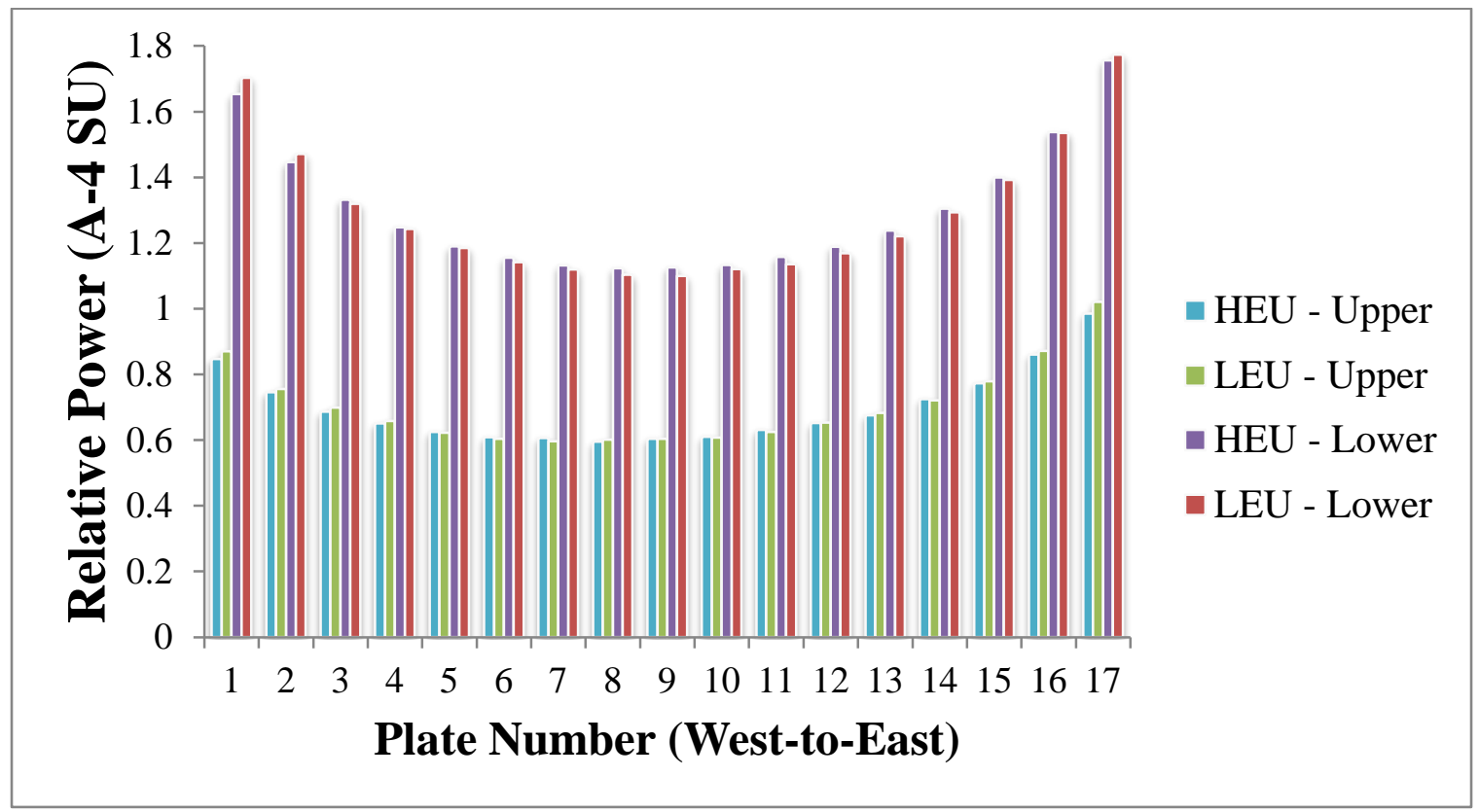

Figure 4.24 Plate-Wise Relative Power for FE A-4 at SU

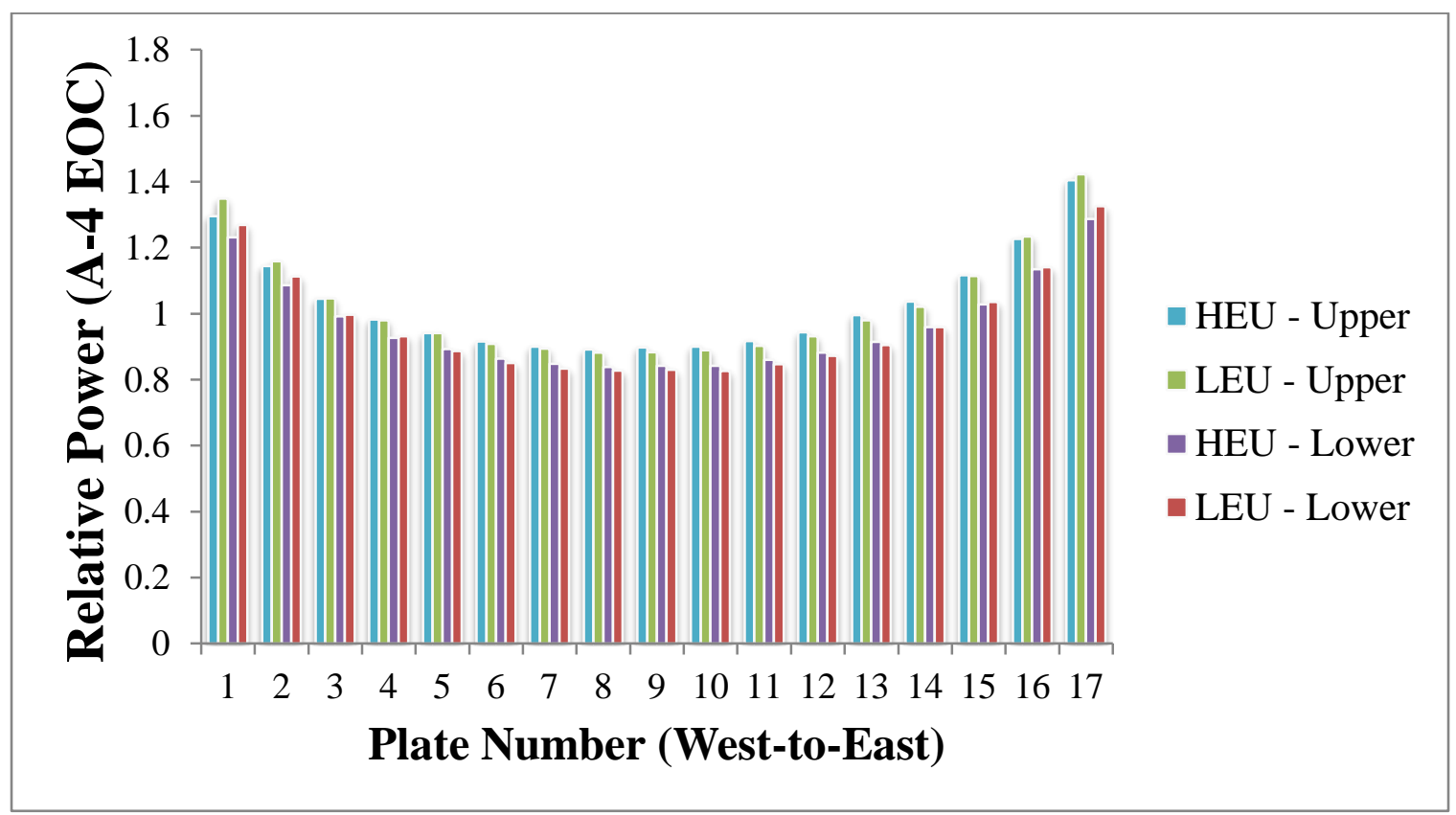

Figure 4.25 Plate-Wise Relative Power for FE A-4 at EOC 


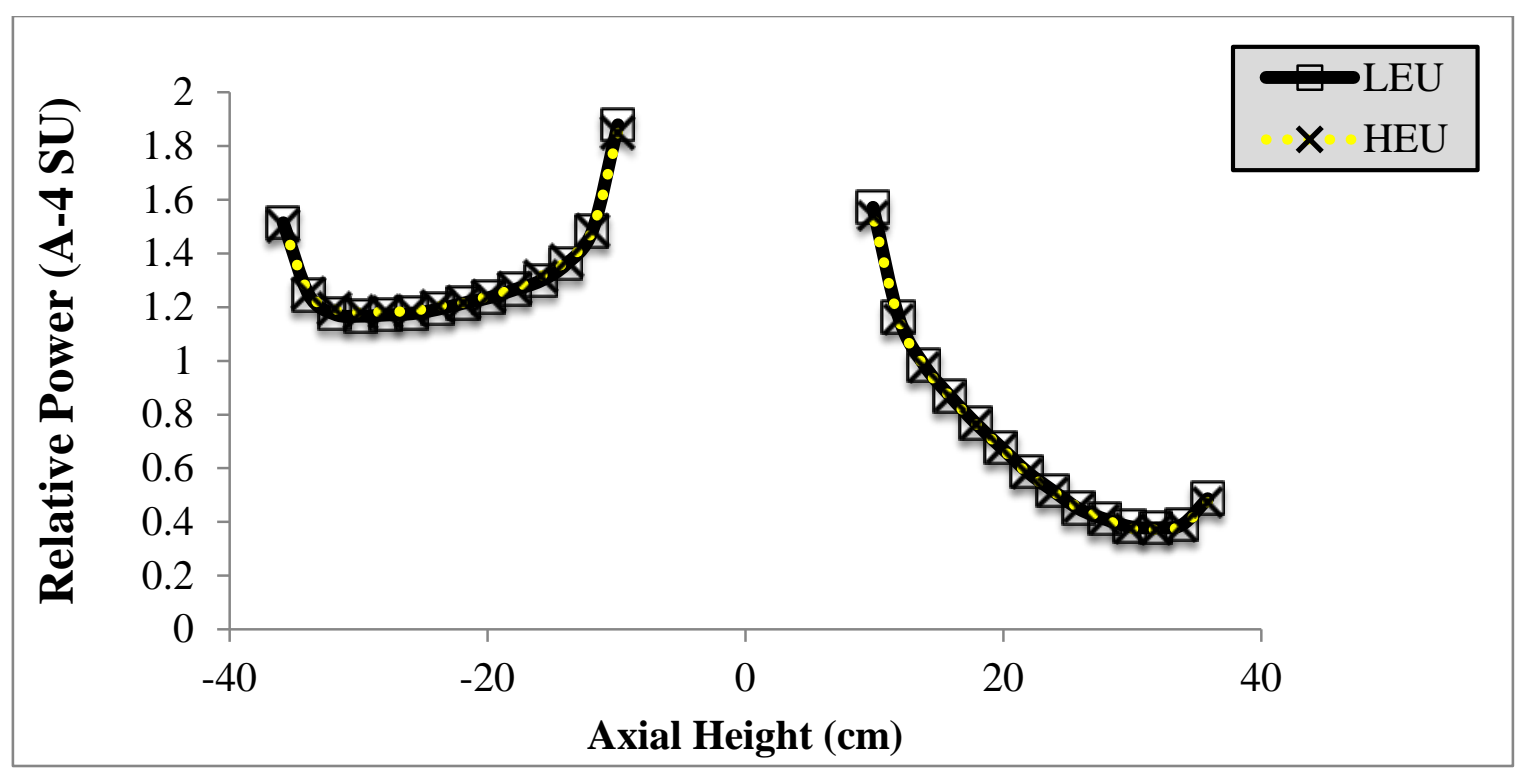

Figure 4.26 Axial Power Distribution for FE A-4 at SU

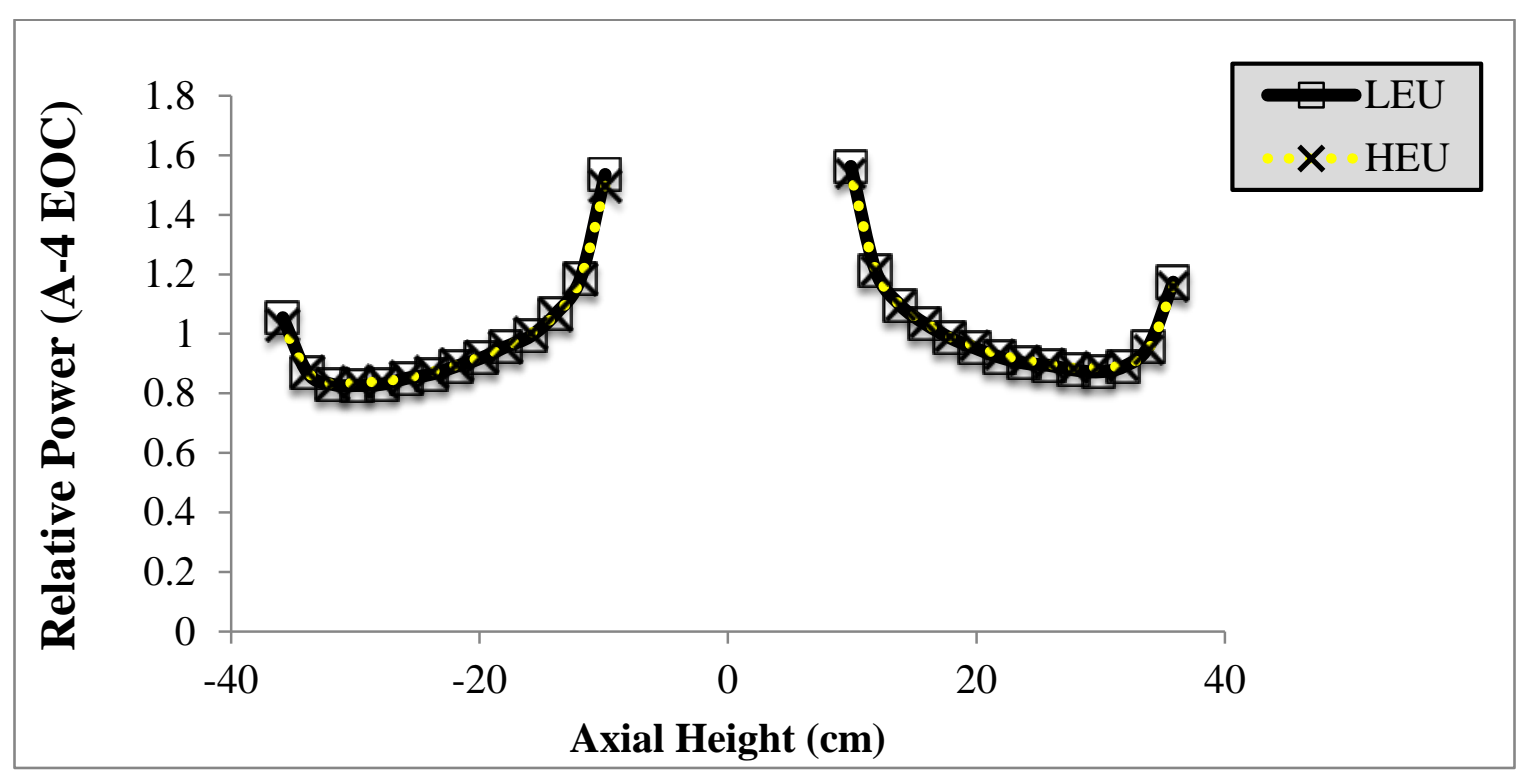

Figure 4.27 Axial Power Distribution for FE A-4 at EOC

\subsubsection{Energy Spectra}

A comparison of the energy spectra throughout the core after conversion was carried out using the MCNPX model of the core. Figure 4.28 shows the thermal spectrum averaged over the entire mid-plane gap, including regions with no FEs for SU and EOC for both the HEU and LEU cores. The results show that qualitatively the spectrum looks similar for both the HEU and LEU cores but the former is larger quantitatively. 


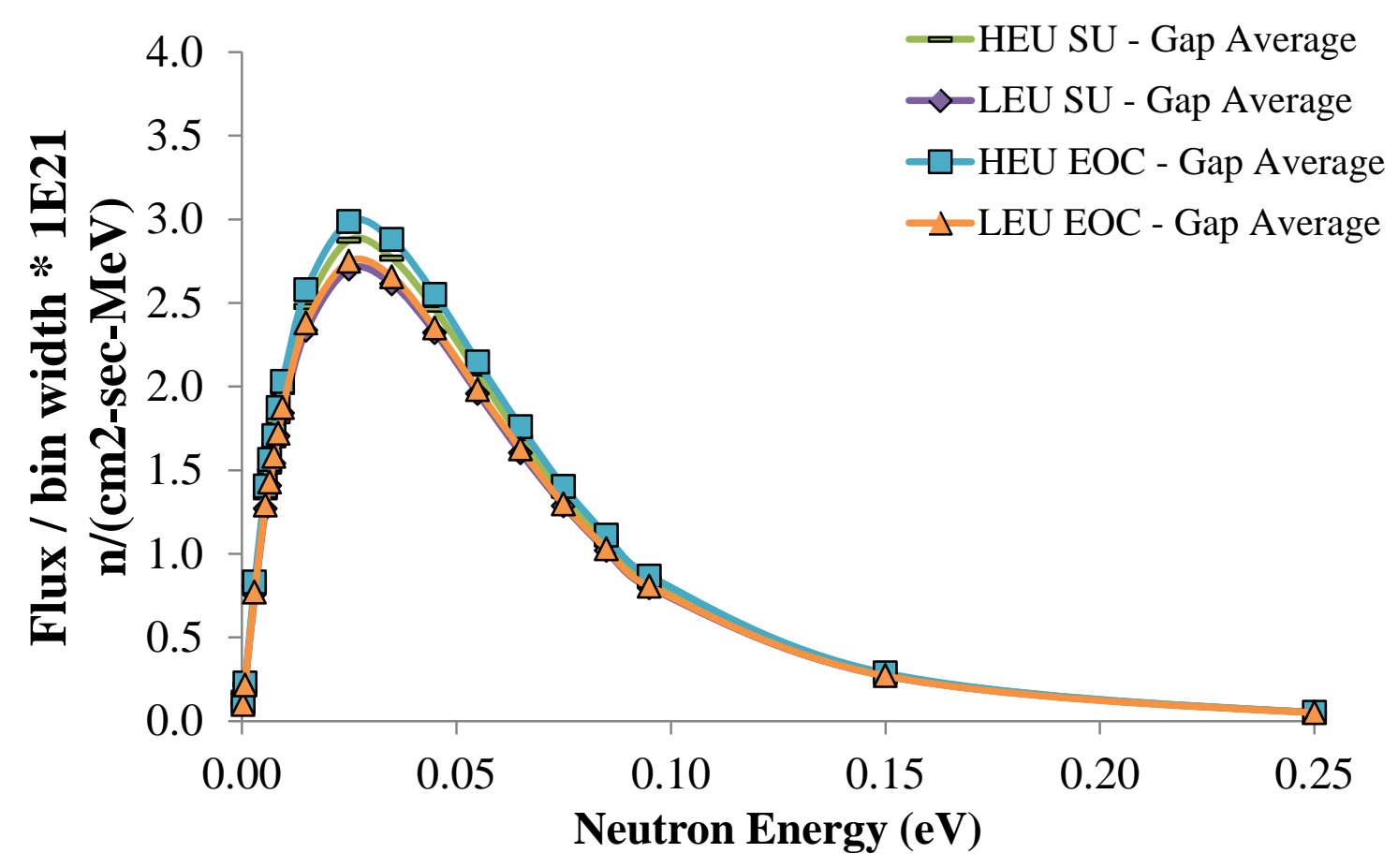

Figure 4.28 Thermal Neutron Energy Spectra in Gap

Figure 4.29 shows the percent change from HEU to LEU in the total thermal $(<1.0 \mathrm{eV})$ flux in the midplane gap at the location of each of the FEs, for both SU and EOC conditions. The shading in the figure (red indicating a decrease) and the numerical values show a decrease in thermal neutrons upon conversion. This decrease is the result of the additional amounts of ${ }^{238} \mathrm{U}$ in the core.

Figure 4.30 shows the percent change from HEU to LEU for the total fast $(>0.01 \mathrm{MeV})$ flux in the midplane gap at the location of each of the FEs, for both SU and EOC conditions. The shading in the figure (red indicating an increase) and the numerical values show a decrease in fast neutrons at the core periphery, where they are needed to provide thermal neutrons to the beam tubes and the CNS. This decrease is the result of the additional amounts of ${ }^{238} \mathrm{U}$ in the core and the shift in power toward the center of the core.

Based on these figures and other calculations, the main conclusions about the relative flux in the HEU and LEU cores are:

- The thermal neutron flux within the central thimble of the LEU core is on average 5\% lower than the corresponding HEU neutron flux.

- The epithermal and fast neutron fluxes within the central thimble of the LEU core are between 5 and $10 \%$ higher than the corresponding HEU core neutron flux.

- The thermal fluxes throughout the mid-plane gap are between 5 and $10 \%$ lower for the LEU core than for the corresponding HEU core. The fast fluxes are higher in the radial center of the LEU core compared to the corresponding HEU core. On average, there is a slight overall decrease in the fast neutron flux in the mid-plane gap of the LEU core when compared to the HEU core. 
$\%$ Change in SU thermal flux in gap, LEU vs. HEU

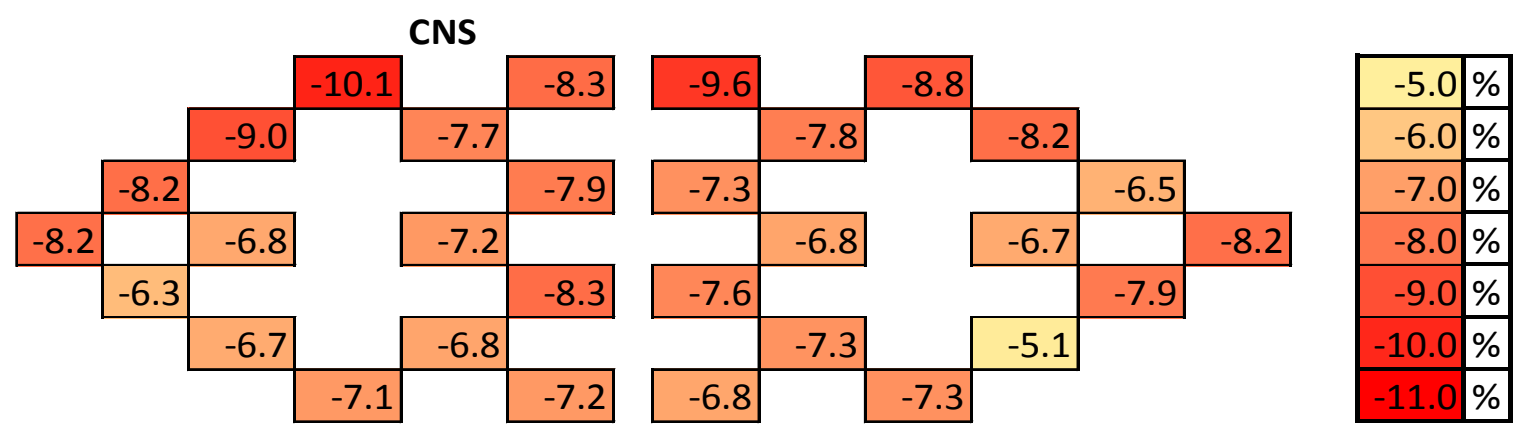

\% Change in EOC thermal flux in gap, LEU vs. HEU

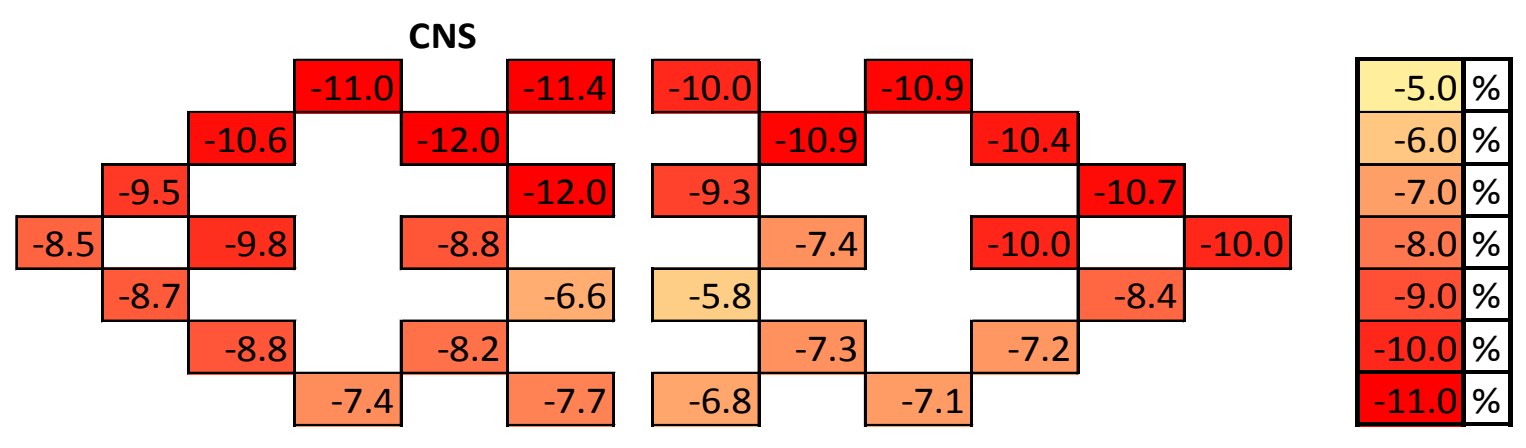

Figure 4.29 Change (\%) in Thermal Flux within the Gap, LEU vs. HEU 
\% Change in SU fast flux in gap, HEU-to-LEU

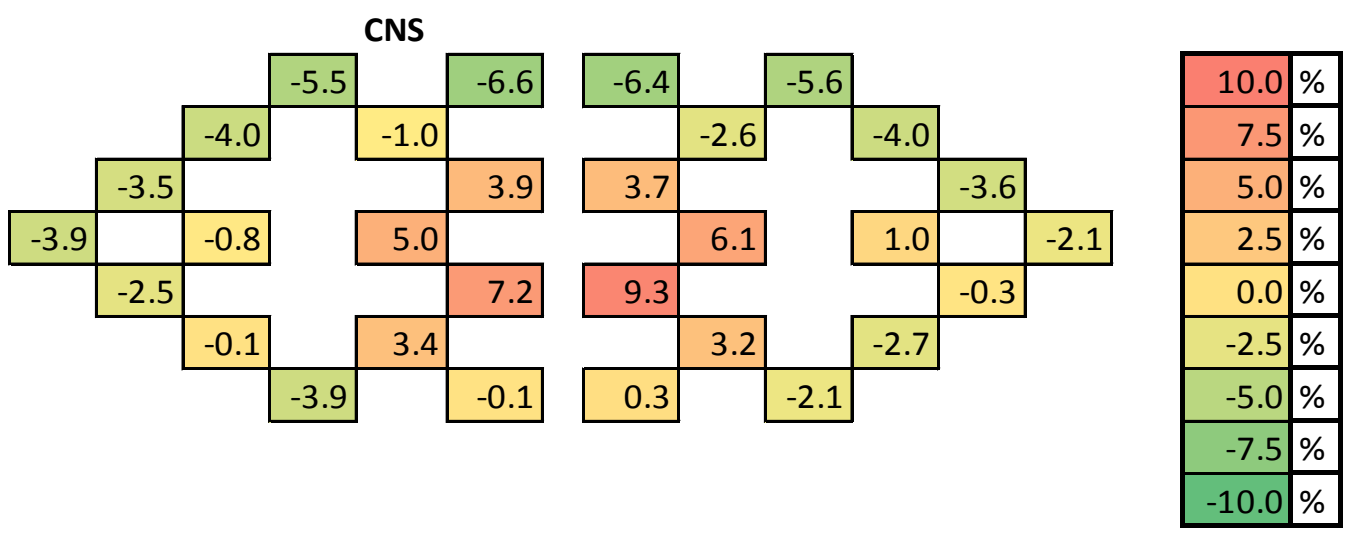

\% Change in EOC fast flux in gap, HEU-to-LEU

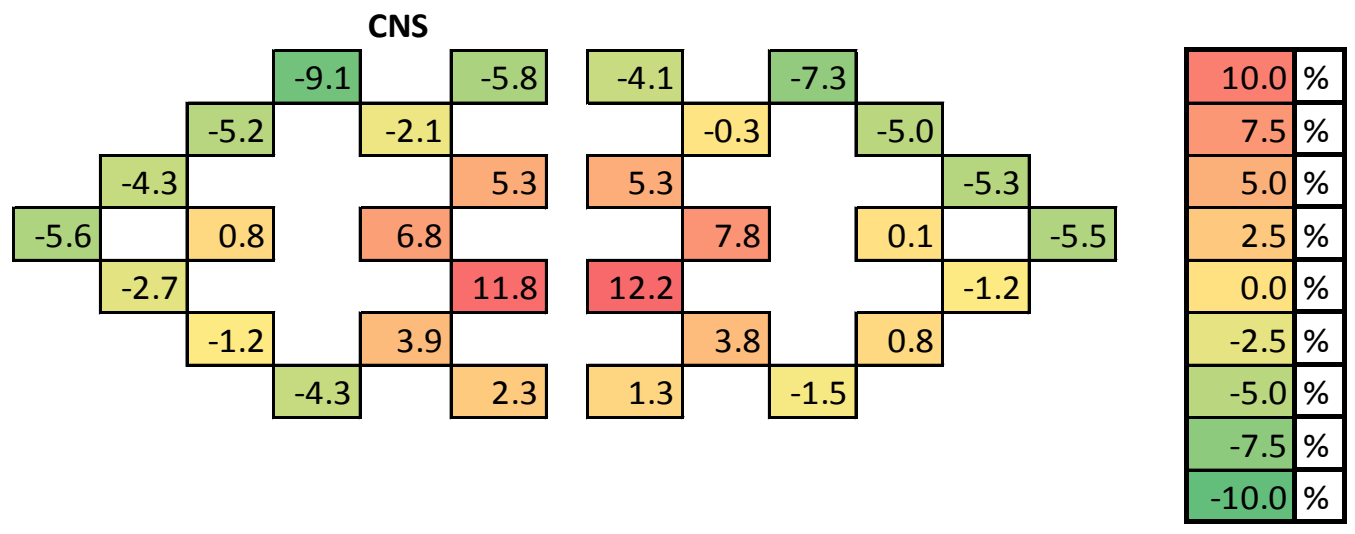

Figure 4.30 Change (\%) in Fast Flux within the Gap, LEU vs. HEU

\subsubsection{Reactor Kinetics Parameters}

The reactor kinetics parameters of interest are the precursor fractions for six delayed neutron groups, their decay constants, and the prompt neutron lifetime. These parameters are used in the point reactor kinetics model used for the accident analysis discussed in Chapter 13. The details of the derivation of these parameters are given in (Hanson, 2012b). The following sections summarize that work.

\subsubsection{Delayed Neutron Parameters}

The capability to calculate values of the delayed neutron fraction from each precursor group, $\beta_{i}$ is incorporated in the MCNP5-1.60 code (Kiedrowski, 2010). $\beta_{i}$ is obtained by an integration over the core using adjoint weighting according to:

$$
\beta_{i}=\frac{\left\langle\psi^{*}, B_{\mathrm{i}} \psi\right\rangle}{\left\langle\psi^{*}, \mathrm{~F} \psi\right\rangle}
$$


In this equation $\psi$ is the (forward) neutron flux, $\psi^{*}$ is the adjoint neutron flux, $B_{i}$ is the delayed neutron operator for each precursor group, $i$, and $\mathrm{F}$ is the fission term operator. All fissionable nuclides are represented within these operators. The brackets, $<>$, represent integration over all phase-space within the NBSR.

The average decay constant, $\lambda_{\mathrm{i}}$ is simply the average of the decay constants $\lambda_{\mathrm{ijk}}$, for the $k$ fission products within that group, which are different for the different isotopes $\mathrm{j}$ fissioned, and may vary with energy of the neutron causing fission. For ENDF/B-VII data, the decay constants are only functions of the isotope fissioned; therefore, the average decay constant for precursor $i$ is found from

$$
\lambda_{i}=\sum_{j} h_{i j} \lambda_{i j}
$$

where $h_{i j}$ is the fraction of fission from isotope $j$ that produced precursor $i$ in the system. The fraction of fissions from each major actinide ( $\geq 0.01 \%$ contribution) as calculated by MCNPX is given in Table 4.15. The values in the table are for the HEU and LEU fuels at both SU and EOC.

Table 4.15 Percent of Fissions as Calculated by MCNPX

\begin{tabular}{|l|c|c|c|c|}
\hline & \multicolumn{2}{|c|}{ HEU } & \multicolumn{2}{c|}{ LEU } \\
\hline & SU & EOC & SU & EOC \\
\hline${ }^{235} \mathrm{U}$ & 99.73 & 99.67 & 96.35 & 95.71 \\
\hline${ }^{236} \mathrm{U}$ & 0.02 & 0.02 & 0.02 & 0.02 \\
\hline${ }^{238} \mathrm{U}$ & 0.01 & 0.01 & 0.49 & 0.49 \\
\hline${ }^{239} \mathrm{Pu}$ & 0.23 & 0.27 & 2.99 & 3.54 \\
\hline${ }^{241} \mathrm{Pu}$ & 0.02 & 0.02 & 0.16 & 0.24 \\
\hline
\end{tabular}

With inventories for SU and EOC, MCNP5-1.60 was used to calculate the delayed neutron parameters. The calculated values of $\beta, \beta_{i}$, and $\lambda_{\mathrm{i}}$ are shown in Table 4.16. Also shown are the statistical standard deviations for the delayed neutron fraction as calculated by MCNP5-1.60. The results show that the LEU core has a slightly smaller delayed neutron fraction relative to the HEU core. This is a result of the increase in the contribution from ${ }^{239} \mathrm{Pu}$ which has a much smaller delayed neutron fraction than ${ }^{235} \mathrm{U}$. 
Table 4.16 Recommended Delayed Neutron Parameters for the HEU and LEU Cores

\begin{tabular}{|c|c|c|c|c|c|c|}
\hline \multicolumn{7}{|c|}{ SU } \\
\hline \multicolumn{4}{|c|}{ HEU } & \multicolumn{3}{|c|}{ LEU } \\
\hline Group & $\lambda_{\mathrm{i}}(1 / \mathrm{s})$ & $\beta_{\mathrm{i}}$ & $\sigma$ & $\lambda_{\mathrm{i}}(1 / \mathrm{s})$ & $\beta_{\mathrm{i}}$ & $\sigma$ \\
\hline 1 & 0.01249 & 0.00022 & 0.00001 & 0.01249 & 0.00020 & 0.00001 \\
\hline 2 & 0.03182 & 0.00111 & 0.00002 & 0.03177 & 0.00108 & 0.00002 \\
\hline 3 & 0.10938 & 0.00107 & 0.00002 & 0.10942 & 0.00105 & 0.00002 \\
\hline 4 & 0.31700 & 0.00301 & 0.00003 & 0.31731 & 0.00301 & 0.00003 \\
\hline 5 & 1.35386 & 0.00092 & 0.00002 & 1.35205 & 0.00085 & 0.00002 \\
\hline 6 & 8.63611 & 0.00032 & 0.00001 & 8.65543 & 0.00030 & 0.00001 \\
\hline$\beta$ & $=\Sigma \beta_{\mathrm{i}}$ & 0.00665 & 0.00005 & & 0.00650 & 0.00005 \\
\hline \multicolumn{7}{|c|}{ EOC } \\
\hline \multicolumn{4}{|c|}{ HEU } & \multicolumn{3}{|c|}{ LEU } \\
\hline Group & $\lambda_{\mathrm{i}}(1 / \mathrm{s})$ & $\beta_{\mathrm{i}}$ & $\sigma$ & $\lambda_{\mathrm{i}}(1 / \mathrm{s})$ & $\beta_{\mathrm{i}}$ & $\sigma$ \\
\hline 1 & 0.01249 & 0.00021 & 0.00001 & 0.01249 & 0.00020 & 0.00001 \\
\hline 2 & 0.03182 & 0.00112 & 0.00002 & 0.03176 & 0.00109 & 0.00002 \\
\hline 3 & 0.10938 & 0.00110 & 0.00002 & 0.10942 & 0.00102 & 0.00002 \\
\hline 4 & 0.31700 & 0.00302 & 0.00003 & 0.31730 & 0.00301 & 0.00003 \\
\hline 5 & 1.35374 & 0.00087 & 0.00002 & 1.35118 & 0.00087 & 0.00002 \\
\hline 6 & 8.63558 & 0.00030 & 0.00001 & 8.65038 & 0.00030 & 0.00001 \\
\hline \multicolumn{2}{|c|}{$\beta=\Sigma \beta_{i}$} & 0.00661 & 0.00004 & & 0.00648 & 0.00004 \\
\hline
\end{tabular}

\subsubsection{Photoneutron Contribution to the Delayed Neutrons}

In the $\mathrm{D}_{2} \mathrm{O}$-moderated NBSR the delayed neutron fraction has a non-negligible contribution from photoneutrons through the ${ }^{2} \mathrm{H}(\gamma, \mathrm{n})^{1} \mathrm{H}$ nuclear reaction. The sources of the gamma rays for the delayed portion of those photoneutrons are from the decay of fission products. The delayed neutrons from the $(\gamma, \mathrm{n})$ reactions are lumped into representative groupings. The values measured by (Johns, 1954) are used for the contribution of the delayed neutrons that result from $(\gamma, \mathrm{n})$ reactions. Those values are shown in Table 4.17.with the groups numbered from 7 to 14 . The contribution of the delayed neutrons from photoneutron interactions is approximately $4.5 \%$ of the total fraction. 
Table 4.17 Delayed Neutrons from the ${ }^{2} \mathbf{H}(\gamma, n){ }^{1} \mathbf{H}$ Nuclear Reaction

\begin{tabular}{|c|c|c|}
\hline Group & $\boldsymbol{\lambda}_{\mathbf{i}} \mathbf{( 1 / s )}$ & $\boldsymbol{\beta}_{\mathbf{i}}$ \\
\hline 7 & 0.278 & 0.000203 \\
\hline 8 & 0.0169 & 0.000065 \\
\hline 9 & 0.0049 & 0.0000223 \\
\hline 10 & 0.00152 & 0.0000107 \\
\hline 11 & $4.27 \times 10-4$ & 0.0000066 \\
\hline 12 & $1.16 \times 10-4$ & 0.0000074 \\
\hline 13 & $4.41 \times 10-5$ & 0.000001 \\
\hline 14 & $3.65 \times 10-6$ & 0.00000033 \\
\hline \multicolumn{2}{|c|}{$\beta=\Sigma \beta_{\mathrm{i}}$} & 0.000316 \\
\hline
\end{tabular}

\subsubsection{Prompt Neutron Lifetime}

The prompt neutron lifetime was calculated using the fundamental definition of the neutron lifetime with adjoint weighting that has been developed for MCNP5-1.60:

$$
\ell_{p}=\frac{\left\langle\psi^{*}, 1 / \mathrm{v} \psi\right\rangle}{\left\langle\psi^{*}, \mathrm{~F} \psi\right\rangle}
$$

where the symbols are defined as for the delayed neutron fraction calculation and $\mathrm{v}$ is neutron speed. The results of the analyses for the HEU and LEU fuels at SU and EOC are presented in Table 4.18 under the heading "MCNP."

(Hanson, 2012a) also provides results for the calculation of $\ell_{p}$ using two other methods.

Although the results are similar, the variation ( $\sim 40 \mathrm{~s})$ demonstrates that the uncertainty in $\ell_{p}$ is much greater than the statistical uncertainty $(\sim 1 \mu \mathrm{s})$ associated with the calculation. The three methods show that the prompt neutron lifetime for the SU condition is less than the prompt neutron lifetime for the EOC condition. The calculations also show that the prompt neutron lifetime for the LEU fuel is expected to be shorter than the prompt neutron lifetime for the HEU fuel.

A conservative value of the prompt neutron lifetime is used for the transient safety analysis. The smaller the lifetime, the faster a transient takes place and therefore, the conservative value must not exceed the smallest calculated value. Based on this approach, the values utilized for the safety analysis in Chapter 13 are $650 \mu$ s and $750 \mu$ s for the HEU core at SU and EOC, respectively, and $600 \mu$ s and $700 \mu$ s for the LEU core at SU and EOC, respectively, as shown in Table 4.18. 
Table 4.18 Prompt Neutron Lifetime for the HEU and LEU Cores

\begin{tabular}{|l|c|c|c|c|}
\hline & \multicolumn{2}{|c|}{ HEU } & \multicolumn{2}{c|}{ LEU } \\
\hline & SU & EOC & SU & EOC \\
\hline MCNP & 698 & 802 & 651 & 730 \\
\hline Recommended & 650 & 750 & 600 & 700 \\
\hline
\end{tabular}

\subsubsection{Technical Specifications}

This section contains the safety limits, limiting safety system settings (LSSSs), and limiting conditions for operation (LCOs) (NIST, 2009) that are changed as a result of conversion; specifically with respect to nuclear design parameters.

\subsubsection{Safety Limits}

To maintain the integrity of the fuel cladding and prevent the release of significant amounts of fission products, Technical Specification (TS) 2.1, Safety Limit, defines the limit based on the temperature at which blistering is first considered possible, which is $450^{\circ} \mathrm{C}\left(842^{\circ} \mathrm{F}\right)$ for the HEU fuel. According to (INL, 2014) this will change for the LEU fuel and TS 2.1 will need to be changed. However, limited information was available at the time this conversion SAR was written and hence, for the purposes of this report, a very conservative blister temperature is used for LEU. The change of TS 2.1 is given below and details of why this blister temperature was chosen are found in Section 13.1.

Specification: The reactor fuel cladding temperature shall not exceed $842^{\circ} \mathrm{F}\left(450^{\circ} \mathrm{C}\right)$ $\underline{716^{\circ} \mathrm{F}\left(380^{\circ} \mathrm{C}\right)}$ for any operating conditions of power and flow.

The approach to protect against the safety limit remains as stated in the Basis for TS 2.1, namely:

Basis: Maintaining the integrity of the fuel cladding requires that the cladding remain

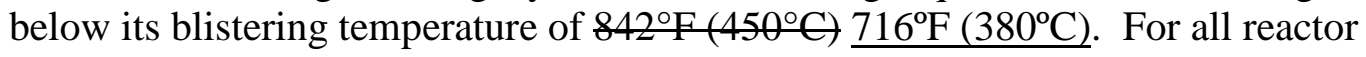
operating conditions that avoid either a departure from nucleate boiling (DNB), or exceeding the Critical Heat Flux (CHF), or the onset of flow instability (OFI), cladding temperatures remain substantially below the fuel blistering temperature. Conservative calculations have shown that limiting combinations of reactor power and reactor coolant system flow and temperature will prevent DNB and thus fuel blistering.

\subsubsection{Limiting Conditions for Operation}

No substantive changes are required for either the LSSSs or LCOs. However, since the fuel has changed, minor modifications must be made to several LCOs.

LCO 3.1.2, Reactivity Limitations, must be modified to recognize that although the reactivity limits expressed in \% do not change, expressing them in dollars does change as the result of the change in delayed neutron fraction. 


\section{Specifications:}

1. The maximum available excess reactivity for the reference core conditions shall not exceed $15 \% \Delta \rho$ (approximately $\$ 2022$ )

2. The reactor shall not be operated unless shutdown margin provided by the shim arm is greater than $0.68757 \% \Delta \rho(\$ 1.0)$ with:

a) The reactor in any core condition, and

b) All movable experiments in their most reactive condition.

LCO 3.1.4, Fuel Burnup, must be modified to account for the different fuel volume. At the time of the writing of this SAR no information was available on potential limits to the maximum fission density, which in turn might also impact the allowable average fission density. The following only addresses the different fuel volume.

Specification: The average fission density shall not exceed $\underline{4.5} 2 \times 10^{27} \underline{\mathrm{fissions}} / \mathrm{m}^{3}$.

Basis: Fuel elements in the NBSR are burned for seven or eight cycles. An eight cycle fuel element has an average fission density of approximately $4.11 .9 \times 10^{27}$ fissions $/ \mathrm{m}^{3}$ (Brown, 2014b). Allowing for a $10 \%$ increase provides the specification. The $\mathrm{U}_{3} \mathrm{O}_{\mathrm{g}}-$ Al dispersion MTR fuels have been in widespread use for over 40 years. Extensive testing of fuel plates has been performed to determine the limits on fission density as a function of fuel loading. Several measurements of swelling in fuel plates show that NBSR fuel, which is moderately loaded at $18 \%$ is well below the curve that represents the allowable limit of burnup.

\subsection{Thermal-Hydraulic Design}

\subsubsection{Design Basis}

The design basis of the thermal-hydraulic design of the NBSR is that there shall be no fuel damage during normal operation and no fuel damage resulting in release of fission products from any credible accident (see also Chapter 13). For normal operating conditions, the criterion chosen was that the heat transfer to the primary coolant shall not exceed critical heat flux (CHF) conditions, including any excursive instability; the latter being defined by "onset of flow instability" (OFI). This would preclude blistering and the potential for fuel damage. The temperature at which blistering might occur is the Safety Limit in the Technical Specifications and hence, also a criterion for fuel damage.

\subsubsection{Flow Distribution in the Core}

The flow geometry for the NBSR is discussed in detail in (Cheng, 2004) where critical dimensions, elevations and other pertinent data are given. The core consists of 30 fuel elements that are fed by two plenums at the bottom of the vessel. One plenum feeds the inner core consisting of six elements in the innermost area of the core, while the other feeds the remaining 24 elements. The primary coolant flow is distributed between these two plenums by the inherent flow resistance of the two different paths, and has been measured at total flows of up to $560 \mathrm{l} / \mathrm{s}$ (8700 gpm) as $148 \mathrm{l} / \mathrm{s}(2300 \mathrm{gpm})$ for the inner plenum and $412 \mathrm{l} / \mathrm{s}$ (6400 gpm) for the outer 
plenum. Approximately 4\% of the flow bypasses the fuel elements in the core (NBS, 1980). The inlet temperature for the coolant is $100^{\circ} \mathrm{F}\left(37.8^{\circ} \mathrm{C}\right)$ and the pressure drop across the core is 12 psi $\left(0.84 \mathrm{~kg} / \mathrm{cm}^{2}\right)$

\subsubsection{Power Distribution in the Core}

The power distribution in the fission plates is assumed to be given by the fission density as calculated by the computer code MCNPX. This is a conservative assumption, as $14 \%$ of the energy is in the form of $\gamma$-rays and neutrons, and will be deposited much more uniformly throughout the core. A conservative estimate of the energy deposited in the fuel is 95\% (Hanson, 2005b). Another conservatism is the fact that burnup is assumed to be uniform over each halfelement. In reality the distribution of burnup in a half-element is roughly proportional to power density and this tends to lower high power densities. This does not apply to fresh fuel but, as will be discussed below, the highest powers are in burned fuel elements. The degree of conservatism that is the result of not taking into account the burnup distribution is discussed in (Brown, 2013).

The fission rate in the fuel plates as a function of shim arm position and core depletion is determined throughout the cycle. The model used represents the geometry of the system in great detail, and gives agreement with startup shim arm positions and liquid hydrogen cold source performance. The limiting case for the thermal-hydraulic design is the SU core. With four new fuel elements, criticality occurs when the shim safety arms are inserted furthest into the core. This insertion results in flux compression into the bottom half of the fuel elements.

For each fuel element in the core, the power produced in each plate is used to calculate a hot channel, which is the coolant channel into which the most heat is deposited from the fuel. The local fission rate, a conservative analog to the local energy deposition, was calculated assuming a (nominal) 2x2 cm mesh throughout the core. The calculations were performed for both the HEU and LEU cores. Thermal-hydraulic analyses were performed using these three-dimensional power distributions to ensure the reactor can be safely operated at all points in the fuel cycle. The model allows definition of a "hot spot," the mesh square with the highest energy deposition, and "hot stripe" the vertical fuel plate "stripe" with the highest energy deposition. A vertical hot stripe represents $1 / 3$ the width of a single fuel plate. In general, the "hot spots" are used for evaluation of the critical heat flux condition and the hot stripes are used for evaluation of the OFI condition. More details are given in (Baek, 2012).

\subsubsection{Determination of Limiting Conditions}

In order to determine how close the reactor operates to CHF or OFI a statistical methodology (Cheng, 2004 and Cuadra, 2011) is first used to determine acceptable limits. Cumulative distribution functions are obtained for critical heat flux ratio (CHFR), and onset of flow instability ratio (OFIR). The methodology is identical to that used for the licensing safety analysis in the past with two important changes: The correlation used for CHF has been changed from that due to Mirshak to one from Sudo-Kaminaga (Kaminaga, 1998) and the correlation for OFI is that of Saha-Zuber (Saha, 1974 and Oh, 1996) rather than Costa. These correlations are discussed in (Baek, 2014) along with their application. 


\subsubsection{Critical Heat Flux}

The Sudo-Kaminaga correlation represents an improvement over the Mirshak correlation due to the enhanced geometric similarity, increased dependence on the full range of actual operating conditions in the NBSR, and an overall approach that is more mechanistic. It was developed for vertical rectangular channels in JRR-3 (Japan Research Reactor unit 3). The CHF experiments included the effect of mass flux, inlet subcooling, outlet subcooling, flow direction, pressure, as well as the channel configuration. Experiments were carried out within the range of pressure of 0.1 to $4 \mathrm{MPa}$, mass flux of $-25,800$ to $6250 \mathrm{~kg} / \mathrm{m}^{2}$-s, including stagnant flow conditions, inlet subcooling of 1 to $213 \mathrm{~K}$, outlet condition with subcooling of 0 to $74 \mathrm{~K}$ and quality of 0 to 1.0 , and the ratio of heated length to equivalent hydraulic diameter L/De of 8 to 240. The correlations proposed by Sudo and Kaminaga are mass flux and flow direction dependent and there are three separate regions, based on the dimensionless mass flux.

\subsubsection{Onset of Flow Instability Correlation}

The most relevant instability for the NBSR, the Ledinegg static instability, has its origin in a simple effect. As water flow in a heated channel is reduced, a point will be reached where boiling will occur. At a later point significant amounts of vapor will be present in the channel. The presence of this vapor will increase the pressure drop, and when this effect is large enough, this increase will overwhelm the decrease in pressure drop arising from the flow decrease. This is known as the onset of flow instability. At this point, the overall pressure drop in the hot channel of a fuel element will increase, and flow will be reduced (if the channel spans an inlet and outlet header, with other, lower power channels in parallel). This condition causes a flow instability, which will result in rapid loss of adequate cooling for that channel.

The OFI is determined by assuming that the onset of net vapor generation is a conservative threshold for OFI, and the Saha-Zuber criteria are used.

\subsubsection{Statistical Analysis of Thermal-Hydraulic Parameters}

The statistical analysis uses a Monte Carlo method and assumes that each factor which contributes to the thermal-hydraulic variables of interest is normally distributed. The cumulative distribution functions (CDFs) are calculated for steady-state full power conditions, and are used to establish acceptance criteria for CHFR and OFIR under accident conditions. For each of these two hot channel variables, the CDF was used to determine the limiting value such that there was a fixed probability of not exceeding this value. The probabilities considered were 90\%, 95\%, and 99.9\%. More information is given in (Cheng, 2004 and Cuadra, 2014).

Table 4.19 shows the dimensionless hot channel factors of interest for the HEU and LEU cores with their corresponding standard deviations $(\sigma)$, assuming a normal distribution. The source of information for these numbers is also given. The analyses assume a constant pressure, and constant thermal properties. 
Table 4.19 Hot Channel Factors and References to Underlying Tolerances

\begin{tabular}{|c|c|c|c|c|c|}
\hline $\begin{array}{c}\text { Source of } \\
\text { Uncertainty }\end{array}$ & $\begin{array}{c}\text { Normalized } \\
\text { Variable } \\
\text { Identification }\end{array}$ & $\begin{array}{c}\text { Standard } \\
\text { Deviation }\end{array}$ & Source & $\begin{array}{c}\text { Standard } \\
\text { Deviation }\end{array}$ & Source \\
\hline $\begin{array}{c}\text { Reactor Power } \\
\text { Measurement }\end{array}$ & $\mathrm{F}_{1}$ & 0.025 & $\begin{array}{c}\text { Table 3.2-1 of } \\
\text { (NBS, 1980) }\end{array}$ & 0.025 & Same as HEU \\
\hline $\begin{array}{c}\text { Power Density } \\
\text { Calculation }\end{array}$ & $\mathrm{F}_{2}$ & 0.040 & $\begin{array}{c}\text { Table 3.2-1 of } \\
\text { (NBS, 1980) / } \\
\text { Engineering } \\
\text { judgment }\end{array}$ & 0.040 & Same as HEU \\
\hline $\begin{array}{c}\text { Channel } \\
\text { Dimensional } \\
\text { Tolerance (local) }\end{array}$ & $\mathrm{F}_{3}$ & 0.042 & $\begin{array}{c}\text { NBSR Dwg \# E- } \\
\text { 04-016 in (NIST, } \\
\text { 2010b) }\end{array}$ & 0.042 & $\begin{array}{c}\text { Fuel element } \\
\text { assembly } \\
\text { assumed same } \\
\text { as HEU }\end{array}$ \\
\hline $\begin{array}{c}\text { Channel } \\
\text { Dimensional } \\
\text { Tolerance } \\
\text { (average) }\end{array}$ & $\mathrm{F}_{4}$ & 0.035 & $\begin{array}{c}\text { Dwg \# E-04-016 } \\
\text { in (NIST, 2010b) }\end{array}$ & 0.035 & $\begin{array}{c}\text { Fuel element } \\
\text { assembly } \\
\text { assumed same } \\
\text { as HEU }\end{array}$ \\
\hline $\begin{array}{c}\text { Velocity } \\
\text { Distribution } \\
\text { Measurement }\end{array}$ & $\mathrm{F}_{5}$ & 0.025 & $\begin{array}{c}\text { Table 3.2-1 of } \\
\text { (NBS, 1980) }\end{array}$ & 0.025 & \begin{tabular}{c} 
Same as HEU \\
\hline $\begin{array}{c}\text { Primary Flow } \\
\text { Rate } \\
\text { Measurement }\end{array}$
\end{tabular} \\
\hline $\begin{array}{c}\text { Fuel Loading } \\
\text { Tolerance (local) }\end{array}$
\end{tabular}


The fuel element plates in the LEU core have identical dimensions to the current HEU fuel, but have fuel meat composed of monolithic U10Mo rather than dispersion fuel. Additionally, the U10Mo foils are thinner than the dispersion fuel, so the portion of the fuel plate that covers the fuel (the cladding) will be thicker. Because of the uncertainty in the fabrication process at the time of writing this SAR, the dimensional tolerances (local and average) and fuel loading tolerances (local and average) are not exactly known, but scoping calculations, with uncertainties based on the HEU values, could be performed to identify trends and provide guidance on “acceptable” values for the LEU tolerances.

The results are shown in Table 4.20 for the normalized random value for CHFR, for three different probability levels for not reaching CHF. Likewise, Table 4.21 shows results for the normalized random value for OFIR.

Table 4.20 Statistical Analysis Results for CHFR

\begin{tabular}{|c|c|c|}
\hline Probability Level & HEU & LEU \\
\hline $90 \%$ & 1.30 & 1.30 \\
\hline $95 \%$ & 1.39 & 1.39 \\
\hline $99.9 \%$ & 1.78 & 1.78 \\
\hline
\end{tabular}

Table 4.21 Statistical Analysis Results for OFIR

\begin{tabular}{|c|c|c|}
\hline Probability Level & HEU & LEU \\
\hline $90 \%$ & 1.31 & 1.31 \\
\hline $95 \%$ & 1.40 & 1.40 \\
\hline $99.9 \%$ & 1.83 & 1.83 \\
\hline
\end{tabular}

During normal operation and for transients, the calculated values for the minimum CHFR and OFIR are determined using the methodology described in Chapter 13. The results for minimum values during normal steady state operation, found in Table 4.22, show very large margins to limiting conditions.

Table 4.22 Steady State Thermal-Hydraulic Parameters

\begin{tabular}{|c|c|c|}
\hline & HEU & LEU \\
\hline CHFR SU & 4.03 & 4.12 \\
\hline CHFR EOC & 3.99 & 3.96 \\
\hline OFIR SU & 5.50 & 5.61 \\
\hline OFIR EOC & 6.17 & 6.15 \\
\hline
\end{tabular}




\subsubsection{Limiting Hot Spot and Hot Stripe Conditions}

For establishment of thermal hydraulic limits, the SU conditions are limiting, as they provide a power distribution that is concentrated in the lower half of the core. For some accident analyses (reactivity excursions) examined in Chapter 13, the EOC conditions are limiting, as a result of the slower rate of insertion of negative reactivity after a reactor trip. In all cases, the hot element is in the outer plenum, the hot channel for each assembly is one between two fuel plates nearest the fuel assembly edge, and the hot stripe is closest to the edge of a plate. The latter two results are readily understood by considerations of moderation-the hot channel and hot stripe are located where they view the most $\mathrm{D}_{2} \mathrm{O}$, as the core is under-moderated.

For the purposes of thermal limit analysis, the SU hot-spot cases for the inner and outer plenums are listed in Table 4.23 and the SU hot-stripe cases for the inner and outer plenums are listed in Table 4.24. The values reported here are derived from the detailed power distribution calculation in MCNPX, with the exception of the peak heat fluxes, which are calculated using RELAP5 (Baek 2012).

Table 4.23 Limiting Hot-Spot Conditions at SU

\begin{tabular}{|l|c|c|c|c|}
\hline & \multicolumn{2}{|c|}{ HEU } & \multicolumn{2}{c|}{ LEU } \\
\hline & $\begin{array}{c}\text { Inner } \\
\text { plenum }\end{array}$ & $\begin{array}{c}\text { Outer } \\
\text { plenum }\end{array}$ & $\begin{array}{c}\text { Inner } \\
\text { plenum }\end{array}$ & $\begin{array}{c}\text { Outer } \\
\text { plenum }\end{array}$ \\
\hline Limiting element & $\mathrm{H}-3$ & $\mathrm{H}-1$ & $\mathrm{~F}-3$ & $\mathrm{~K}-2$ \\
\hline Total element power & $726 \mathrm{~kW}$ & $776 \mathrm{~kW}$ & $772 \mathrm{~kW}$ & $654 \mathrm{~kW}$ \\
\hline Radial peaking factor & 1.09 & 1.16 & 1.16 & 0.98 \\
\hline Upper half-element & $299 \mathrm{~kW}$ & $368 \mathrm{~kW}$ & $323 \mathrm{~kW}$ & $258 \mathrm{~kW}$ \\
\hline Lower half-element & $427 \mathrm{~kW}$ & $408 \mathrm{~kW}$ & $449 \mathrm{~kW}$ & $396 \mathrm{~kW}$ \\
\hline Hot-spot peaking factor & 2.09 & 2.48 & 2.40 & 2.43 \\
\hline Peak heat flux & $1241 \mathrm{~kW} / \mathrm{m}^{2}$ & $1472 \mathrm{~kW} / \mathrm{m}^{2}$ & $1425 \mathrm{~kW} / \mathrm{m}^{2}$ & $1443 \mathrm{~kW} / \mathrm{m}^{2}$ \\
\hline
\end{tabular}

Table 4.24 Limiting Hot-Stripe Conditions at SU

\begin{tabular}{|l|c|c|c|c|}
\hline & \multicolumn{2}{|c|}{ HEU } & \multicolumn{2}{c|}{ LEU } \\
\hline & $\begin{array}{c}\text { Inner } \\
\text { plenum }\end{array}$ & $\begin{array}{c}\text { Outer } \\
\text { plenum }\end{array}$ & $\begin{array}{c}\text { Inner } \\
\text { plenum }\end{array}$ & $\begin{array}{c}\text { Outer } \\
\text { plenum }\end{array}$ \\
\hline Limiting element & $\mathrm{H}-3$ & $\mathrm{H}-1$ & $\mathrm{H}-3$ & $\mathrm{H}-1$ \\
\hline Total element power & $727 \mathrm{~kW}$ & $776 \mathrm{~kW}$ & $770 \mathrm{~kW}$ & $722 \mathrm{~kW}$ \\
\hline Radial peaking factor & 1.09 & 1.16 & 1.15 & 1.08 \\
\hline Upper half-element & $299 \mathrm{~kW}$ & $368 \mathrm{~kW}$ & $369 \mathrm{~kW}$ & $342 \mathrm{~kW}$ \\
\hline Lower half-element & $427 \mathrm{~kW}$ & $408 \mathrm{~kW}$ & $451 \mathrm{~kW}$ & $380 \mathrm{~kW}$ \\
\hline Hot-stripe peaking factor & 1.34 & 1.68 & 1.49 & 1.62 \\
\hline Hot-stripe power & $297 \mathrm{~kW}$ & $373 \mathrm{~kW}$ & $330 \mathrm{~kW}$ & $360 \mathrm{~kW}$ \\
\hline
\end{tabular}




\subsubsection{Shutdown Cooling}

The NBSR is equipped with shutdown cooling [see Chapter 5 in (NIST, 2010a)], which provides ample cooling for all shutdown conditions. One of the accidents analyzed herein (see Chapter 13) includes loss of off-site power (and hence main primary pumps), followed by failure of both redundant shutdown pumps. This scenario results in no damage to the fuel, showing that natural convection and pool boiling cooling is adequate to provide cooling of the fuel in the shutdown condition, even immediately following a scram due to loss of all primary pumps.

The decay heat that must be removed after shutdown is shown in Figure 4.31 for both HEU and LEU fuel at end-of-cycle. The curves were generated using RELAP5 (see Section 13.2). As can be seen, there is essentially no difference between the two curves.

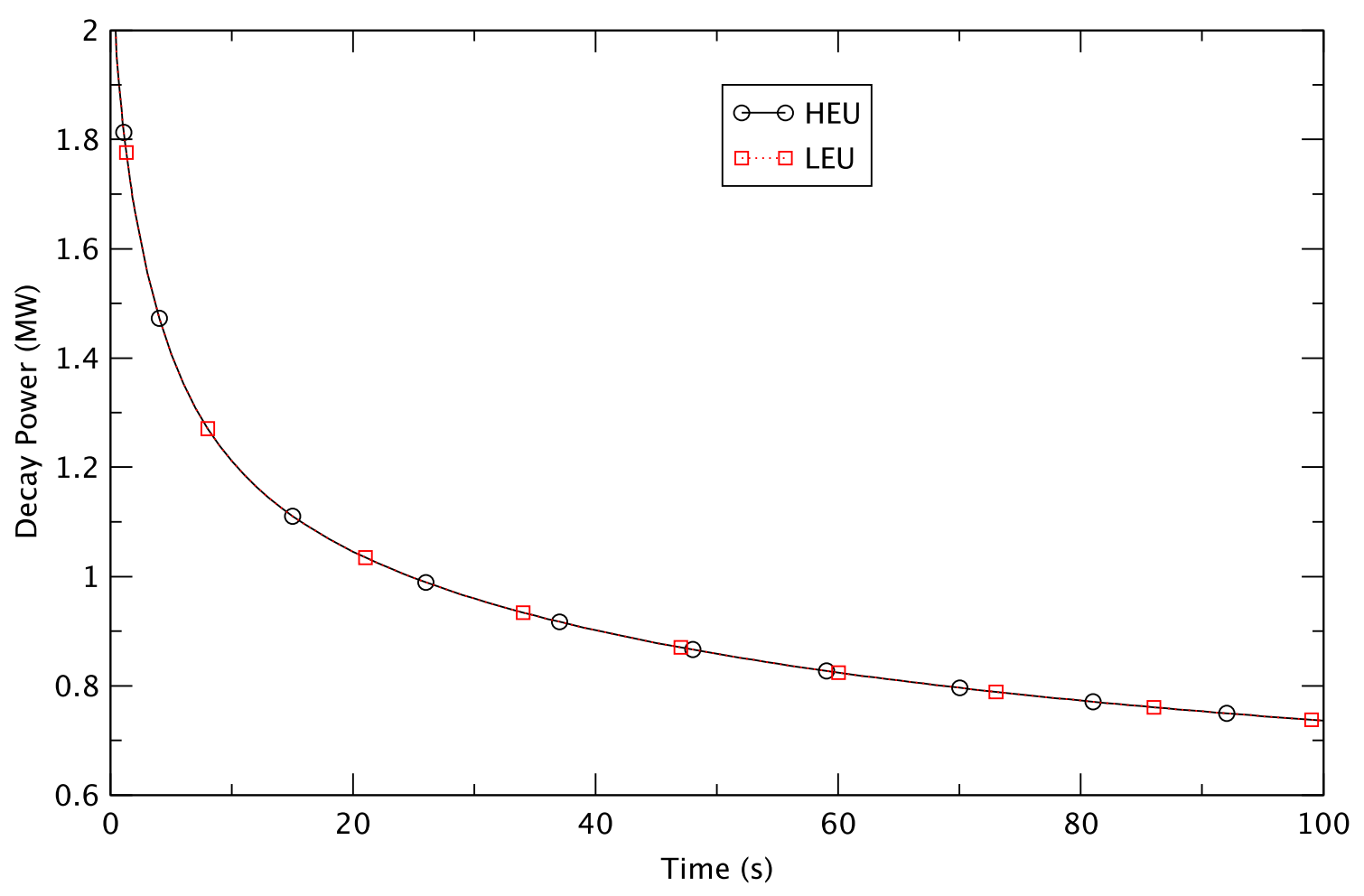

Figure 4.31 Decay Power at EOC

\subsubsection{Operation with Natural Convection}

A limiting safety systems setting states (NIST, 2009) that "Reactor power, with natural circulation cooling flow, shall not exceed $10 \mathrm{~kW}$." The RELAP5 code has been used to analyze operation at $100 \mathrm{~kW}$ with natural convection allowed, and shows that safe operation is possible at this power. The peak fuel centerline temperature is about $54 \mathrm{~K}$ below the saturation temperature. The peak heat flux is at least an order of magnitude below the calculated CHF and the wall heat flux corresponding to the OFI condition. These conditions are explained in Chapter 13 in the context of accident analysis (see Section 13.7). 


\subsection{References}

Baek, J-S., “Power distribution in NBSR Core for RELAP5 Safety Analysis,” BNL Technical Report, Brookhaven National Laboratory, Upton, NY, May 25, 2012.

Baek, J.S., Cheng, L.-Y., Hanson, A.L., Cuadra, A., Brown, N.R., and Diamond, D.J., Accident Analysis for the NIST Research Reactor Before and After Fuel Conversion - Revision 2,” BNL98524-2014-IR-R2, Brookhaven National Laboratory, Upton, NY, July 22, 2014.

Bess, J., "September 2011 Status Update for the NRAD Reactor Benchmark Models," Proceedings of the TRTR Meeting, Idaho Falls, ID, 2011.

Brown, N.R., Hanson, A.L., and Diamond, D.J., "Local Burn-up Effects in the NBSR Fuel Element,” BNL-99145-2013-IR, Brookhaven National Laboratory, Upton, NY, January 23, 2013.

Brown, N.R., Hanson, A.L., and Diamond, D.J., "Revised Estimates for the Maximum Fission Density in the NBSR,” BNL Memorandum, Brookhaven National Laboratory, February 21, 2014a.

Brown, N.R., Baek, J.S., Hanson, A.L., Cuadra, A., Cheng, L-Y. and Diamond, D.J., “Irradiation Experiment Conceptual Design Parameters for NBSR Fuel Conversion, Rev.2,” BNL-998972014-IR-R2, Brookhaven National Laboratory, Upton, NY, April 30, 2014b.

Burkes, D.E., Mickum, G.S. and Wachs, D.M., “Thermophysical Properties of U-10Mo Alloy,” INL/EXT-10-19373, Idaho National Laboratory, Idaho Falls, ID, November 2010.

Cheng, L-Y. et al., "Physics and Safety Analysis for the NIST Research Reactor,” BNL-NIST0803, Rev. 1, Brookhaven National Laboratory, Upton, NY, April 2004.

Cheng, L-Y., "Heat Conduction in an NBSR Fuel Plate-Effect on Wall Heat Flux,” BNL memorandum, Brookhaven National Laboratory, Upton, NY, April 6, 2010.

Cuadra, A., and Cheng, L-Y., "Statistical Hot Channel Analysis for the NBSR,” BNL-1052882014-IR, Brookhaven National Laboratory, Upton, NY, May 27, 2011.

Gazit, M., “Accuracy of Measurements,” Email to L-Y. Cheng, National Institute of Standards and Technology, Gaithersburg, MD, July 31, 2002.

Hanson, A. and Diamond, D., "Determination of Inventories and Power Distributions for the NBSR,” Proceedings of the TRTR/IGORR Joint Meeting, Gaithersburg, MD, September 12-16, 2005a.

Hanson, A. and Diamond, D., “Energy Deposition in the NBSR,” BNL internal memo, Brookhaven National Laboratory, February 2, 2005b. 
Hanson, A.L. and Diamond, D.J., "Calculation of Design Parameters for an Equilibrium LEU Core in the NBSR,” Technical Report, Brookhaven National Laboratory, Upton, NY, September 29, 2011a.

Hanson, A., and Diamond, D., "A Neutronics Methodology for the NIST Research Reactor Based on MCNPX," in 19th International Conference on Nuclear Engineering (ICONE19), Chiba, Japan, May 16-19, 2011b.

Hanson, A.L., and Diamond, D.J., "Prompt Neutron Lifetime for the NBSR Reactor,” Trans. Amer. Nucl. Soc., tbd June 2012a.

Hanson, A.L., and Diamond, D.J., “Calculation of Kinetics Parameters for the NBSR,” BNL97007-2012, Brookhaven National Laboratory, Upton, NY, March 2012b.

Hanson, A.L., Brown, N.R., and Diamond, D.J, "Effect of Shim Arm Depletion in the NBSR,” BNL-99764-2013-IR, Brookhaven National Laboratory, Upton, NY, February 21, 2013.

INL, “Specification for Low Enriched Uranium Monolithic Fuel Plates,” SPC-1635, Idaho National Laboratory (INL), August 16, 2013.

INL, Discussions at the High Performance Research Reactor Working Group Meeting in Pasco, WA, Idaho National Laboratory (INL), July 2014.

Johns, M.S.B., "Photoneutrons in a Heavy Water Pile," Canadian J. of Physics, 32, pp. 136-152, 1954.

Kaminaga, M., Yamamoto, K., and Sudo, Y., "Improvement of Critical Heat Flux Correlation for Research Reactors using Plate-Type Fuel,” J. Nucl. Sci. Technol. 35[12], 943-951, 1998.

Kiedrowski, B. et al., "MCNP5-1.6 Feature Enhancements and Manual Clarifications, LA-UR10-06217," Los Alamos National Laboratory, Los Alamos, NM, 2010.

LANL, "MCNP — A General Monte Carlo N-Particle Transport Code, Version 5 Volume I: Overview and Theory (LA-UR-03-1987)," Los Alamos National Laboratory, Los Alamos, NM, 2008.

NBS, "Final Safety Analysis Report on the National Bureau of Standards Reactor," NBSR 9, The National Bureau of Standards (NBS), Gaithersburg, MD, 1966 and Addendum 1, November 1980.

NIST, “Technical Specifications for the NIST Test Reactor (NBSR),” Appendix A to License No. TR-5, National Institute of Standards and Technology (NIST), Gaithersburg, MD, 2009.

NIST, "Safety Analysis Report (SAR) for License Renewal for the National Institute of Standards and Technology Reactor - NBSR; NBSR 14, Rev 4" National Institute of Standards and Technology (NIST), Gaithersburg, MD, 2010a. 
NIST, "Specification for Aluminum Clad Fuel Elements for the National Bureau of Standards Reactor," NCNR-ACFESpec-01, Rev. 5, National Institute of Standards and Technology (NIST), Gaithersburg, MD, September 3, 2010b.

Oh, C.H., and Chapman, J.C., "Two-phase Instability for Low-flow Boiling in Vertical Uniformly Heated Thin Rectangular Channels,” Nuclear Technology, 113, March 1996.

Pelowitz, D.B., "MCNPX User's Manual Version 2.7.0," Los Alamos National Laboratory, Los Alamos, NM, 2011.

Rest, J. et al, "U-Mo Fuels Handbook, Version 1.0," RERTR Program, Argonne National Laboratory, June 2006.

Rowe, J.M., "Choice of Mesh Size for Hot Stripes, “ NIST Memorandum, National Institute of Standards and Technology (NIST), Gaithersburg, MD, May 15, 2008.

Saha, P., and Zuber, N., "Point of Net Vapor Generation and Vapor Void Fraction in Subcooled Boiling,“ Proc. $5^{\text {th }}$ Int. Heat Transfer Conf., Vol. IV, p. 175, Tokyo, Japan, September 3-7, 1974.

Williams, R.E., “Old Shim Data,” Email to A.L. Hanson, NIST Center for Neutron Research, June 20, 2012.

Wilson, W. B., Cowell, S. T., England, T. R., Herman, M., Hayes, A. C., and Moller, P., "A Manual for Cinder'90 Version 07.4 Codes and Data," LA-UR-07-8412, Los Alamos National Laboratory, Los Alamos, NM, Update March 2008.

Woolstenhulme, N.E., "DDE-NBSR Status Report of Conceptual Design Activities,” INL/EXT12-27079, Idaho National Laboratory, September 2012. 


\section{REACTOR COOLANT SYSTEMS}

It is not expected that there will be any changes to the reactor coolant systems of the NBSR as a result of conversion; information on this subject cab be found in the current SAR.

\section{ENGINEERED SAFETY FEATURES}

It is not expected that there will be any changes to engineered safety features of the NBSR as a result of conversion; information on this subject can be found in the current SAR.

\section{INSTRUMENTATION AND CONTROL SYSTEMS}

It is not expected that there will be any changes to instrumentation and control systems of the NBSR as a result of conversion; information on this subject cab be found in the current SAR.

\section{ELECTRICAL POWER SYSTEMS}

It is not expected that there will be any changes to electrical power systems of the NBSR as a result of conversion; information on this subject cab be found in the current SAR.

\section{AUXILIARY SYSTEMS}

Changes to operational characteristics or in components of the auxiliary systems required by conversion will be discussed in this chapter. This may include fuel handling and storage systems. However, currently there is no information available as to what changes might be necessary.

\section{EXPERIMENTAL FACILITIES AND UTILIZATION}

It is not expected that there will be any changes to experimental facilities or their utilization in the NBSR as a result of conversion; information on this subject cab be found in the current SAR. 


\section{RADIATION PROTECTION AND RADIOACTIVE WASTE MANGEMENT PROGRAMS}

Changes to radiation protection and radioactive waste management programs required by conversion will be discussed in this chapter. Currently there is no information available as to what changes might be necessary. In Chapter 4 there is a discussion of particle flux (shielding) calculations to analyze the effectiveness of the concrete biological shield surrounding the core.

\section{CONDUCT OF OPERATIONS}

Various topics related to conduct of operations will be discussed in this chapter. Currently there is no information available as to what, if any, changes will be necessary except that it is known that a startup test plan for the LEU core will have to be developed. 


\section{ACCIDENT ANALYSIS}

\subsection{Introduction}

This chapter presents analyses to show that the health and safety of the public and workers are protected in the event of an accident. This protection results from the facility design features, the Technical Specifications (e.g., Safety Limits, Limiting Safety System Settings (LSSS), and Limiting Conditions for Operation (LCOs)), and the well-qualified and trained staff of NCNR. This holistic approach ensures that no credible accident could lead to unacceptable consequences to the public, workers, or the environment.

The accident scenarios that need to be considered for the equilibrium core with low enriched uranium (LEU) fuel are identical to those considered in the Safety Analysis Report (SAR) (NIST, 2010a) for the NBSR with high enriched uranium (HEU) fuel; namely,

- reactivity insertion accidents

- loss-of-flow accidents

- loss-of-coolant accidents

- natural circulation cooling at low power operation

- flow blockage in one fuel element

- misloaded fuel elements

- experiment malfunctions and external events

- loss of normal power

The analyses are discussed in Sections 13.4-13.12 and take into account worst-case credible assumptions expected to lead to the most severe consequences and bound all possible events. The progression of each accident is analyzed to the extent necessary to determine the degree of potential hazard and results are compared to acceptance criteria based on whether the accident is considered credible or not. The flow blockage in one fuel element is not considered credible and is treated as the "maximum hypothetical accident." The results of the accidents with the LEU fuel are compared to the corresponding results with HEU fuel in order to see how the responses of the NBSR reactor are affected by fuel conversion.

In general, accidents are analyzed at two points in the fuel cycle: startup (SU, which is at the beginning of a cycle before equilibrium xenon has built into the core) and end-of-cycle (EOC). At SU there are four fresh fuel elements in the core and the short-lived fission product poisons such as ${ }^{135}$ Xe have decayed away during the refueling period since the previous cycle. The power peaking is highest at this state point making it the limiting state point for some events. However, some events are most limiting at EOC because differential shim arm worth is lowest when the shim arms are inserted from the fully withdrawn (EOC) position.

A detailed neutronics model used to calculate physics parameters for the HEU- and LEU-fueled cores for use in the accident analysis is discussed in Chapter 4. These parameters are the SU and EOC power distributions, neutron kinetics parameters, and the reactivity worth of the shim arms. The neutronics model includes a plate-by-plate representation of each fuel element, the water gap 
at the axial mid-plane, beam tubes, shim arms, regulating rod, axial and radial reflectors, cold neutron sources, and other structures internal to the NBSR.

A major portion of the safety analysis utilizes the systems analysis code RELAP5 (ISL, 2001). The RELAP5 model, discussed in Section 13.2, includes the primary piping from vessel inlet to outlet, primary and shutdown pumps and their flow paths, heat exchanger, fuel elements, flow channels for the six inner and twenty-four outer fuel elements, and special items like the hold-up pan and the inner reserve tank. Most initial conditions (e.g., flows and temperatures) were assumed to be at their most limiting values or at the LSSSs. The NBSR reactor protection system logic was modeled and initiated a reactor trip, upon reaching a setpoint and after the appropriate instrumentation response delay. Fuel and clad temperatures are calculated to assure that no fuel damage can take place. In addition, the critical heat flux ratio (CHFR) and onset of flow instability ratio (OFIR) are evaluated as supplementary parameters indicative of a potential threat to the integrity of fuel elements.

The RELAP5 model was the basis for a similar model using the TRACE systems analysis code (NRC, 2010) to calculate the draining of coolant during a loss-of-coolant accident (LOCA). The TRACE analysis is combined with heat conduction analysis for a fuel element using the three dimensional heat conduction code HEATING7.3 (ORNL, 2007) to determine the time dependent peak clad temperature during the accident. The LOCA methodology is discussed in Section 13.3.

The acceptance criterion for all credible accidents is given by the U.S. Nuclear Regulatory Commission (NRC) as no loss of fuel integrity [Chapter 2 in (NRC, 1996a)]. A clad temperature of $582^{\circ} \mathrm{C}$, the solidus temperature, would certainly cause the release of fission products. However, at the much lower temperature where blistering is possible fuel integrity might be challenged. Hence, herein, the blister temperature is considered as the acceptance criterion. The current NBSR Technical Specification Safety Limit (i.e., for HEU fuel), which is $450^{\circ} \mathrm{C}$, is the minimum blister temperature for aluminum clad dispersion fuel (NIST, 2010b). It is used as a conservative surrogate to preclude the release of fission products and act as the acceptance criterion for HEU accidents.

For LEU fuel, the information available regarding blister temperature (INL, 2014) is still being interpreted. For U10Mo fuel the blister threshold has been determined experimentally as a function of fission density but many more tests are yet to be completed. For the LEU reactor, the maximum fission density is conservatively estimated to be $7.2 \times 10^{21}$ fissions $/ \mathrm{cm}^{3}$ (Brown, 2014b), occurring at the bottom of upper section fuel plates near the midplane gap at EOC. The isothermal blister threshold based on the experimental data (INL, 2014) is $380 \pm 55^{\circ} \mathrm{C}$ at this fission density. However, the measured fission density is an average over the experimental plate and not the fission density in the locale of the observed blisters, which would be higher. This means that the value cited above may be conservative estimate of the blister temperature. Also, the fact that the blister temperature is not a single value but depends on burnup (and hence, location in the fuel element, means that $380^{\circ} \mathrm{C}$ is a conservative estimate for a large fraction of the fuel at lower fission density. Nevertheless, in the absence of more information, it will be used herein for LEU fuel as the acceptance criterion for credible accidents. 
This acceptance criterion does not apply to any non-credible accident such as the maximum hypothetical accident (MHA) wherein, even without a known cause, it is assumed that there is complete flow blockage of one fuel element and fission products are released. This event is analyzed to see if radiation dose limits as specified in the Code of Federal Regulations (10 CFR 100) are exceeded (NRC, 1996b).

\subsection{Methodology for Non-LOCA Events}

\subsubsection{General Model}

RELAP5 (ISL, 2001) is a light and heavy water reactor transient analysis code developed for the U.S. Nuclear Regulatory Commission (NRC). It is capable of analyzing a wide variety of thermal-hydraulic transients in nuclear and non-nuclear systems involving mixtures of steam, water (light/heavy), non-condensables, and solute. RELAP5 is one of the most widely used system codes for analyzing power and research reactor accidents/transients. The Department of Energy (DOE) research/test reactors ATR (Advanced Test Reactor) and HFIR (High Flux Isotope Reactor) used RELAP5 to analyze design basis accidents in their Safety Analysis Reports (SARs). RELAP5 also has been applied to the HFBR (High Flux Beam Reactor), which was similar to the NBSR in many respects, especially with respect to the coolant (heavy water) and the geometry of the fuel element (Materials Testing Reactor (MTR) plate type).

The RELAP5/MOD3.3 model of the NBSR simulates the transport of heat and coolant in the primary system. A schematic diagram showing the main components of the NBSR primary system is shown in Figure 13.1 (see also Figure 4.5). Figure 13.2 shows the corresponding nodal diagram for the RELAP5 model. The reactor vessel is divided into a number of interconnected hydrodynamic volumes and heat structures with internal heat generation used to model the fuel plates. In the nodal diagram, hydraulic components are described by numbers with the background color of light gray and heat structures are represented by the red background color. The numbers after " $H$ " depict heat structure node numbers and " 1 " and " -2 " illustrate the heat structures associated with hydraulic flow channels in the lower and upper cores, respectively. Details of the model are found in (Baek, 2014b). The following sections summarize that model.

CHFR and OFIR are evaluated by post-processing RELAP5 output. The correlation used for CHF is due to Sudo-Kaminaga (Kaminaga, 1998) and for OFI, the Saha-Zuber criteria are used (Saha, 1974) (see Section 4.6.2).

\subsubsection{Fuel Element Modeling}

It is unnecessary to model each of the 17 fuel plates and 18 coolant channels in each of the upper and lower halves of the thirty fuel elements. A "hottest cell" channel is defined as the channel containing the axial mesh interval with the highest power density calculated by MCNPX and a "hottest stripe" channel is defined as the channel representing the highest axially integrated (along one-third of the plate width) power density calculated by MCNPX.

The inner six fuel elements are modeled as an inner group and the outer 24 fuel elements as an outer group. The inner group is divided into five different channel types, each with a different 
heating rate and flow area. The five types of channels are the hottest cell channel and hottest stripe channel with no mixing of coolant in the mid-plane (central unfueled) gap (e.g., see volumes 103, 105, 107, 113, 115, and 117 in Figure 13.2); the hottest cell channel with mixing of coolant from the other channels in the fuel element (e.g., see volumes 203, 205, and 207 in Figure 13.2); channel for 16 non-hot fuel plate channels with mixing of coolant from the hottest cell channel in the hot fuel element (e.g., see volumes 213, 205, and 217 in Figure 13.2); and a channel for non-hot (average) channels in five elements (volumes 303, 305, and 307 in Figure 13.2). Similarly, the outer group is divided into five channel types, and three additional channels corresponding to eighteen average elements in subsets of six fuel elements.

Figure 13.3 is a schematic representation of the five types of flow channels. The hottest cell channel, the hottest stripe channel, and the average element channel are similar in their composition of hydraulic volumes that constitute the flow path for the coolant in a fuel element. Another hottest cell channel is modeled with a mid-plane gap shared with hot element channel as shown in Figure 13.3. This arrangement is to simulate the effects of coolant mixing in the midplane flow areas of a fuel element.

The power generated by fission and fission product decay is assumed to deposit in the fuel meat with no direct heating of the coolant/moderator assumed. Energy deposition outside the fuel (Hanson, 2005) lowers the local power peaking in the fuel meat and thus, neglecting this effect is conservative.

Since each fuel plate is cooled on both sides, it is reasonable to model only the half thickness of a plate as shown in Figure 13.4 to give the correct wall heat flux into the coolant channel. The fuel is modeled as a volumetric heat source and thermal energy is transferred by conduction in the fuel meat and the clad. In the RELAP5 model, each NBSR fuel plate is assumed to have a heat transfer surface that has the same height as the fuel meat, that is no credit is given for heat transfer to the axial and lateral edges of the plate. 


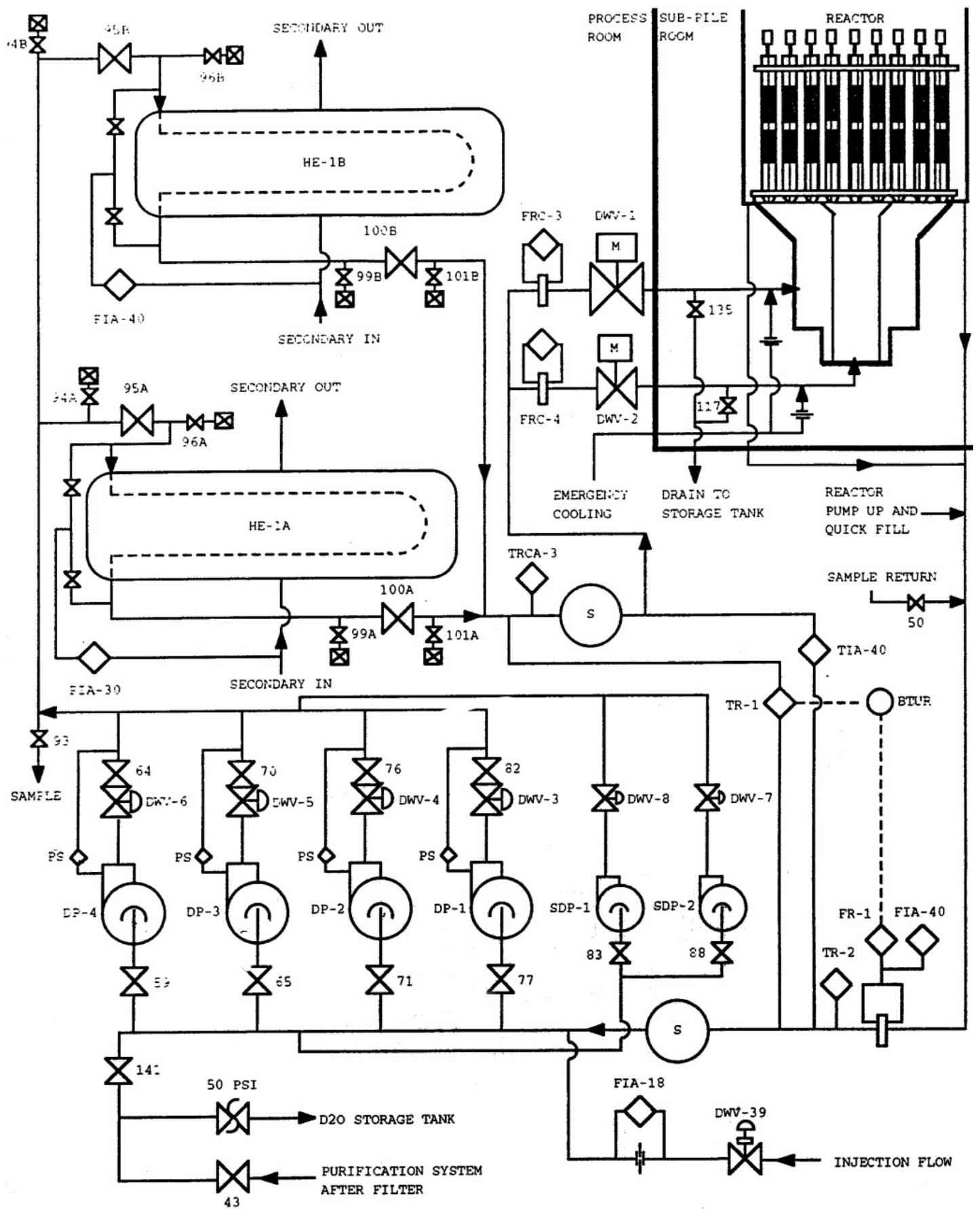

Figure 13.1 NBSR Primary System 


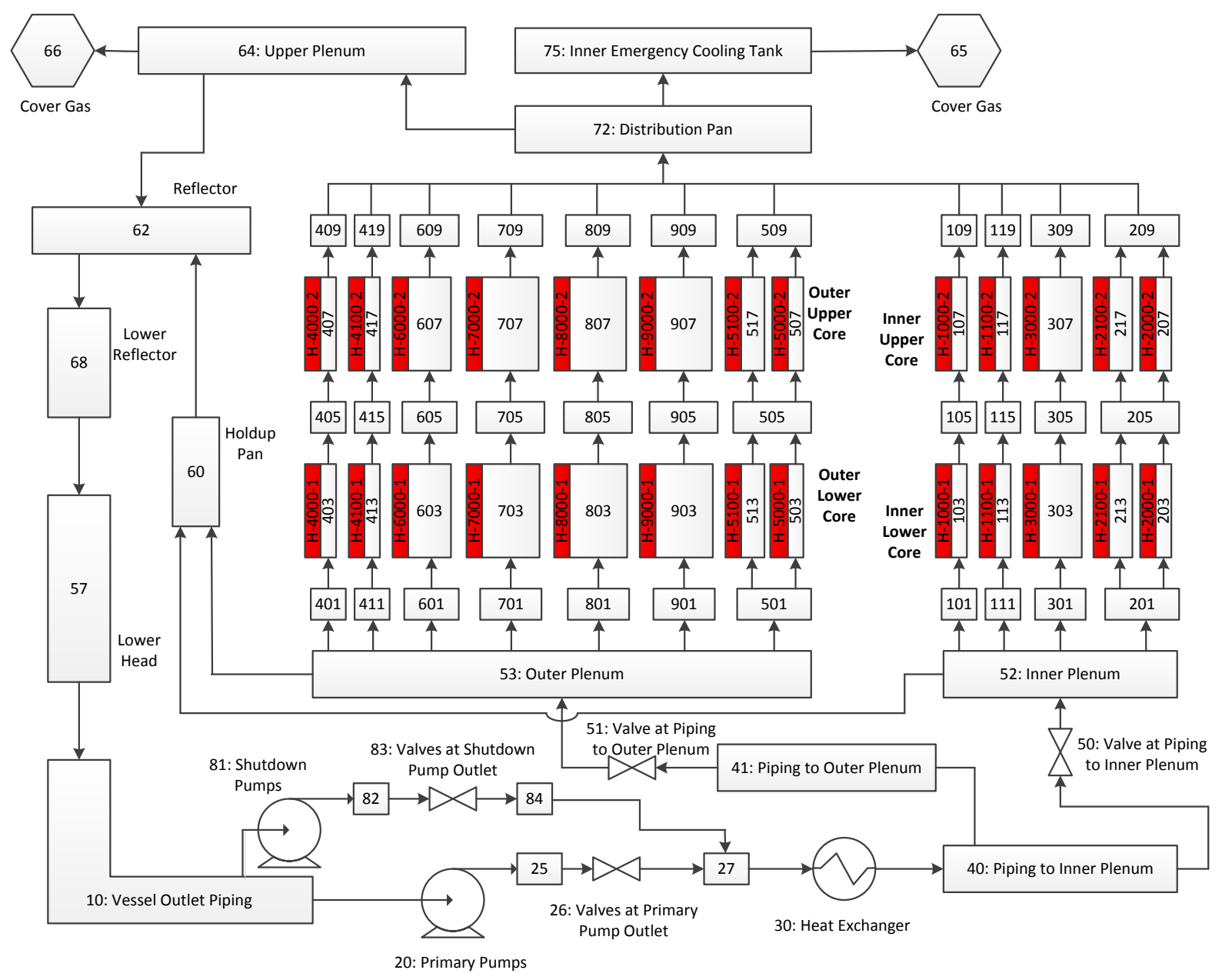

Figure 13.2 Nodal Diagram of RELAP5 Model 


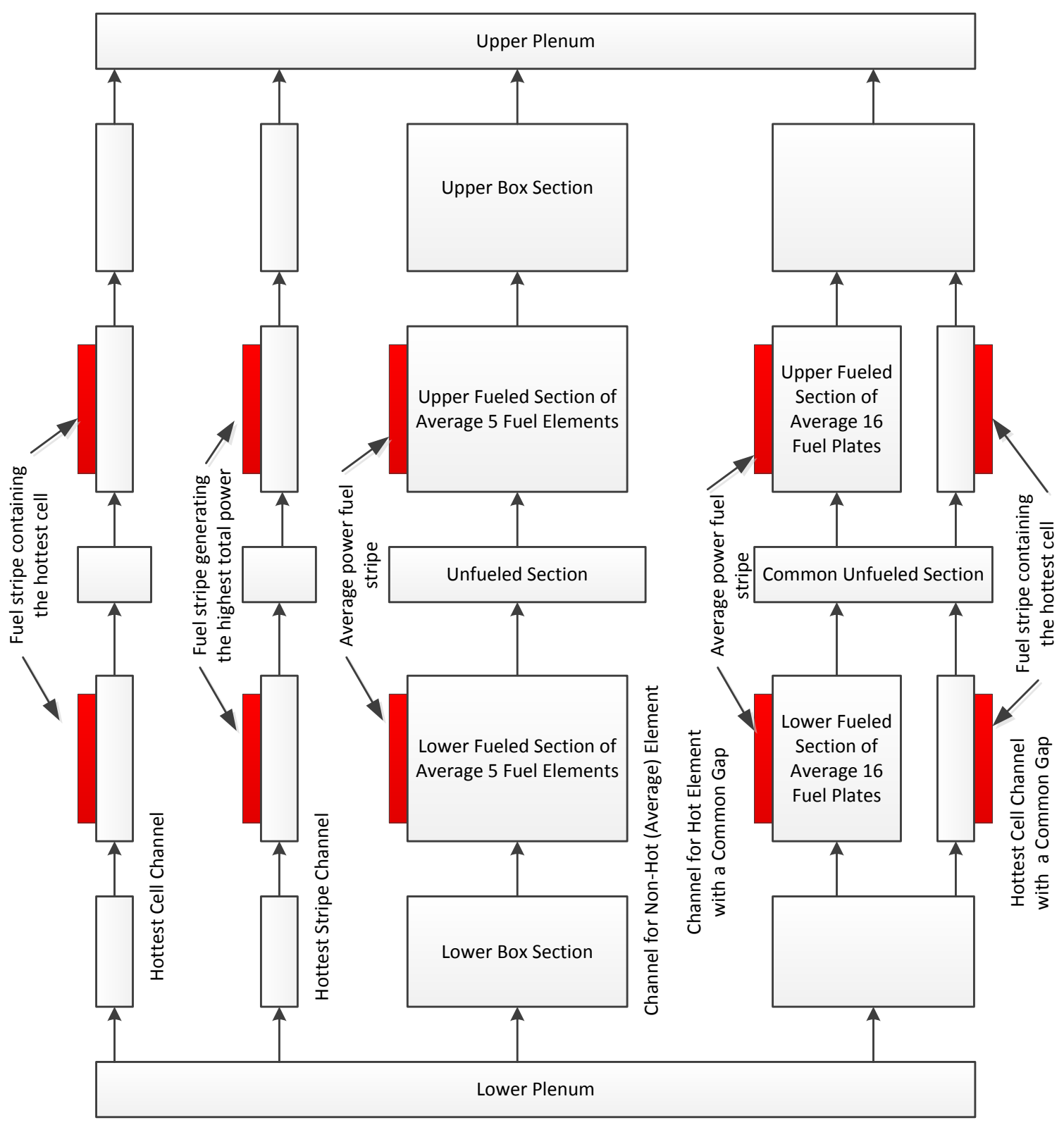

Figure 13.3 Schematic of Coolant Channels of Fuel Elements

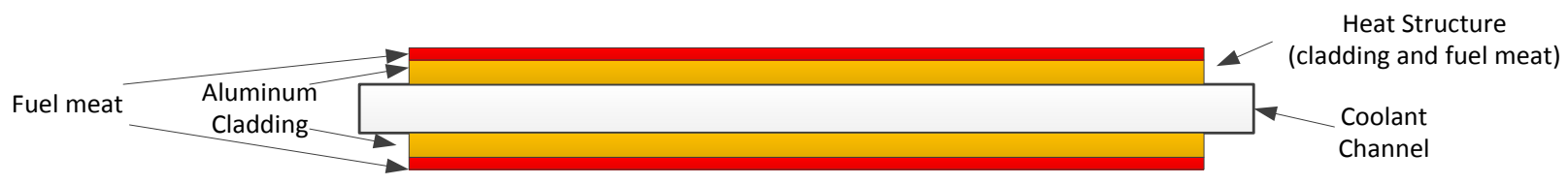

Figure 13.4 Top-View of Single Coolant Channel with Fuel Plates 
The power distributions come from an MCNPX model in which burnup is assumed to be uniform throughout each half element. This assumption is necessary due to computational restrictions. However, calculations based on a single element model show that the effect of distributed burnup within the half element is quite important in changing the power distribution (Brown, 2013). The higher burnup near the midplane gap, due to the high thermal flux in this region, reduces the power peaking as the fuel element moves through seven or eight fuel cycles. Hence, the power distributions being used in this accident analysis are conservative.

\subsubsection{Modeling Components in the Coolant Loops}

Parallel flow paths in the NBSR primary coolant loop are modeled by combining them into a single effective flow path. This applies to the two outlet pipes from the reactor vessel, the three branches going into and out of the three primary pumps, and the two branches of the shutdown pumps as well as two primary heat exchangers. This simplification does not have a significant effect on the RELAP5 analysis since the parallel flow paths are thermally and hydraulically similar.

The three primary pumps are lumped into one effective pump. The pump characteristics are developed from vendor diagrams. A comparison between actual NBSR plant data and the RELAP5 prediction of pump coastdown (Cheng, 2004) during the first few seconds signify that the model is conservative during this period. The friction torque coefficient for the pump in the RELAP5 input has been adjusted to obtain good agreement with the data in the later part of the coastdown.

When the NBSR is shutdown, the shutdown pumps can be running to remove the decay power from the core. In the event of a loss of offsite power the primary pumps will coast down, the reactor will scram due to low system flow, and the shutdown pumps will remove the decay power for long-term cooling.

The two NBSR primary heat exchangers are combined into one unit. All heat transfer plates are lumped into a single rectangular plate with the appropriate total heat transfer area and a rectangular coolant channel on each side of the plate. Primary and secondary coolant flow counter-currently in the rectangular channels. A fouling factor is applied to the heat transfer surface to maintain a heat exchanger heat removal rate that agrees with the initial reactor power. The inputs for the heat exchangers are based on plant drawings and vendor specifications. The secondary cooling loop is modeled simply as a once-through circuit. At one end a source supplies the cooling water to the primary heat exchangers. After the heat exchangers the secondary coolant (light water) flows to a sink.

About $4 \%$ of the total primary flow bypasses the fuel elements. This is true in the current HEU core and the mechanical design of the fuel element and supporting structure for the LEU core will provide similar bypass flow. In RELAP5 the areas of the bypass flow junctions have been adjusted so that $4 \%$ of flow to the inner and outer plenums is bypassed. 


\subsubsection{Point Kinetics Modeling}

The RELAP5 model calculates the total reactor power as the sum of fission power and fission product decay power. Fission power is calculated from the point kinetics model. Decay power is calculated using decay heat data from the 1994 ANS Standard (ANS, 1994) for four fissionable isotopes $\left({ }^{235} \mathrm{U},{ }^{238} \mathrm{U},{ }^{239} \mathrm{Pu}\right.$, and $\left.{ }^{241} \mathrm{Pu}\right)$ and it is a function of the input values for the isotopic fission fractions (Table 4.15; see also Figure 4.31).

The delayed neutron contribution directly from fission products uses six delayed neutron groups each having its own delayed neutron precursor fraction and decay constant (Table 4.16) and the delayed neutron contribution from photoneutrons (the ${ }^{2} \mathrm{H}(\gamma, n)^{1} \mathrm{H}$ reaction) is divided into eight delayed neutron groups (Table 4.17). The neutron lifetimes (or the prompt neutron generation times, as used in RELAP5) are also calculated using the neutronics model and slightly more conservative values actually used (Table 4.18)

No credit is taken for the moderator density and temperature feedback or for fuel temperature feedback. Although the moderator feedback is negative, the time constant for heat to reach the moderator (outside the fuel element) is too long to have a significant effect on the events analyzed. Fuel temperature feedback is primarily from the Doppler effect and is only significant when there is a large amount of ${ }^{238} \mathrm{U}$ present. This is not the case for HEU fuel but is true for LEU fuel. Therefore, analysis of over-power events with LEU fuel will have added conservatism by neglecting the fuel temperature feedback.

The reactivity curves for the four shim arms as a function of position are shown in Figure 4.13 at SU for both the HEU and LEU cores and similarly, in Figure 4.14 at EOC. The curves actually used in RELAP5 are generated for a set of shim arms after 25 fuel cycles before they are replaced because of the depletion of $\mathrm{Cd}$. Hence, they represent a conservative reactivity worth over the previous 24 cycles. These curves are shown in Figure 13.5 for SU and Figure 13.6 for EOC. Initial position of the shim arms is $19.7^{\circ}$ at SU with the HEU fuel, $20.5^{\circ}$ at SU with the LEU fuel, and $41^{\circ}$ at EOC for both HEU and LEU fuels. The shim arm worth is defined as zero at its initial positions as shown in the two figures.

The shim arm travel as a function of time after scram is in the form of a nonlinear fit developed from measured data. The fit takes into account any mechanical delay and assumes that starting from any position the first $5^{\circ}$ insertion will take $240 \mathrm{~ms}$. This is the Technical Specification maximum allowable time requirement, which is verified before each startup. 


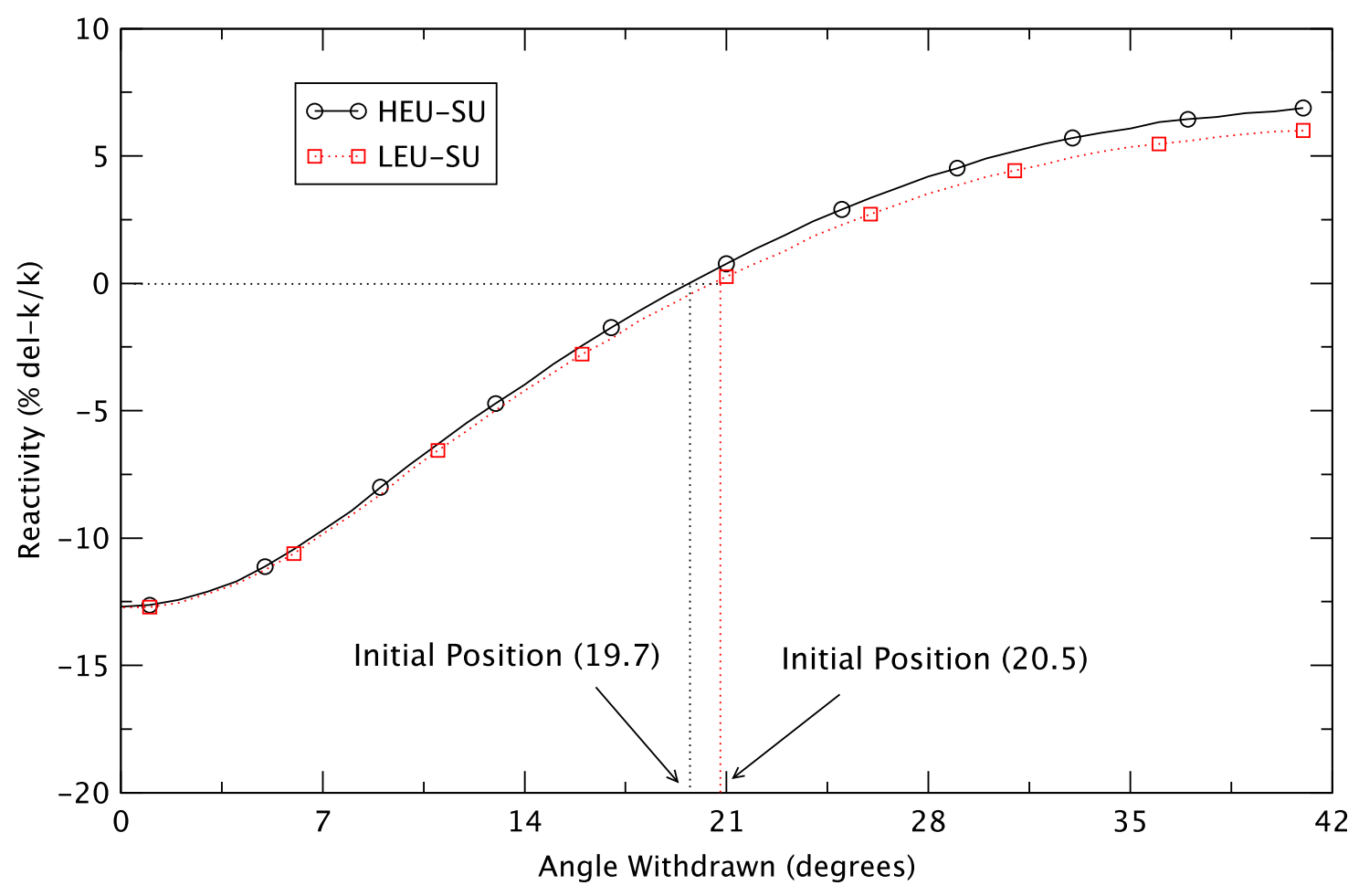

Figure 13.5 Reactivity Worth of Shim Arms at SU with HEU and LEU Fuels

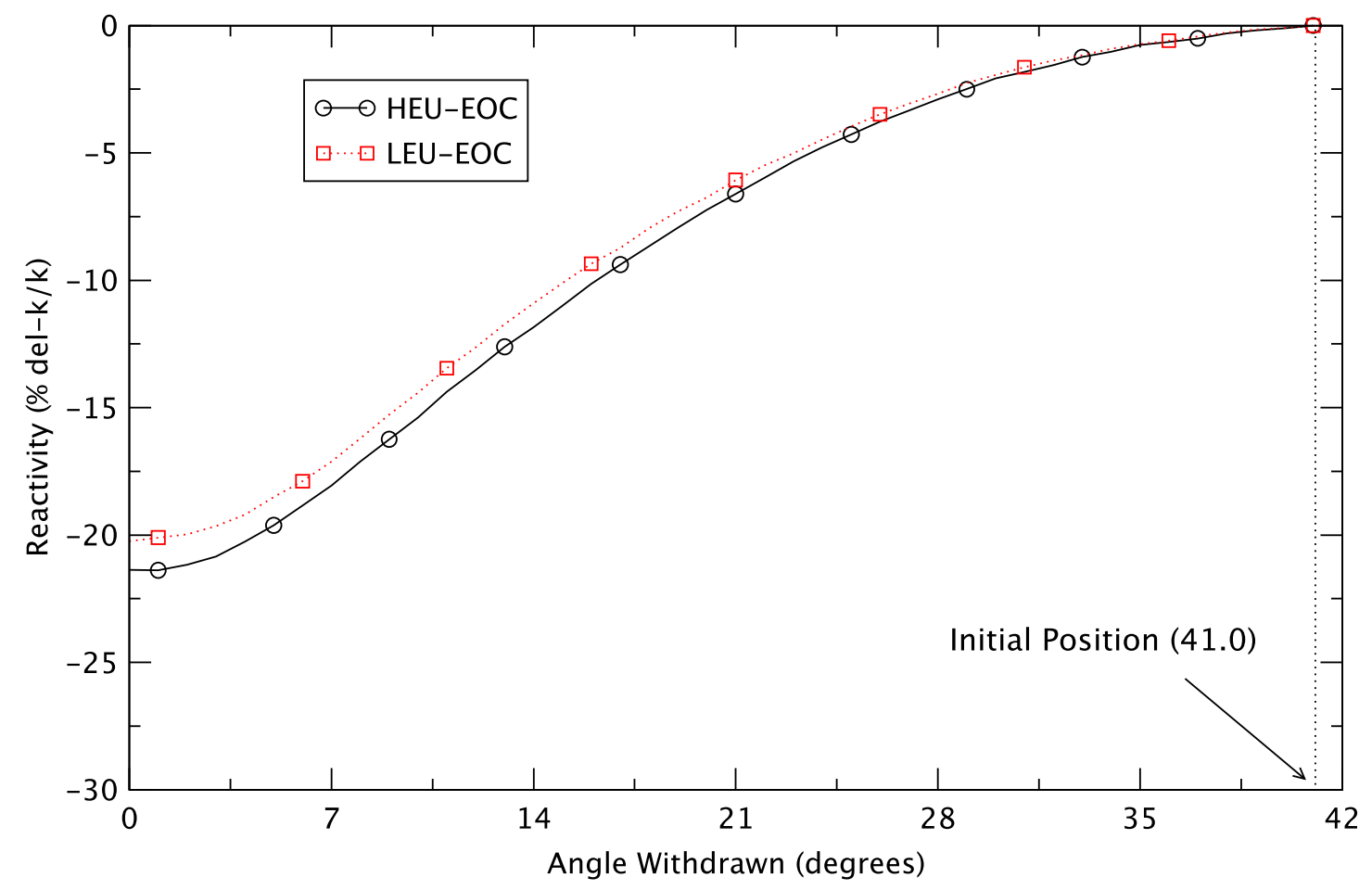

Figure 13.6 Reactivity Worth of Shim Arms at EOC with HEU and LEU Fuels 


\subsubsection{Control Variables and Trips}

The more important control variables used in the NBSR transient analyses are listed in (Baek, 2014b). The initiation of safety systems is defined in RELAP5 in the form of trip variables. Each trip is identified by a number. The NBSR input deck uses three types of trips; pump trip, reactor trip and valve trip (open and close). A pump trip is usually initiated at time zero according to the accident scenario. A reactor trip or scram can be initiated by a number of conditions in the reactor. The reactor trips that have been modeled are the power and flow trips; no trip on reactor period is taken into account. This would be conservative for some events (starting from low power) where trip on reactor period may be earlier. Table 13.1 lists the trip setpoints and the corresponding time delays assumed in the RELAP5 model.

Table 13.1 Setpoints for Reactor Trip

\begin{tabular}{|c|c|c|}
\hline Reactor Trip & Setpoint & Instrument Delay Time (s) \\
\hline Total Primary Flow & 372 \&/s (5900 gpm) & 0.4 \\
\hline Outer Plenum Flow & 297 l/s (4700 gpm) & 0.4 \\
\hline Inner Plenum Flow & 75.7 l/s (1200 gpm) & 0.4 \\
\hline Reactor Power & $26 \mathrm{MW}^{1}$ & $0.0^{2}$ \\
\hline
\end{tabular}

\subsection{Methodology for LOCA Events}

Based on a 2013 review of the piping for the NBSR, there were three locations that would cover the limiting locations for pipe breaks: (1) the 18-inch pipe between the reactor vessel outlet and the control valve DWV-19 (located upstream of the main $\mathrm{D}_{2} \mathrm{O}$ pumps); (2) the 14-inch pipe between the control valve DWV-1 (see Figure 13.1) and the outer plenum; and (3) the 10-inch pipe between the control valve DWV-2 (see Figure 13.1) and the inner plenum. The first pipe is upstream of the primary and shutdown pumps and the others are downstream of the pumps. The following methodology was developed to model up to double-ended guillotine pipe breaks at these locations. The scenarios that are analyzed are discussed in Section 13.6.

\subsubsection{TRACE Modeling of Water Levels}

The well-known TRACE computer code (NRC, 2010) is used to calculate the water level inside the reactor vessel after a LOCA. The model is based on the RELAP5 input model developed for other safety analyses as described above. That model was converted to a TRACE model because of difficulties applying RELAP5 at atmospheric pressure and with non-condensable gas. The model to determine the draining of the fuel is independent of whether the fuel is HEU or LEU.

Figure 13.7 shows the nodal diagram of the TRACE model for the NBSR. The model consists of the reactor vessel, primary piping from vessel outlet to inlet, upper plenum, inner reserve tank, distribution pan, holdup pan, primary pumps, heat exchangers, fuel elements and flow channels. The right and left parts of the figure represent the inner core and outer core, respectively. The 
inner and outer cores include 6 and 24 fuel elements, respectively. The nodes with red color represent the fuel plates even though they are not thermally modeled in the TRACE simulations. The responses of the clad and fuel are simulated using HEATING7.3 (see Section 13.3.2) in order to be able to evaluate three-dimensional heat conduction and temperature distribution in the fuel element in the detail needed for LOCA conditions.

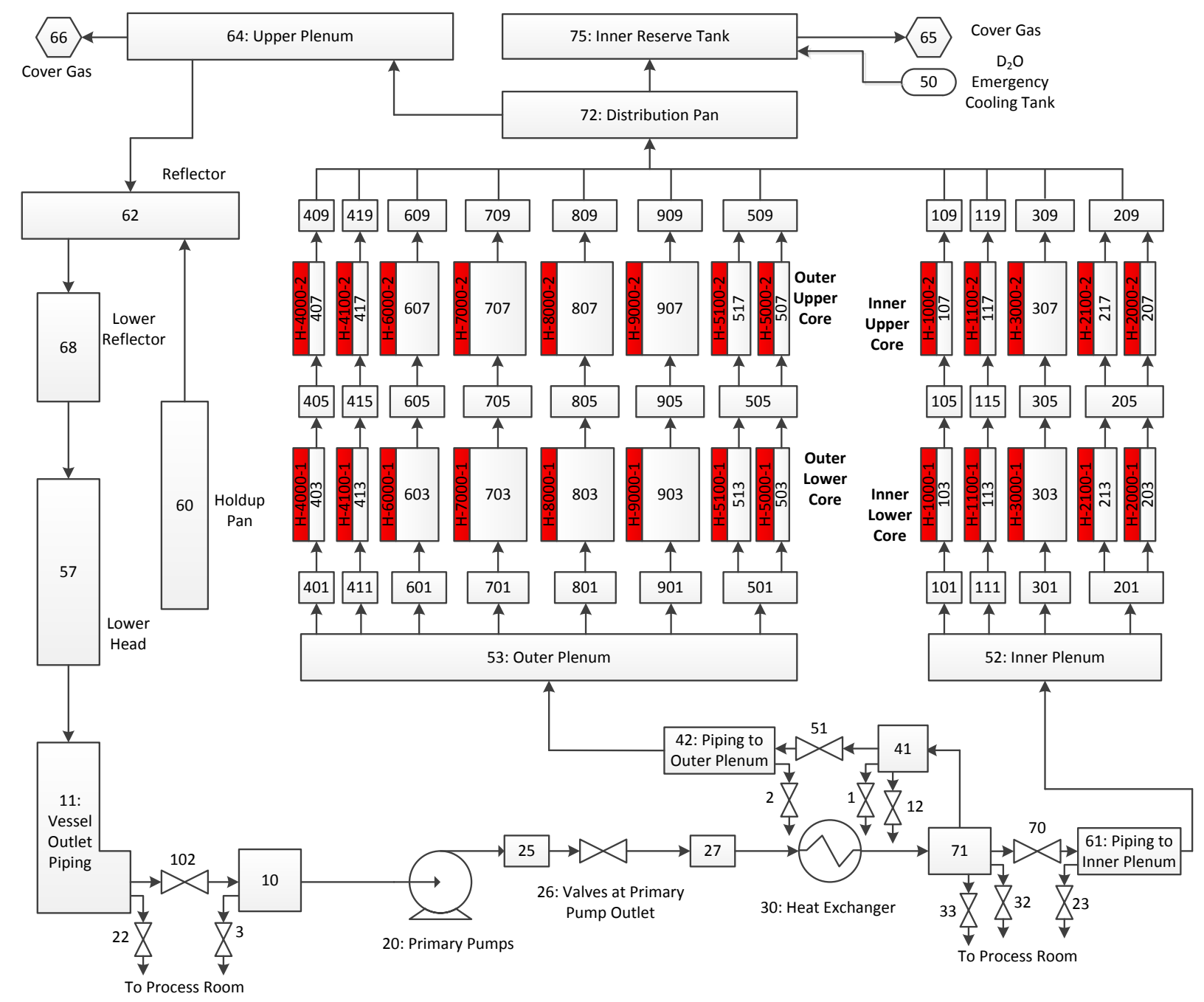

Figure 13.7 Nodal Diagram of TRACE Model

Figure 13.7 also shows "VALVE" components with arrows to simulate different pipe breaks through which the coolant is discharged into the Process Room. LOCAs are simulated by opening these valve components and, if necessary, closing the valves connecting the two adjacent pipes to model guillotine breaks. VALVE-51 and VALVE-70 are also separately used to represent the actual DWV-1 and DWV-2 valves (the control valves to isolate the outer and inner cores) at the NBSR in the SBLOCA simulations. 
Three break locations are considered. VALVEs-3, -22, and -102 represent the guillotine break at the 18-inch pipe between the reactor vessel outlet and the control valve DWV-19. The guillotine break at the 14-inch pipe between the control valve DWV-1 and the outer plenum is modeled using VALVEs-1, -2, and -51. VALVE-12 is used to simulate a SBLOCA in the outer plenum inlet pipe. The guillotine break of the 10-inch pipe between the control valve DWV-2 and the inner plenum is simulated by opening VALVEs-23 and -32 and closing VALVE-70. A small break at the inner plenum inlet pipe is modeled using VALVE-33.

The inner reserve tank (IRT) is mounted above the emergency cooling distribution pan. Figure 13.8 is a view looking down onto the IRT (the perimeter annular tank) and the distribution pan (further down at the top of the core). The empty center region is the upper plenum of the reactor.

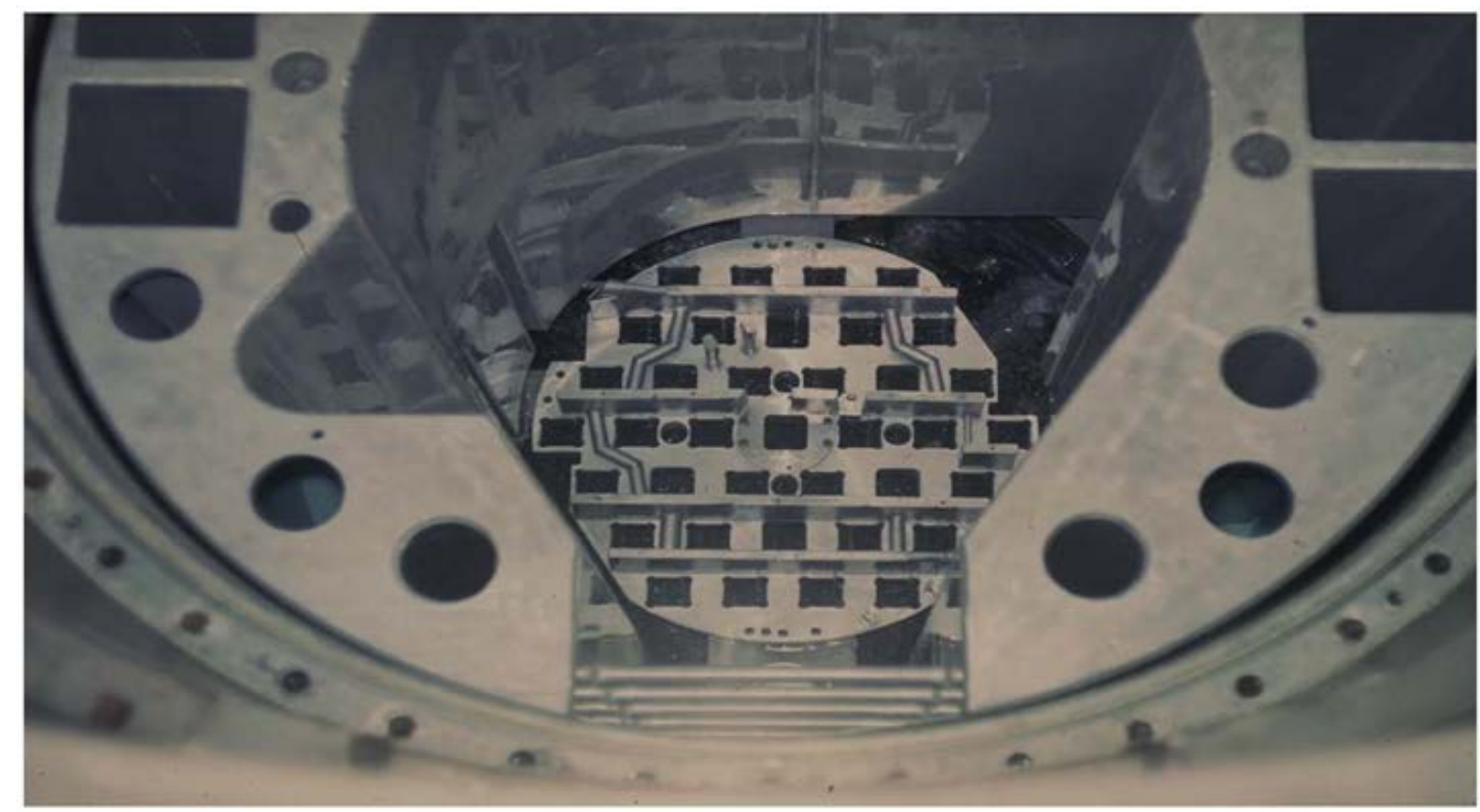

Figure 13.8 Inner Reserve Tank, Emergency Distribution Pan, and Upper Plenum

When the water level in the vessel falls below the water level of the IRT, water from the IRT starts to flow into the distribution pan. When the level is below the nozzles in the distribution pan, the flow from the IRT forms 37 water streams flowing into each of the thirty fuel elements and seven other locations as shown in Figure 13.9. The streams hit the sides of the upper end adaptors (the top part of the fuel elements) and to some extent forms a liquid film flowing downward. Figure 13.10 shows the water impingement in a mockup with the upper part of the fuel element including the upper end adapter. This liquid film spreads horizontally on the surface until the momentum is balanced with surface tension, and flows down the side plate of the element. When it reaches the elevation of the fuel plates, the liquid film is distributed over the 18 flow channels (at the elevation where the fuel plates begin), and flows further down on the surface of one side plate of the fuel element (see Figure 4.2). 


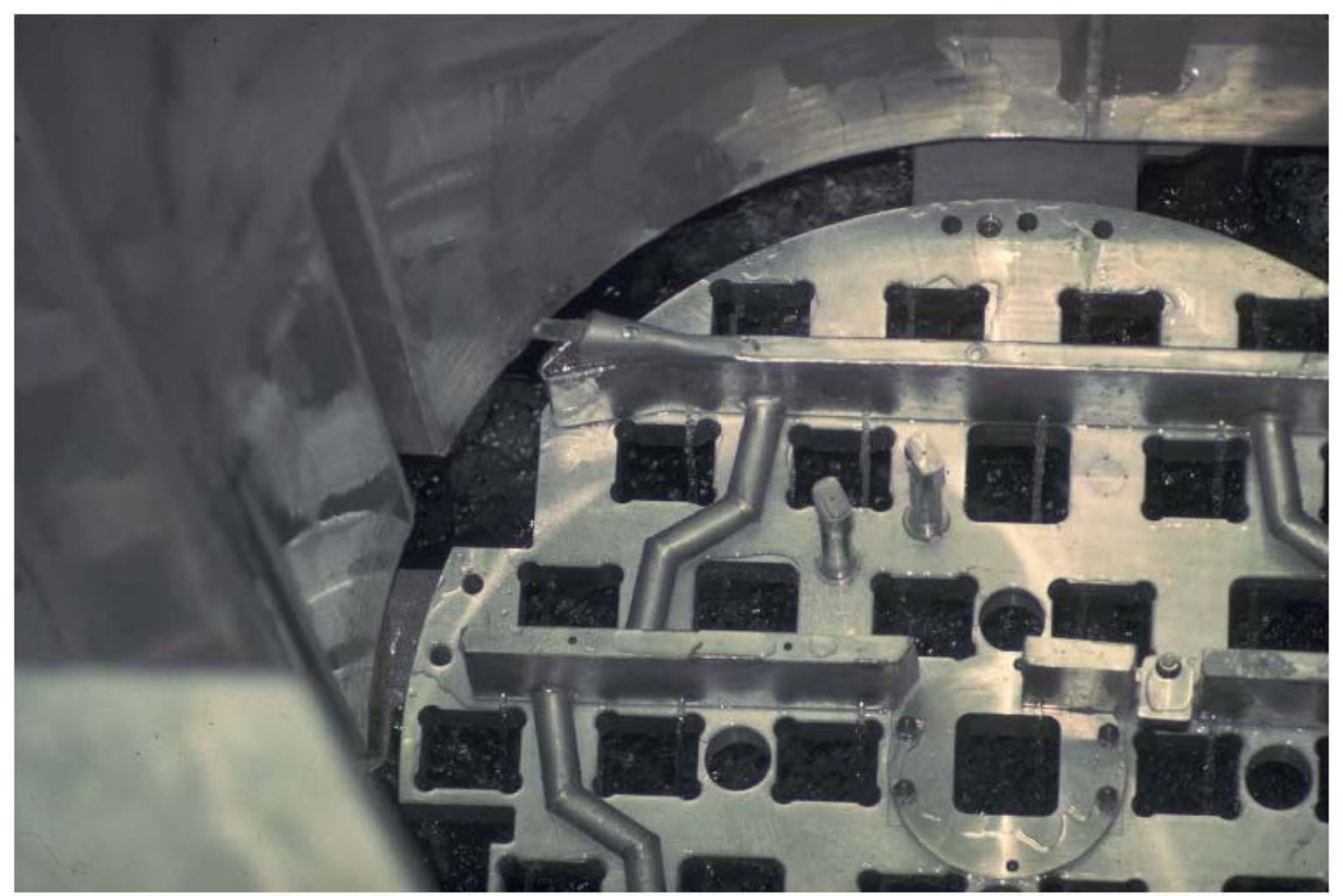

Figure 13.9 Emergency Distribution Pan and IRT Water Streams 


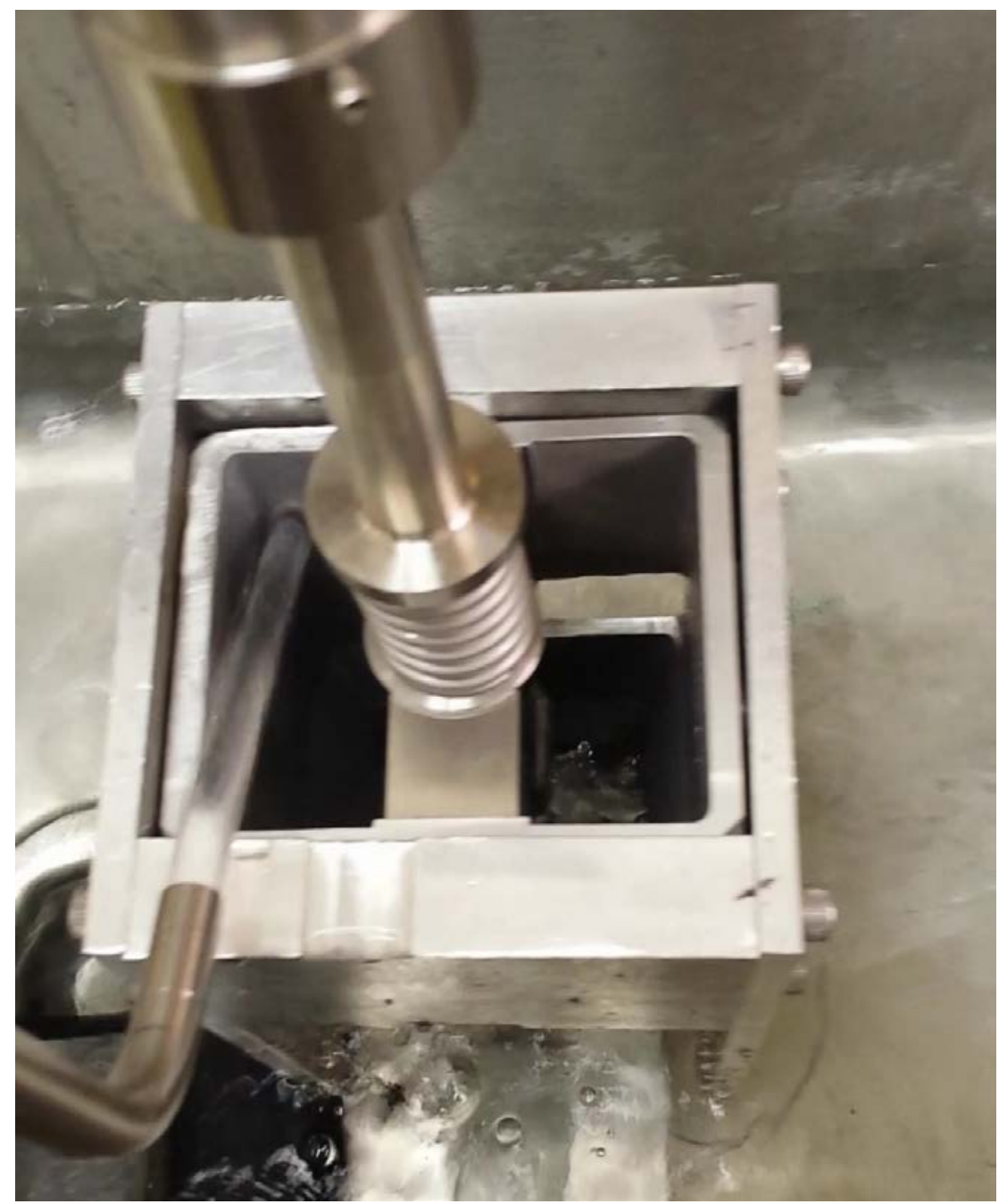

Figure 13.10 Water Impingement in Mockup Test with Upper Part of Fuel Element

\subsubsection{HEATING7.3 Modeling of Heat Conduction}

\subsubsection{Fuel Element Geometry Modeling}

The clad temperature on multiple fuel plates following a LOCA was calculated using the software HEATING7.3 (ORNL, 2007) to obtain the peak value spatially and then the maximum over time. HEATING7.3 solves steady-state and/or transient heat conduction problems in one-, two-, or three-dimensional Cartesian, cylindrical, or spherical coordinates. The analysis was done with different assumptions regarding the heat transfer to the falling film and to the quiescent water outside the fuel elements. The following discussion of the modeling is based on the geometry of the HEU fuel. The modeling for the LEU fuel is almost identical except for the dimensions of the fuel meat and cladding.

The fuel plate with the highest plate power (hot plate) at end-of-cycle (to maximize decay heat) and its side plates, the eight adjacent fuel plates, one outside plate, and the fuel box above and 
below the heated section, are modeled in the simulations. Figure 13.11 shows the mesh regions of the $17^{\text {th }}$ plate (the hot plate) in the $\mathrm{X}-\mathrm{Y}$ plane (top view). The figure is not to scale and the units of the dimensions are 'cm.' The 13 regions that need to be considered (and other regions explained below) are listed in Table 13.2 with their identification number, name, and material. The liquid film is taken into consideration by providing a boundary condition (heat transfer coefficient, HTC) to the outer surfaces of R-9 and R-4009 (facing the Y-direction) and R-10 and R-12 (facing the X-direction).

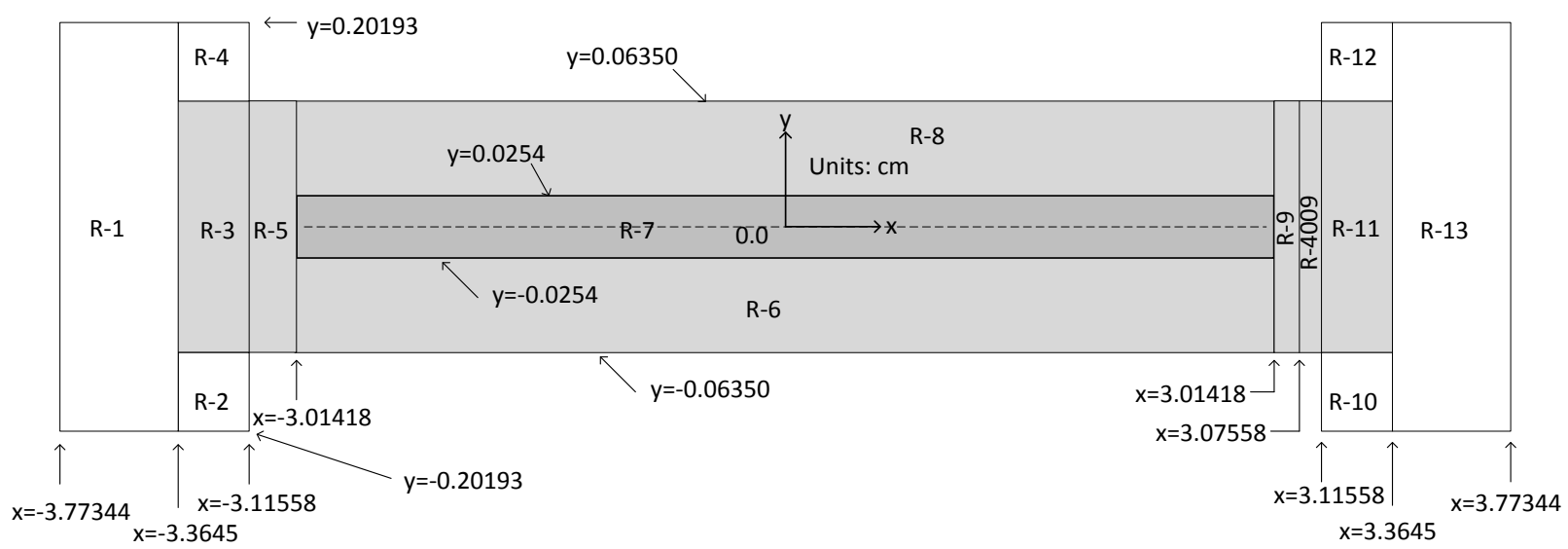

Figure 13.11 Fuel Plate (Grey Regions with Fuel Meat Darker Grey) and Side Plates in XY Plane (not to scale)

Table 13.2 Regions in X-Y and X-Z Planes

\begin{tabular}{|c|c|c|}
\hline Region No. & Name & Material \\
\hline $\begin{array}{c}\text { 1, 2, 4, 10, 12, 13, 2001, 2002, 2004, 2010, 2012, } \\
\text { 2013, 3001, 3002, 3004, 3010, 3012, and 3013 }\end{array}$ & Side Plate & Aluminum alloy 6061 T6 \\
\hline $3,5,6,8,9,11,14,15$, and 4009 & Clad & Aluminum alloy 6061 O \\
\hline 7 & Fuel & $\begin{array}{c}\mathrm{U}_{3} \mathrm{O}_{8} \text { in an aluminum } \\
\text { powder dispersion }\end{array}$ \\
\hline \multicolumn{2}{|c|}{ Region 4009 alone is used only for very thin $(0.04 \mathrm{~cm}$ ) liquid film (discussed below). } \\
\hline
\end{tabular}

The fuel plate and side plates are also divided into regions axially as shown in Figure 13.12 for the upper section of the fuel element. The information for the regions in the $\mathrm{X}-\mathrm{Z}$ plane is presented in Table 13.2. In the table, the region numbers in the 2000 and 3000 series represent the vertical extensions of the side plates (R-1, R-13, R-2, R-4, R-10, and R-12). The 2000regions are below the fuel plates and the 3000-regions are above as shown in Figure 13.12. The fuel plate axial region extends from $\mathrm{z}=0.0 \mathrm{~cm}$ to $33.02 \mathrm{~cm}$ in this model.

In the simulations nine fuel plates (the $9^{\text {th }}$ to $17^{\text {th }}$ plates) and one outside plate are considered as shown in Figure 13.13. The X- and Z-coordinates of the plates are the same as those shown in Figure 13.11 and Figure 13.12. The regions identified as 4000s are used for the very thin liquid film $(0.04 \mathrm{~cm})$ discussed later in Section 13.6.3.2. Numbers with "F" represent the identification numbers of the liquid film flowing on the side plate. 


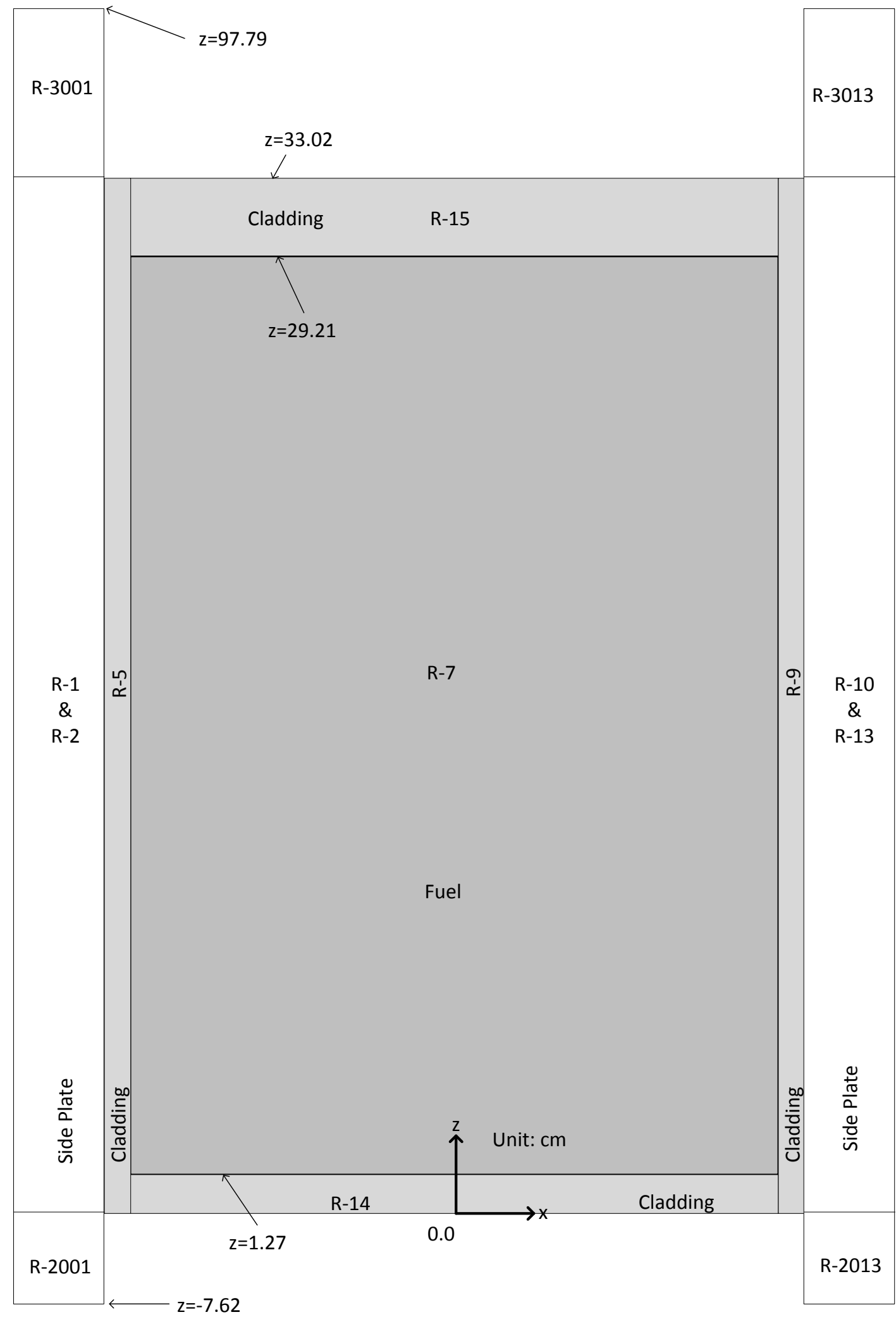

Figure 13.12 Regions of Fuel Plate and Side Plates of Upper Fuel Element in X-Z Plane (not to scale) 

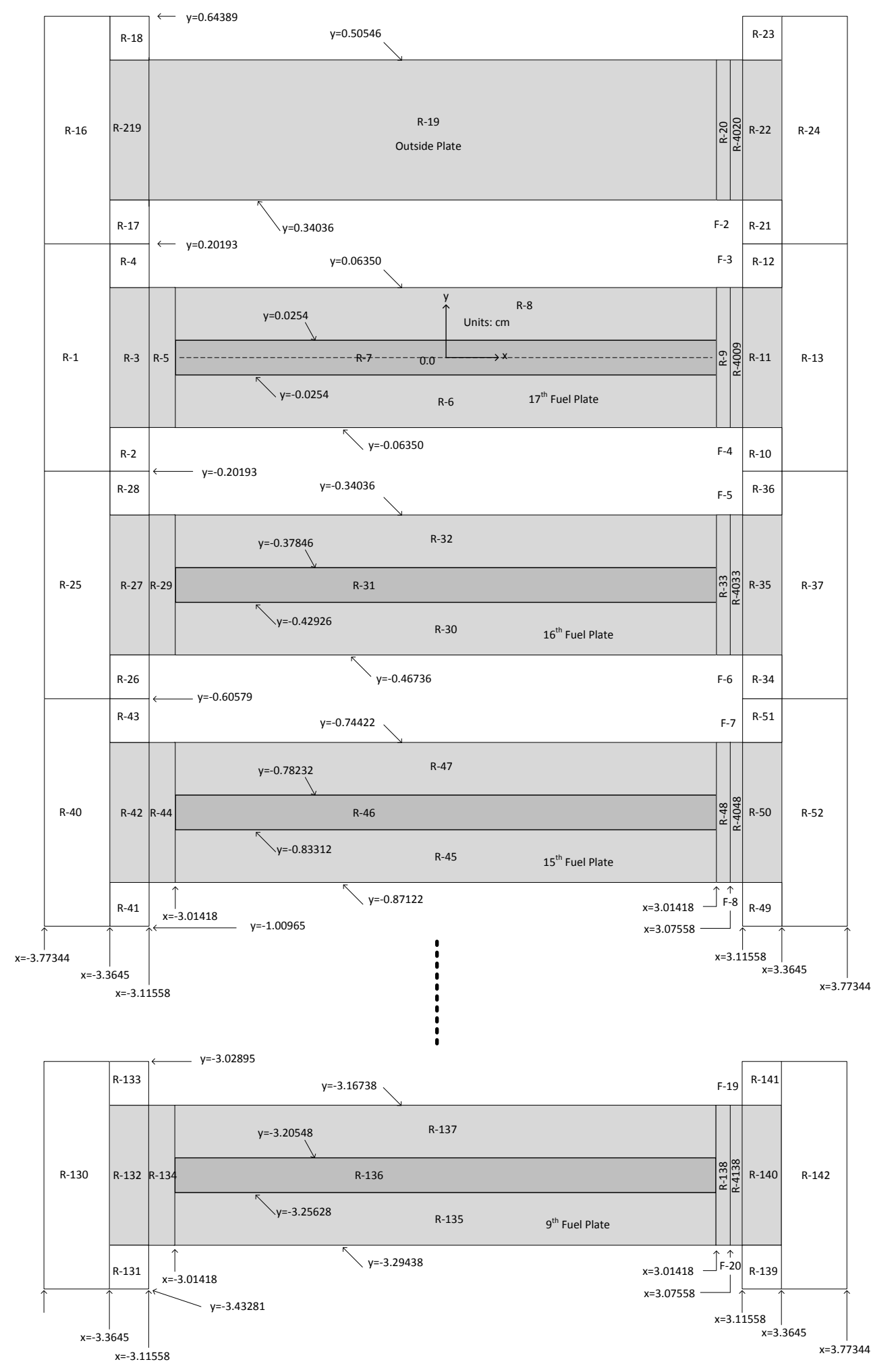

Figure 13.13 Regions of Nine Fuel Plates, Side Plates and Outside Plate in X-Y Plane (not to scale) 


\subsubsection{Modeling of Heat Transfer to Liquid}

The largest possible mass flowrate from the IRT is $2.8 \mathrm{~kg} / \mathrm{s}\left(\dot{m}_{I R T}\right)$ when the water level in the vessel is lower than the bottom elevation of the IRT. The distribution pan distributes this flow to the 30 fuel elements and seven other in-core positions. The liquid film mass flowrate in each of the 18 flow channels in each fuel element is then $4.2 \mathrm{~g} / \mathrm{s}$.

In Figure 13.11 the total length of R-9 and R-4009 is about $0.1 \mathrm{~cm}$ in the X-direction. This is consistent with a film thickness of $0.1 \mathrm{~cm}$, conservatively chosen as the base film thickness. (Baek, 2014a) discusses how the film thickness is calculated to be $0.12 \mathrm{~cm}$ with the concept of open channel flow. The falling liquid film is simulated by applying a boundary condition (heat transfer coefficient). It is to the outer surfaces of R-9 and R-4009 (facing the Y-direction), and R-10 and R-12 (facing the X-direction) while the other outer surfaces of the fuel plate and side plate are assumed to be insulated.

The Wilke correlation (Wolverine, 2001), shown in Eq. (13-1) for turbulent subcooled film flow, is used to calculate the HTC of the falling film on the inside of one side plate.

$$
h\left(\frac{\mu^{2}}{k^{3} \rho^{2} g}\right)^{\frac{1}{3}}=0.0087\left(\frac{4 \Gamma}{\mu}\right)^{0.4}\left(\frac{c \mu}{k}\right)^{0.34}
$$

where, $\mu, k, \rho, g, \Gamma$, and $c$ represent the dynamic viscosity, thermal conductivity, density, gravitational acceleration, mass flowrate per length, and specific heat, respectively, of the fluid.

The evaluated HTC is $0.7041 \mathrm{~W} / \mathrm{cm}^{2}-^{\circ} \mathrm{C}$ with the film mass flowrate of $4.2 \mathrm{~g} / \mathrm{s}$ per flow channel.

The bottom section of the fuel element will have quiescent water on the outside of the fuel element due to the presence of the holdup pan (see Figure 4.9) after any LOCA. In addition, depending upon break location and size the upper section will also have quiescent water on the outside of the fuel element (see Section 13.6.2.1). Boundary conditions are applied to the outer surfaces of the side plates using a heat flux. (The outer surface of the outside plate is conservatively assumed to have an adiabatic boundary condition.) The heat transfer coefficients are first evaluated using the Churchill and Chu correlation (Incropera and Dewitt, 1996) which is appropriate for natural convection from a vertical surface and the Gorenflo correlation (Wolverine, 2006) for nucleate boiling. The former and latter correlations depend upon the difference between the surface temperature $\left(\mathrm{T}_{\mathrm{s}}\right)$ and the surrounding water temperature $\left(\mathrm{T}_{\mathrm{b}}\right)$ and the difference between the surface temperature and the liquid saturation temperature $\left(\mathrm{T}_{\mathrm{sat}}\right)$, respectively. Heat flux from the surface of the side plate is calculated using the heat transfer coefficients and the temperature differences. The evaluated heat flux as a function of temperature difference between the surface temperature $\left(T_{s}\right)$ and the surrounding water temperature $\left(\mathrm{T}_{\mathrm{b}}\right)$ is depicted in Figure 13.14. 


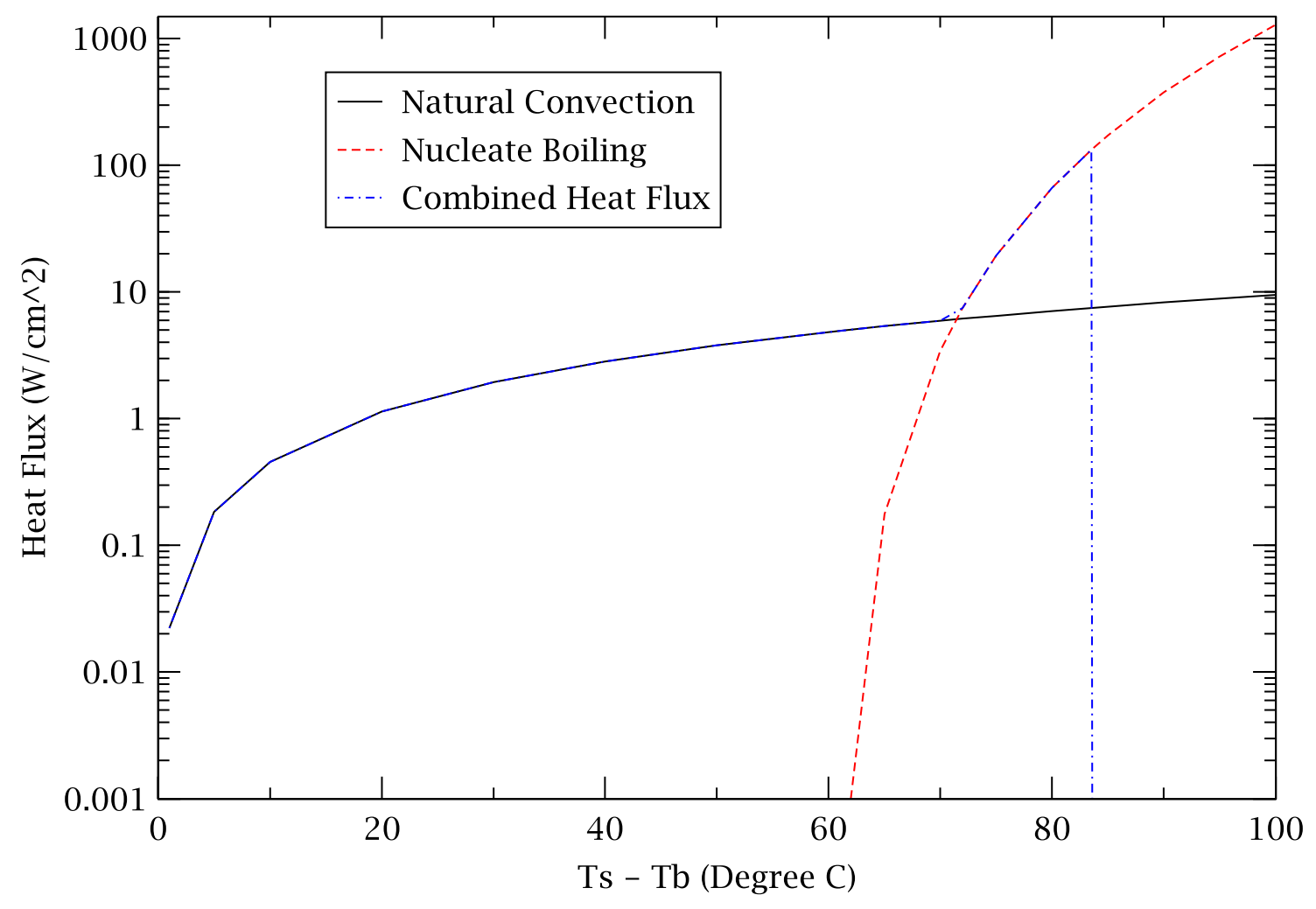

Figure 13.14 Heat Flux as Boundary Condition Applied to Outer Surface of Side Plate

In Figure 13.14 the "Combined Heat Flux" is the larger of the heat fluxes due to natural convection and nucleate boiling. It is assumed that the water temperature in the hold-up pan is $41^{\circ} \mathrm{C}$ and that nucleate boiling starts when the side plate surface temperature becomes $101^{\circ} \mathrm{C}$ (saturation temperature of heavy water at atmospheric pressure). In the HEATING7.3 simulations the boundary temperature is considered to be $0^{\circ} \mathrm{C}$ so nucleate boiling is assumed to occur when the predicted temperature of the side plate surface is $60^{\circ} \mathrm{C}$. The "Combined Heat Flux" is applied to the side plate surface as the boundary condition. In Figure 13.14 the heat flux becomes zero when the surface temperature is $83.6^{\circ} \mathrm{C}$. This implies reaching boiling crisis with a critical heat flux of $q_{C H F}^{\prime \prime}=132.2 \frac{\mathrm{W}}{\mathrm{cm}^{2}}$ and a surface temperature of $83.5^{\circ} \mathrm{C}$. (Mourgues, 2013) presents experimental results for the critical heat flux $\left(\sim 130 \mathrm{~W} / \mathrm{cm}^{2}\right)$ on a vertical plate with water.

\subsubsection{Fuel Plate Power}

The fuel element modeled is that with the hottest plate in the core at end-of-cycle when decay heat is expected to be largest (and closest to the infinite irradiation condition utilized in obtaining decay power). Approximately $50 \%$ of the decay power is due to alpha and beta radiation which can be assumed to be deposited in the fuel at the site at which it originated. Hence, the steadystate power distribution (the source of the fission products) is used to determine the energy deposition distribution for that portion of the decay heat. 
The gamma energy deposition, the other $50 \%$ of decay power, could be assumed to also follow that source distribution. However, since calculations of gamma transport using a Monte Carlo method were available (Williams, 2014), the distribution of gamma energy deposition in the fuel meat, clad, and other parts of the fuel element was explicitly taken into account.

The decay power fraction used in the analysis for the fuel at end-of-cycle is from the decay heat model in RELAP5 (ISL, 2001); known to be conservative (Brown, 2014a).

\subsection{Reactivity Insertion Accidents}

\subsubsection{Steady-State}

The steady-state operating conditions are summarized in Table 13.3. This table shows the anticipated range and the design basis values that are used in the accident and transient analysis. The design basis values generally represent the conservative end of the range. For the thermalhydraulic analysis, the primary flow is assumed to split between the inner and outer plenums at $145.1 \mathrm{l} / \mathrm{s}(2,300 \mathrm{gpm})$ and $403.8 \mathrm{l} / \mathrm{s}$ (6,400 gpm), respectively. This flow distribution is based on historic flow measurements that indicated a minimum flow of 6,411 gpm to the outer plenum, where the most limiting fuel element is located. The pressure of the cover gas above the core is only slightly above atmospheric and for simplicity all analyses are done with the assumption that the pressure in the cover gas region is constant at one atmosphere. 
Table 13.3 Steady-State Operating Conditions

\begin{tabular}{|c|c|c|c|}
\hline PARAMETER & Alarm & Normal Operating Range & $\begin{array}{c}\text { Design Basis } \\
\text { Value }\end{array}$ \\
\hline \multirow{3}{*}{ Reactor Power $^{1}$} & High & 102\% (Alarm - servo deviation) & \multirow{3}{*}{$\begin{array}{c}20.0 \mathrm{MW} \\
(100 \%)\end{array}$} \\
\hline & Normal & 100\% (Normal - servo deviation: $\pm 0.5 \%$ ) & \\
\hline & Low & 98\% (Alarm - servo deviation) & \\
\hline \multirow{3}{*}{$\begin{array}{c}\text { Reactor Water } \\
\text { Level }^{2}\end{array}$} & High & 164 in (Alarm) & \multirow{3}{*}{$\begin{array}{l}3.81 \mathrm{~m} \\
\text { (150 in) }\end{array}$} \\
\hline & Normal & 159 in (Normal) & \\
\hline & Low & 150 in (Alarm) & \\
\hline \multirow{3}{*}{$\begin{array}{c}\text { Core Inlet } \\
\text { Temperature }\end{array}$} & High & $110^{\circ} \mathrm{F}$ (Alarm) & \multirow{3}{*}{$\begin{array}{l}316.5 \mathrm{~K} \\
\left(110^{\circ} \mathrm{F}\right)\end{array}$} \\
\hline & Normal & $100^{\circ} \mathrm{F}$ (Normal) & \\
\hline & Low & $80^{\circ} \mathrm{F}$ (Alarm) & \\
\hline \multirow{3}{*}{ Primary Flow $^{3}$} & High & 9,000 gpm & \multirow{3}{*}{$\begin{array}{c}548.9 \text { l/s } \\
(8,700 \mathrm{gpm})\end{array}$} \\
\hline & Normal & 8,800 gpm & \\
\hline & Low & 8,700 gpm & \\
\hline \multirow{3}{*}{$\begin{array}{l}\text { Pressure Above } \\
\text { Core }\end{array}$} & High & 0.37 psig & \multirow{3}{*}{$\begin{array}{l}101.3 \mathrm{kPa} \\
(0.0 \text { psig) }\end{array}$} \\
\hline & Normal & 0.15 psig & \\
\hline & Low & 0.00 psig & \\
\hline \multicolumn{4}{|c|}{$\begin{array}{l}{ }^{1} \text { Rated reactor power is } 20 \mathrm{MW} \text {. Uncertainty in power is taken into account in the statistical } \\
\text { analysis. } \\
{ }^{2} \text { Reactor water level is referenced to the bottom of the lower grid plate. } \\
{ }^{3} \text { There is no alarm on primary flow. The range of flow is defined by different combinations of } \\
\text { main pumps. The ideal and high operating flow is } 2,300 \text { gpm to the inner plenum and 6,700 gpm } \\
\text { to the outer plenum while the actual total flow with three pumps is 8,800 gpm. } \\
{ }^{4} \text { This is the pressure of the helium cover gas. }\end{array}$} \\
\hline
\end{tabular}

\subsubsection{Startup Accident}

\subsubsection{Simulation of Accident}

The analysis of a startup accident uses assumptions that are selected to maximize the reactivity insertion. The reactor is assumed to be initially critical at a power level of $100 \mathrm{~W}$. Contrary to operating procedures and all previous training and experience, the operator is then assumed to withdraw the shim arms steadily without any pause, until the reactor is scrammed by a high power level trip. The accident model uses a reactivity insertion rate for the shim arm withdrawal equal to $5 \times 10^{-4} \Delta \mathrm{k} / \mathrm{k} / \mathrm{s}$. This rate is greater than the maximum measured and calculated (from the results shown in Figure 13.5 and Figure 13.6) rate at any shim arm initial position (and greater than the rate that moving the regulating rod would produce).

The shim arms are assumed to trip from what would be their initial critical position at full power (19.7 ${ }^{\circ}$ with the HEU fuel at the SU equilibrium core, 20.5 with the LEU fuel at SU, and $41^{\circ}$ with the HEU and LEU fuels at EOC as shown in Figure 13.5 and Figure 13.6). The trip is due to a high power signal. The high power level trip is set to $26 \mathrm{MW}$ (130\% of full power). This is conservative because the setting is actually at $125 \%$ of power. For conservatism the calculation 
does not consider any fuel or moderator reactivity feedback and does not consider the period scram which is active below $2 \mathrm{MW}$.

The predicted reactor power is shown in Figure 13.15 from zero to $18 \mathrm{~s}$ (to show short term behavior where conditions are most limiting). The power increases exponentially and its increase becomes significant after $15 \mathrm{~s}$ in all cases. After reaching its peak, the power decreases suddenly as the shim arms are inserted after the reactor trip signal. For the HEU core, reactor trips occur at $16.2 \mathrm{~s}$ at EOC and $15.9 \mathrm{~s}$ at SU; the corresponding trip times for the LEU core are $15.9 \mathrm{~s}$ at EOC and $15.6 \mathrm{~s}$ at SU. Table 13.4 shows the reactor peak powers.

From Figure 13.15 it can be observed that the significant power increase starts earlier with the LEU fuel than with the HEU fuel. This is the result of the smaller delayed neutron fraction and shorter neutron lifetime with the LEU fuel. It is also observed that the power rises faster at SU than at EOC, a result primarily of the difference in neutron lifetime as a result of the shim arm presence at SU and absence at EOC.

Higher peak powers are predicted at EOC with both the HEU and LEU fuels. This results from the fact that the initial shim arm positions are different, and at EOC the rate of reactivity insertion from the shim arms after trip is lower. The peak powers are slightly higher with the LEU fuel at both EOC and SU.

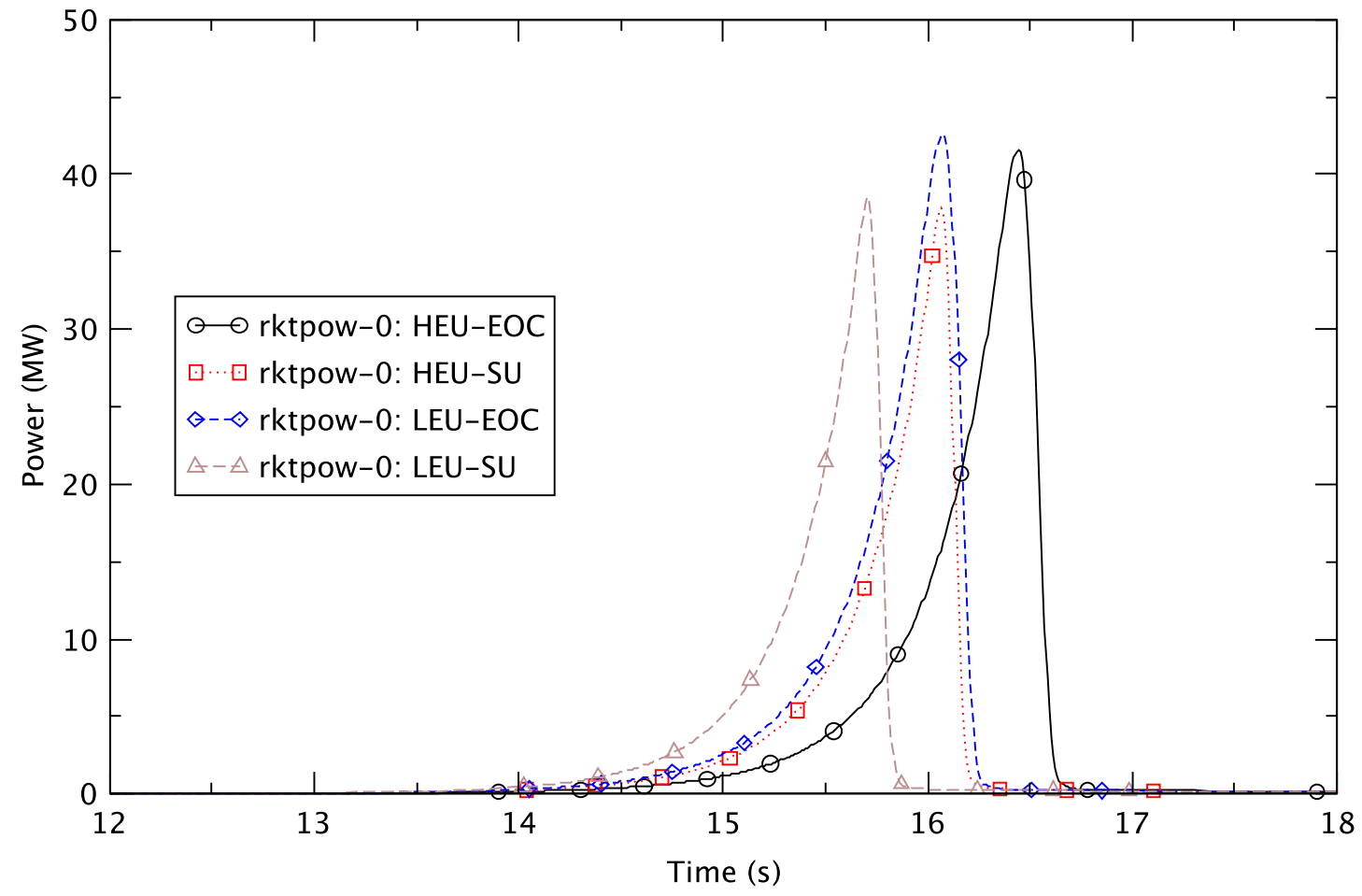

Figure 13.15 Reactor Power in Startup Accident 
Table 13.4 Reactor Peak Power in Startup Accident

\begin{tabular}{|c|c|c|}
\hline Case & Peak Power (MW) & Time (s) \\
\hline HEU EOC & 41.6 & 16.4 \\
\hline HEU SU & 37.9 & 16.1 \\
\hline LEU EOC & 42.7 & 16.1 \\
\hline LEU SU & 38.5 & 15.7 \\
\hline
\end{tabular}

\subsubsection{Limiting Parameters}

Figure 13.16 shows the clad temperatures from zero to $18 \mathrm{~s}$ in the fuel element nodes where the highest peak clad temperature (PCT) occurs. As expected, the clad temperature behavior is very similar to the power behavior shown in Figure 13.15. The clad temperatures start increasing exponentially from time zero. After reaching peak values between $15.7 \mathrm{~s}$ and $16.5 \mathrm{~s}$, they decrease rapidly due to the insertion of shim arms after reactor trip. The peak clad temperatures range from $128^{\circ} \mathrm{C}$ to $135^{\circ} \mathrm{C}$, much below the blister temperature, and corresponding to temperature increases of approximately $100^{\circ} \mathrm{C}$.

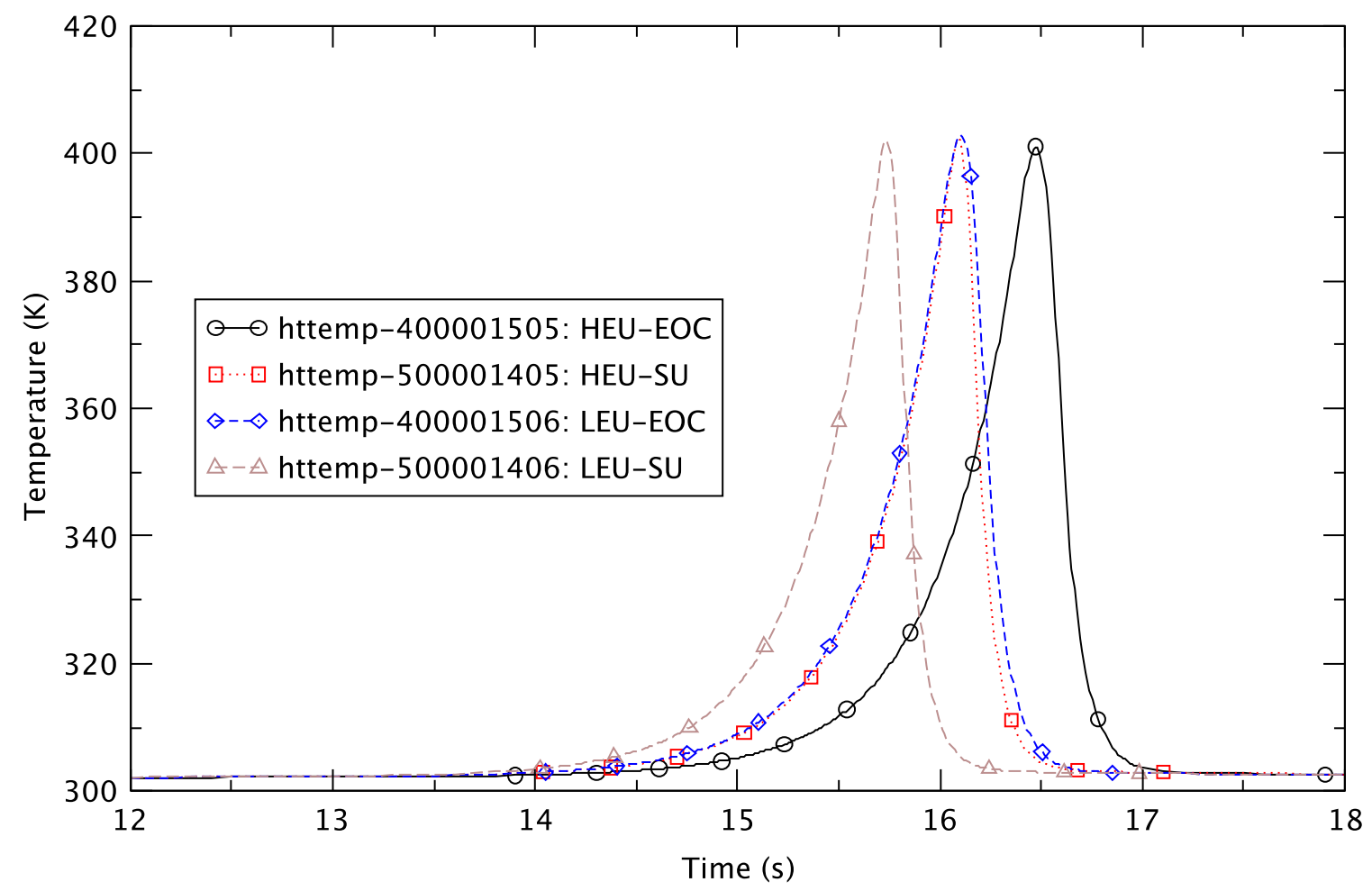

Figure 13.16 Clad Temperature in Startup Accident

Critical-heat-flux ratios are evaluated using the Sudo-Kaminaga correlations (see Section 4.6.2.1) and are shown in Figure 13.17 from zero to 20 s. The CHFR is very large initially because the initial power is only $100 \mathrm{~W}$. When the CHFR is larger than 1000, its value remains at 1000 in the figures. The hydraulic nodes used for the figures are the ones where minimum CHFR takes place. The CHFRs reach minimum values between $15.7 \mathrm{~s}$ and $16.5 \mathrm{~s}$, then they 
increase very rapidly and becomes larger than 1000 from about $19.5 \mathrm{~s}$ in all cases. The minimum CHFRs are shown in Table 13.5 along with the corresponding time and the hydraulic node number.

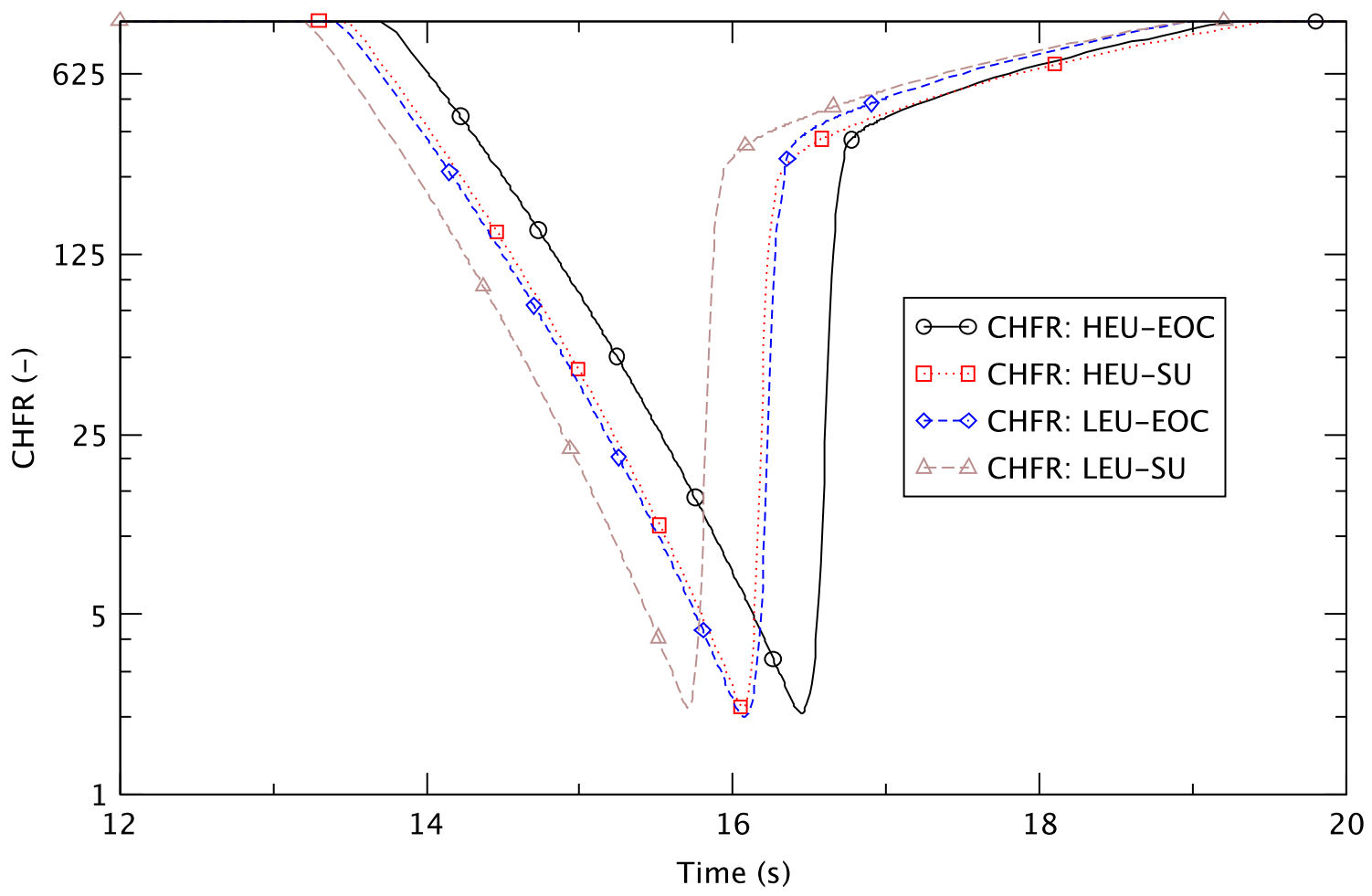

Figure 13.17 Critical-Heat-Flux Ratios in Startup Accident

Table 13.5 Minimum CHFR in Startup Accident

\begin{tabular}{|c|c|c|c|}
\hline Case & $\begin{array}{l}\text { Minimum } \\
\text { CHFR }\end{array}$ & Time (s) & Hydraulic Node No. \\
\hline HEU EOC & 2.09 & 16.5 & $407-02^{1}$ \\
\hline HEU SU & 2. 17 & 16.1 & $407-02^{2}$ \\
\hline LEU EOC & 2.01 & 16.1 & $417-02^{3}$ \\
\hline LEU SU & 2. 19 & 15.7 & $417-02^{4}$ \\
\hline \multicolumn{4}{|c|}{$\begin{array}{l}{ }^{1} \text { The minimum CHFR occurs in the node where the hottest cell (highest } \\
\text { power cell in the core region) is located. } \\
{ }^{2} \text { The minimum CHFR occurs in the next heated (or powered) node above } \\
\text { the one where the hottest cell is located. } \\
{ }^{3} \text { The minimum CHFR occurs in the node where the highest power cell in } \\
\text { the hottest fuel stripe is located. This cell is different from the hottest } \\
\text { cell among all cells in the core region. } \\
{ }^{4} \text { The minimum CHFR occurs in the next heated (or powered) node above } \\
\text { the one where the highest power cell in the hottest fuel stripe is located. }\end{array}$} \\
\hline
\end{tabular}


The minimum CHFRs take place when the reactor reaches the peak power and are slightly larger at SU than at EOC for both the HEU and LEU fuels. In the cases with HEU fuel the minimum CHFR takes place in the flow channel where the hottest cell is located while in the cases with LEU fuel it happens in the flow channel where the sum of each cell power of a fuel strip is highest. The minimum CHFR occurs in the hottest hydraulic cell of the given flow channel at EOC while it happens in the next powered node above the hottest hydraulic cell of the given flow channel at SU.

It is observed from Figure 13.17 and Table 13.5 that the minimum CHFRs are all larger than 1.78. This means that with either HEU or LEU fuel the probability of precluding CHF in this accident is greater than $99.9 \%$ (see Table 4.20 ).

Onset-of-flow-instability ratios, evaluated using the Saha-Zuber criteria (see Section 4.6.2.2), are shown in Figure 13.18 from zero to 20 s. When the OFIR is larger than 1000, its value remains at 1000 in the figures. The nodes in the figures are the ones where minimum OFIR takes place among all hydraulic nodes in the core region. As shown in those figures, the OFIRs reach minimum values between $15.7 \mathrm{~s}$ and $16.5 \mathrm{~s}$. Then they increase very rapidly and become larger than 1000 from about $17.8 \mathrm{~s}$ in all cases. The minimum OFIRs are shown in Table 13.6 along with the corresponding times and hydraulic node number.

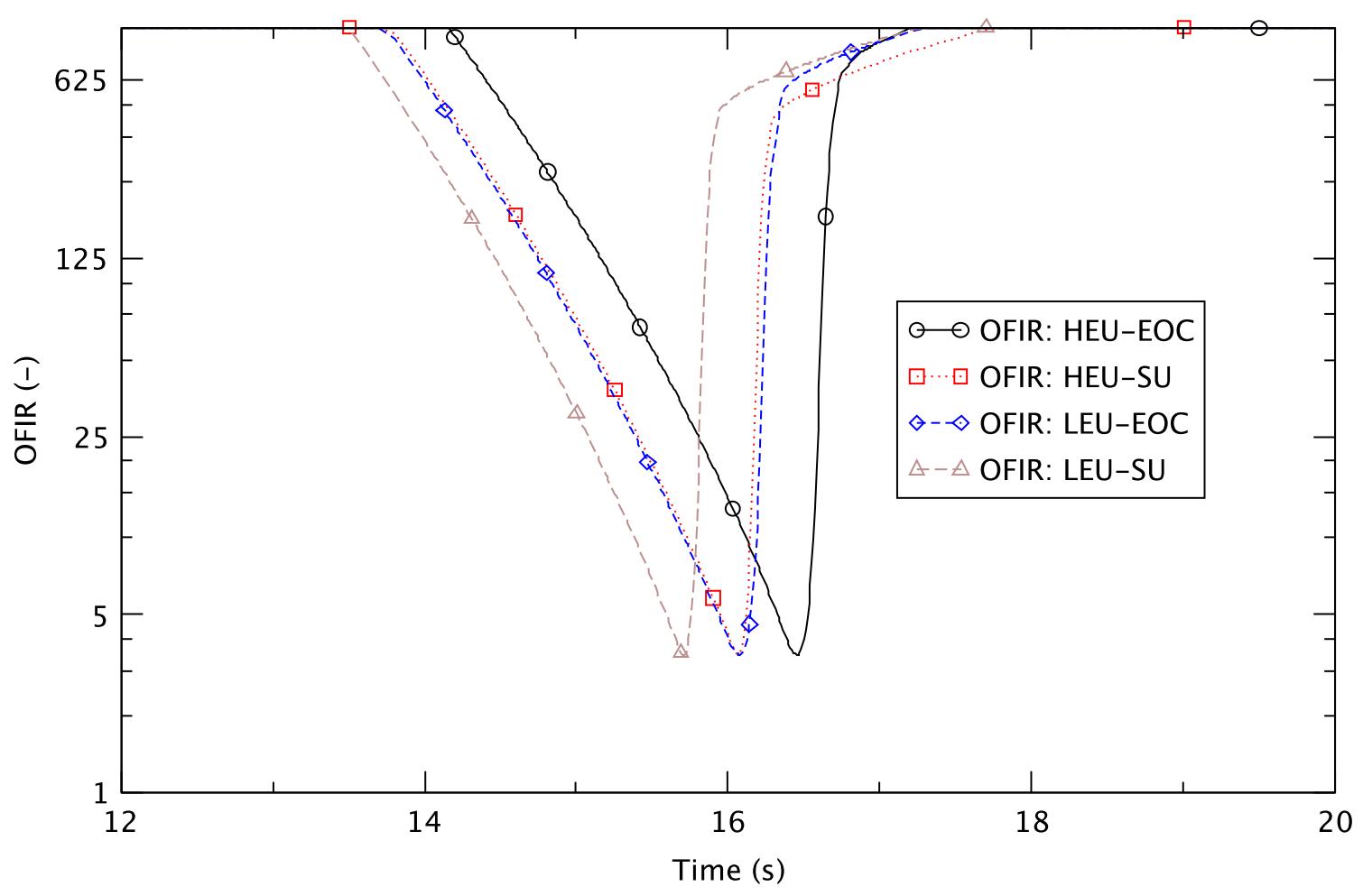

Figure 13.18 Onset-of-Flow-Instability Ratio in Startup Accident 
Table 13.6 Minimum OFIR in Startup Accident

\begin{tabular}{|c|c|c|c|}
\hline Case & $\begin{array}{l}\text { Minimum } \\
\text { OFIR }\end{array}$ & Time (s) & Hydraulic Node No. \\
\hline HEU EOC & 3.48 & 16.5 & $417-15^{(1)}$ \\
\hline HEU SU & 3.47 & 16.1 & $503-15^{(2)}$ \\
\hline LEU EOC & 3.48 & 16.1 & $417-02^{(3)}$ \\
\hline LEU SU & 3.48 & 15.7 & $503-15^{(2)}$ \\
\hline \multicolumn{4}{|c|}{$\begin{array}{l}{ }^{1} \text { The minimum OFIR occurs in the powered top node of the flow } \\
\text { channel with the hottest fuel stripe. } \\
{ }^{2} \text { The minimum OFIR occurs in the hottest node (highest power cell in } \\
\text { the core region). The flow channel with this node has a mid-plane gap } \\
\text { shared with the flow channel for } 16 \text { average fuel plates. } \\
{ }^{3} \text { The minimum OFIR occurs in the hottest node of the hottest stripe } \\
\text { channel. }\end{array}$} \\
\hline
\end{tabular}

Table 13.6 shows that the minimum OFIR takes place when the reactor power is highest in all cases. In the case of the HEU fuel at EOC the minimum OFIR occurs in the powered top node of the flow channel for the hottest fuel stripe while in the case of the LEU fuel at EOC it happens in the highest power node in the channel containing the hottest fuel stripe. In the SU cases with either HEU or LEU fuel, the minimum OFIR occurs in the hottest node of a flow channel that has a common mid-plane gap with another parallel flow channel for 16 average fuel plates as shown in Figure 13.2. Note that the power distributions along the heat structure in flow channel 403 (without common mid-plane gap) and 503 (with common mid-plane gap) are the same but RELAP5 predicts lower coolant mass flow rate to channel 503 relative to that for channel 403.

It is observed from Figure 13.18 and Table 13.6 that the evaluated minimum OFIRs are all much larger than 1.83. This means that with either HEU or LEU fuel onset-of-flow-instability is precluded with a probability greater than $99.9 \%$ (see Table 4.21 ).

\subsubsection{Maximum Reactivity Insertion Accident}

\subsubsection{Simulation of Accident}

The maximum reactivity insertion accident is analyzed using the RELAP5 point kinetics model discussed in Section 13.2.4. For conservatism the calculation does not consider any fuel or moderator reactivity feedback. For this accident a ramp reactivity insertion of $0.005 \Delta \mathrm{k} / \mathrm{k}$ is assumed to occur in $0.5 \mathrm{~s}$. This amount of reactivity is the Technical Specification limit for the reactivity of any experiment.

The predicted reactor powers are shown in Figure 13.19 from zero to $2 \mathrm{~s}$. The power increases exponentially from 20.0 MW at time zero and reaches its peak at $0.40 \mathrm{~s}$ at SU with the LEU fuel and HEU fuel and at $0.47 \mathrm{~s}$ at EOC with the LEU and HEU fuels. The power then decreases suddenly as the shim arms are inserted into the core region after a reactor trip signal on high power is generated. Reactor trip at $26 \mathrm{MW}$ occurs for the HEU core at $0.28 \mathrm{~s}$ at EOC and $0.27 \mathrm{~s}$ 
at SU, and for the LEU core at $0.27 \mathrm{~s}$ at EOC and $0.26 \mathrm{~s}$ at SU. The peak power varies from 32.3 MW to 34.9 MW.

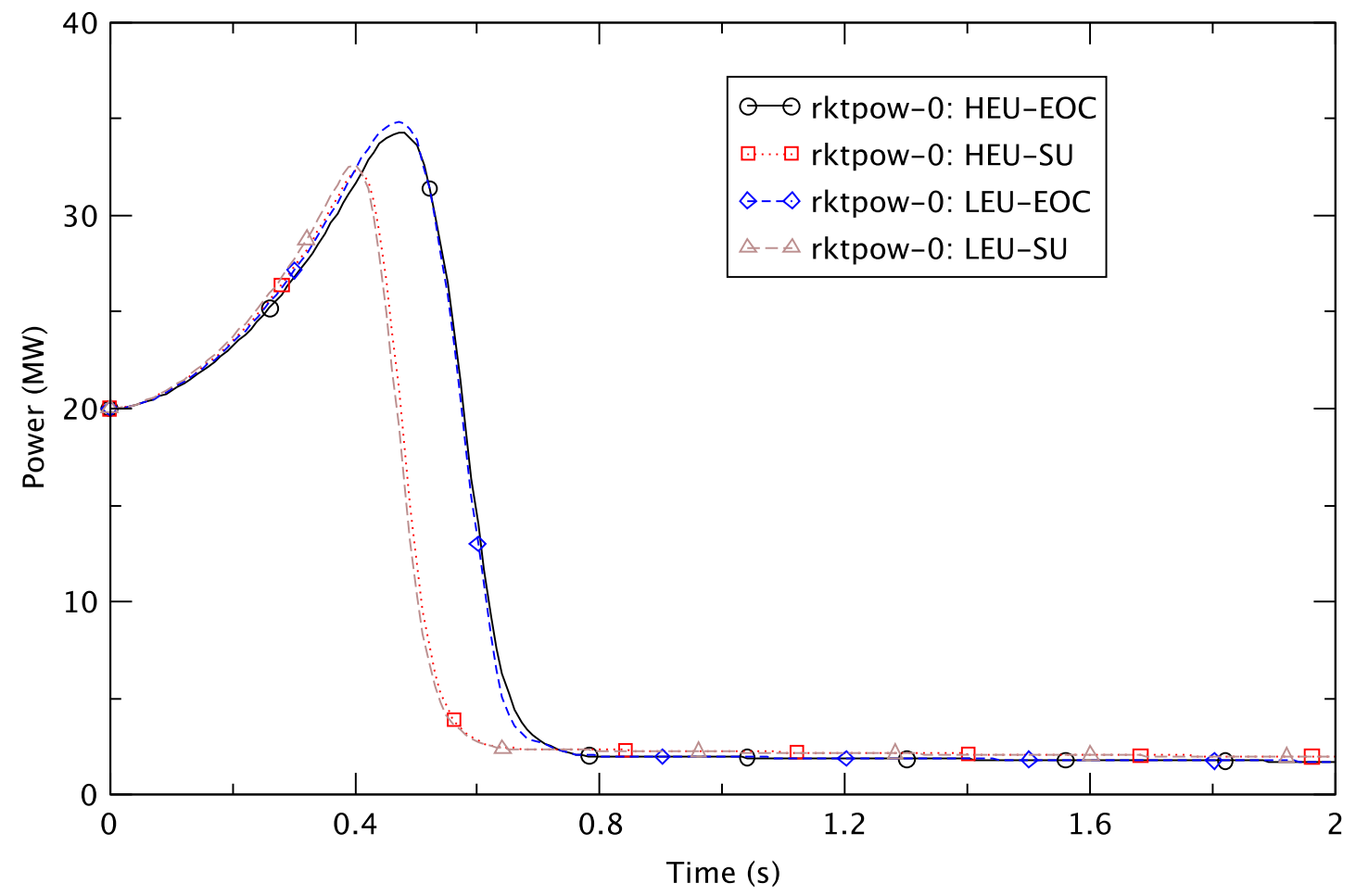

Figure 13.19 Reactor Power in Maximum Reactivity Insertion Accident

From Figure 13.19 it can be observed that the power increase starts slightly earlier with LEU fuel than with HEU fuel. It is also seen that the power rises slightly faster at SU than at EOC. These results are similar to what was observed for the startup accident.

Higher peak powers are predicted at EOC than at SU with both HEU and LEU fuel and this results from the fact that the initial shim arm positions are different, $41^{\circ}$ at EOC and about $20^{\circ}$ at SU (Figure 13.5 and Figure 13.6) and this causes a smaller initial negative reactivity insertion rate after the reactor trip at EOC.

\subsubsection{Limiting Parameters}

Figure 13.20 compares the clad temperatures from zero to $2 \mathrm{~s}$ in the fuel element nodes where the highest PCT is predicted. As expected, the clad temperature behavior is very similar to the power behavior shown in Figure 13.19. The clad temperatures start increasing exponentially from time zero. After reaching peak values between $0.42 \mathrm{~s}$ and $0.51 \mathrm{~s}$, they decrease rapidly due to the insertion of shim arms after the reactor trip signal. The peak clad temperatures range from $124^{\circ} \mathrm{C}$ to $128^{\circ} \mathrm{C}$, much below the blister temperature, and corresponding to temperature increases of approximately $26^{\circ} \mathrm{C}$ to $29^{\circ} \mathrm{C}$. 


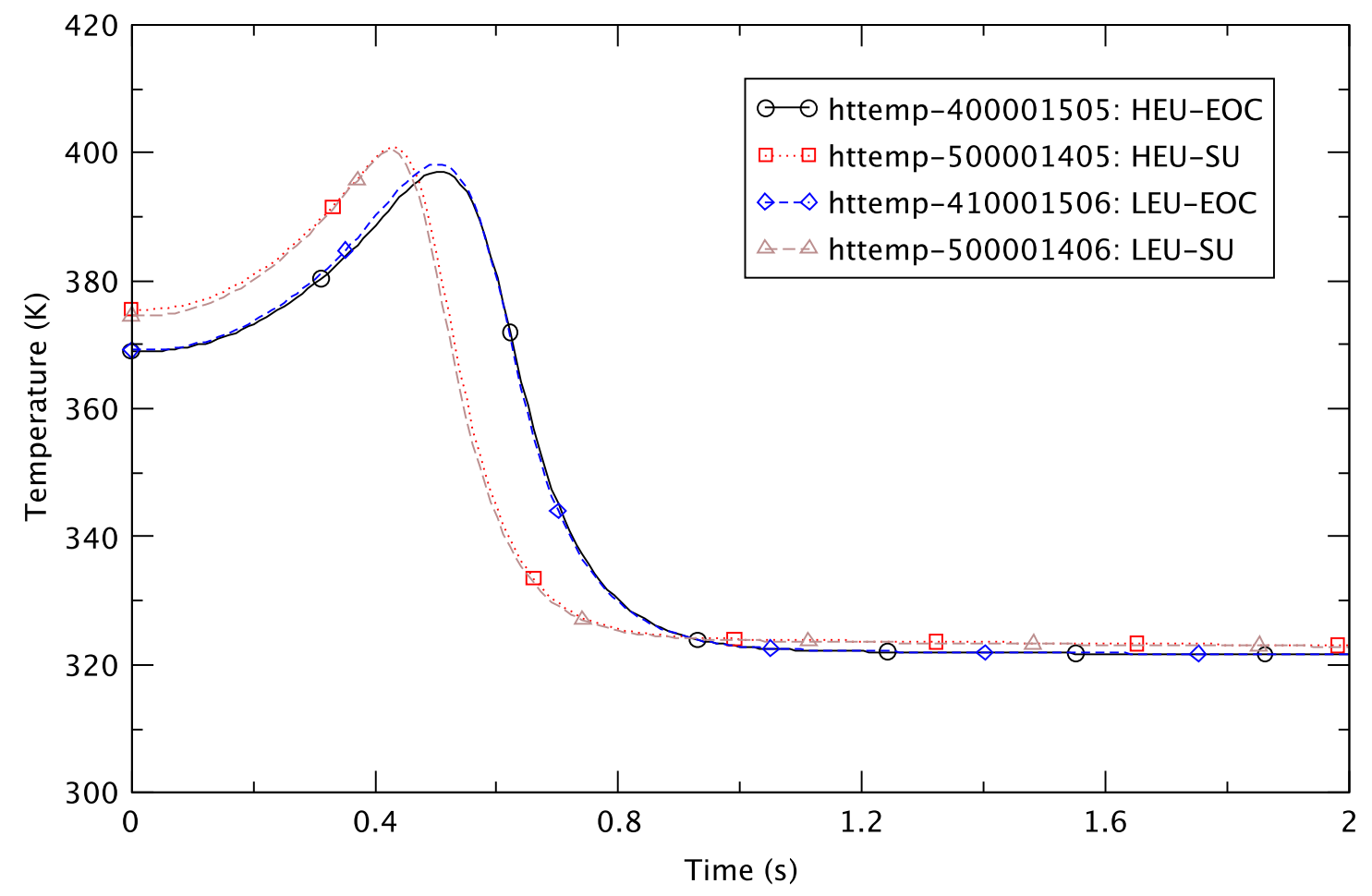

Figure 13.20 Clad Temperature in Maximum Reactivity Insertion Accident

Critical-heat-flux ratios are evaluated using the Sudo-Kaminaga correlations (see Section 4.6.2.1) and the CHFR as a function of time is shown in Figure 13.21 from zero to $2 \mathrm{~s}$. The hydraulic nodes used for the figures are where minimum CHFR takes place. The CHFRs reach minimum values between $0.40 \mathrm{~s}$ and $0.48 \mathrm{~s}$. Then they increase very rapidly and become larger than 37 from $1.0 \mathrm{~s}$ in all cases. The calculated minimum CHFRs are shown in Table 13.7 along with the corresponding time and hydraulic node number.

It can be seen from Table 13.7 that the minimum CHFRs take place when the reactor reaches the peak power and the CHFR behavior is very similar for both the HEU and the LEU fuel. It is observed from Figure 13.21 and Table 13.7 that the minimum CHFRs are all much larger than 1.78. This indicates that for either the HEU or the LEU fuel the probability of precluding CHF is greater than $99.9 \%$ (see Table 4.20 ).

Onset-of-flow-instability ratios are evaluated using the Saha-Zuber criteria (see Section 4.6.2.2) and are shown in Figure 13.22 from zero to $2 \mathrm{~s}$. The nodes in the figures are the ones where minimum OFIR occurs among all hydraulic nodes in the core region. The OFIRs reach minimum values between $0.40 \mathrm{~s}$ and $0.49 \mathrm{~s}$. Then they increase very rapidly and become larger than 50 from $1.0 \mathrm{~s}$ in all cases. The minimum OFIRs are shown in Table 13.8 along with the corresponding times and hydraulic node number. 


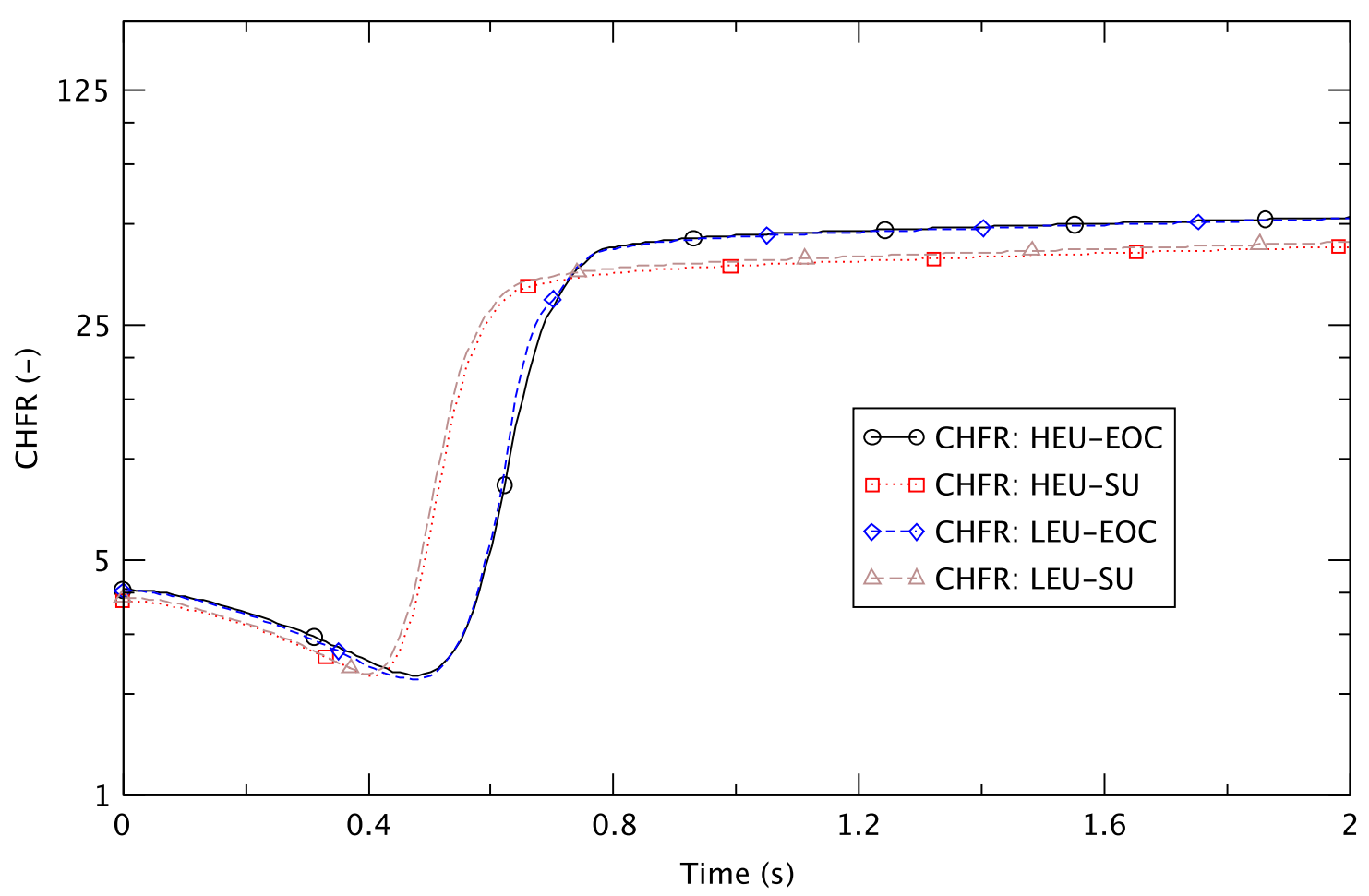

Figure 13.21 Critical-Heat-Flux Ratio in Maximum Reactivity Insertion Accident

Table 13.7 Minimum CHFR in Maximum Reactivity Insertion Accident

\begin{tabular}{|c|c|c|c|}
\hline Case & $\begin{array}{c}\text { Minimum } \\
\text { CHFR }\end{array}$ & Time (s) & Hydraulic Node No. \\
\hline HEU EOC & 2.28 & 0.48 & $407-02^{1}$ \\
\hline HEU SU & 2.26 & 0.41 & $407-02^{2}$ \\
\hline LEU EOC & 2.21 & 0.48 & $417-02^{3}$ \\
\hline LEU SU & 2.29 & 0.40 & $417-02^{4}$ \\
\hline \multicolumn{4}{|c|}{$\begin{array}{l}{ }^{1} \text { The minimum CHFR occurs in the node where the hottest cell (highest } \\
\text { power cell in the core region) is located. } \\
{ }^{2} \text { The minimum CHFR occurs in the next heated (or powered) node above } \\
\text { the one where the hottest cell is located. } \\
{ }^{3} \text { The minimum CHFR occurs in the node where the highest power cell in } \\
\text { the hottest fuel stripe is located. This cell is different from the hottest } \\
\text { cell among all cells in the core region. } \\
{ }^{4} \text { The minimum CHFR occurs in the next heated (or powered) node above } \\
\text { the one where the highest power cell in the hottest fuel stripe is located. }\end{array}$} \\
\hline
\end{tabular}




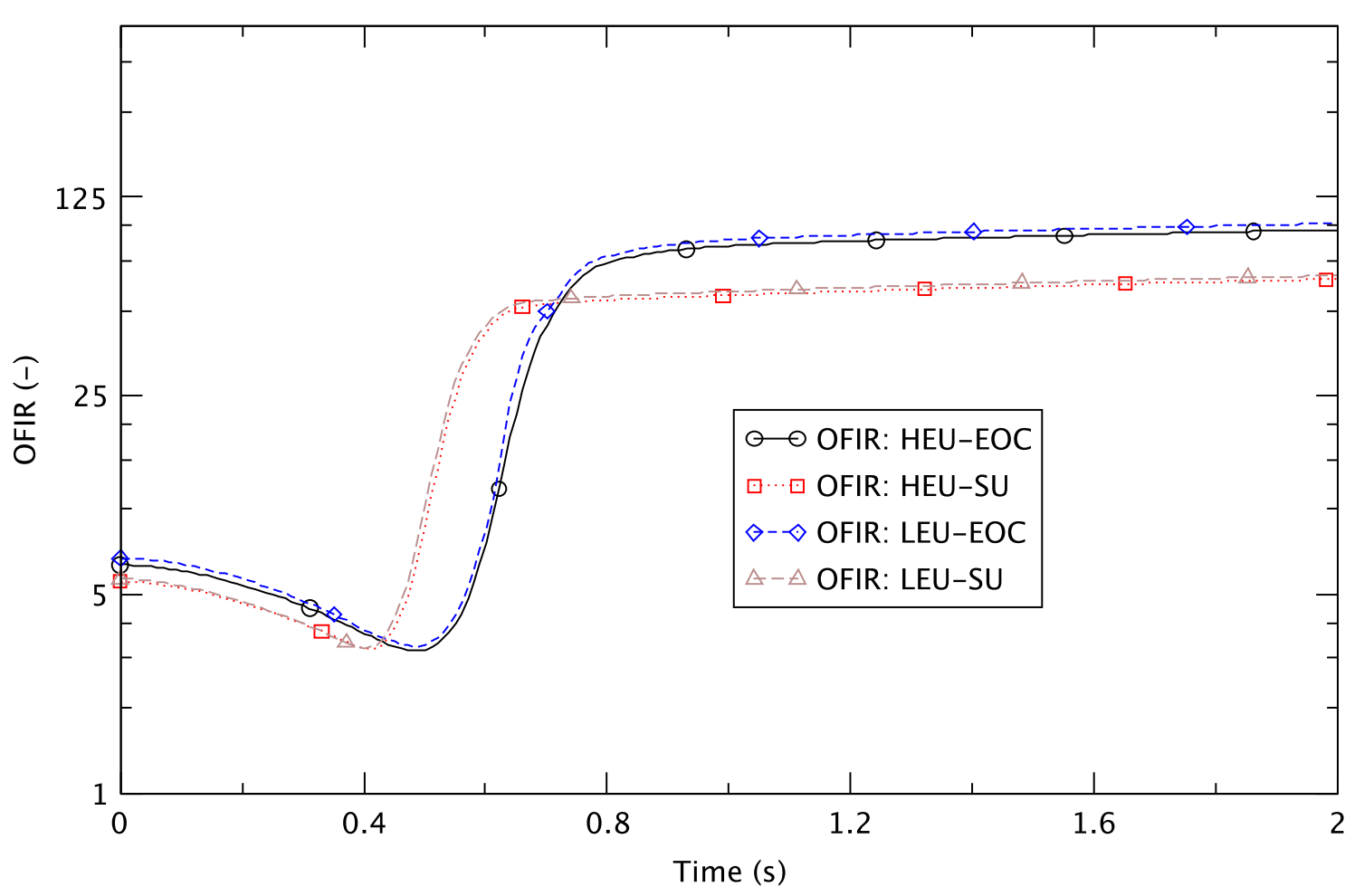

Figure 13.22 Onset-of-Flow-Instability Ratio in Maximum Reactivity Insertion Accident

Table 13.8 Minimum OFIR in Maximum Reactivity Insertion Accident

\begin{tabular}{|c|c|c|c|}
\hline Case & $\begin{array}{c}\text { Minimum } \\
\text { OFIR }\end{array}$ & Time (s) & Hydraulic Node No. \\
\hline HEU EOC & 3.19 & 0.49 & $417-15^{1}$ \\
\hline HEU SU & 3.23 & 0.41 & $503-15^{2}$ \\
\hline LEU EOC & 3.31 & 0.48 & $417-15^{1}$ \\
\hline LEU SU & 3.26 & 0.40 & $503-15^{2}$ \\
\hline \multicolumn{4}{|c|}{$\begin{array}{l}{ }^{1} \text { The minimum OFIR occurs in the powered top node of the flow } \\
\text { channel with the hottest fuel stripe. } \\
\text { 2The minimum OFIR occurs in the hottest node (highest power cell in } \\
\text { the core region). The flow channel with this node has a common mid- } \\
\text { plane gap shared with the flow channel for } 16 \text { average fuel plates. }\end{array}$} \\
\hline
\end{tabular}

Table 13.8 shows that the minimum OFIR occurs when the reactor power is near the maximum and the calculated values are similar in all cases. It is observed from Figure 13.22 and Table 13.8 that the minimum OFIRs are all much larger than 1.83. This means that for either the HEU or the LEU fuel the onset-of-flow-instability is precluded with a probability greater than $99.9 \%$ (see Table 4.21). 


\subsubsection{Other Reactivity Insertion Accidents}

It is not credible that excess reactivity can be added to the NBSR by dropping a fuel element into an empty position in a critical core, since there are no empty positions. Refueling is only performed when the reactor is fully shut down with shim safety arms fully inserted.

Furthermore, only one element is ever moved at one time, so that an empty position could only arise from an element that had already been removed, making the reactor even more subcritical. When the core is being restored from the storage pool, it is possible to have empty locations in a nearly critical core, but procedural controls are in place to ensure that the shim safety arms are fully inserted when fuel is being moved. Having the shim safety arms inserted would preclude criticality even if the fuel were inserted improperly. No other mechanisms have been identified for a step or fast ramp insertion of reactivity.

\subsubsection{Summary of Reactivity Insertion Accidents}

Two postulated reactivity insertion accidents have been simulated: constant rod withdrawal (startup) accident and maximum reactivity insertion accident. Two limiting state-points in a fuel cycle have been considered, namely, startup and end-of-cycle. Reactor power, peak clad temperature, minimum CHFR, and minimum OFIR have been examined in detail.

In both the startup and maximum reactivity insertion accidents, the system response calculated for LEU fuel is similar to that with HEU fuel. These events are driven by a fixed reactivity insertion and terminated by shim arm reactivity, which has been shown to be equivalent for both reactor fuels. Changes in flow are not significant. Feedback is assumed to be zero for both fuels. In reality, the presence of significant ${ }^{238} \mathrm{U}$ in the LEU fuel would give rise to Doppler feedback and tend to mitigate the power excursion relative to the HEU situation where there is little ${ }^{238} \mathrm{U}$.

The reactor power increases exponentially, due to the constant positive reactivity insertion of $5 \times 10^{-4} \Delta \mathrm{k} / \mathrm{k} / \mathrm{s}$ in the startup accident and the positive reactivity insertion of $0.005 \Delta \mathrm{k} / \mathrm{k}$ in $0.5 \mathrm{~s}$ in the maximum reactivity insertion accident, and drops very rapidly when shim arms are inserted after a reactor trip signal. Clad temperature rises owing to the energy deposition that occurs during the power spike. The highest peak clad temperature occurs in the startup accident with the LEU fuel at $\mathrm{EOC}$ and it is $135^{\circ} \mathrm{C}$ (much lower than the expected blister temperature) corresponding to a temperature rise of $100^{\circ} \mathrm{C}$. Hence, no fuel damage is expected in both the startup and maximum reactivity insertion accidents with either HEU or LEU fuel.

Minimum CHFR and OFIR are also evaluated in all hydraulic nodes in the core region and they are all higher than the value needed to assure fuel integrity with a probability of $99.9 \%$. 


\subsection{Loss-of-Flow Accidents}

\subsubsection{Loss of Offsite Power}

\subsubsection{Simulation of Accident}

The accident scenario assumes all three primary pumps trip upon loss of offsite power (LOSP) and bounds any loss-of-normal-power accident.. The three primary coolant pumps coast down and eventually the primary coolant flow drops to a value where one or more of the primary coolant flow monitors generates a scram signal. The scram occurs $0.4 \mathrm{~s}$ after flow has reached the trip value taking into account instrumentation delays. The primary pump discharge valves (DWV-3, 4, and 5) start closing at 1.0 s on the primary pump trip signal. The stroke time of the valves is $2.0 \mathrm{~s}$.

The shutdown pumps (SDPs) operate on both AC and DC power so they would be expected to operate normally during the LOSP. In the present analysis only one of the two SDPs are assumed to operate to remove the decay power. The valves at the outlets of the SDPs begin to open at $0.7 \mathrm{~s}$ with the stroke time of $1.5 \mathrm{~s}$. The normal flowrate of one SDP is $800 \mathrm{gpm}$ ( 55 $\mathrm{kg} / \mathrm{s})$. The situation without any SDP is considered in Section 13.5.1.3.

As the primary pumps coast down from time zero, the system flow starts decreasing as shown in Figure 13.23. In the legend 'PMP Outlet', 'SDP Outlet', 'Total', and 'Measured Data: Total' represent the predicted mass flowrate at the primary pump discharge line, shutdown pump discharge line, inlet to the heat exchanger, and the measured total flow, respectively.

Figure 13.23 shows that the total mass flowrate predicted with LEU fuel at SU (expected to be the same at EOC and for HEU fuel), is similar to the measured value. It is observed that in the simulation, the flow becomes zero at the outlet of the primary pumps at $3.0 \mathrm{~s}$ when the valves at that location close completely.

Figure 13.23 also shows that the predicted flow at the shutdown pump discharge becomes slightly negative for a short time as the shutdown pump discharge valve opens at $0.7 \mathrm{~s}$. Following this, the flow increases due to flow inertia as the valve opens. Then the total flow continues decreasing after the primary pump discharge valves close at $3.0 \mathrm{~s}$ and becomes $\sim 53$ $\mathrm{kg} / \mathrm{s}$ (766 gpm) for the rest of the simulation.

By comparing the predicted total mass flowrate to the measured one, it can be observed that RELAP5 calculates a smaller flowrate than the measurement at the beginning of the transient (up to around $10 \mathrm{~s}$ ), but is only $11 \%$ smaller where the limiting thermal-hydraulic behavior occurs. The predicted and measured flowrates show very similar behavior after $10 \mathrm{~s}$. From this comparison it can be deduced that RELAP5 predicts the total mass flowrate conservatively. 


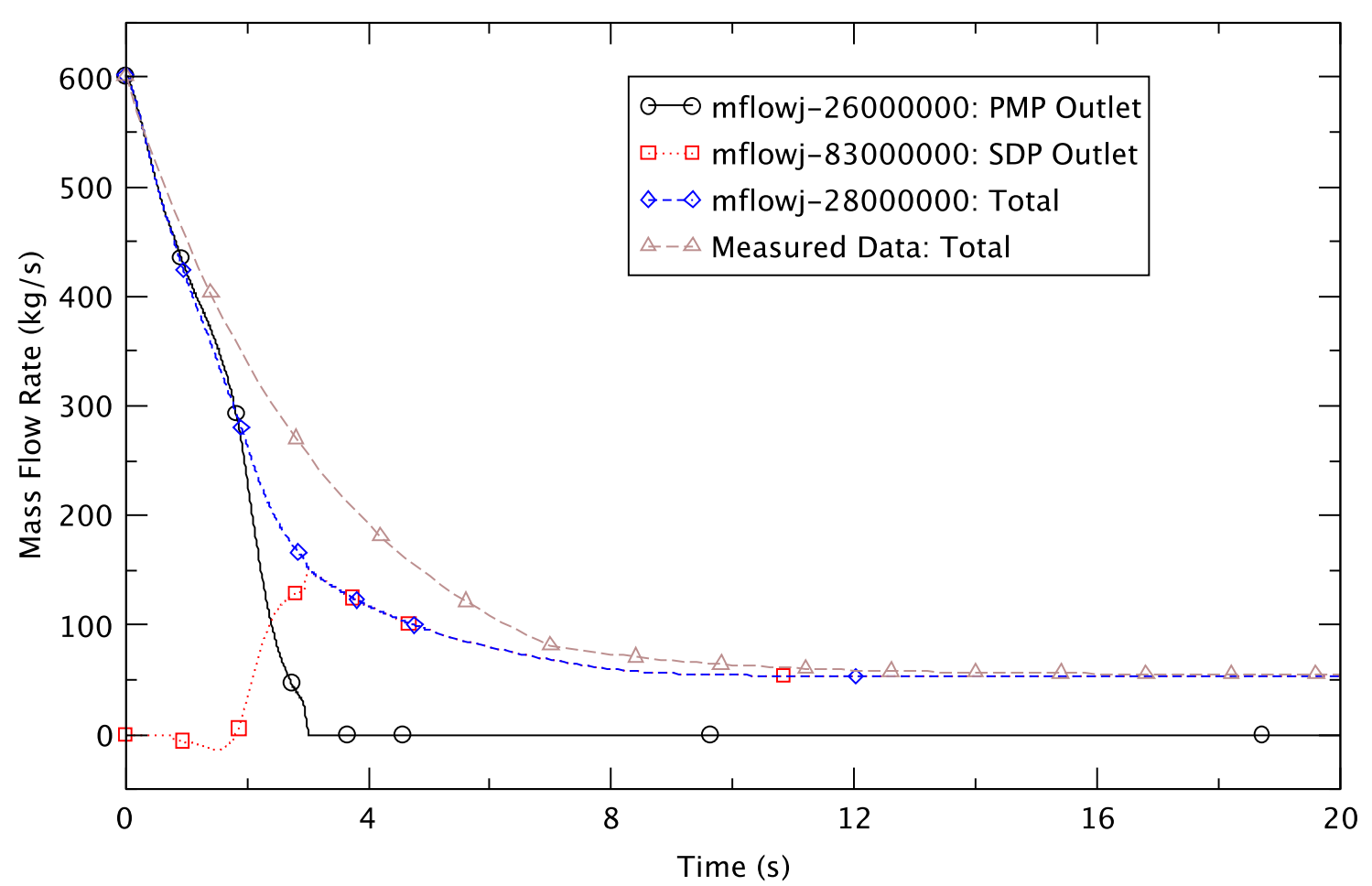

Figure 13.23 Primary System Flow after Loss of Offsite Power with LEU Fuel at SU

Figure 13.24 shows reactor power from zero to $2 \mathrm{~s}$. The reactor power decreases very rapidly after $1.4 \mathrm{~s}$ in all cases. The trip setpoint for low outer plenum flow $(297 \mathrm{l} / \mathrm{s})$ is reached at about $0.9 \mathrm{~s}$ in all cases. A reactor trip signal is generated after a $0.4 \mathrm{~s}$ delay and the shim arms start to insert into the core and shutdown the reactor.

The power transients with LEU fuel are very similar to those with HEU fuel. The power drops more rapidly in the cases at SU compared to the cases at EOC. This results from the different initial shim arm positions (about $20^{\circ}$ at $\mathrm{SU}$ and $41^{\circ}$ at EOC; Figure 13.5 and Figure 13.6) causing the larger initial negative reactivity insertion rate in the cases at SU. 


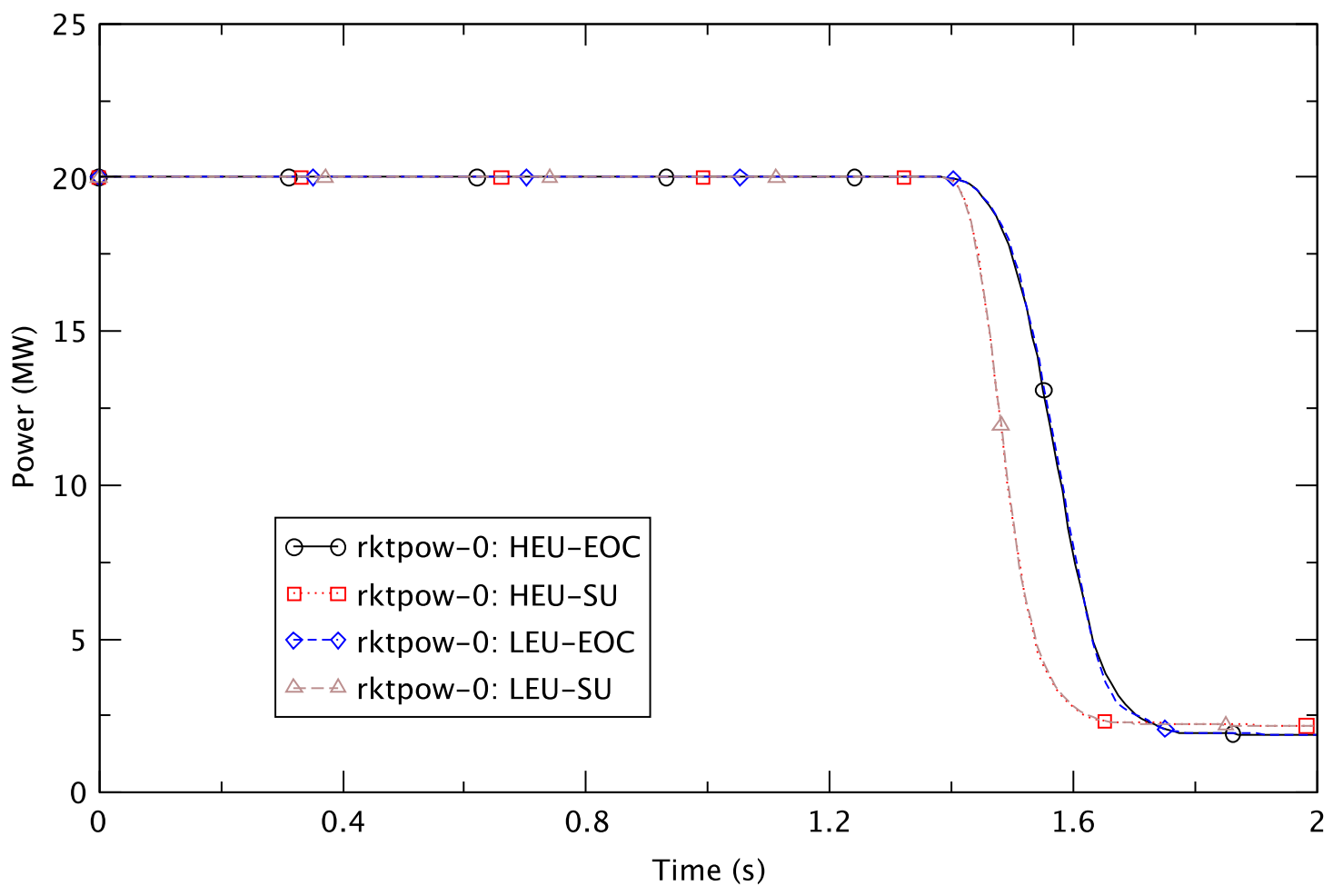

Figure 13.24 Reactor Power after Loss of Offsite Power

\subsubsection{Limiting Parameters}

Figure 13.25 shows clad temperature from zero to $5 \mathrm{~s}$ in the fuel element nodes corresponding to where RELAP5 predicts the highest PCT. The clad temperatures increase due to reduced heat transfer as fluid velocity decreases after the primary pumps trip. Clad temperature reaches a maximum value at $1.41 \mathrm{~s}$ with both HEU and LEU fuels at SU and at $1.45 \mathrm{~s}$ with both HEU and LEU fuels at EOC and then begins decreasing rapidly because of decreasing reactor power. The peak clad temperatures range from $118^{\circ} \mathrm{C}$ to $124^{\circ} \mathrm{C}$ (much lower than the blister temperature), corresponding to temperature increases of $22^{\circ} \mathrm{C}$ in all cases.

Critical-heat-flux ratios are evaluated using the Sudo-Kaminaga correlations (see Section 4.6.2.1) and are shown in Figure 13.14 from zero to $5 \mathrm{~s}$. The hydraulic nodes used for the figures are where minimum CHFR takes place. CHFR starts decreasing slowly from time zero as the primary pumps coast down and reaches a minimum at $1.40 \mathrm{~s}$ at SU with both HEU and LEU fuel and at $1.42 \mathrm{~s}$ at EOC with both HEU and LEU fuels, respectively. Then CHFR increases very rapidly and remains larger than 8 for the rest of the simulation in all cases. The calculated minimum CHFRs are shown in Table 13.9 along with the corresponding times and hydraulic node numbers. 


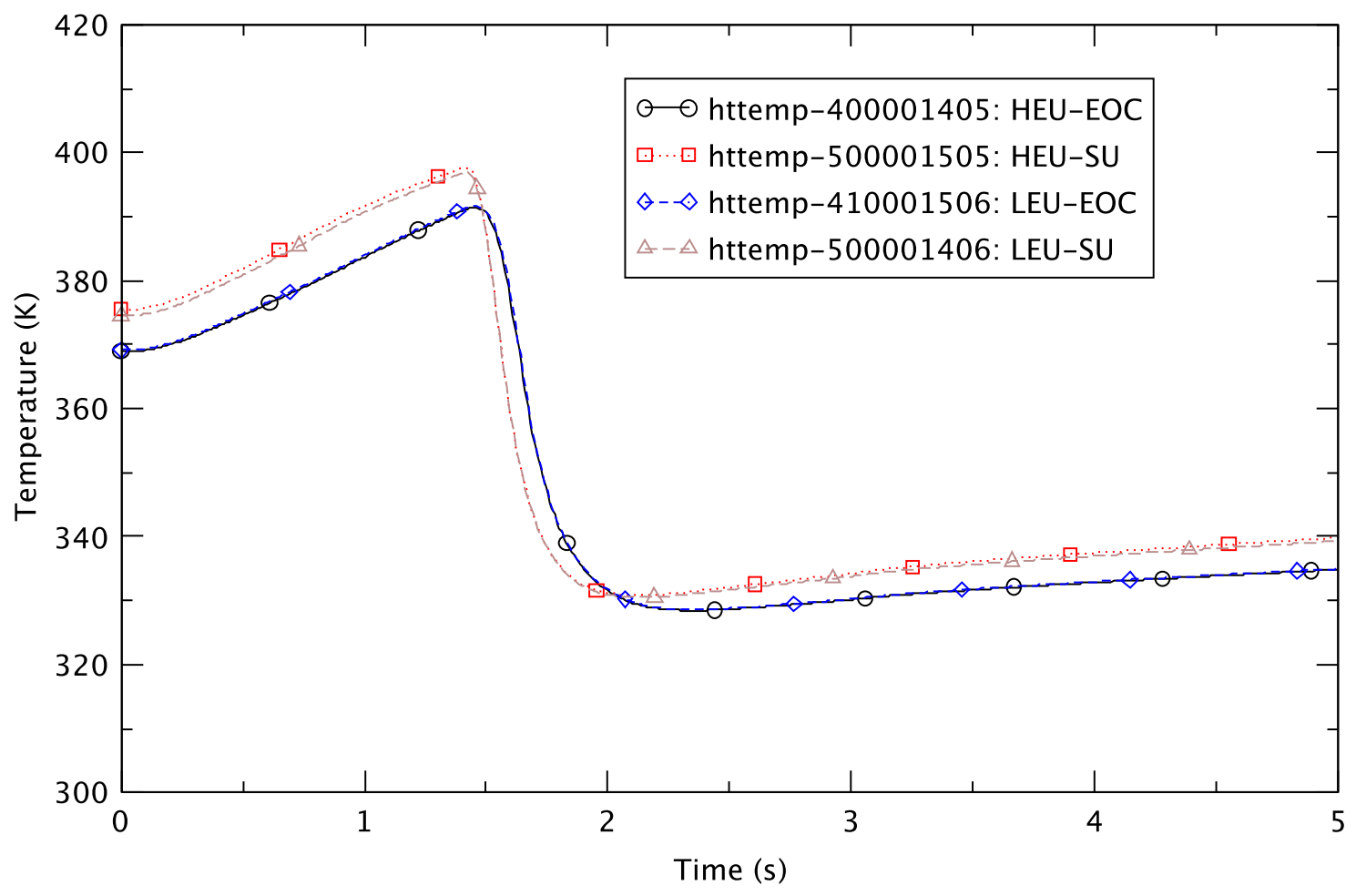

Figure 13.25 Clad Temperature after Loss of Offsite Power

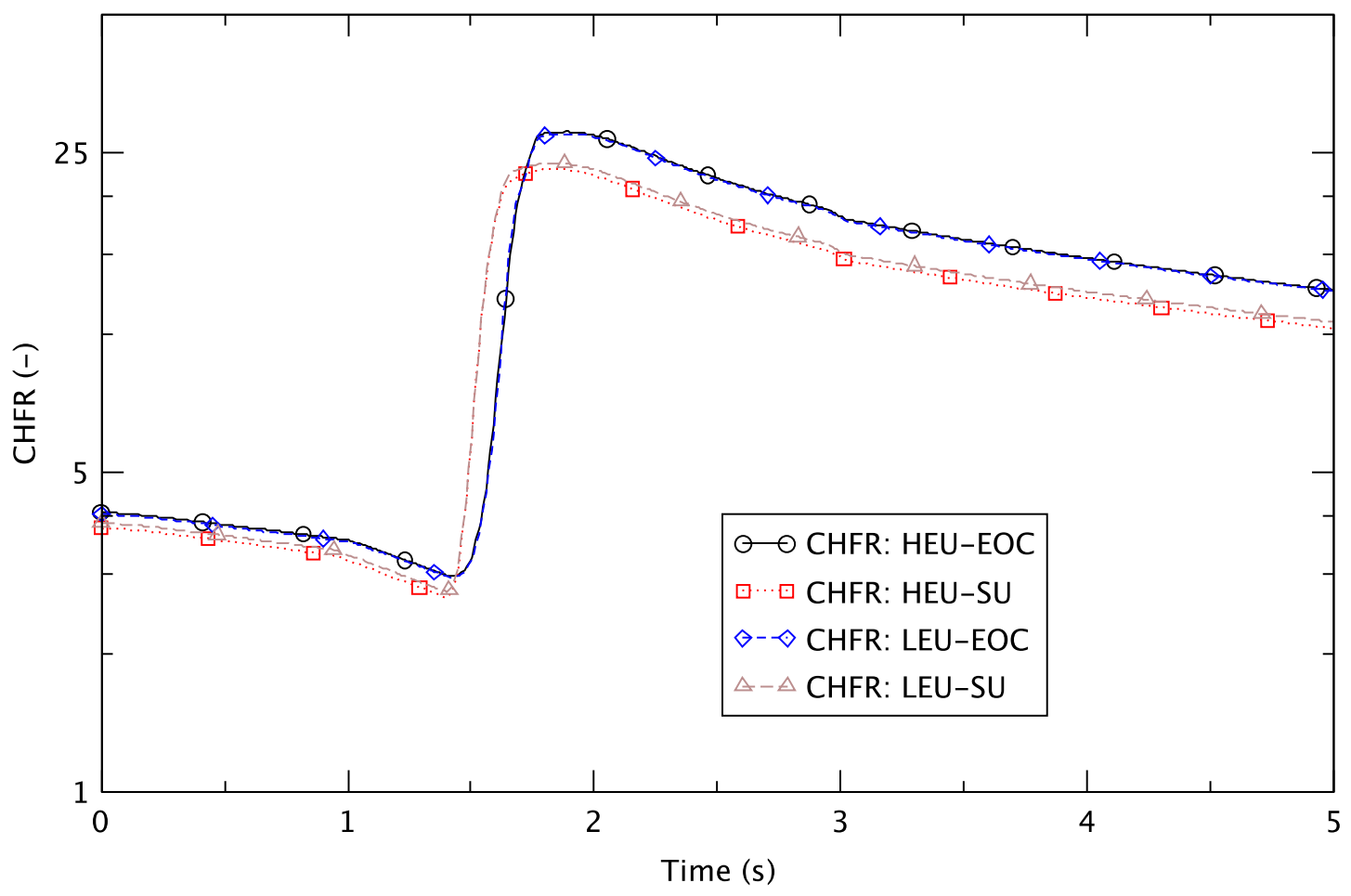

Figure 13.26 Critical-Heat-Flux Ratio after Loss of Offsite Power 
Table 13.9 Minimum CHFR after Loss of Offsite Power

\begin{tabular}{|c|c|c|c|}
\hline Case & $\begin{array}{c}\text { Minimum } \\
\text { CHFR }\end{array}$ & Time (s) & Hydraulic Node No. \\
\hline HEU EOC & 2.96 & 1.42 & $407-02^{1}$ \\
\hline HEU SU & 2.67 & 1.40 & $407-02^{2}$ \\
\hline LEU EOC & 2.95 & 1.42 & $417-02^{3}$ \\
\hline LEU SU & 2.75 & 1.40 & $417-02^{4}$ \\
\hline
\end{tabular}

${ }^{1}$ The minimum CHFR occurs in the node where the hottest cell (highest power cell in the core region) is located.

${ }^{2}$ The minimum CHFR occurs in the next heated (or powered) node above the one where the hottest cell is located.

${ }^{3}$ The minimum CHFR occurs in the node where the highest power cell in the hottest fuel stripe is located. This cell is different from the hottest cell among all cells in the core region.

${ }^{4}$ The minimum CHFR occurs in the next heated (or powered) node above the one where the highest power cell in the hottest fuel stripe is located.

It can be seen from Figure 13.26 that the CHFR behavior is very similar in both the HEU and the LEU fuels. It is also observed from the figure and Table 13.9 that the minimum CHFRs are all significantly larger than 1.78 . This implies that CHF is precluded with a probability greater than 99.9\% (see Table 4.20) with either the HEU or the LEU fuel.

Onset-of-flow-instability ratios are evaluated using Saha-Zuber criteria (see Section 4.6.2.2) and are shown in Figure 13.27 from zero to $3 \mathrm{~s}$. The hydraulic nodes used for the figures are the ones where minimum OFIR occurs. The results are similar to those for CHFR. OFIR begins to decrease slowly from time zero as the system flow decreases and reaches a minimum value between $1.40 \mathrm{~s}$ and $1.43 \mathrm{~s}$. It then increases very rapidly and becomes larger than 20 after $1.7 \mathrm{~s}$ in all cases. The minimum OFIRs are shown in along with the corresponding times and hydraulic node numbers.

Table 13.10 shows that the minimum OFIR occurs when the reactor power is still very high (Figure 13.24) but mass flow rate becomes small (Figure 13.23) in all cases. It is observed from Figure 13.27 and Table 13.10 that the minimum OFIRs are all much larger than 1.83. This means that with either the HEU or the LEU fuel the onset-of-flow-instability is precluded with a probability higher than 99.9\% (see Table 4.21). 


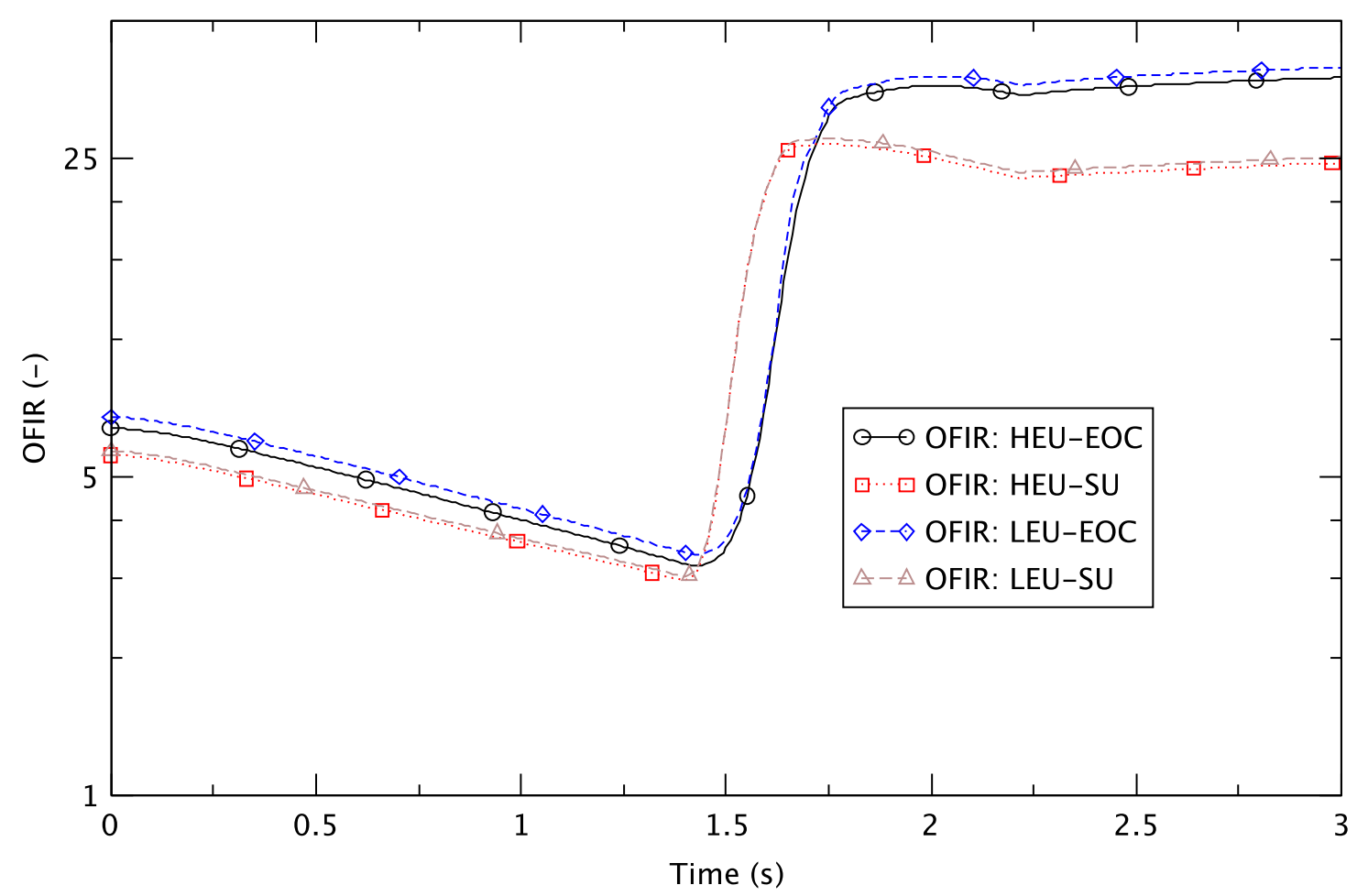

Figure 13.27 Onset-of-Flow-Instability Ratio after Loss of Offsite Power

Table 13.10 Minimum OFIRs after Loss of Offsite Power

\begin{tabular}{|c|c|c|c|}
\hline Case & $\begin{array}{c}\text { Minimum } \\
\text { OFIR }\end{array}$ & Time (s) & Hydraulic Node No. \\
\hline HEU EOC & 3.20 & 1.43 & $417-15^{1}$ \\
\hline HEU SU & 2.97 & 1.40 & $503-15^{2}$ \\
\hline LEU EOC & 3.38 & 1.42 & $417-13^{1}$ \\
\hline LEU SU & 3.03 & 1.40 & $503-15^{2}$ \\
\hline $\begin{array}{l}{ }^{1} \text { The minimum OFIR occurs in the powered top node of the flow } \\
\text { channel with the hottest fuel stripe. } \\
\text { 2The minimum OFIR occurs in the hottest node (highest power cell in } \\
\text { the core region). The flow channel with this node has a common mid- } \\
\text { plane gap shared with the flow channel for 16 average fuel plates. }\end{array}$ \\
\hline
\end{tabular}

\subsubsection{Loss of Offsite Power with Shutdown Pump Failure}

The accident begins with a loss of offsite power and coastdown of the primary pumps. A reactor trip signal is generated on low primary flow. It is assumed that both shutdown pumps and all of the secondary coolant pumps associated with the heat exchanger coast down, since there has been a failure of all backup power sources. The valves at the outlet of the primary pumps start closing at $1 \mathrm{~s}$ on the primary pump trip signal due to the loss of offsite power, whereas the valves 
at the outlet of the shutdown pumps begin opening at $0.7 \mathrm{~s}$. The opening of the valves at the outlet of the shutdown pumps provides the primary system with a path through which the coolant can flow when natural circulation is established. However, significant natural circulation through the entire primary loop is not expected because the elevation of the heat exchangers (heat sink) is lower than that of the core (heat source).

A RELAP5 simulation (Baek, 2014b) of this process is followed until the fuel reaches a relatively stable temperature, when it is being cooled in a pool boiling mode. The large inventory of water in the core, inner emergency cooling tank, and upper plenum will then be involved in a very gradual warm-up. It will take a much longer time (several hours) for the bulk water temperature to reach the boiling point, allowing time for shutdown cooling to be restored.

The clad temperature reaches a maximum and the CHFR and OFIR have minima at around the same time (1.4 s) as in the accident with the one SDP operating indicating that it is the reactor trip that determines the timing of these limiting parameters. Furthermore, as in the case with one SDP, the increase in clad temperature is only $22^{\circ} \mathrm{C}$ and the CHFR and OFIR are sufficient large so as to preclude any fuel damage with at least a $99.9 \%$ probability.

\subsubsection{Seizure of One Primary Pump}

\subsubsection{Simulation of Accident}

It is assumed that through some failure, such as a faulty bearing, the rotor of one pump suddenly becomes locked. Because of its momentum, coolant flow through the primary loop will decrease over a finite time interval until a one-third flow reduction is achieved. Since the RELAP5 model lumps all three pumps into one effective pump, the seizure of one of the pumps is modeled by an instantaneous step reduction in the pump speed to two-thirds of full speed. This is conservative since the flow with only two pumps operating would actually be more than two-thirds of full flow.

Figure 13.28 shows the flows in the primary system. In the legend 'Total', 'To Inner Plenum', and 'To Outer Plenum' stand for the mass flowrates at the inlets to the heat exchanger, to the inner plenum, and to the outer plenum, respectively, predicted with LEU fuel at SU. The flow behavior in the other cases is almost the same as that in Figure 13.28. As one of the three primary pumps is locked, all mass flowrates start decreasing rapidly from time zero. They become two-thirds of their normal operating values within $1.0 \mathrm{~s}$ and remain constant for the rest of the simulation.

Reactor powers are compared during the transient from zero to $2 \mathrm{~s}$ in Figure 13.29. Reactor power decreases very rapidly from around $0.8 \mathrm{~s}$ in all cases. The trip setpoint for low outer plenum flow (297 $\mathrm{\ell} / \mathrm{s})$ is reached at approximately $0.3 \mathrm{~s}$ in all cases. A reactor trip signal is then generated after a $0.4 \mathrm{~s}$ delay and the shim arms start being inserted into the core as indicated by the power in the figure. 


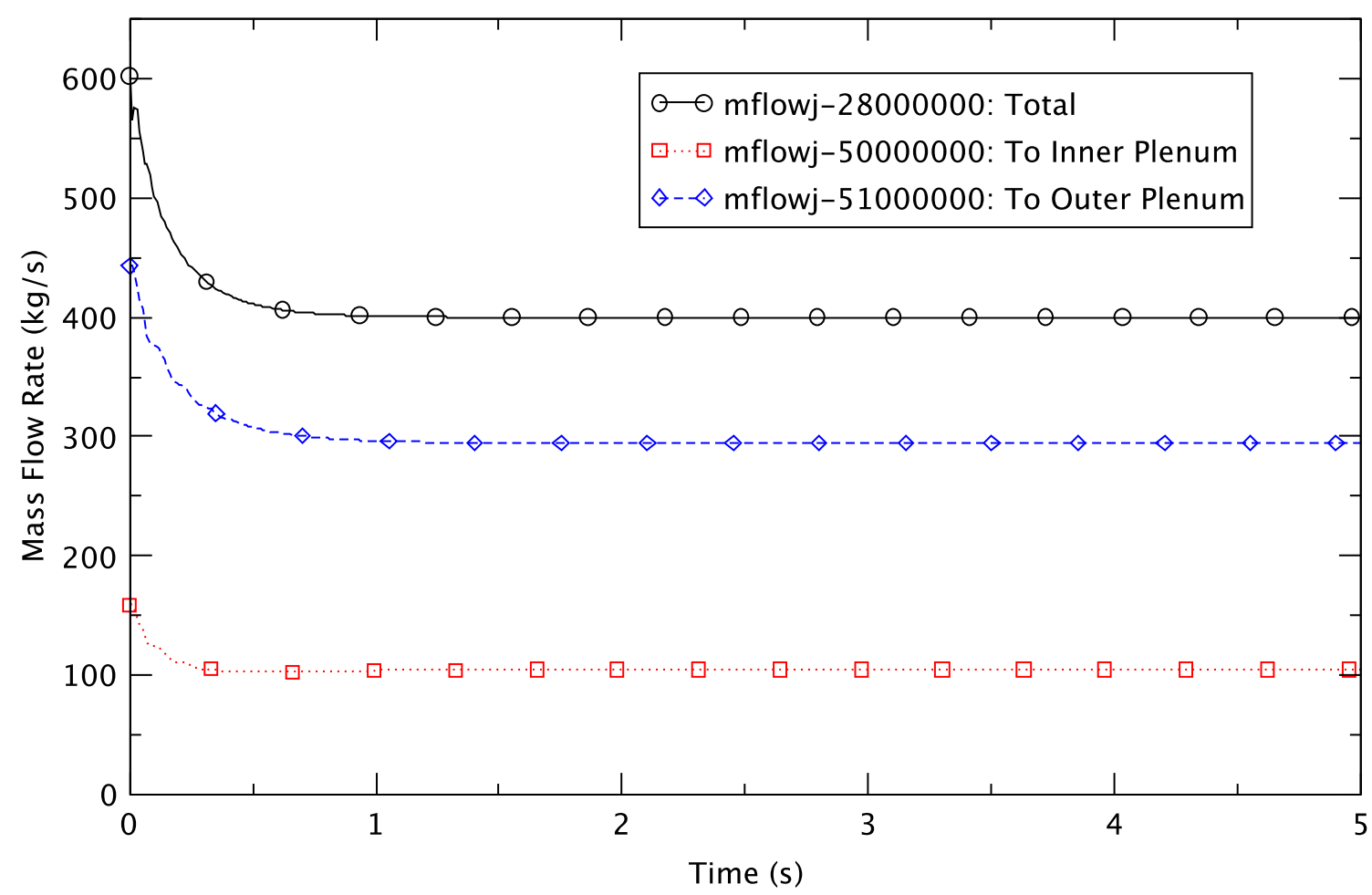

Figure 13.28 Primary System Flows after Seizure of One Primary Pump; LEU Fuel at SU

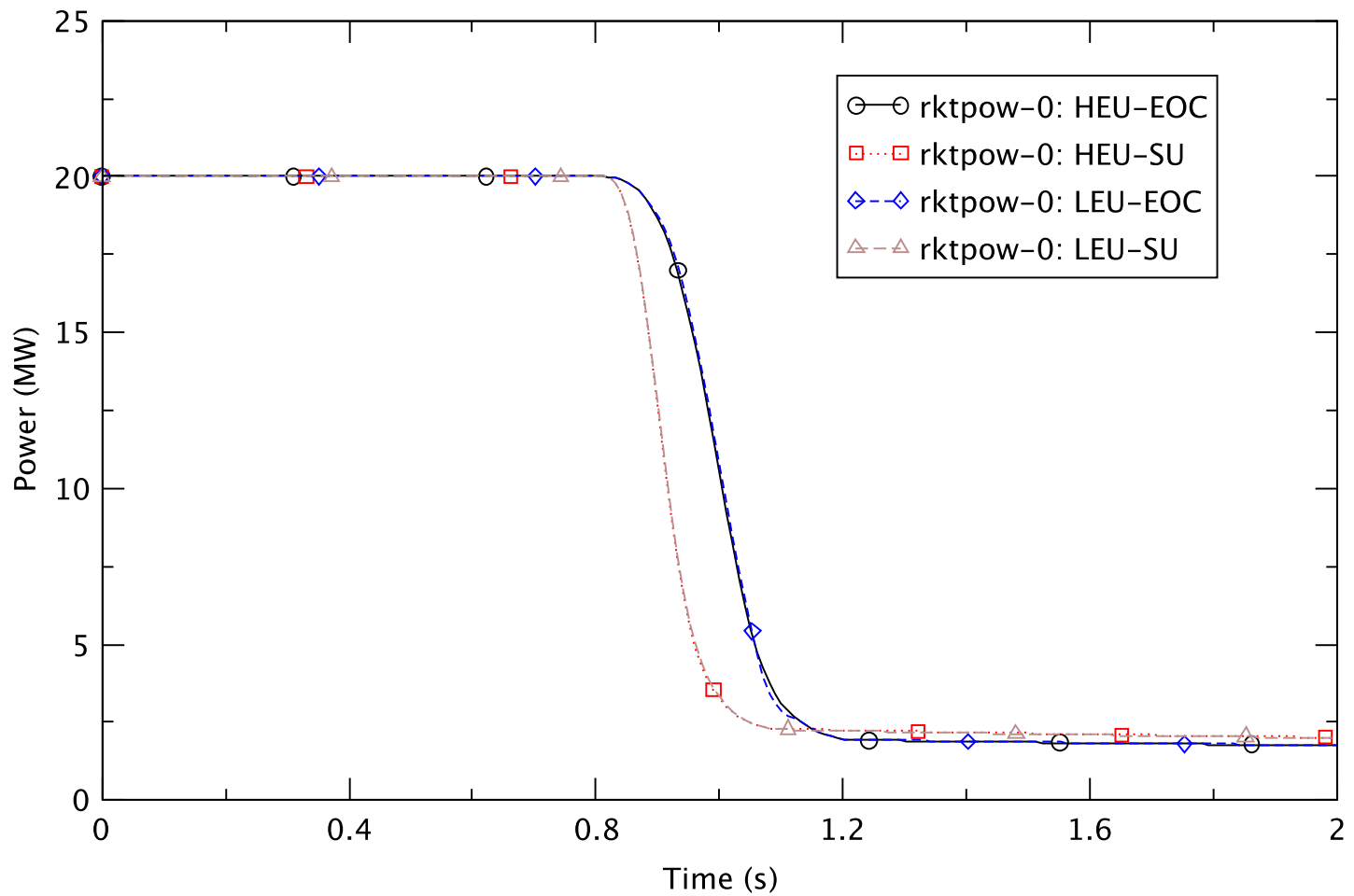

Figure 13.29 Reactor Power after Seizure of One Primary Pump 
The reactor trip occurs earlier in this accident than in the accident with loss of offsite power discussed in Section 13.5.1.1. This is because of the more rapid decrease in core flow early in this accident.

Figure 13.29 shows that the power in the LEU and HEU cores is very similar. The power drops more rapidly in the cases at SU compared to the cases at EOC. This results from the different initial shim arm positions (about $20^{\circ}$ at SU and $41^{\circ}$ at EOC; Figure 13.5 and Figure 13.6), which causes a larger initial negative reactivity insertion rate at $\mathrm{SU}$.

\subsubsection{Limiting Conditions}

Figure 13.30 shows clad temperatures from zero to $2 \mathrm{~s}$ in the fuel element nodes corresponding to where the highest PCT occurs. The clad temperatures start increasing from time zero due to heat transfer becoming less efficient as the mass flow rate decreases after pump seizure. Temperature reaches a maximum shortly after reactor trip and then begins decreasing rapidly because of the reduction of reactor power. The peak clad temperatures range from $114^{\circ} \mathrm{C}$ to $121^{\circ} \mathrm{C}$ (much lower than the blister temperature) and the increase in temperature is $18^{\circ} \mathrm{C}$ to $19^{\circ} \mathrm{C}$ in all cases.

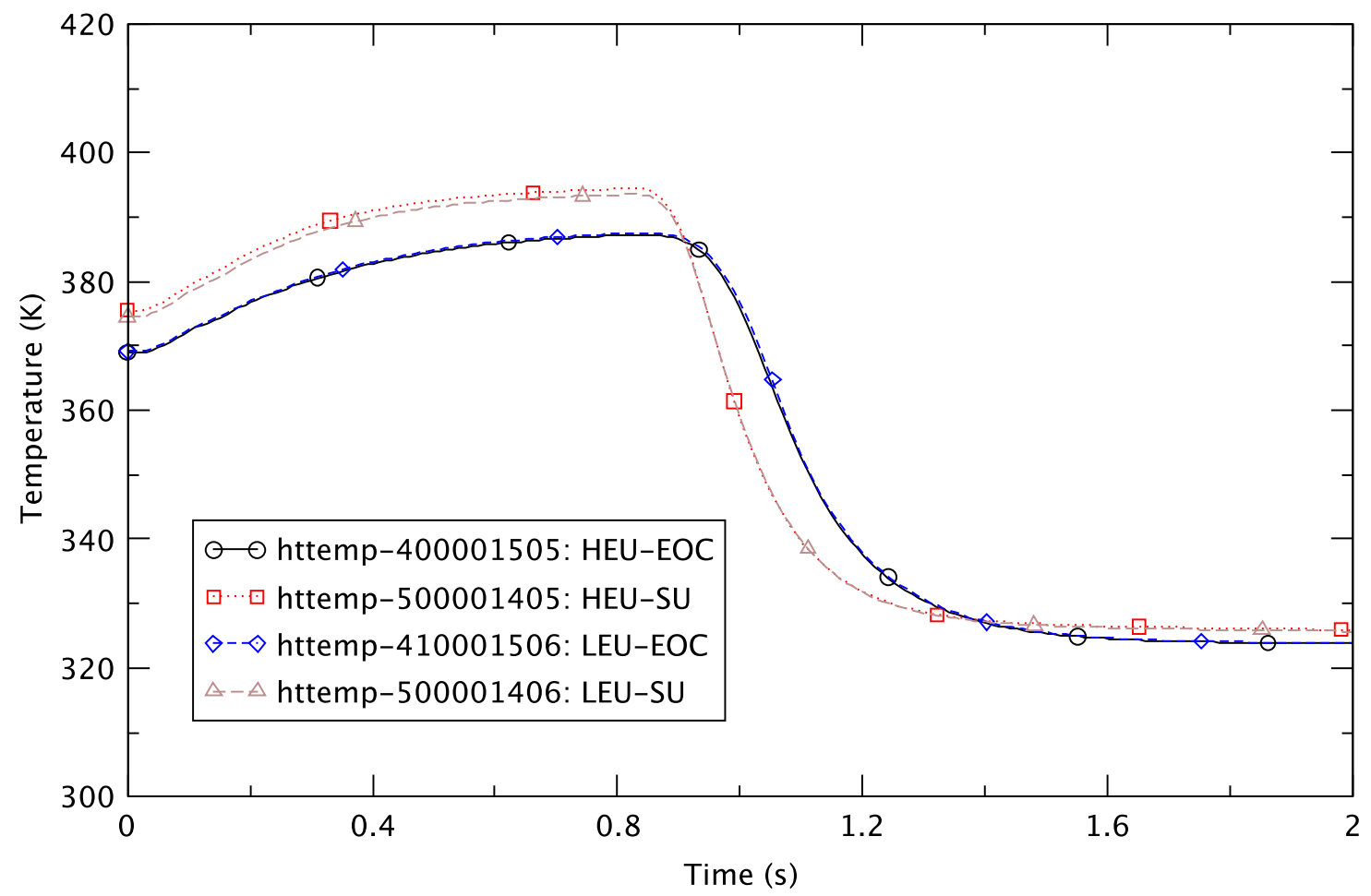

Figure 13.30 Clad Temperature after Seizure of One Primary Pump

Critical-heat-flux ratios are evaluated using the Sudo-Kaminaga correlations (see Section 4.6.2.1) and they are compared in Figure 13.31 from zero to 2 s. The hydraulic nodes used for the figures are the ones where minimum CHFRs are predicted. CHFR starts decreasing slowly from time zero and reaches a minimum at $0.81 \mathrm{~s}$ at $\mathrm{SU}$ and $0.82 \mathrm{~s}$ at EOC. CHFR then increases 
very rapidly and becomes larger than 30 from $1.2 \mathrm{~s}$ in all cases. The calculated minimum CHFRs are shown in Table 13.11 along with the corresponding times and hydraulic node numbers.

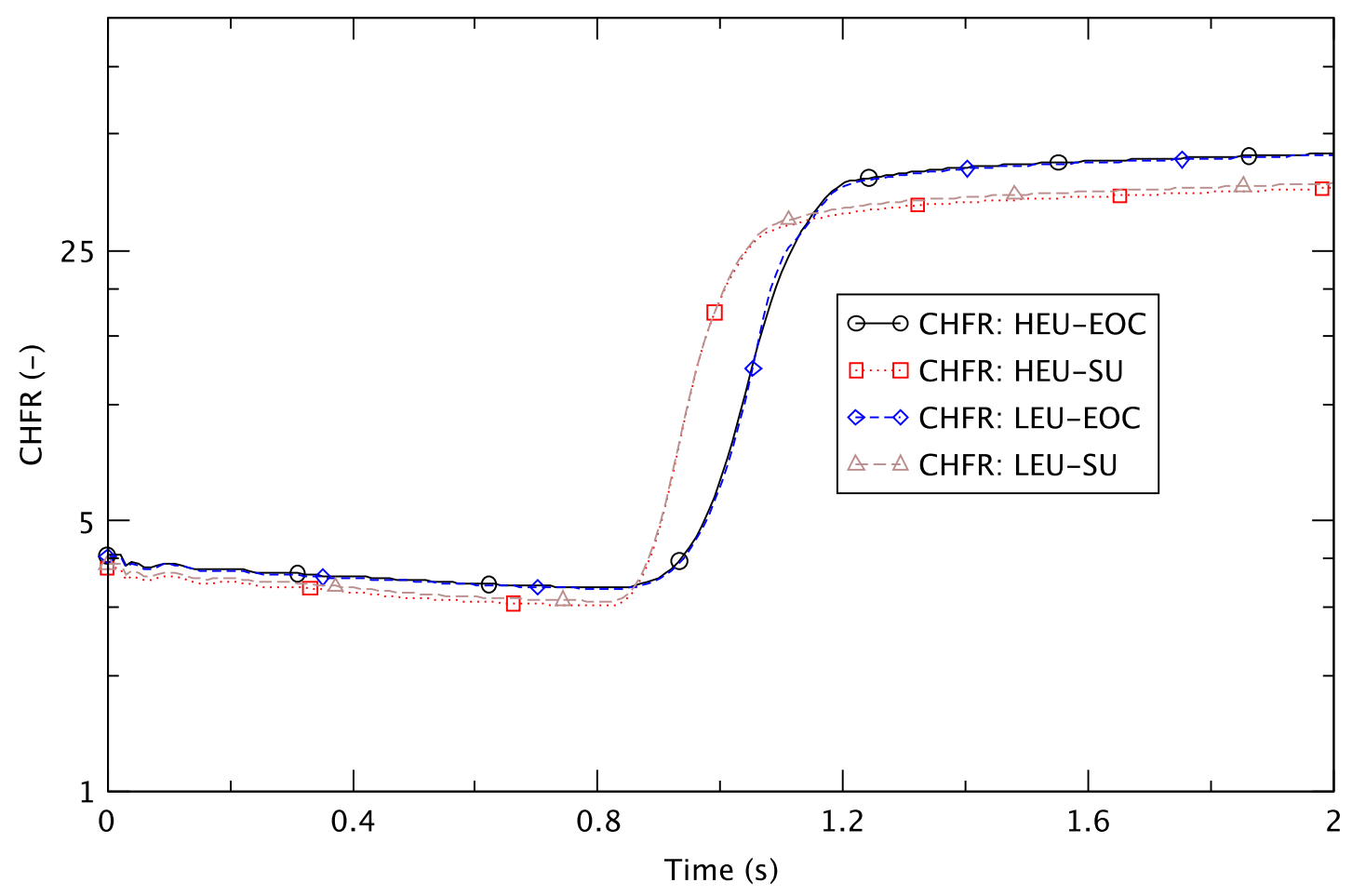

Figure 13.31 Critical Heat Flux Ratio after Seizure of One Primary Pump

Table 13.11 Minimum CHFR after Seizure of One Primary Pump

\begin{tabular}{|c|c|c|c|}
\hline Case & $\begin{array}{c}\text { Minimum } \\
\text { CHFR }\end{array}$ & Time (s) & Hydraulic Node No. \\
\hline HEU EOC & 3.37 & 0.82 & $407-02^{1}$ \\
\hline HEU SU & 3.02 & 0.81 & $407-02^{2}$ \\
\hline LEU EOC & 3.35 & 0.82 & $417-02^{3}$ \\
\hline LEU SU & 3.11 & 0.81 & $417-02^{4}$ \\
\hline
\end{tabular}

${ }^{1}$ The minimum CHFR occurs in the node where the hottest cell (highest power cell in the core region) is located.

${ }^{2}$ The minimum CHFR occurs in the next heated (or powered) node above the hottest cell.

${ }^{3}$ The minimum CHFR occurs in the node where the highest power cell in the hottest fuel stripe is located. This cell is different from the hottest cell among all cells in the core region.

${ }^{4}$ The minimum CHFR occurs in the next heated (or powered) node above the one where the highest power cell in the hottest fuel stripe is located.

Figure 13.31 and Table 13.11 show that the minimum CHFR occurs shortly after reactor trip when the reactor power is still high. This indicates that the fluid conditions change rapidly and 
the critical heat flux at these conditions decreases faster with time than the decrease of the heat flux to the coolant until the minimum CHFR occurs. Then the decrease of the critical heat flux becomes slower than that of the heat flux to the coolant and CHFR begins increasing. Figure 13.31 also shows that the CHFR with LEU fuel is very similar to that with HEU fuel. It is also observed that the minimum CHFRs are greater than 1.78 in all cases. Hence, CHF is precluded, with either HEU or LEU fuel, with a probability greater than 99.9\% (see Table 4.20).

Onset-of-flow-instability ratios are evaluated using Saha-Zuber criteria (see Section 4.6.2.2) and are shown in Figure 13.32 from zero to $2 \mathrm{~s}$. The hydraulic nodes used for the figures are the ones where minimum OFIR occurs. As shown in these figures, OFIR starts decreasing slowly from time zero and reaches a minimum value at $0.81 \mathrm{~s}$ at SU with both the HEU and LEU fuels and at 0.83 and $0.82 \mathrm{~s}$ at EOC with the HEU and LEU fuels, respectively. OFIR then increases very rapidly and becomes larger than 35 after $1.2 \mathrm{~s}$ in all cases. The minimum OFIR is shown in Table 13.12 along with the corresponding times and hydraulic node numbers. As with the minimum CHFR, the minimum OFIR occurs shortly after reactor trip when the power is still high.

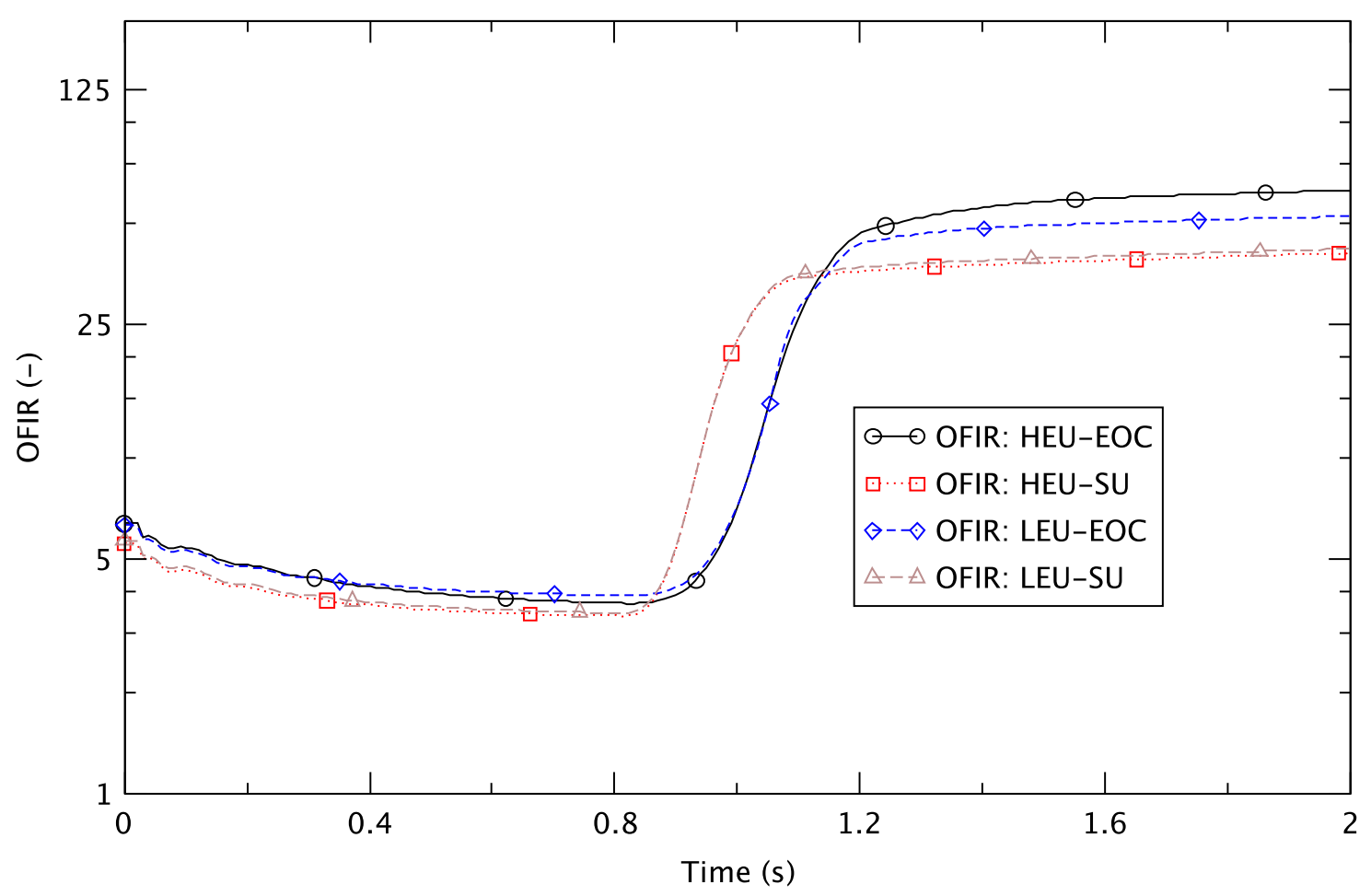

Figure 13.32 Onset-of-Flow-Instability Ratio after Seizure of One Primary Pump

Table 13.12 shows that the minimum OFIR does not take place around the hottest node at EOC in this accident but rather at the top of the channel. It can be seen from Figure 13.32 that the OFIR with LEU fuel is very similar to that with the HEU fuel. It is also observed from the figure and the table that the minimum OFIR is greater than 1.83 and hence, fuel element damage is precluded with either the HEU or the LEU fuel, with a probability greater than 99.9\% (see Table 4.21). 
Table 13.12 Minimum OFIR after Seizure of One Primary Pump

\begin{tabular}{|c|c|c|c|}
\hline Case & $\begin{array}{c}\text { Minimum } \\
\text { OFIR (-) }\end{array}$ & Time (s) & Hydraulic Node No. \\
\hline HEU EOC & 3.69 & 0.83 & $417-15^{1}$ \\
\hline HEU SU & 3.39 & 0.81 & $503-15^{2}$ \\
\hline LEU EOC & 3.90 & 0.82 & $417-15^{1}$ \\
\hline LEU SU & 3.46 & 0.81 & $503-15^{2}$ \\
\hline \multicolumn{4}{|c|}{$\begin{array}{l}{ }^{1} \text { The minimum OFIR occurs in the powered-top node of the flow } \\
\text { channel corresponding to the hottest fuel stripe. } \\
{ }^{2} \text { The minimum OFIR occurs in the hottest node (highest power cell in } \\
\text { the core region). The flow channel with this node has a common mid- } \\
\text { plane gap shared with the flow channel for } 16 \text { average fuel plates. }\end{array}$} \\
\hline
\end{tabular}

\subsubsection{Throttling of Coolant Flow to Outer Plenum}

\subsubsection{Simulation of Accident}

In this accident scenario, the flow control valve DWV-1 (VALVE-51 in Figure 13.2) is assumed to close in $60 \mathrm{~s}$, reducing the flow through the outer plenum and generating a reactor trip signal $0.4 \mathrm{~s}$ after the flow reaches the low flow trip point of 4,700 gpm (297 l/s). The complete closure of the flow control valve isolates the lower plenum of the outer core and cuts off the supply of forced coolant flow. The RELAP5 simulation shows that since all coolant channels in the fuel elements in the outer core share the same inlet and outlet plenums, closed loop recirculation flow paths are established between hotter and cooler coolant channels in the outer core. Buoyancy induces upflow through the hotter coolant channels, while downflow through the cooler channels completes the closed flow loop. The recirculation flow removes heat from the fuel elements by natural convection.

Figure 13.33 shows the mass flowrates at the inlet to the heat exchanger (Total), inlet to the inner plenum (To Inner Plenum), and inlet to the outer plenum (To Outer Plenum), predicted with LEU fuel at SU. The flow behavior is almost the same in the other cases. While the flowrate to the outer plenum decreases from time zero as DWV-1 starts closing, it increases at the inlet to the inner plenum because the primary pumps are running at constant speed. The figure also shows that the primary pump flow decreases due to the increase of the total pressure drop through the primary system owing to the increase of mass flowrate in the inner core. When DWV-1 closes completely at $60 \mathrm{~s}$, the total flowrate to the inner plenum becomes constant (about $275 \mathrm{~kg} / \mathrm{s}$ ) and the flow to the outer plenum becomes zero. 


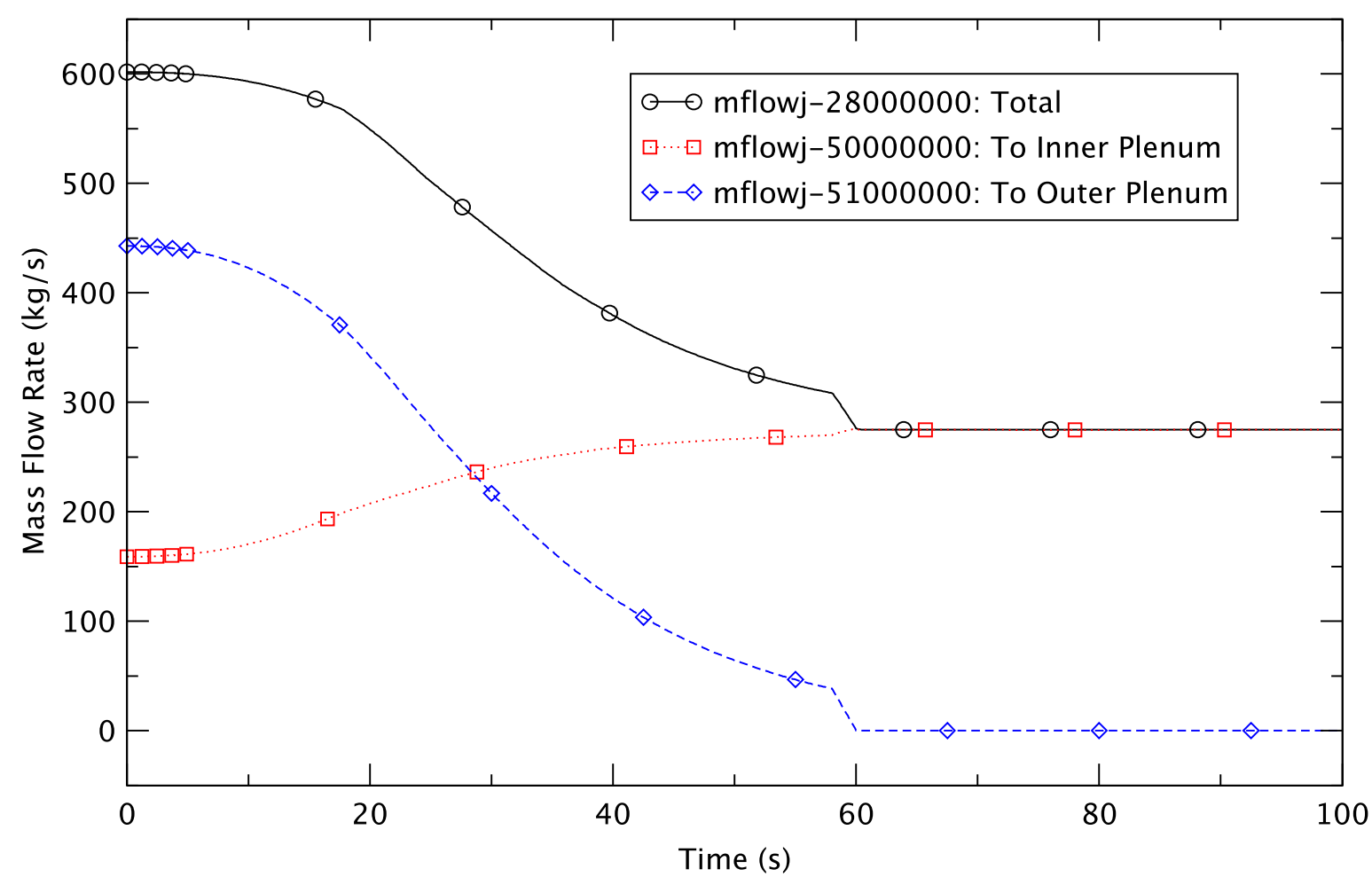

Figure 13.33 Primary System Flows after Throttling of Coolant Flow to Outer Plenum; LEU Fuel at SU

Reactor power from zero to $100 \mathrm{~s}$ is shown in Figure 13.34. The reactor power decreases rapidly from around $21.8 \mathrm{~s}$ in all cases. The trip setpoint on low outer plenum flow (297 $\mathrm{l} / \mathrm{s})$ is reached at $21.3 \mathrm{~s}$ with both HEU and LEU fuels. Reactor trip begins after a $0.4 \mathrm{~s}$ delay and the shim arms start to be inserted into the core.

The power plots in Figure 13.34 show that the behavior is similar in both the LEU and HEU cores. A closer examination would show that the power drops more rapidly in the cases at SU compared to the cases at EOC. This results from the different initial shim arm positions (about $20^{\circ}$ at SU and $41^{\circ}$ at EOC; Figure 13.5 and Figure 13.6), which lead to a larger initial negative reactivity insertion rate at $\mathrm{SU}$. 


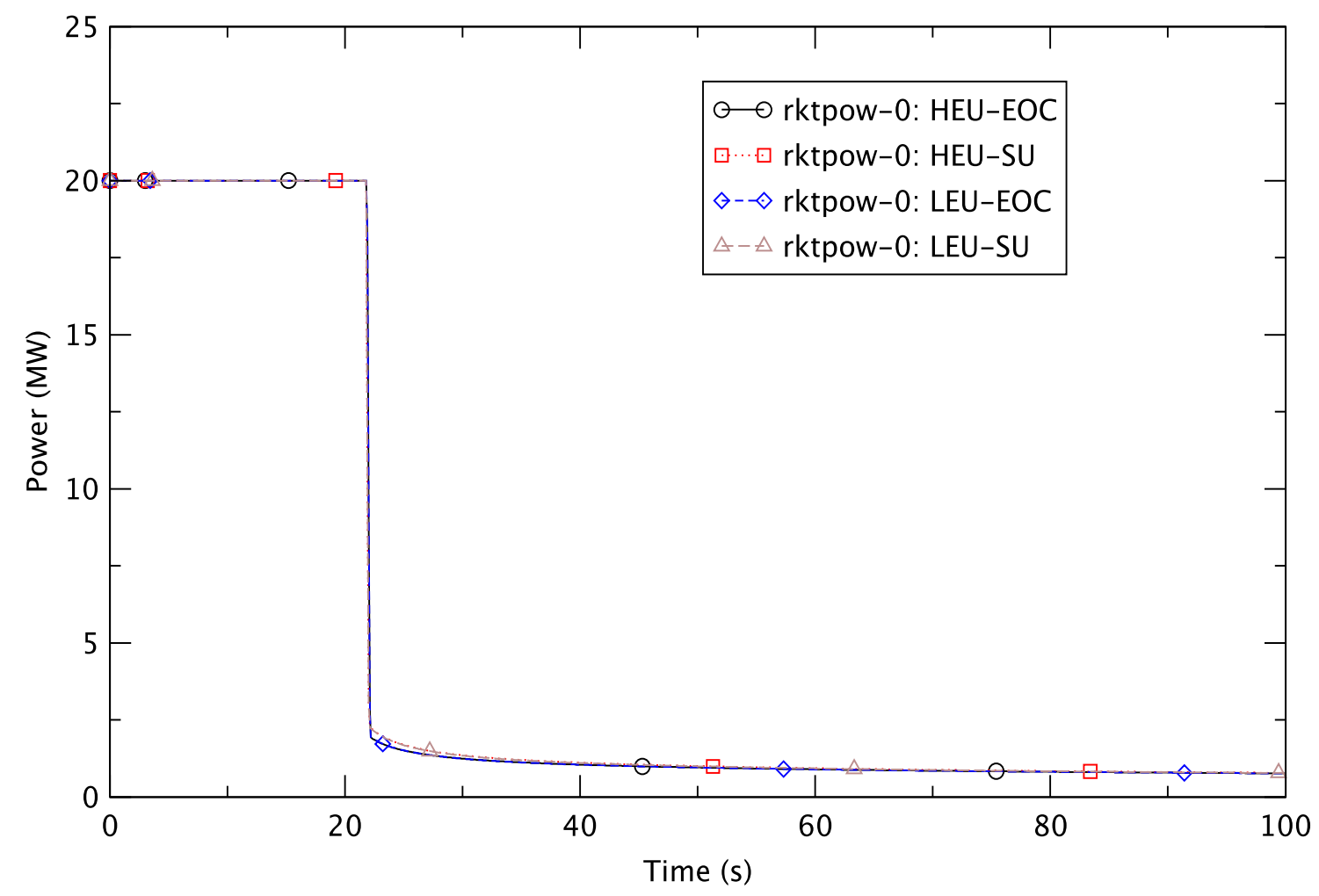

Figure 13.34 Reactor Power after Throttling of Coolant Flow to Outer Plenum

\subsubsection{Limiting Conditions}

Figure 13.35 shows clad temperatures in the fuel element nodes corresponding to the channel cell where the highest PCT is expected to occur. Heat structure numbers 4100 and 5000 in the legend indicate the fuel stripes with the highest stripe power and the hottest fuel cell (highest cell power), respectively, in the outer core. The flow channel with heat structure number 5000 shares a mid-plane gap with 16 average fuel plates while the flow channel with heat structure number 4100 does not.

The general behavior of the clad temperature for LEU fuel is very similar to that for HEU fuel until around $60 \mathrm{~s}$ at which time the control valve (DMV-1) closes completely. The clad temperature starts increasing from time zero due to heat transfer becoming less efficient as the mass flow rate to the outer core decreases. The temperature reaches a first peak when reactor trip occurs and then begins decreasing rapidly because of reduction of the reactor power. The temperature starts increasing again around $30 \mathrm{~s}$ as the mass flow rate decreases further and heat transfer from the fuel elements to the coolant becomes less efficient.

The clad temperatures show oscillatory behavior from around $60 \mathrm{~s}$ to $130 \mathrm{~s}$ because the mass flow rates in flow channels fluctuate around zero. As the valve at the inlet to the outer plenum is being closed, the coolant flow velocity decreases very rapidly, fluctuates around zero, and then stable natural circulation flow is established between hotter and cooler flow channels inside the outer core, as shown in Figure 13.36. The figure shows the flow behavior in the hottest channel at SU with the LEU fuel where the minimum CHFR takes place. During the flow fluctuations, 
RELAP5 predicts almost zero flow velocity several times when flow direction changes. This results in poor heat transfer from the fuel to the coolant and clad temperature increases. As flow velocity increases after change of the flow direction, the heat transfer increases and the clad temperature decreases. This behavior occurs several times during the flow fluctuations in all cases and it causes oscillations of the clad temperature as shown in Figure 13.35. However, the highest clad temperatures during the flow fluctuations are still very low especially as compared to the blister temperature.

Figure 13.35 shows that the clad temperature at SU with LEU fuel is much lower than in the other cases after around $110 \mathrm{~s}$. This is the result of relatively large (negative) flow through the minimum CHFR channel compared to the other three cases. For example, the mass flow rate in the minimum CHFR channel at $110 \mathrm{~s}$ is about $-0.03 \mathrm{~kg} / \mathrm{s}$ at SU with LEU fuel while it is around $0.02 \mathrm{~kg} / \mathrm{s}$ in the other cases, which enhances heat transfer from the fuel to the coolant in the former case. Also, Figure 13.35 shows that the clad temperature at SU with HEU fuel is slightly higher than at EOC with both HEU and LEU fuels. This is caused by a power fraction that is higher at SU than at EOC in the hottest cell. The peak clad temperatures vary from $116^{\circ} \mathrm{C}$ to $118^{\circ} \mathrm{C}$ (much lower than the blister temperature) corresponding to fuel temperature increases of only $16^{\circ} \mathrm{C}$ to $23^{\circ} \mathrm{C}$.

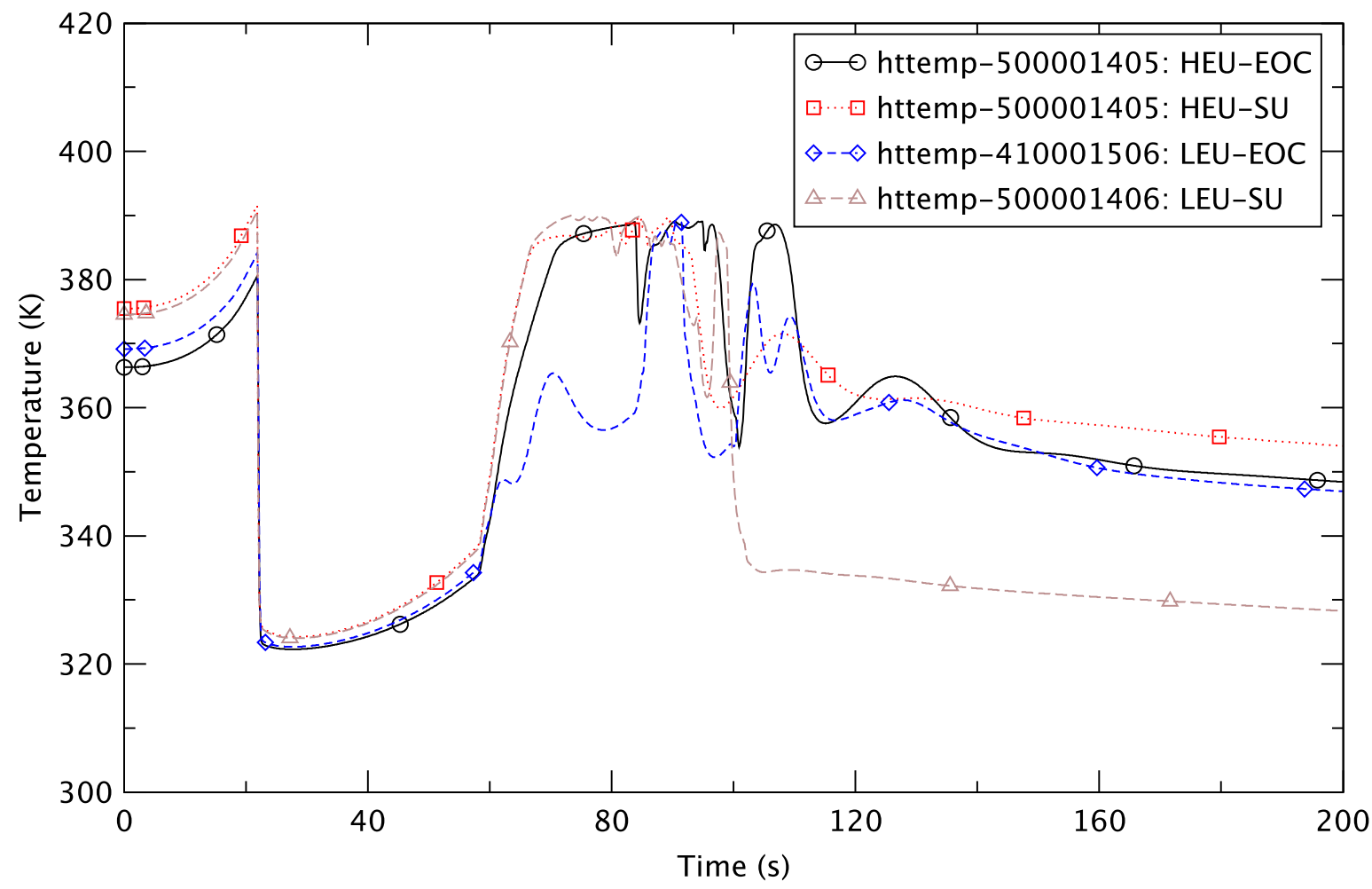

Figure 13.35 Clad Temperature after Throttling of Coolant Flow to Outer Plenum 


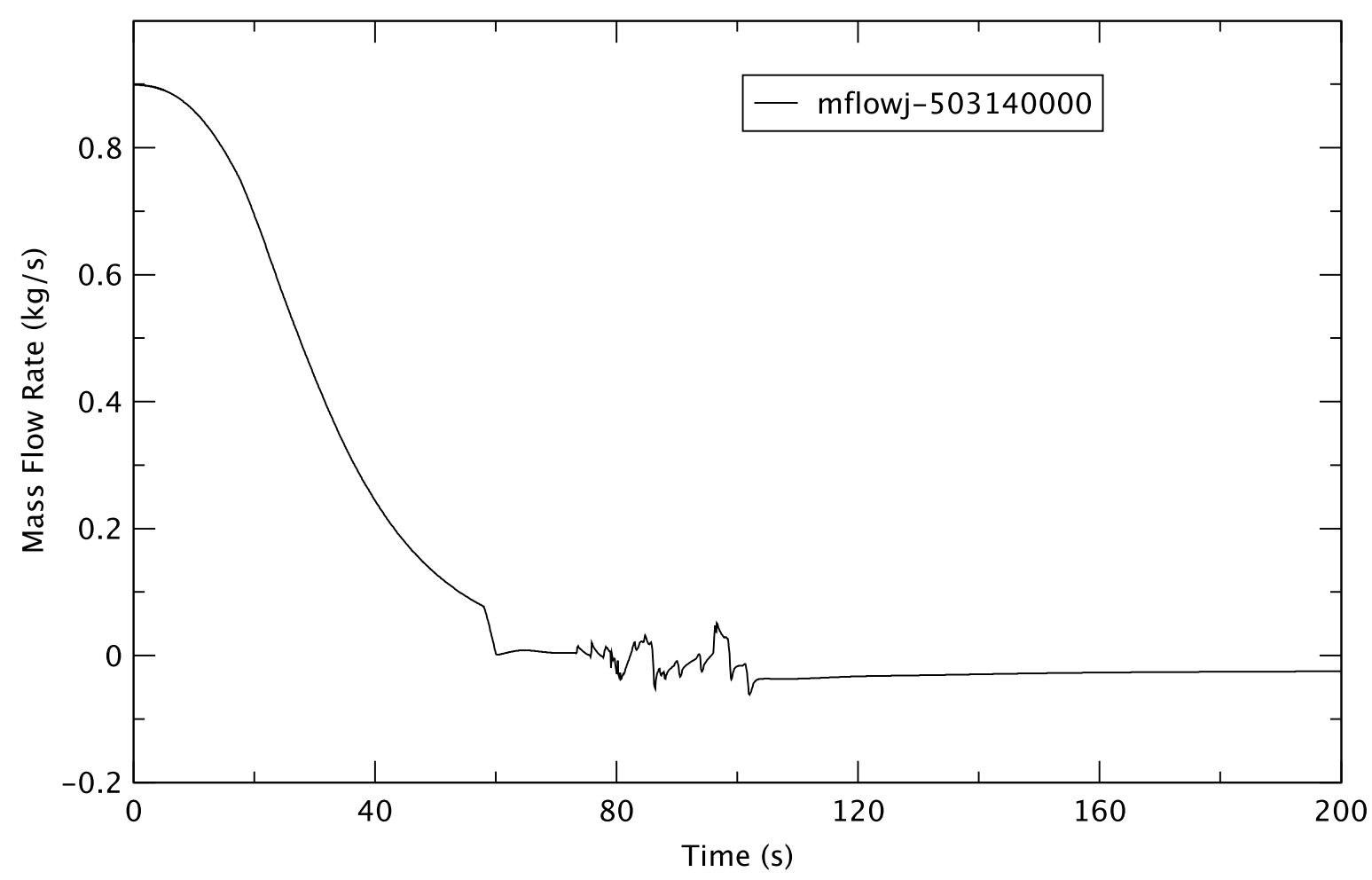

Figure 13.36 Mass Flow Rate in Hottest Channel after Throttling of Coolant Flow to Outer Plenum; LEU Fuel at SU

CHFRs were evaluated and are shown in Figure 13.37. The evaluation of CHFR stops at a certain time in all cases except at EOC with LEU fuel. Sudo and Kaminaga performed experiments and developed the correlation that is used to evaluate CHF. One of the experimental conditions was channel inlet subcooling which was $1 \mathrm{~K}$ to $74 \mathrm{~K}$ (Sudo, 1993). During the transients one channel's inlet subcooling became smaller than $1 \mathrm{~K}$ in the outer core between $89 \mathrm{~s}$ and $94 \mathrm{~s}$ and the Sudo-Kaminaga correlation could not be applied. For LEU fuel at EOC the inlet subcooling was larger than $1 \mathrm{~K}$ in all nodes during the transient.

Channel inlet subcooling less than $1 \mathrm{~K}$ is caused by flow oscillations around zero in channels of the outer core (see Figure 13.36). When flow velocity becomes very small or zero during the flow fluctuations, the fluid temperature increases because it receives a relatively large amount of heat as it stays in the channel for a relatively long time. Sometimes the liquid temperature becomes high enough to be close to or higher than the saturation temperature. As shown in Figure 13.37, CHFRs slowly decrease from time zero as the flow to the outer plenum decreases. The hydraulic nodes used for the figure are the ones where minimum CHFRs are predicted while the Sudo-Kaminaga correlation is applicable. CHFRs stop decreasing at around $22 \mathrm{~s}$ in all cases and then increase very rapidly. CHFRs decrease very quickly at around $58 \mathrm{~s}$ as DWV-1 becomes almost fully closed and oscillate from around $72 \mathrm{~s}$ due to the fluctuations of the channel flow in the outer core. Table 13.13 shows the minimum CHFRs, along with the corresponding times and hydraulic node numbers, for the period during which the Sudo-Kaminaga correlation was applicable. 


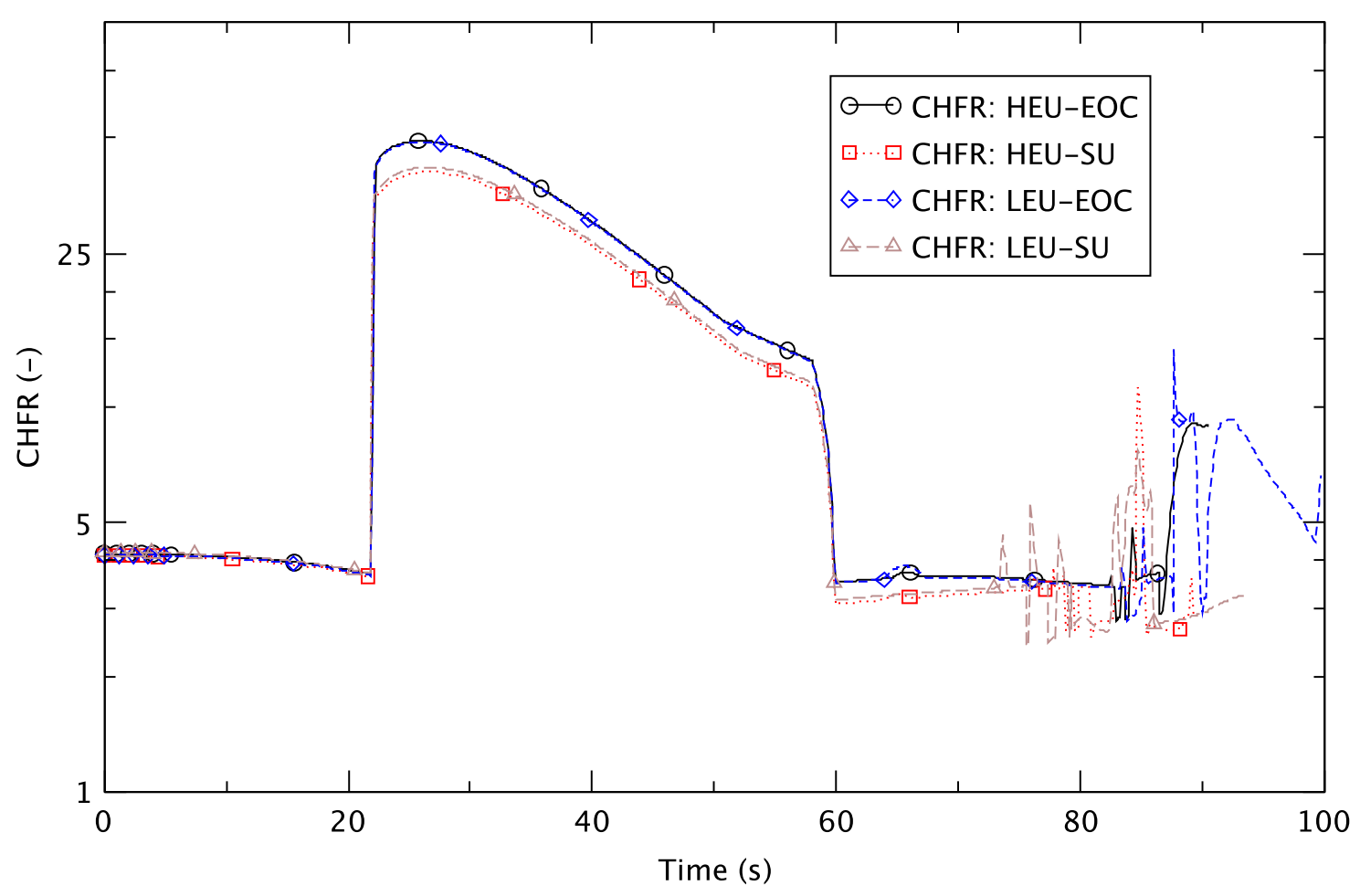

Figure 13.37 Critical Heat Flux Ratio after Throttling of Coolant Flow to Outer Plenum

Table 13.13 Minimum CHFR after Throttling of Coolant Flow to Outer Plenum

\begin{tabular}{|c|c|c|c|}
\hline Case & $\begin{array}{c}\text { Minimum } \\
\text { CHFR }\end{array}$ & Time (s) & Hydraulic Node No. \\
\hline HEU EOC & 2.80 & 82.9 & $507-02^{1}$ \\
\hline HEU SU & 2.53 & 80.8 & $503-15^{2}$ \\
\hline LEU EOC & 2.80 & 83.8 & $507-02^{1}$ \\
\hline LEU SU & 2.39 & 75.7 & $503-15^{2}$ \\
\hline $\begin{array}{l}{ }^{1} \text { The minimum CHFR occurs in the hottest node (highest power cell in } \\
\text { the core region). The flow channel with this node has a common mid- } \\
\text { plane gap shared with the flow channel for 16 average fuel plates. }\end{array}$ \\
$\begin{array}{l}\text { 2The minimum CHFR occurs in the hottest node (highest power cell in } \\
\text { the core region). The flow channel with this node has a common mid- } \\
\text { plane gap shared with the flow channel for 16 average fuel plates. }\end{array}$ \\
\hline
\end{tabular}

Table 13.13 shows that the CHFR with LEU fuel is similar to that with HEU fuel. It is also observed that the minimum CHFRs are greater than 1.78 in all cases. Hence, CHF is precluded, with either HEU or LEU fuel, with a probability greater than 99.9\% (see Table 4.20). After the correlation is no longer applicable, the integrity of fuel elements is assured by examining peak clad temperature. As discussed above, the peak clad temperatures are predicted to be less than $118^{\circ} \mathrm{C}$, which is much lower than the blister temperature. 
Onset-of-flow-instability ratios are shown in Figure 13.38. The hydraulic nodes used for the figure are the ones where minimum OFIR occurs. The core configuration with multiple channels is subject to a potential static instability called flow excursion (FE). The condition under which excursive instability will occur can be expressed mathematically:

$$
\frac{d\left(\Delta P_{\text {ext }}\right)}{d Q}>\frac{d\left(\Delta P_{d e m}\right)}{d Q}
$$

where $d\left(\Delta P_{\text {ext }}\right), d\left(\Delta P_{\text {dem }}\right)$, and $d Q$, respectively, represent the change of pressure-drop of external system, change of pressure-drop of coolant, and change of flowrate. The equation indicates that the instability occurs when the slope of change of pressure-drop (demand) vs. change of flowrate is smaller than that of the external supply system. The external supply system is the primary pumps or shutdown pumps in the NBSR. Equation (13-2) implies that if there is no forced flow from pumps, a system is not subject to excursive instability. When the control valve at the inlet to the outer plenum closes completely at $60 \mathrm{~s}$, no forced flow is provided to the outer plenum and the outer core is no longer subject to excursive instability. Therefore, OFIR is investigated only for the first $60 \mathrm{~s}$ in this accident.

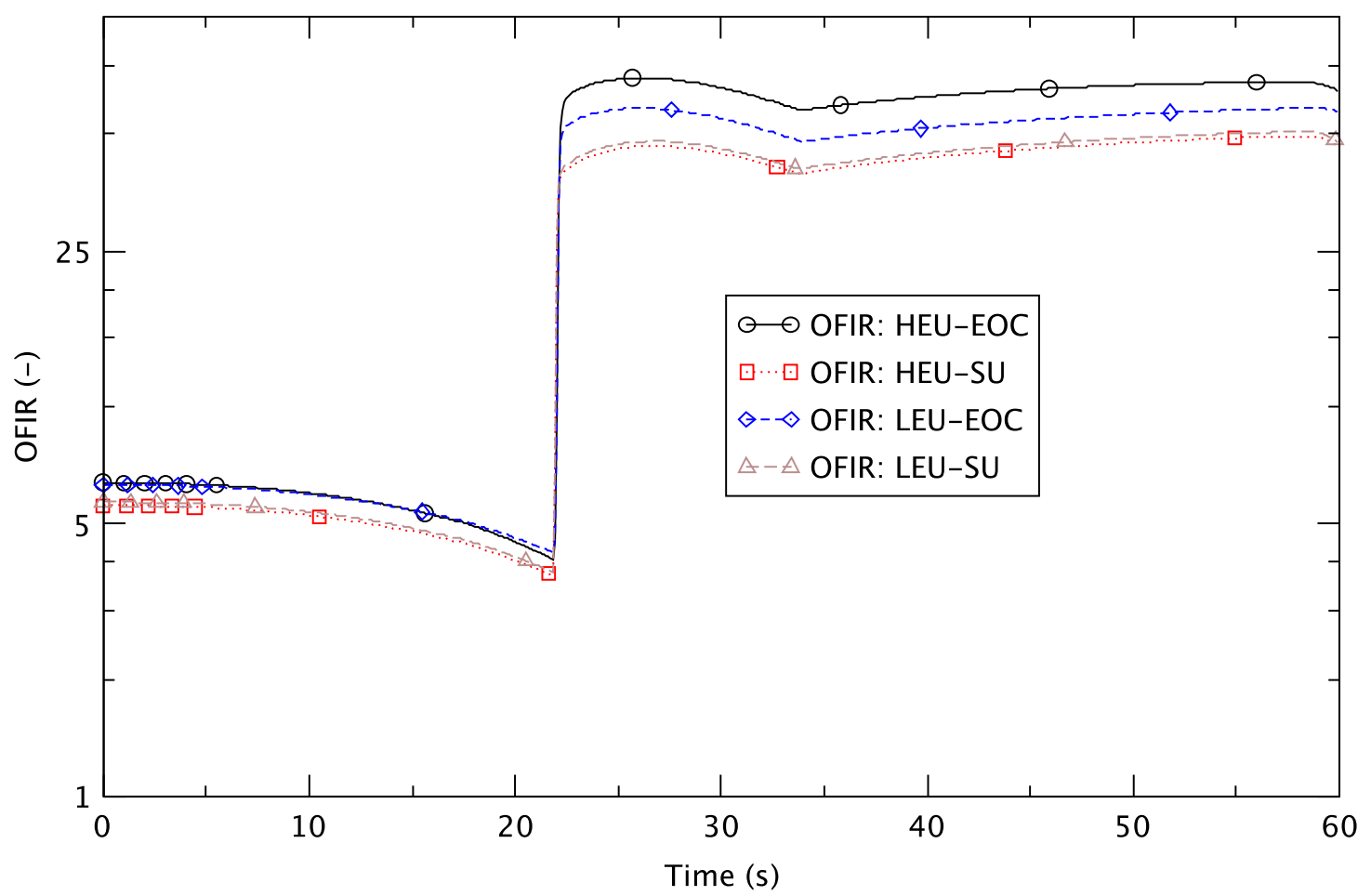

Figure 13.38 Onset-of-Flow-Instability Ratio after Throttling of Coolant Flow to Outer Plenum

As shown in Figure 13.38, OFIRs start decreasing slowly from time zero and reach minimum values at $21.8 \mathrm{~s}$ in all cases. OFIR then increases very rapidly and becomes larger than 38 . The minimum OFIR is shown in Table 13.14 along with the corresponding times and hydraulic node numbers. The minimum OFIR occurs shortly after reactor trip when the power is still high. It 
can be seen from Figure 13.38 and Table 13.14 that the minimum OFIRs are all much higher than 1.83 and hence, fuel element damage is not expected, with either the HEU or the LEU fuel, with a probability greater than $99.9 \%$ (see Table 4.21 ).

Table 13.14 Minimum OFIR after Throttling of Coolant Flow to Outer Plenum

\begin{tabular}{|c|c|c|c|}
\hline Case & $\begin{array}{l}\text { Minimum } \\
\text { OFIR }\end{array}$ & Time (s) & Hydraulic Node No. \\
\hline HEU EOC & 4.07 & 21.8 & $417-15^{1}$ \\
\hline HEU SU & 3.70 & 21.8 & $503-15^{2}$ \\
\hline LEU EOC & 4.24 & 21.8 & $417-02^{3}$ \\
\hline LEU SU & 3.78 & 21.8 & $503-15^{2}$ \\
\hline \multicolumn{4}{|c|}{$\begin{array}{l}\text { 1The minimum OFIR occurs in the powered-top node of the flow } \\
\text { channel corresponding to the hottest fuel stripe. } \\
\text { } 2 \text { The minimum OFIR occurs in the hottest node (highest power cell in } \\
\text { the core region). The flow channel with this node has a common mid- } \\
\text { plane gap shared with the flow channel for } 16 \text { average fuel plates. } \\
\text { 37 The minimum OFIR occurs in the node where the highest power cell in } \\
\text { the hottest fuel stripe is located. This cell is different from the hottest } \\
\text { cell among all cells in the core region. }\end{array}$} \\
\hline
\end{tabular}

\subsubsection{Throttling of Coolant Flow to Inner Plenum}

\subsubsection{Simulation of Accident}

In this accident scenario, the flow control valve DWV-2 (VALVE-50 in Figure 13.2) is assumed to close, decreasing the flow through the inner plenum and generating a reactor trip signal $0.4 \mathrm{~s}$ after the flow reaches the low flow trip point of 1,200 gpm (75.7 l/s). The 8-inch flow control valve has a stroke time of $30 \mathrm{~s}$. The complete closure of the flow control valve isolates the lower plenum of the inner core and at the same time cuts off the supply of forced coolant flow. The RELAP5 calculation shows that since all coolant channels in the fuel elements in the inner core share the same inlet and outlet plenums, closed loop recirculation flow paths are established between hotter and cooler coolant channels in the inner core. Buoyancy induces upflow through the hotter coolant channels, while downflow through the cooler channels completes the closed flow loop. The recirculation flow removes heat from the fuel elements by natural convection.

Primary system flowrates predicted with LEU fuel at SU are shown in Figure 13.39. The flow behavior in the other cases is almost identical to that in the figure. The flowrates are shown at the inlet to the heat exchanger (Total), inlet to the inner plenum (To Inner Plenum), and inlet to the outer plenum (To Outer Plenum). As the valve closes at the inlet to the inner plenum starting at time zero, the mass flowrate increases to the outer plenum and decreases to the inner plenum. The flow increase to the outer plenum is because the speed of the primary pumps doesn't change even with the valve closure. Figure 13.39 shows that the primary pump flow slightly decreases because of the increase of the total pressure drop through the primary system, especially through the outer core due to the increase of flowrate. When DWV-2 closes completely at $30 \mathrm{~s}$, the total flowrate becomes constant ( $\sim 60 \mathrm{~kg} / \mathrm{s})$ and the flow to the inner plenum becomes zero. 


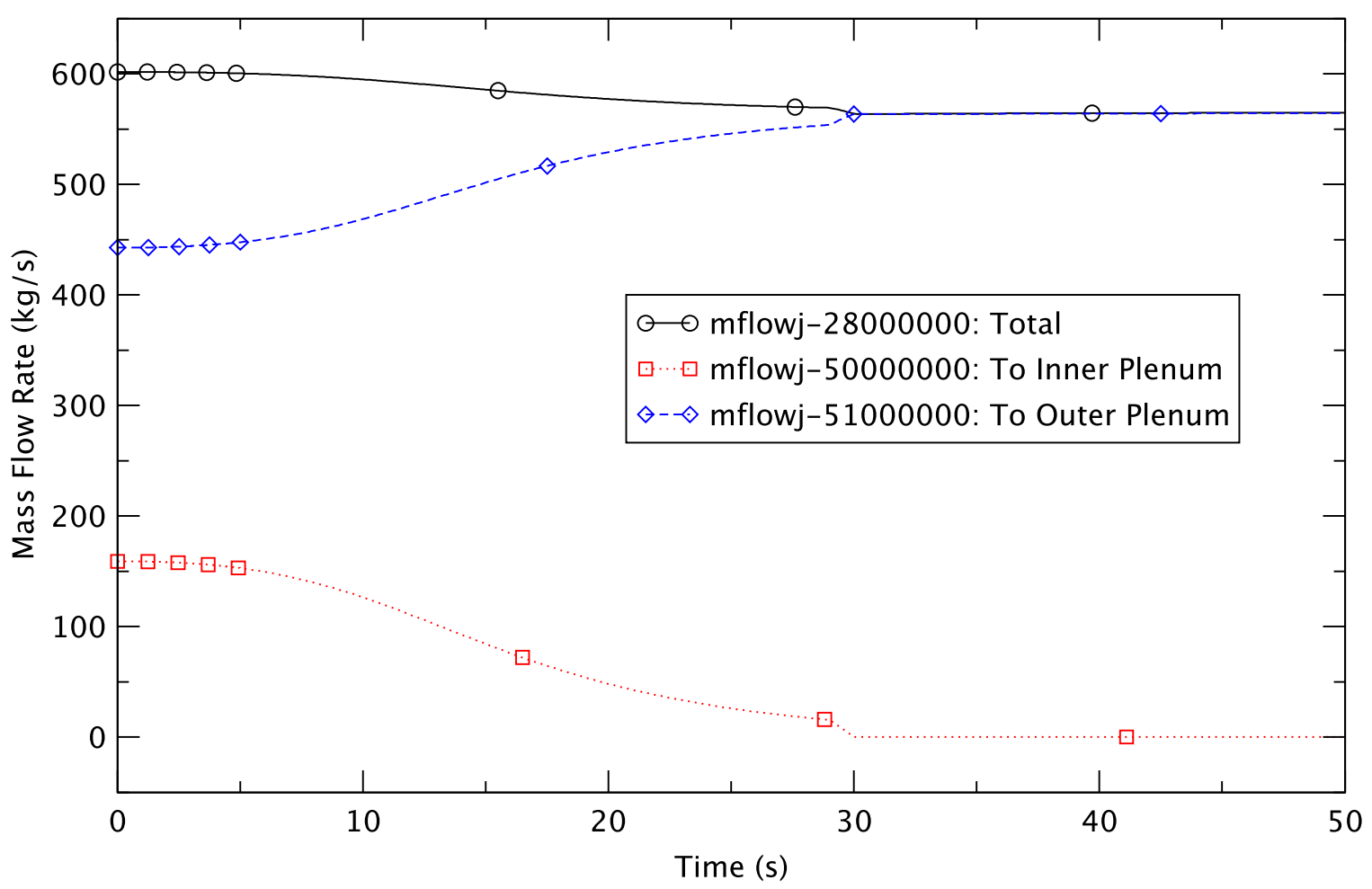

Figure 13.39 Primary System Flows after Throttling of Coolant Flow to Inner Plenum with LEU Fuel at SU

Figure 13.40 shows reactor power from zero to $50 \mathrm{~s}$. The reactor power decreases rapidly after $15.6 \mathrm{~s}$ in all cases. The trip setpoint on low inner plenum flow $(75.7 \mathrm{l} / \mathrm{s})$ is reached at $15.1 \mathrm{~s}$ in all cases. The shim arms are inserted into the core region after the $0.4 \mathrm{~s}$ instrument delay time. The general behavior of the power with the LEU fuel is similar to that with the HEU fuel. The power decrease occurs slightly faster in the cases at SU than in the cases at EOC. This is because differential shim arm worth is lowest when the shim arms are inserted from the fully withdrawn (EOC) position.

\subsubsection{Limiting Conditions}

Figure 13.41 shows clad temperatures from zero to $150 \mathrm{~s}$ in the fuel element nodes corresponding to the channel cell where the highest PCT is predicted. Heat structure numbers 1000 and 2000 in the legend indicate the fuel stripe containing the hottest fuel cell (highest cell power) in the inner core. The flow channel with the latter heat structure shares a mid-plane gap with 16 average fuel plates while the one with the former does not (see Figure 13.3). 


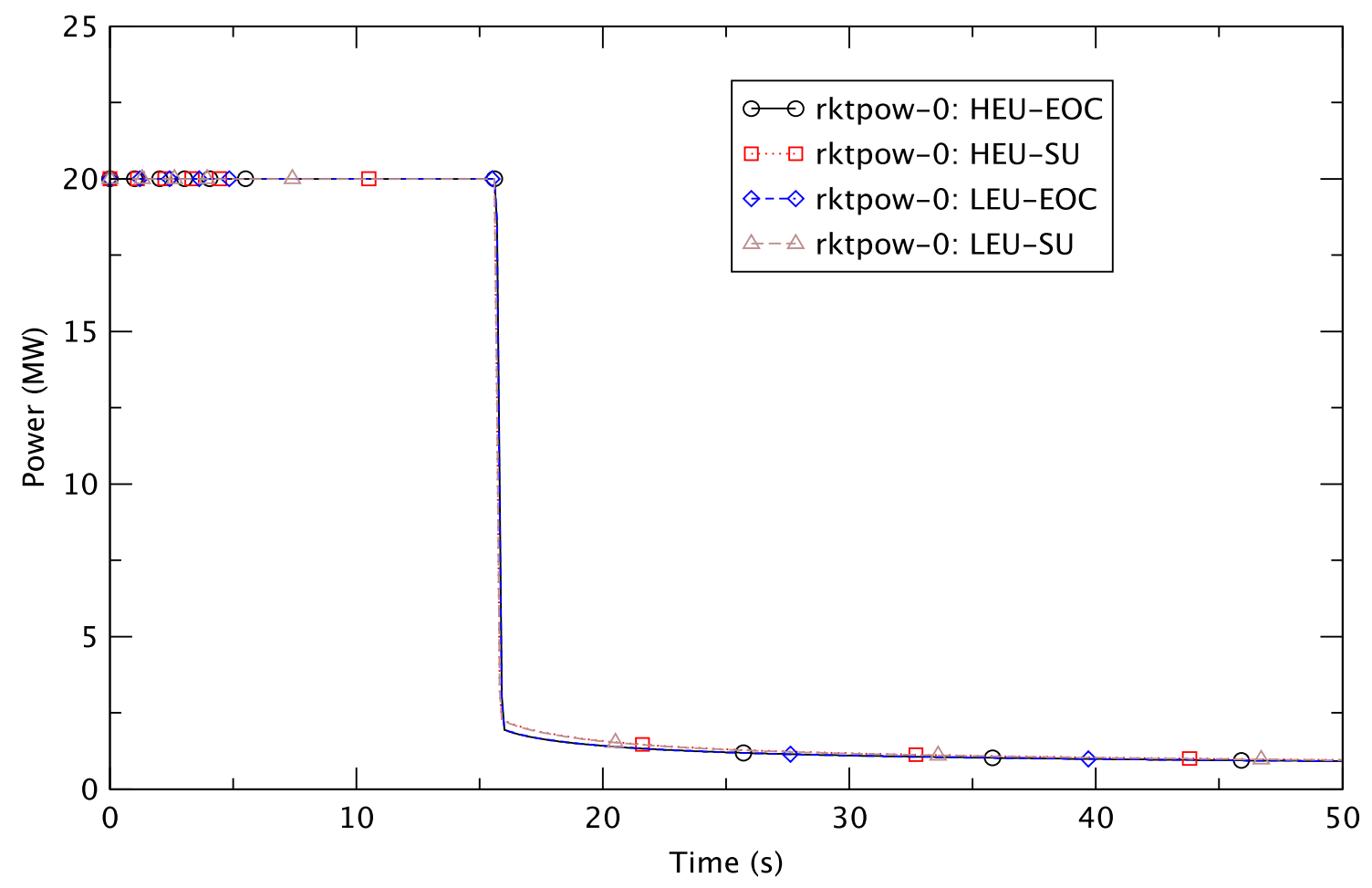

Figure 13.40 Reactor Power after Throttling of Coolant Flow to Inner Plenum

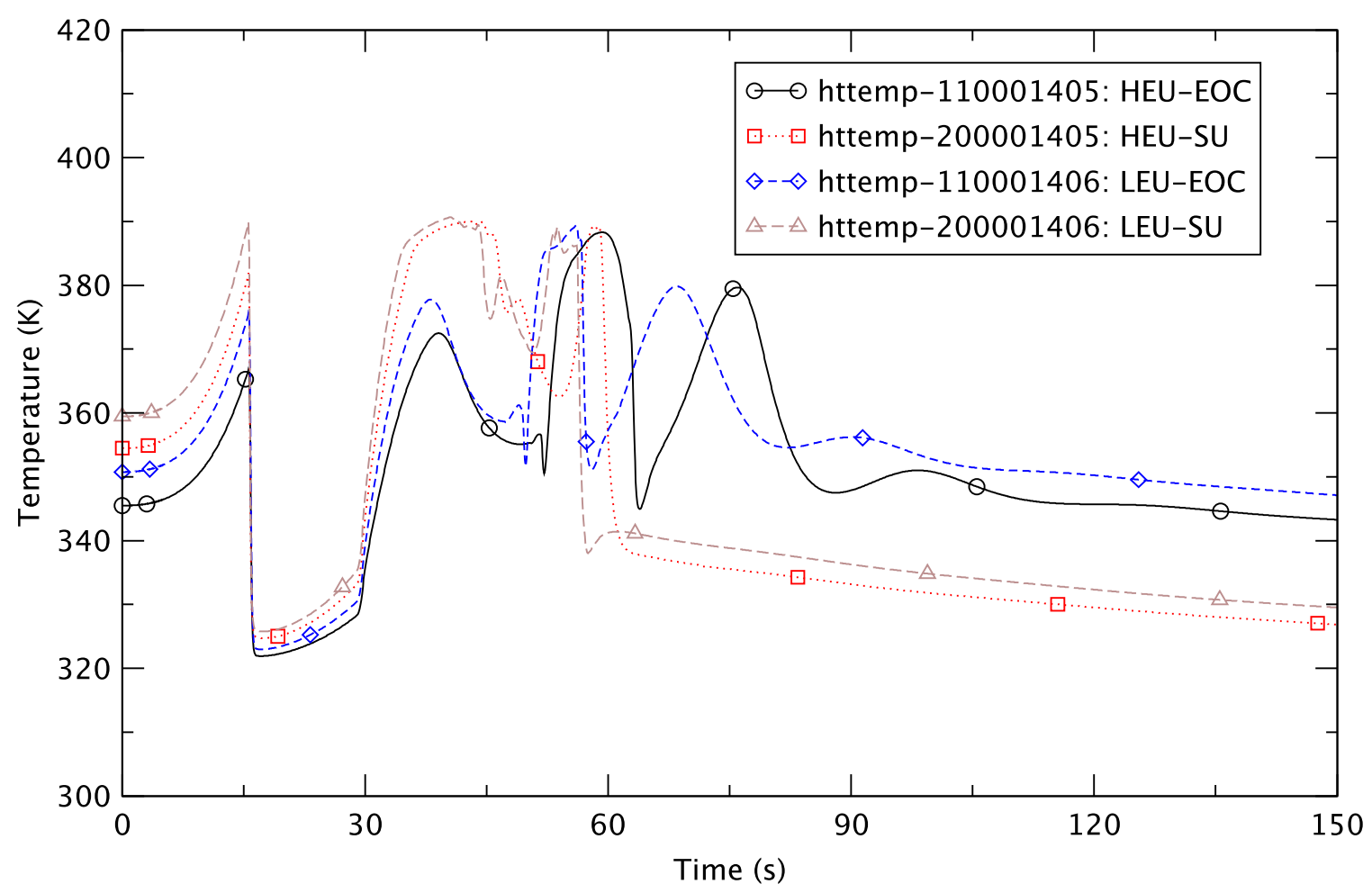

Figure 13.41 Clad Temperature after Throttling of Coolant Flow to Inner Plenum 
The general behavior of the clad temperature for LEU fuel is very similar to that for HEU fuel. The clad temperature starts increasing from time zero due to heat transfer becoming inefficient as the mass flow rate to the inner core decreases. The temperature reaches a first peak shortly after reactor trip and then begins decreasing rapidly because of reduction of the reactor power. The temperature starts increasing again from around $17 \mathrm{~s}$ as the mass flow rate decreases further and heat transfer from the fuel elements to the coolant becomes less efficient. The clad temperatures show some oscillatory behavior from around $30 \mathrm{~s}$ to $100 \mathrm{~s}$ because of fluctuations of the mass flow rates around zero in these channels. As the valve (DWV-2) at the inlet to the inner plenum is being closed, the coolant flow velocity decreases very rapidly, fluctuates around zero, and then stabilizes to natural circulation flow inside the inner core. During the flow fluctuations, RELAP5 predicts almost zero flow velocity a few times when flow direction changes. This results in poor heat transfer from the fuel to coolant and increased clad temperatures. As flow velocity increases after change of the flow direction, the heat transfer becomes more efficient again and the clad temperature decreases. This behavior occurs a few times during the flow fluctuations in all cases and it causes oscillations of the clad temperature as shown in the figure.

Figure 13.41 also shows that the clad temperatures at SU with both HEU and LEU fuel are much lower than those in the other cases, after $\sim 60 \mathrm{~s}$. This is caused by relatively large negative flow through those channels while positive flow is predicted in the other two channels at EOC with the HEU and LEU fuels. The peak clad temperatures vary from $115^{\circ} \mathrm{C}$ to $118^{\circ} \mathrm{C}$, much lower than the blister temperature, and the increases are between $31^{\circ} \mathrm{C}$ and $43^{\circ} \mathrm{C}$.

Critical-heat-flux ratios are compared in Figure 13.42. The hydraulic nodes used for the figure are the ones where minimum CHFRs are predicted. Evaluation of CHFR stops at $70.9 \mathrm{~s}$ at SU with HEU fuel and at $56.0 \mathrm{~s}$ at EOC with LEU fuel when conditions are outside the range of validation of the Sudo-Kaminaga correlation. In the other cases there is no problem with the correlation limits. CHFR starts decreasing slowly from time zero and stops decreasing at around $16 \mathrm{~s}$ in all cases. CHFRs then increase very rapidly because of reduction of the core power and then suddenly decrease when the valve (DWV-2) completely closes at 30s. After fluctuating from $40 \mathrm{~s}$ to $60 \mathrm{~s}$, CHFRs become high (larger than 5.8) and almost constant from approximately $100 \mathrm{~s}$. The calculated minimum CHFRs and the corresponding times and hydraulic node numbers are shown in Table 13.15.

As shown in Figure 13.42 and Table 13.15, the minimum CHFR occurs during flow oscillations in all cases. It is also observed that the minimum CHFRs are greater than 1.78 in all cases. Hence, CHF is precluded, with either HEU or LEU fuel, with a probability greater than $99.9 \%$ (see Table 4.20). After the Sudo-Kaminaga correlation is no longer applicable, the integrity of fuel elements is assured by examining peak clad temperature. As discussed above, the peak clad temperatures are predicted to be less than $118^{\circ} \mathrm{C}$, which is much lower than the blister temperature. 


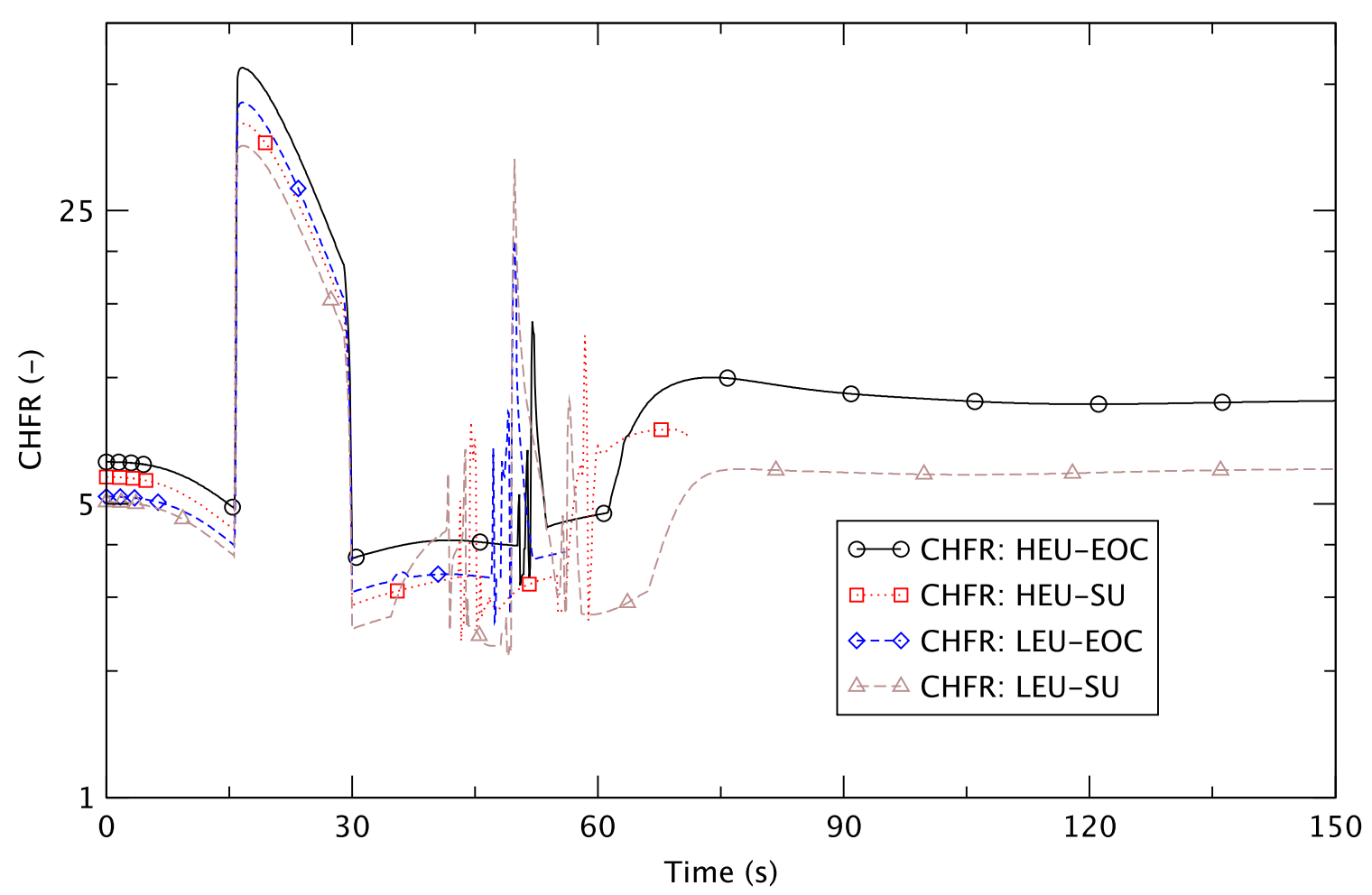

Figure 13.42 Critical Heat Flux Ratio after Throttling of Coolant Flow to Inner Plenum

Table 13.15 Minimum CHFR after Throttling of Coolant Flow to Inner Plenum

\begin{tabular}{|c|c|c|c|}
\hline Case & $\begin{array}{l}\text { Minimum } \\
\text { CHFR }\end{array}$ & Time (s) & Hydraulic Node No. \\
\hline HEU EOC & 3.20 & 50.5 & $207-02^{1}$ \\
\hline HEU SU & 2.36 & 43.3 & $203-15^{2}$ \\
\hline LEU EOC & 2.62 & 47.4 & $207-02^{1}$ \\
\hline LEU SU & 2.17 & 49.0 & $103-15^{3}$ \\
\hline \multicolumn{4}{|c|}{$\begin{array}{l}{ }^{1} \text { The minimum CHFR occurs in the hottest node (highest power cell in } \\
\text { the inner core region). The flow channel with this node has a common } \\
\text { mid-plane gap shared with the flow channel for } 16 \text { average fuel plates. } \\
{ }^{2} \text { The minimum CHFR occurs in the hottest node (highest power cell in } \\
\text { the inner core region). The flow channel with this node has a common } \\
\text { mid-plane gap shared with the flow channel for } 16 \text { average fuel plates. } \\
{ }^{3} \text { The minimum CHFR occurs in the node where the hottest cell (highest } \\
\text { power cell in the core region) is located. }\end{array}$} \\
\hline
\end{tabular}

Onset-of-flow-instability ratios are shown in Figure 13.43. OFIRs were evaluated for the first 30 $\mathrm{s}$ while forced flow is provided to the inner core until the valve (DWV-2) closes completely. The hydraulic nodes used for the figure are the ones where minimum OFIR occurs. As shown in the figure, OFIR starts decreasing slowly from time zero and reaches a minimum value at $15.6 \mathrm{~s}$ in all cases. OFIRs then increase very rapidly and become larger than 30. The minimum OFIRs are shown in Table 13.16. The minimum OFIR occurs shortly after reactor trip when the power 
is still high and they are all much higher than1.83 and hence, fuel element damage is not expected, with either the HEU or the LEU fuel, with a probability greater than $99.9 \%$ (see Table 4.21).

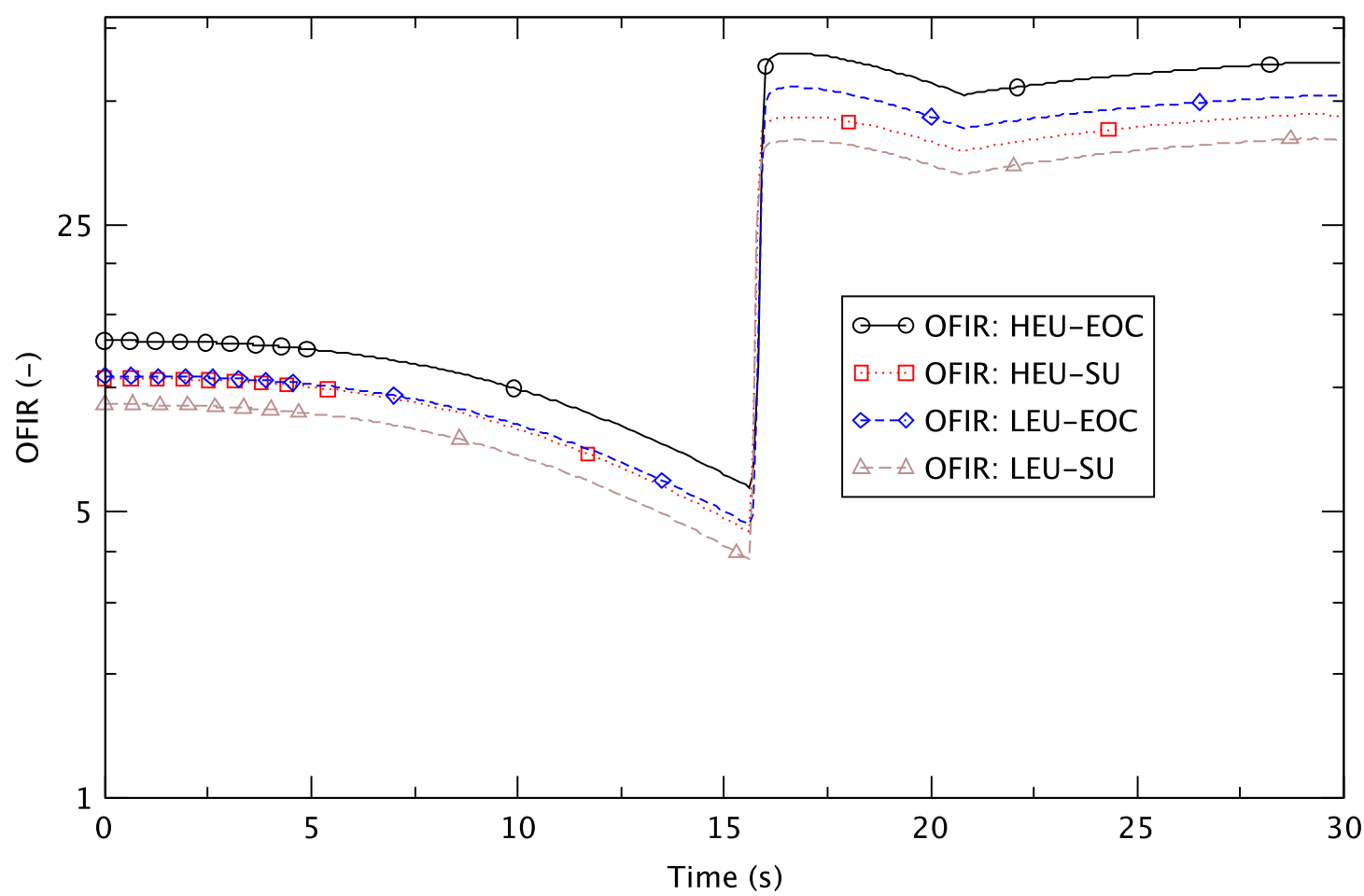

Figure 13.43 Onset-of-Flow-Instability Ratio after Throttling of Coolant Flow to Inner Plenum

Table 13.16 Minimum OFIR after Throttling of Coolant Flow to Inner Plenum

\begin{tabular}{|c|c|c|c|}
\hline Case & $\begin{array}{c}\text { Minimum } \\
\text { OFIR }\end{array}$ & Time (s) & Hydraulic Node No. \\
\hline HEU EOC & 5.73 & 15.6 & $107-02^{1}$ \\
\hline HEU SU & 4.46 & 15.6 & $203-15^{2}$ \\
\hline LEU EOC & 4.64 & 15.6 & $107-02^{1}$ \\
\hline LEU SU & 3.81 & 15.6 & $203-15^{2}$ \\
\hline $\begin{array}{l}\text { The minimum OFIR occurs in the hottest node (highest power cell in } \\
\text { the inner core region). } \\
\text { 2 The minimum OFIR occurs in the hottest node (highest power cell in } \\
\text { the inner core region). The flow channel with this node has a common } \\
\text { mid-plane gap shared with the flow channel for } 16 \text { average fuel plates. }\end{array}$ \\
\hline
\end{tabular}




\subsubsection{Closure of Valve DWV-19}

\subsubsection{Simulation of Accident}

Valve DWV-19 is a motorized 18-inch butterfly valve, mounted in the outlet line. Although this valve is only used during maintenance when the reactor is shut down, it is assumed that it could receive a spurious signal while the reactor is operating at full power, resulting in a loss of primary flow. It is not shown in the schematic of the primary system in Figure 13.1, nor is it shown explicitly in the RELAP5 nodal diagram in Figure 13.2 where it would be within node 10. However, it was added to the RELAP5 model in order to analyze the event (and it is shown in the TRACE diagram in Figure 13.7 as valve 102). The current valve has a measured stroke time, fully open to fully closed, of $21 \mathrm{~s}$. In the future this valve is to be replaced with one having a closing time of $120 \mathrm{~s}$. Since the shorter closing time results in more conservative consequences, it is the only one modeled.

The analysis is done only for the HEU core. Because of the low probability of this event, the large safety margin, and the similarity in the response for both the HEU and LEU fueled cores in all of the above analyzed loss-of-flow accidents, it is not necessary to separately analyze the LEU core.

As the valve closes, the primary loop becomes completely blocked. Note that this might cause physical damage to the primary pumps if they are not also tripped. Figure 13.44 shows the coolant flow at the outlet of the primary pumps. As a result of a low flow signal, the reactor trips at $9.3 \mathrm{~s}$.

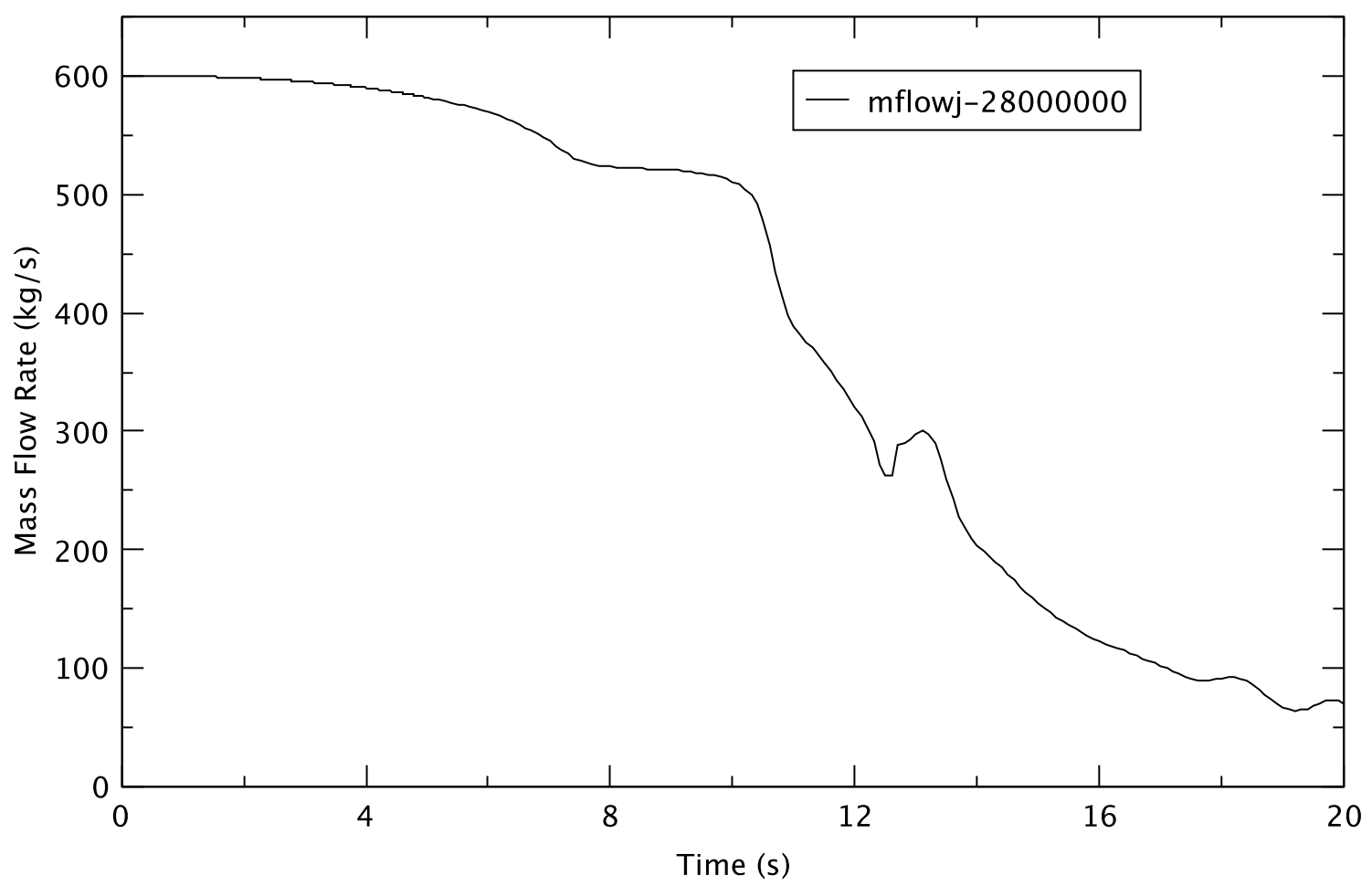

Figure 13.44 Coolant Flowrate at Outlet of Primary Pumps 
Total reactor power is shown in Figure 13.45. The power decreases rapidly after the insertion of the shim arms and remains at decay power levels thereafter.

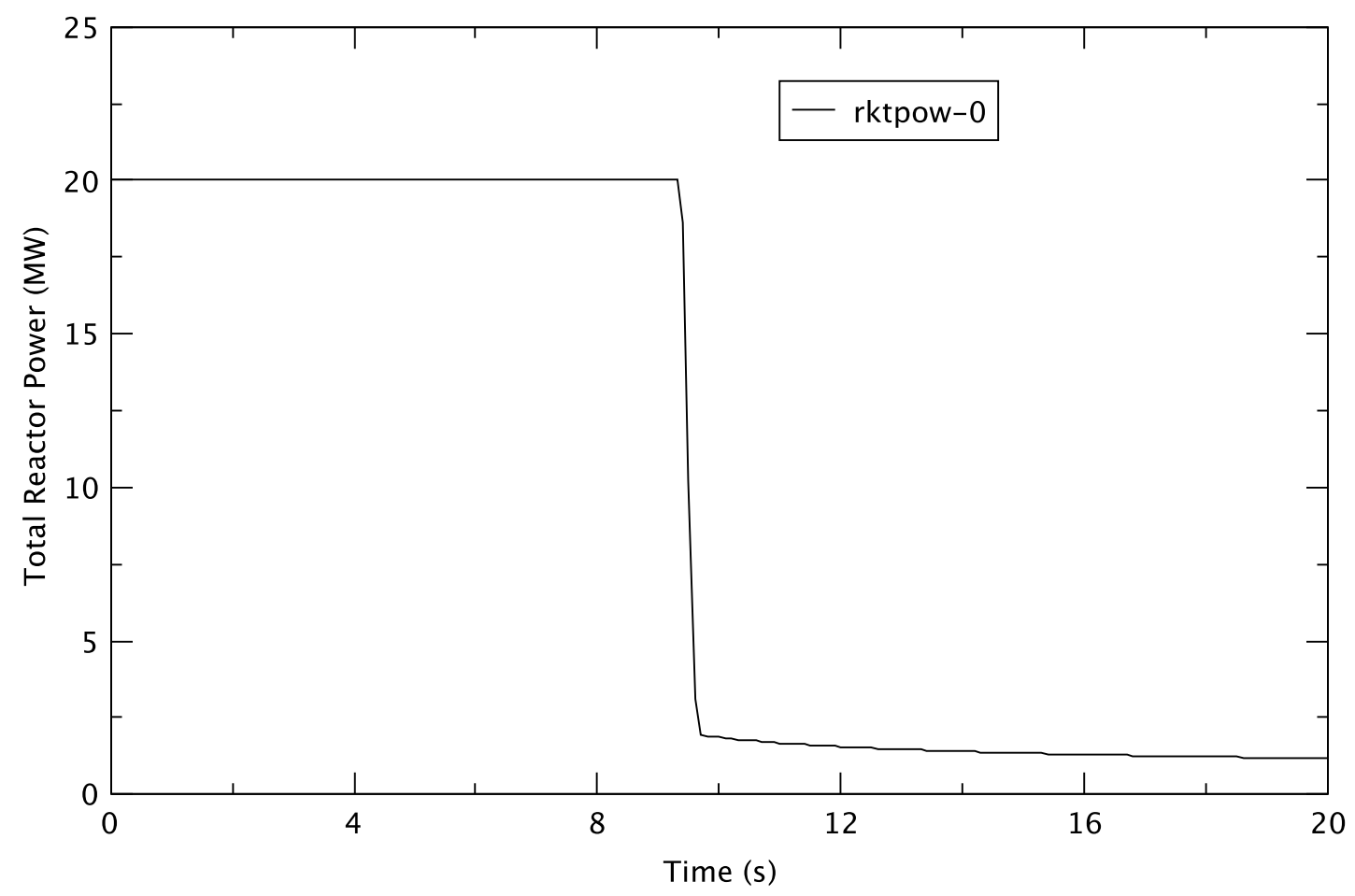

Figure 13.45 Reactor Power after Closure of DWV-19

\subsubsection{Limiting Conditions}

Figure 13.46 shows clad temperatures from zero to $20 \mathrm{~s}$ in the fuel element nodes corresponding to the channel cell where the highest PCT is predicted. The clad temperature increases slightly and reaches $102.1^{\circ} \mathrm{C}$ at $9.3 \mathrm{~s}$ as the coolant mass flowrate decreases. It decreases significantly after reactor trip. The clad temperature starts increasing slowly again from around $11 \mathrm{~s}$ as the coolant flowrate to the core becomes smaller.

Figure 13.47 shows CHFR and Figure 13.48 shows OFIR. Both parameters only decrease slightly from their steady state values up to the point when reactor trip occurs. The minimum CHFR is 3.71 and the minimum OFIR is 5.25; both at $9.3 \mathrm{~s}$. After that point both parameters increase and the probability of any increase in clad temperature is insignificant. 


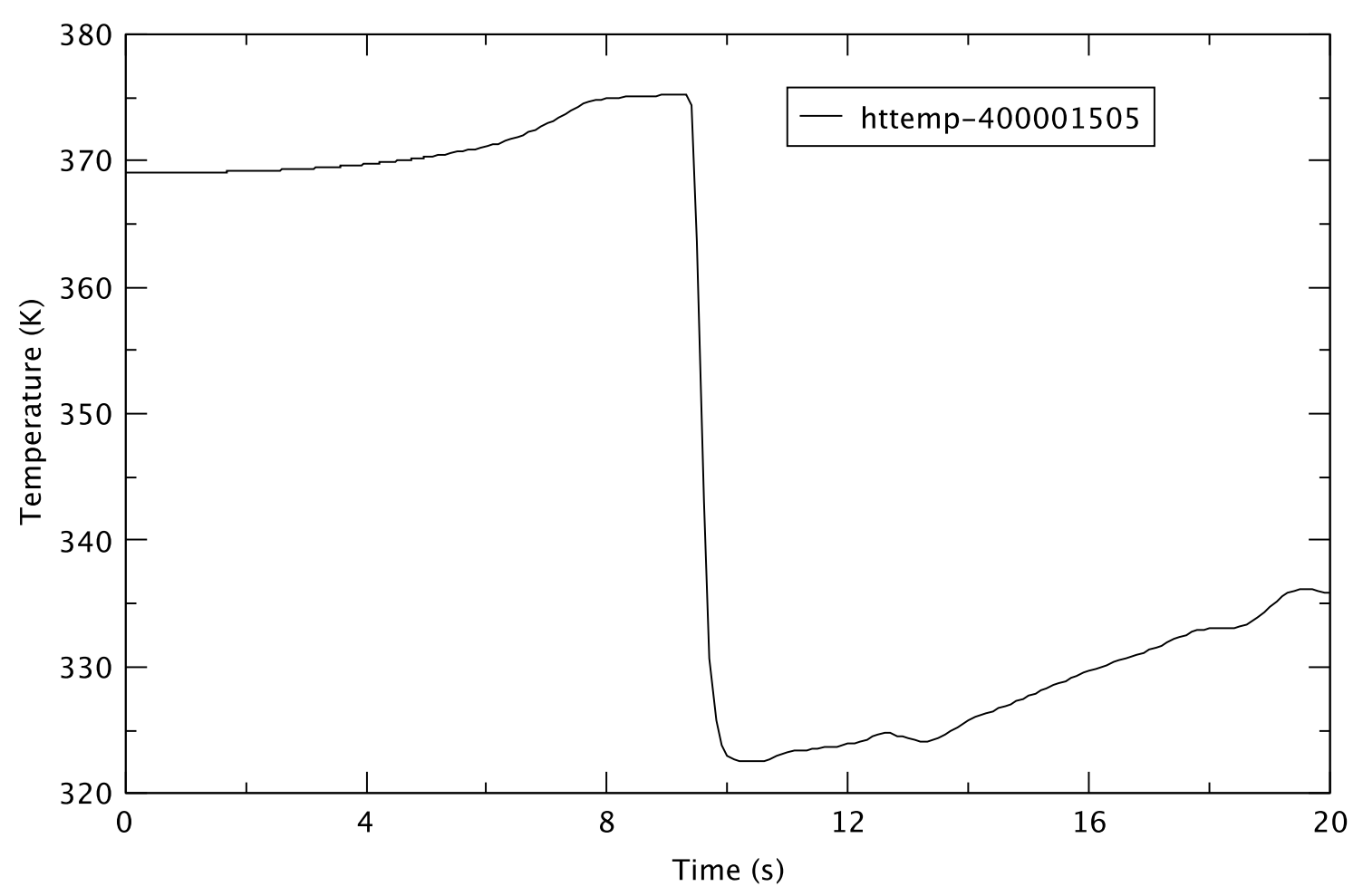

Figure 13.46 Clad Temperature after Closure of DMW-19

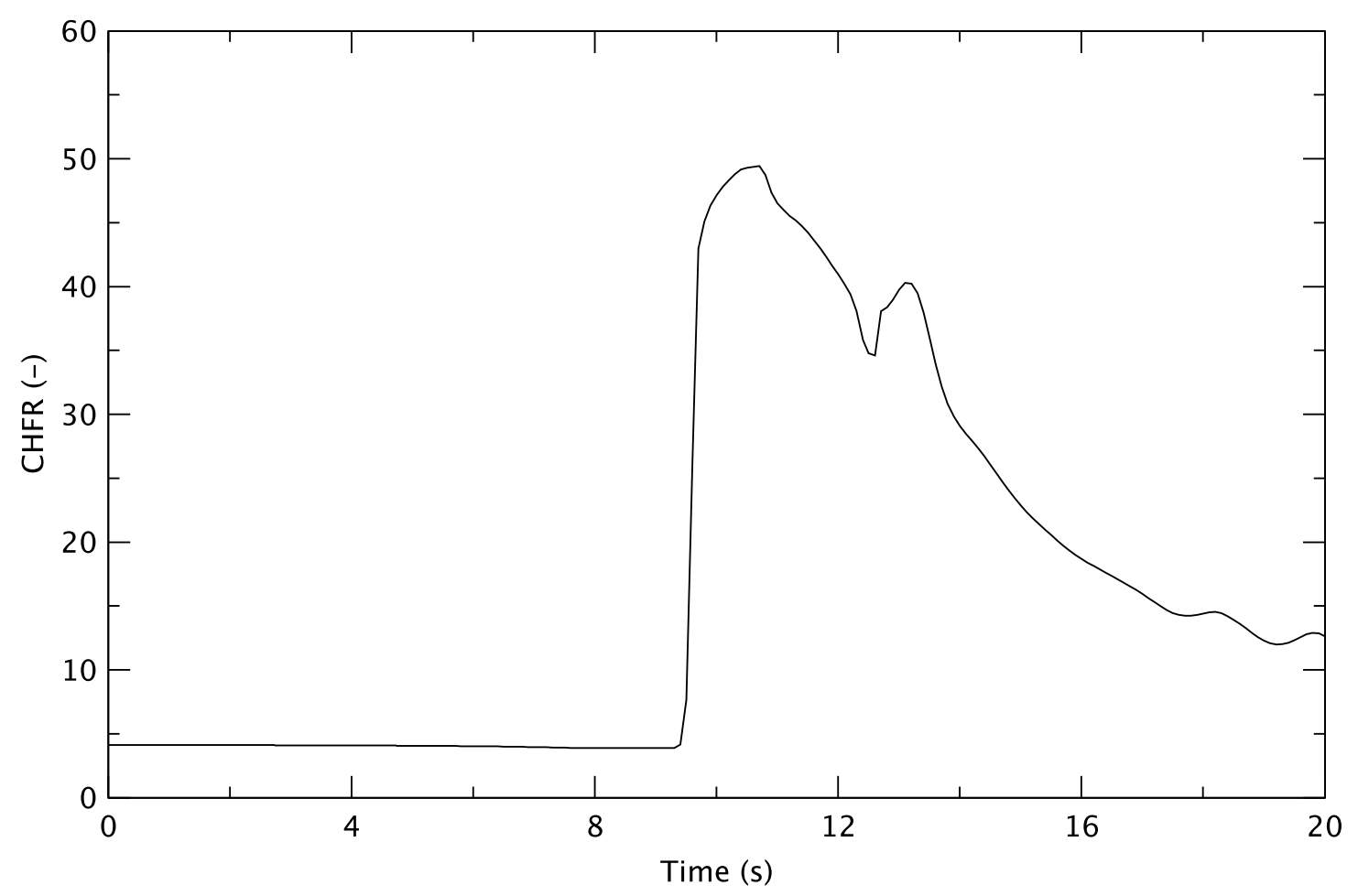

Figure 13.47 CHFR after Closure of DWV-19 


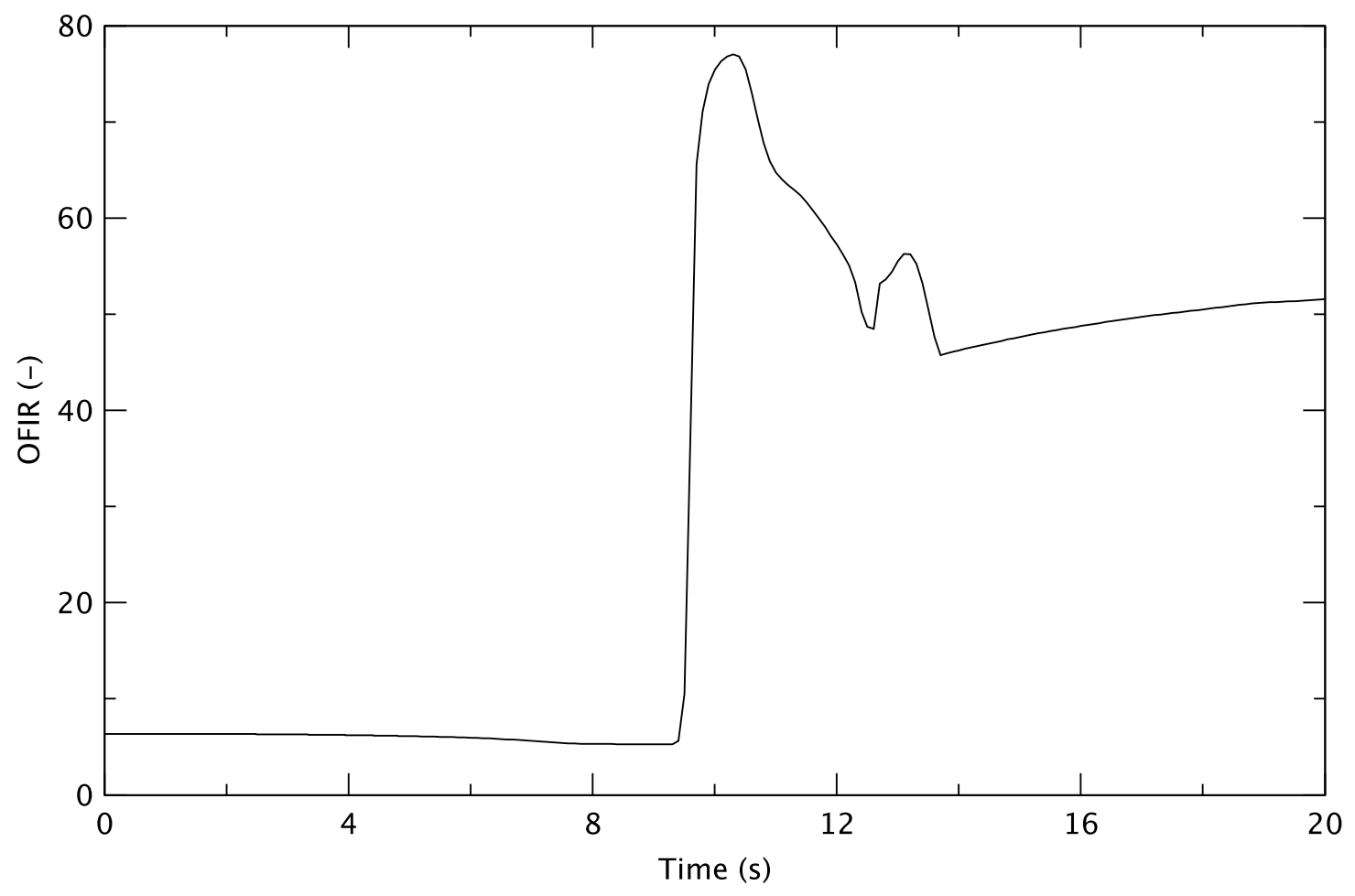

Figure 13.48 OFIR after Closure of DWV-19

\subsubsection{Summary of Loss-of-Flow Accidents}

Several postulated loss-of-flow accidents have been simulated: loss-of-offsite-power, seizure of one primary pump, and throttling of coolant flow based on closure of valves at either the inner plenum, the outer plenum, or at the location of DWV-19. The accident simulations involve both forced flow and natural circulation flow cooling in the core. Two limiting state-points in a fuel cycle have been considered, namely, startup and end-of-cycle. Primary system flow, reactor power and peak clad temperature have been examined in detail along with minimum CHFR and OFIR.

In all of the accidents, the general system behavior with LEU fuel is very similar to that with HEU fuel. RELAP5 predicts the flow behavior of the primary system very well in the loss-offlow accidents, especially during the flow coastdown period. The calculated total system flowrate is conservatively smaller than the measured data in the case with loss of offsite power. The reactor power starts decreasing very rapidly from full power after reactor trip due to low flow. For the accidents with loss-of-offsite-power and throttling of coolant flow to the outer plenum, the trip signal is a result of low flow to the outer plenum. For the accident with throttling of coolant flow to the inner plenum, the trip signal is a result of low flow to the inner plenum. Clad temperature rises from time zero because mass flow rate decreases in the core.

The highest peak clad temperature occurs after loss of offsite power with the HEU fuel at SU and is $124^{\circ} \mathrm{C}$ (much lower than the blister temperature) corresponding to a temperature rise of $22^{\circ} \mathrm{C}$. Hence, no fuel damage is expected with either HEU or LEU fuel for all the accidents caused by 
loss of flow to the core. The evaluated minimum CHFRs and OFIRs are all much higher than target values to ensure that fuel element damage is precluded from occurring with a probability greater than $99.9 \%$.

All accidents are seen to be terminated by reactor trip, that is, after trip, the power-to-flow ratio is low enough so that there is no threat to the integrity of the cladding. The reactor remains flooded with water after all of the events with a loss of forced circulation. The minimal natural circulation that occurs is sufficient to prevent overheating of the fuel. This is explained in Section 13.7.3.

\subsection{Loss-of-Coolant Accidents}

\subsubsection{Introduction}

The licensing analysis of the loss-of-coolant accident (LOCA) in the NIST research reactor (NBSR) addressed in the current Safety Analysis Report (SAR) (NIST, 2010a) is still relevant. Chapter 6 of the SAR discusses the emergency cooling system (ECS), and Chapter 13 discusses the low probability of a significant pipe break: "the main piping is located in protected areas, system pressures are low, and flow rates are small so that wear is not an issue." Therefore, the probability of a large break (LB), including a double-ended guillotine break (GB), is extremely low. For smaller breaks where the operator has time to take action, procedures are in place (NIST, 2011) to a) mitigate a loss of water by tripping pumps and closing control valves after the falling water level in the vessel is detected by instrumentation, and b) assure that emergency cooling water continues to flow for as long as needed.

Chapter 13 also refers to an analysis (Cheng, 2004) of why the ECS will provide sufficient water to cool the fuel elements (FEs) in a LOCA if the flow channels between two fuel plates (or a fuel plate and an outside plate) remain filled with water. That analysis is based on assuming that the emergency water would flow from the distribution pan above the fuel elements into all the flow channels replacing any water that boils away.

A recent study (Baek, 2014a) indicates that some scenarios may lead to the draining of water from the coolant channels. In these cases, the cooling on the inside of the fuel element (see Figure 13.9 and Figure 13.10) is from water that falls only along the inner surface of one of the side plates in the fuel elements; the remaining surfaces within the fuel element will be exposed to gas. The analysis herein discusses what would happen when this was the cooling available in scenarios where the coolant channels within the fuel elements are drained.

Three locations that cover the limiting locations for pipe breaks were considered (see Figure 13.1): (1) the 18-inch pipe between the reactor vessel outlet and the control valve DWV-19 (located upstream of the main $\mathrm{D}_{2} \mathrm{O}$ pumps); (2) the 14-inch pipe between the control valve DWV-1 and the outer plenum; and (3) the 10-inch pipe between the control valve DWV-2 and the inner plenum. The first pipe is upstream of the primary and shutdown pumps and the others are downstream of the pumps. Both GBLOCAs and small break (SB) LOCAs were considered. Table 13.17 shows the break locations which were considered with the case identification 
number. As will be discussed below, only Cases 2 and 3 needed analysis with the coolant channels drained.

Table 13.17 Break Locations and Sizes

\begin{tabular}{|c|l|l|}
\hline Case No. & \multicolumn{1}{|c|}{ Location } & \multicolumn{1}{|c|}{ Size / Remark } \\
\hline Guillotine Break & $2 \times 0.1508 \mathrm{~m}^{2}$ \\
\hline 1 & $\begin{array}{l}\text { 18-inch pipe between the reactor vessel } \\
\text { outlet and the control valve DWV-19 }\end{array}$ & $2 \times 0.089 \mathrm{~m}^{2}$ \\
\hline 2 & $\begin{array}{l}14-\text {-inch pipe between the control valve } \\
\text { DWV-1 and the outer plenum }\end{array}$ & $2 \times 0.0509 \mathrm{~m}^{2}$ \\
\hline 3 & $\begin{array}{l}10 \text {-inch pipe between the control valve } \\
\text { DWV-2 and the inner plenum }\end{array}$ & Not simulated \\
\hline Small Break & $\begin{array}{l}18 \text {-inch pipe between the reactor vessel } \\
\text { outlet and the control valve DWV-19 }\end{array}$ & $\begin{array}{l}\text { TRACE simulation } \\
\text { only }\end{array}$ \\
\hline 4 & $\begin{array}{l}14-\text {-inch pipe between the control valve } \\
\text { DWV-1 and the outer plenum - }\end{array}$ & $\begin{array}{l}\text { TRACE simulation } \\
\text { only }\end{array}$ \\
\hline 6 & $\begin{array}{l}10 \text {-inch pipe between the control valve } \\
\text { DWV-2 and the inner plenum }\end{array}$ &
\end{tabular}

The analysis consists of two types of calculations. The first (see also Section 13.3.1) examines how the water would drain from the primary system following a break and the potential for the loss of coolant within the fuel element flow channels. This analysis is independent of whether the fuel is HEU or LEU. The second (see also Section 13.3.2) investigates the fuel and clad temperature behavior for those cases where the water has drained from some of the flow channels. The latter analysis is done for both HEU and LEU fuel elements. Note that this analysis differs somewhat from that reported in (Baek, 2014a) and (Baek, 2014b). For those previous studies the shutdown pumps came on automatically when the primary pumps trip due to low water level. However, new instrumentation is being introduced so that upon receiving a LOCA signal (low water level), the shutdown pumps will not start and the outlet valves (VALVE-83 in Figure 13.7) will not automatically open. The analysis reported on herein assumes this new mode of operation.

\subsubsection{Analysis of Water Drainage}

\subsubsection{Guillotine Break LOCA}

\section{$\underline{\text { Guillotine break at vessel outlet pipe (Case 1) }}$}

A GBLOCA is simulated (see Figure 13.7) by closing VALVE-102 between the vessel outlet and the main coolant pumps and opening VALVE-3 and VALVE-22 near VALVE-102 with flow areas the same as the pipe flow area of $0.1508 \mathrm{~m}^{2}$. The water level in the upper plenum drops rapidly from its normal operating level of $4.04 \mathrm{~m}$ (159 in) as the coolant is discharged from the vessel through the break. Figure 13.49 shows the mass flowrates discharged through the break. In the legend 'Break flow from vessel side' refers to the flowrate through the break at the 
vessel outlet (VALVE-22) The 'Break flow from pump side' refers to the break upstream of the main pumps (VALVE-3). As shown in the figure, the break flow is only from the vessel side. There is no discharge of coolant from the pump side because the shutdown pump outlet valve (VALVE-83) remains closed and the primary pumps (PUMP-20 in Figure 13.7) keep the coolant flowing away from the break until they trip at $2.6 \mathrm{~s}$. At that point, the outlet valves (VALVE-26) close in three seconds and there is no path for the coolant to drain from the fuel elements.

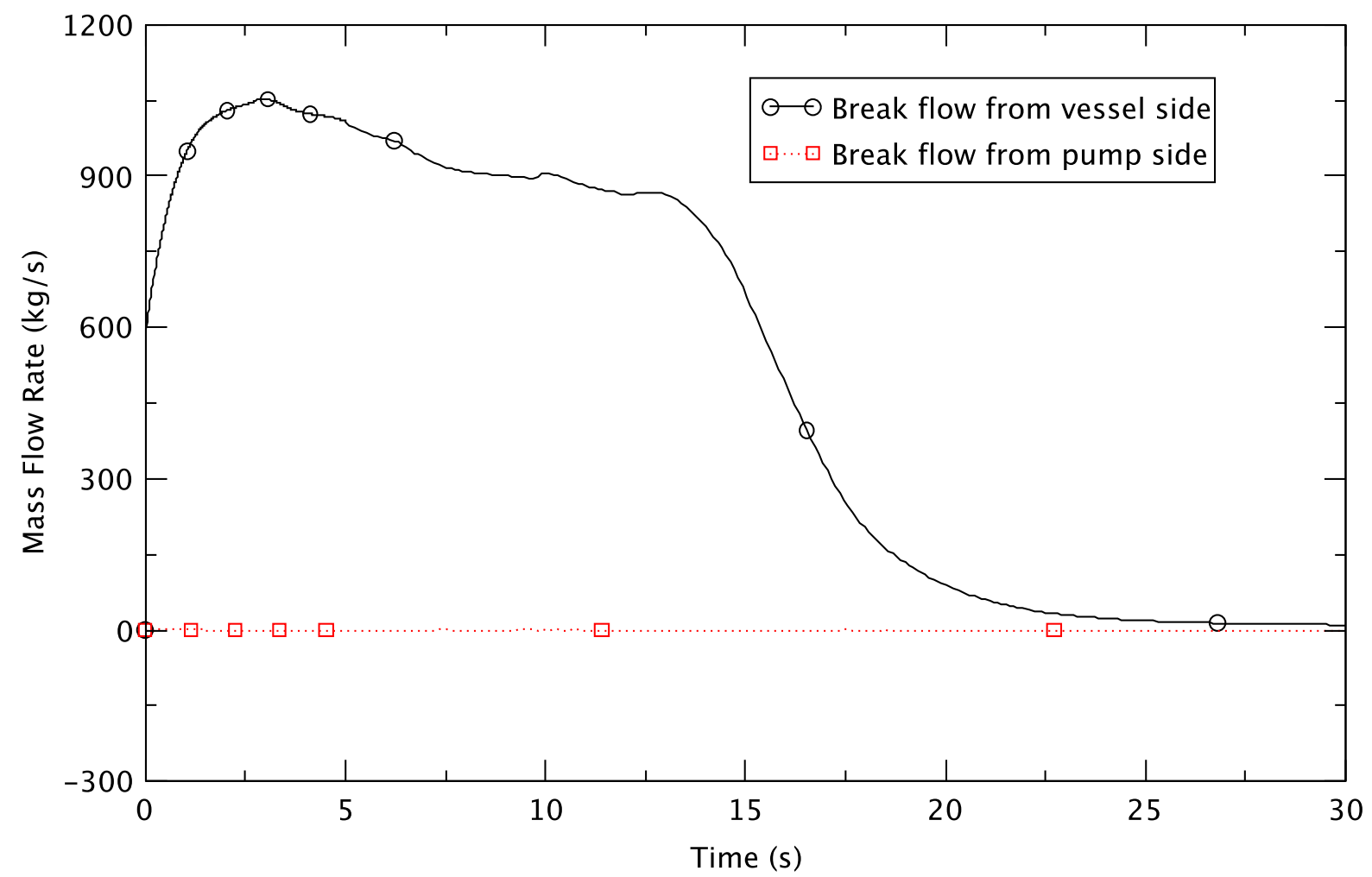

\section{Figure 13.49 Mass Flowrate at Guillotine Break Between Vessel Outlet and Control Valve DWV-19}

The water level inside the vessel (but outside the fuel elements) is shown in Figure 13.50. The level reaches $3.56 \mathrm{~m}$ (140 in) at $2.6 \mathrm{~s}$ and a LOCA signal is generated along with reactor trip. The water level reaches the elevation of the top of the upper fuel plates at $9.4 \mathrm{~s}$, the bottom of the upper fuel plates at $10.5 \mathrm{~s}$, and the top of the hold-up pan at $10.9 \mathrm{~s}$. The water level inside the fuel elements is not affected by the break because there is no pathway from the bottom of the elements through the inner or outer plenums to the break. The closure of VALVES-83 and 26 negate the possibility of the draining of the elements in this case.

The water from the IRT flows into the vessel via the distribution pan at time zero when the water level starts to drop in the vessel. The IRT is a passive system, and its flowrate is determined by the difference between the water level in the upper plenum and the level inside the tank. When the vessel water level is below the bottom of the IRT, the IRT flowrate is dependent only on the water level in the tank. 


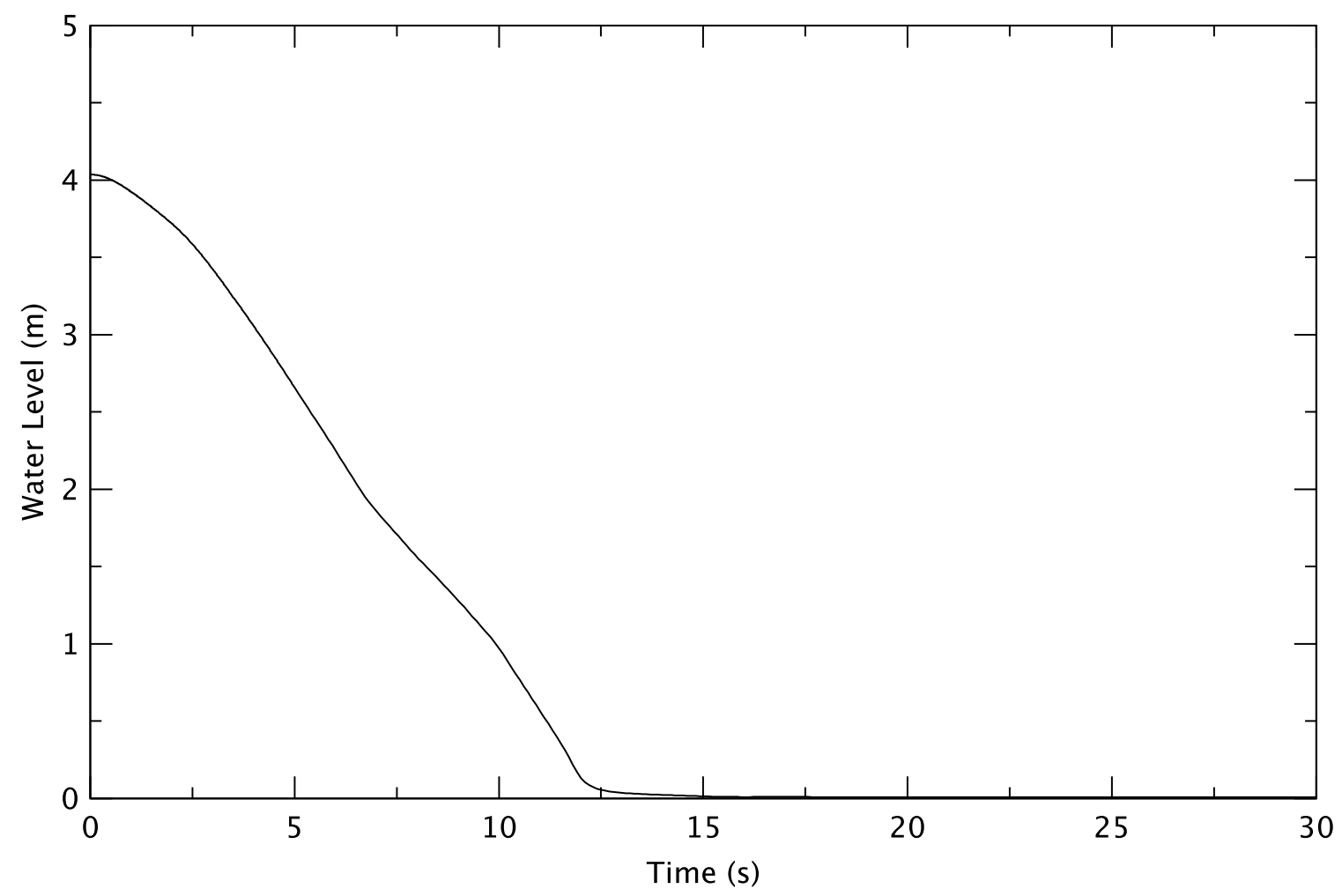

Figure 13.50 Vessel Water Level after GBLOCA Between Vessel Outlet and Control Valve DWV-19

Procedures are in place for the operator to close control valves DWV-1, DWV-2, and DWV-19 after a LOCA signal; however, it is assumed that this cannot happen in the time frame of interest for a GBLOCA. Until any operator action, the coolant continues to drain from the vessel and the water level keeps decreasing. VALVE-51, VALVE-70, and VALVE-102 can be considered to be the control valves DWV-1, DWV-2, and DWV-19, respectively, even though, as shown in Figure 13.7, they are actually used to simulate pipe breaks. However, even without operator action the fact that valves at the primary pumps' outlets close and the valves at the shutdown pumps' outlets remain closed, means that water cannot drain from within the fuel elements. Hence, for this scenario coolant will be available within the coolant channels and replenished from the IRT.

Table 13.18 shows the sequence of important events after this guillotine break. The quasiequilibrium after around $10 \mathrm{~s}$ has water distribution in the NBSR vessel as shown in Figure 13.51. The grey color indicates the available heavy water. The upper sections of the fuel elements are exposed to gas, which might be helium or air, on the outside only. The Helium Sweep Gas System supplies additional gas when the pressure drops due to the break and there is the possibility of air entering through the break. The outside of the lower sections are submerged in the water of the hold-up pan. Because the end fittings of the fuel elements and any other tubes inserted into the lower grid plate are conical, leakage of water down through the fuel element seats is not expected (NIST, 2010a) and the figure shows the inside of the fuel elements filled with coolant. 
Table 13.18 Sequence of Events after Guillotine Break Between Vessel Outlet and DWV-19

\begin{tabular}{|c|c|}
\hline Time (s) & Event (Case 1) \\
\hline 0.0 & $\begin{array}{l}\text { - Guillotine break occurs at the 18-inch pipe between the vessel outlet and } \\
\text { DWV-19. } \\
\text { - Water level drops in the upper plenum. } \\
\text { - Water flows into the vessel from the IRT via the distribution pan. }\end{array}$ \\
\hline 2.5 & $\begin{array}{l}\text { - Flowrate at the vessel outlet pipe decreases to the setpoint of low total } \\
\text { primary flow }(\leq 4,700 \mathrm{gpm}) \text {. }\end{array}$ \\
\hline 2.6 & $\begin{array}{l}\text { - LOCA signal is generated due to low level }(\leq 3.56 \mathrm{~m}) \text {. } \\
\text { - } \quad \text { First reactor scram signal is generated due to low level. } \\
\text { - Main coolant pumps are tripped. }\end{array}$ \\
\hline 5.6 & - Valves at the main coolant pumps' outlets are completely closed. \\
\hline $9.4(6.8)^{1}$ & $\begin{array}{l}\text { - Water level outside the fuel elements reaches the elevation of the top of } \\
\text { the upper fuel plate. }\end{array}$ \\
\hline $10.5(7.9)$ & $\begin{array}{l}\text { - Water level outside the fuel element reaches the elevation of the bottom of } \\
\text { the upper fuel plate. }\end{array}$ \\
\hline$\sim 10.9$ (8.3) & $\begin{array}{l}\text { - Water level outside the fuel elements reaches the elevation of the top of } \\
\text { the hold-up pan. }\end{array}$ \\
\hline 30.0 & - Simulation ends. \\
\hline
\end{tabular}

In this situation, decay power can be removed simply by boiling, as the coolant channels remain filled with coolant (see also Section 13.7.3). This is based on the analysis discussed in (Cheng, 2004). That analysis determined that the flooding-limited critical power is $3.58 \mathrm{~kW}$ for a coolant channel. Any coolant channel (considering the upper and lower sections within a fuel element together) with power less than this can have heat removed by boiling without problem and the clad temperature will not rise much above $101^{\circ} \mathrm{C}$ (heavy water saturation temperature at atmospheric pressure).

The hottest fuel plate (always next to an outside plate, the $17^{\text {th }}$ fuel plate in Figure 13.13) in the upper section in the LEU core has a calculated power of $31.4 \mathrm{~kW}$ at time zero at EOC; for HEU the value is slightly lower. The power of the fuel plate in the lower section beneath the hottest fuel plate is $27.5 \mathrm{~kW}$ for the LEU fuel at EOC at time zero. The total power of the upper and lower fuel plates becomes $58.9 \mathrm{~kW}$. The powers of the fuel plate (the $16^{\text {th }}$ fuel plate) next to the hottest fuel plate are $27.3 \mathrm{~kW}$ in the upper section and $24.0 \mathrm{~kW}$ in the lower section (total power of $51.3 \mathrm{~kW}$ ). If it is assumed that the hottest flow channel gets its heat from half of the $17^{\text {th }}$ fuel plate and half of the $16^{\text {th }}$ plate, the amount of power transferred is $55.1 \mathrm{~kW}$ at time zero. As shown in Table 13.18, the outside of the fuel plate begins to be uncovered at $6.8 \mathrm{~s}$ after reactor scram. Based on the decay heat curve for HEU and LEU fuels shown in Figure 4.31, the decay power fraction is 0.065 at $6.8 \mathrm{~s}$. This leads to the power of $3.56 \mathrm{~kW}$ transferred to the hottest flow channels when the outside fuel plates begin to be uncovered. This power is smaller than the flooding-limited critical power of $3.58 \mathrm{~kW}$. Hence, it can be assured that decay power is removed by boiling with a continuous supply of liquid from the upper region of the hottest flow channel. 


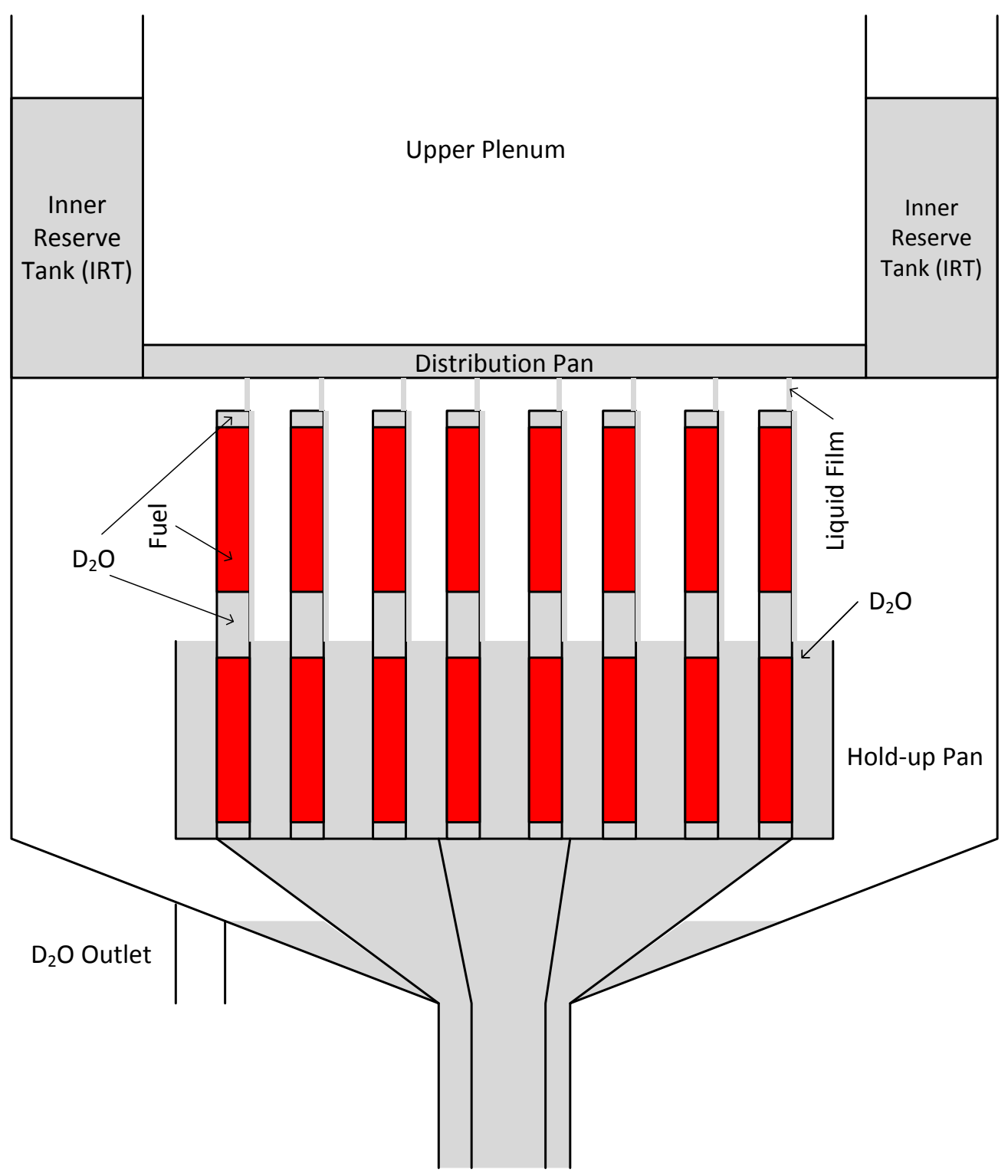

Figure 13.51 End-state of Coolant Inside Vessel after Break at Vessel Outlet

There are two factors that should be considered in more realistically evaluating counter-current flow being limited in a flow channel inside the fuel element after a GBLOCA. The first is that the flooding-limited critical power of $3.58 \mathrm{~kW}$ was conservatively calculated with the assumption of the saturated liquid in the region above the hottest channel. In reality, the water in that region is subcooled during normal operation. Reactor inlet and outlet temperatures are $38^{\circ} \mathrm{C}$ and $46^{\circ} \mathrm{C}$, respectively, during normal operation (NIST, 2010a). If this subcooling of the water is taken into account in the analysis, the flooding-limited critical power will be $3.97 \mathrm{~kW}$. The second is that the effect of power in the lower section is diluted in the mid-plane gap because vapor, if generated, flowing from all flow channels in the lower section will be mixed there and some of it will be condensed by subcooled coolant. This causes the effective power in the hottest flow channel to be smaller than $3.56 \mathrm{~kW}$ at the time when the outside of the fuel plate starts to be uncovered. These factors imply that the power generated in the fuel plates is low enough and 
precludes the occurrence of counter-current flow limitation in the hottest flow channel. In this GBLOCA scenario, therefore, decay power can be removed simply by boiling without significant increase in clad temperatures. Furthermore, there is no need to do the HEATING7.3 analysis.

\section{Guillotine break at outer plenum inlet pipe (Case 2)}

A guillotine break LOCA at the outer plenum inlet pipe is simulated by closing VALVE-51 at the outer plenum inlet pipe and opening VALVE-1 and VALVE-2 near VALVE-51 (see Figure 13.7 ). The flow areas of those valves are the same as the pipe flow area of $0.089 \mathrm{~m}^{2}$. Figure 13.52 and Figure 13.53 depict the mass discharge rate through the break and the water level inside the vessel, respectively.

Figure 13.52 shows that the coolant is initially discharged through both sides of the break in this case. The break flow from the pump side (VALVE-1), however, is limited due to the closure of the valves at the outlets of the primary pumps when the main pumps trip at $1.5 \mathrm{~s}$. The discharge flow through the break close to the outer plenum (VALVE-2) is almost negligible until around $0.6 \mathrm{~s}$ due to the initial flow inertia because the coolant is flowing to the outer plenum and upward in the core as during normal operation. The break flow becomes very small after $15 \mathrm{~s}$ as the coolant water is essentially drained from the fuel elements, outer plenum, and the broken pipe and the only water that continues to drain is the water entering the fuel elements from the IRT.

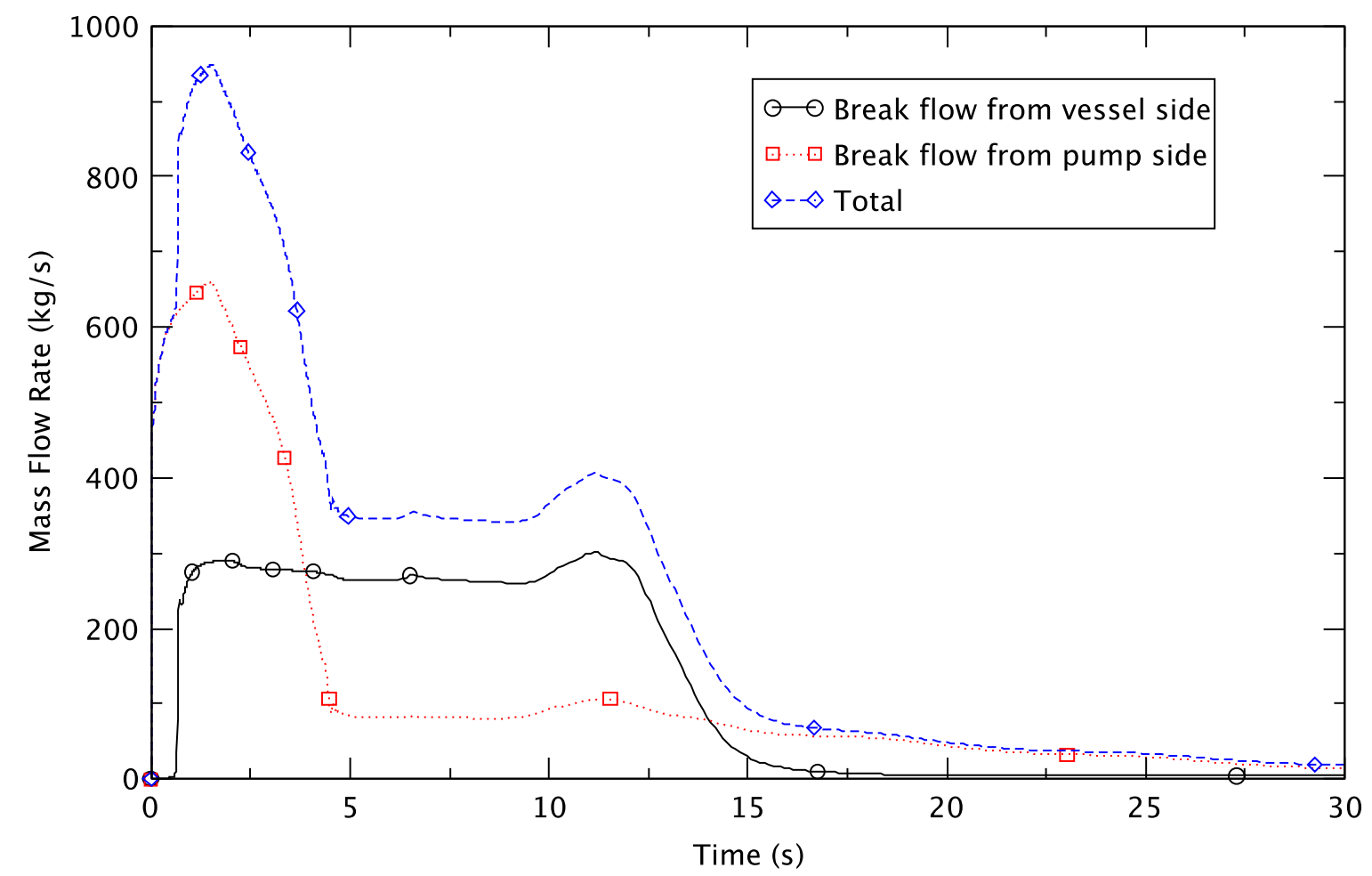

Figure 13.52 Mass Flowrate at Guillotine Break Between Outer Plenum and Control Valve DWV-1 
The vessel water level shows change in behavior at around $4 \mathrm{~s}$. This change is caused by the main pumps' trip. The pumps trip on a low level signal at $1.5 \mathrm{~s}$ and the pumps' discharge valves are closed in three seconds. The coolant is drained only through the flow channels after the closure of the valves and Figure 13.53 shows that the vessel water level stops decreasing at 1.92 $\mathrm{m}$ after around $10 \mathrm{~s}$ as it reaches the top of the fuel elements. The fuel plates begin draining from around $8.6 \mathrm{~s}$ and are completely drained in $12.4 \mathrm{~s}$ as can be seen in Figure 13.54 which shows water level within both the upper and lower sections of hot plate channel (Node-407 and Node-403 in Figure 13.7).

There appears to be an inconsistency in the prediction of the water level in this case. This is because the hot channel (Node-401 to Node-409 in Figure 13.7) is connected to the distribution pan (Node-72) conservatively using a side junction in the TRACE model. If it is connected using a main junction of Node-72, TRACE will predict the behavior of the water level decrease more reasonably, and the fuel plate will be uncovered after the vessel water level reaches the top of the fuel element at $10 \mathrm{~s}$. In the analysis, however, the conservative way of modeling the hot channel is taken into consideration.

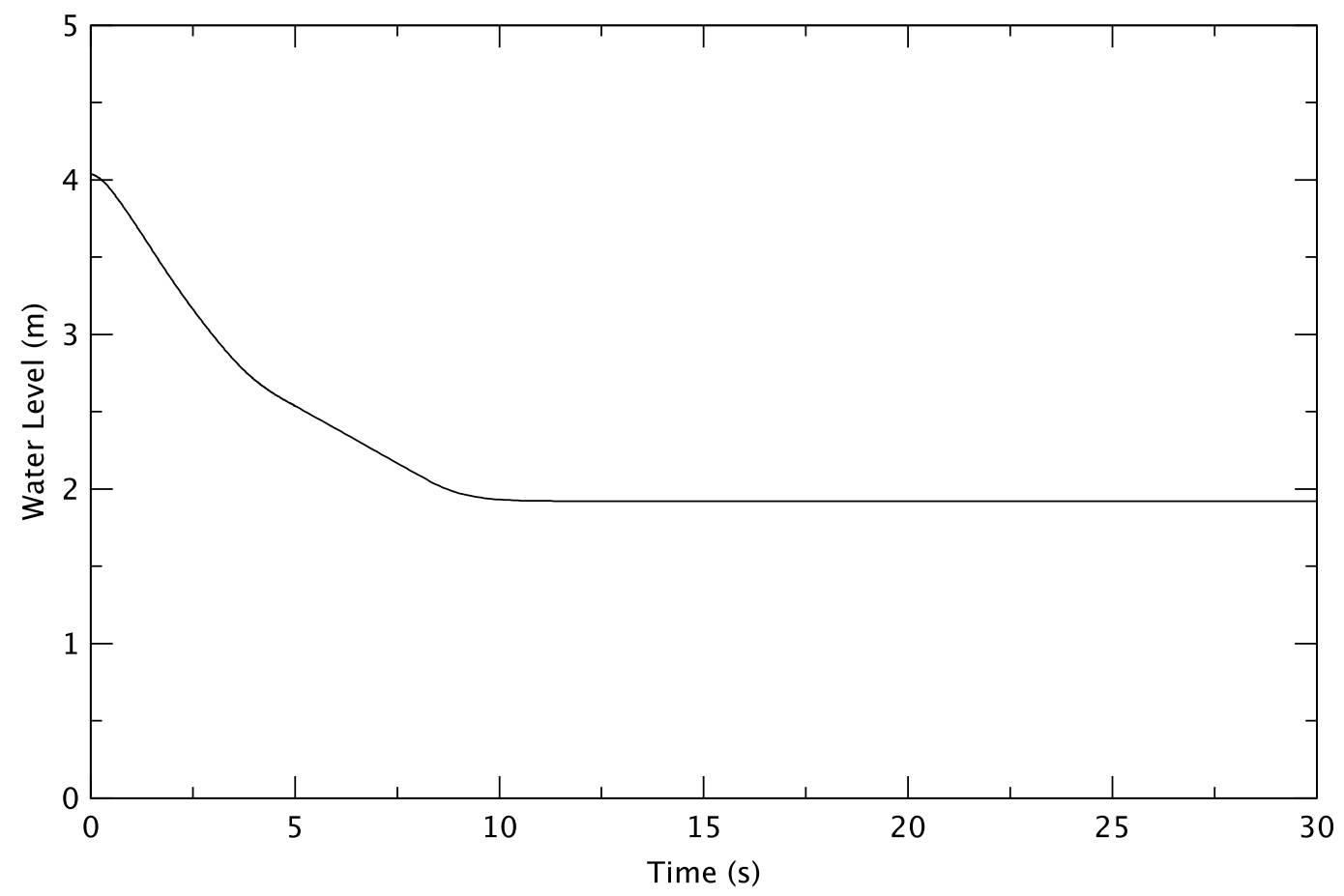

Figure 13.53 Vessel Water Level after Guillotine Break Between Outer Plenum and Control Valve DWV-1 


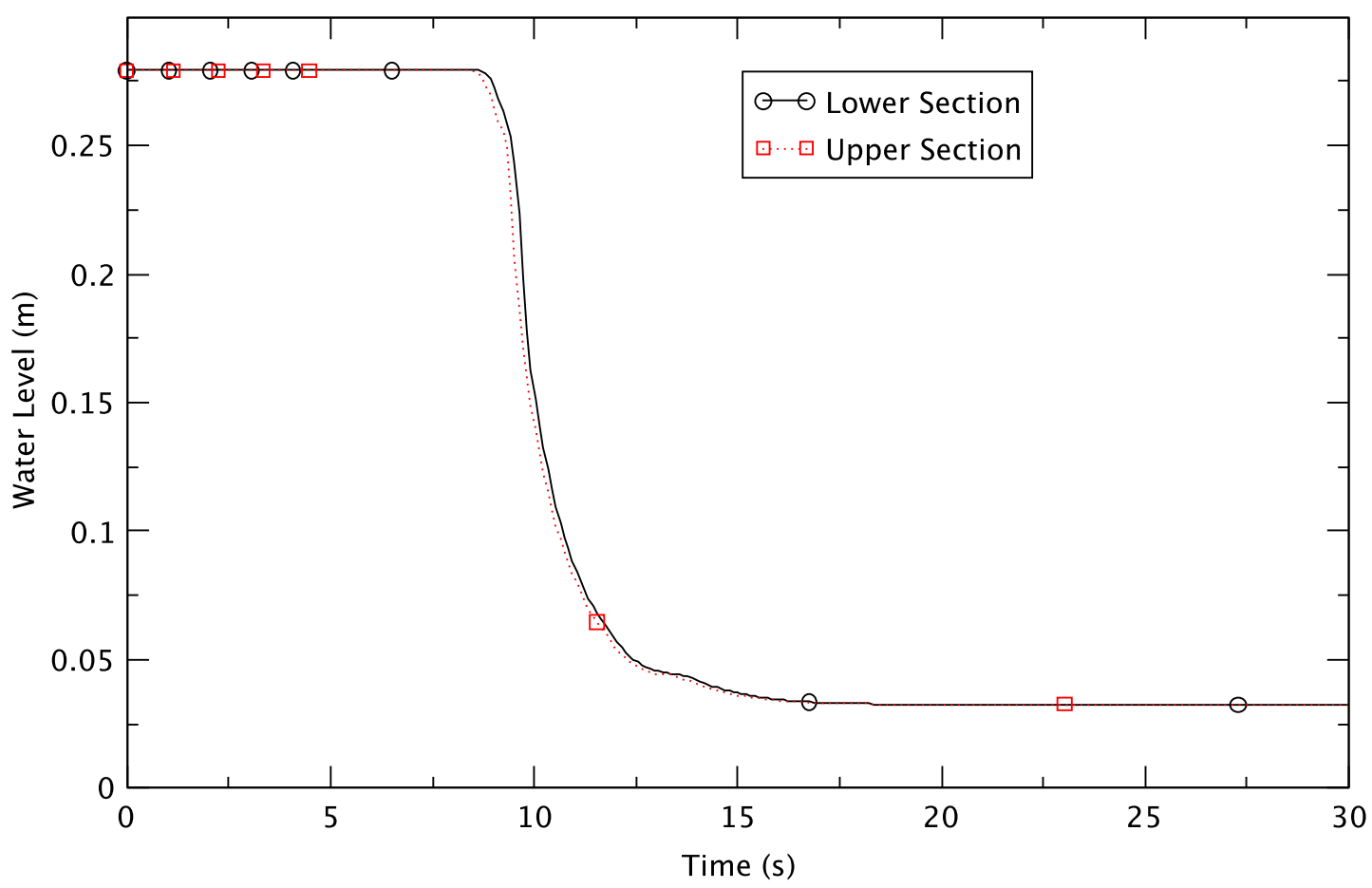

Figure 13.54 Water Level in Fuel Elements after Guillotine Break Between Outer Plenum and Control Valve DWV-1

Table 13.19 shows the sequence of important events in Case 2. The first reactor scram signal is generated at $0.4 \mathrm{~s}$, earlier than in Case 1. This is due to the fact that the coolant flows in reverse at the flowrate measuring point in the inner plenum inlet pipe after the break occurs. The LOCA signal is also created earlier (1.5 s) in this accident. The coolant is discharged through both sides of the break in this case as shown in Figure 13.52. However, in Case 1 (vessel outlet pipe break) the main coolant pumps will continue to function until they are tripped, delivering to the vessel the remaining water in the broken pipe.

If the operator actions to close the control valves in the primary system are not taken for at least 15 seconds after the LOCA signal, this accident will lead to the quasi-equilibrium end-state shown in Figure 13.55.

As shown in Table 13.19, the fuel plate starts to be uncovered at $7.8 \mathrm{~s}$ after reactor scram (8.6 s after the break) in the upper section. This 7.8 s needs to be "time zero" in the HEATING7.3 simulations because those calculations take the initial condition that the flow channels are completely drained. To add conservatism, $7 \mathrm{~s}$ instead of $7.8 \mathrm{~s}$ is used in the simulations to determine the initial decay power. 
Table 13.19 Sequence of Events after Guillotine Break Between Outer Plenum and Control Valve DWV-1

\begin{tabular}{|c|c|}
\hline Time (s) & Event (Case 2) \\
\hline 0.0 & $\begin{array}{l}\text { - Guillotine break takes place at the 14-inch pipe between the control valve } \\
\text { DWV-1 and the outer plenum. } \\
\text { - Water level drops in the upper plenum. } \\
\text { - Water flows into the vessel from the IRT via the distribution pan. }\end{array}$ \\
\hline 0.4 & $\begin{array}{l}\text { - Flowrate at the inner plenum inlet pipe decreases to the setpoint of low inner } \\
\text { plenum flow ( } \leq 1,200 \mathrm{gpm}) \text {. }\end{array}$ \\
\hline 0.8 & - $\quad$ First reactor scram signal is generated due to low inner plenum flow. \\
\hline 1.5 & $\begin{array}{l}\text { - LOCA signal is generated due to low level }(\leq 3.56 \mathrm{~m}) \text {. } \\
\text { - } \quad \text { Main coolant pumps are tripped. }\end{array}$ \\
\hline 4.5 & - Valves at the main coolant pumps’ outlets are completely closed. \\
\hline $8.6(7.1)^{1}$ & $\begin{array}{l}\text { - The fuel plate starts to be uncovered in the upper section of the FE (Node- } \\
\text { 407). }\end{array}$ \\
\hline $8.7(7.2)$ & $\begin{array}{l}\text { - The fuel plate starts to be uncovered in the lower section of the FE (Node- } \\
\text { 403). }\end{array}$ \\
\hline $\begin{array}{l}\sim 12.3 \\
(\sim 10.8)\end{array}$ & $\begin{array}{l}\text { - The fuel plate is completely uncovered in the upper section of the FE (Node- } \\
\text { 407). }\end{array}$ \\
\hline $\begin{array}{c}\sim 12.4 \\
(\sim 10.9)\end{array}$ & $\begin{array}{l}\text { - The fuel plate is completely uncovered in the lower section of the FE (Node- } \\
\text { 403). }\end{array}$ \\
\hline 30.0 & - $\quad$ Simulation ends. \\
\hline
\end{tabular}




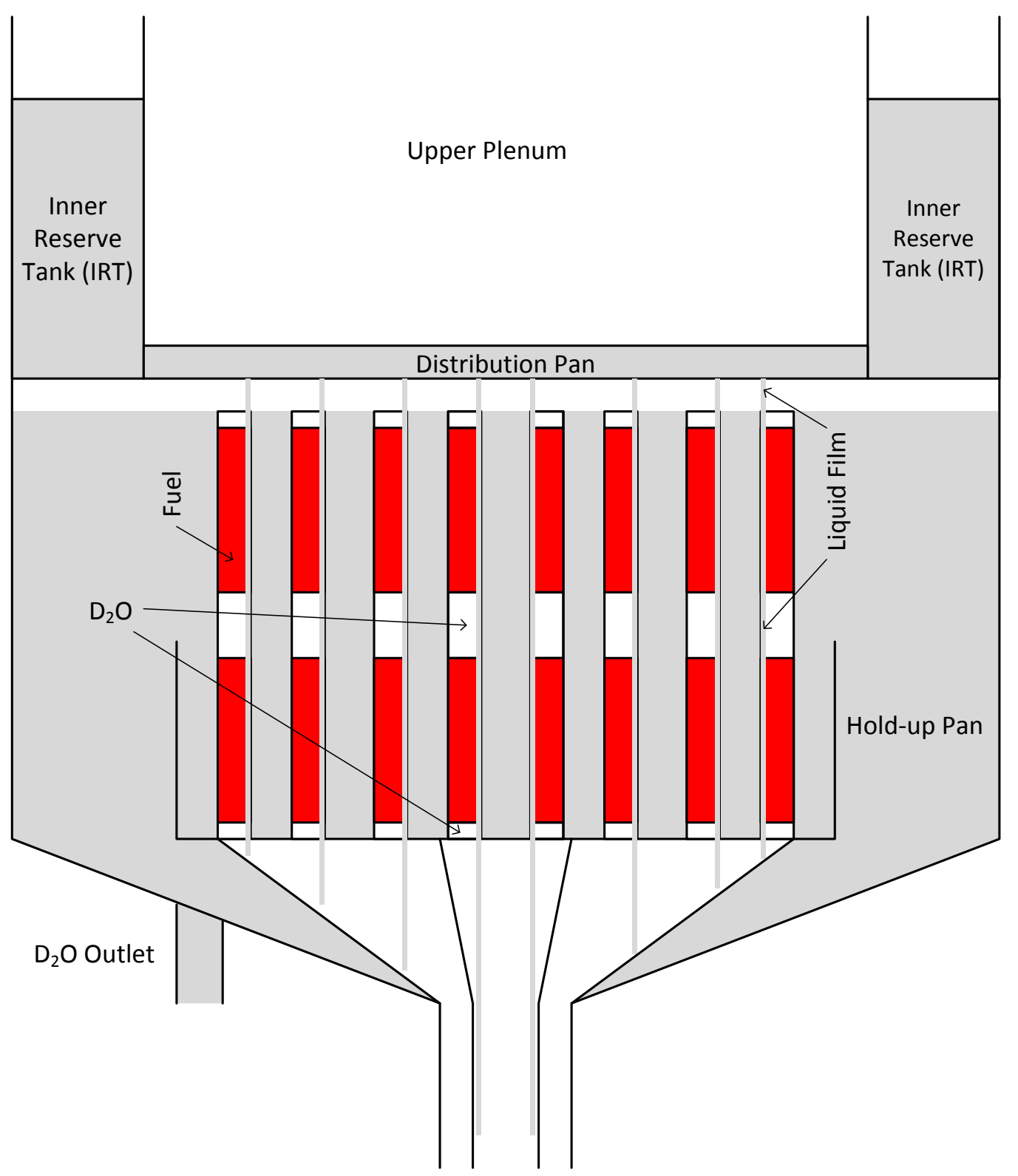

Figure 13.55 End-state of Coolant after GBLOCA at Inlet Pipes to Outer or Inner Plenums

\section{Guillotine break at inner plenum inlet pipe (Case 3)}

In this scenario a guillotine break is assumed to occur at the pipe between the control valve DWV-2 and the inner plenum. The break areas are the same as the pipe flow area of $0.0509 \mathrm{~m}^{2}$. This accident is simulated by closing VALVE-70 at the inner plenum inlet pipe and opening nearby VALVE-23 and VALVE-32 (see Figure 13.7). The NBSR response to this accident is similar to that in Case 2, but the events occur with different timing because of the smaller break flow due to smaller break areas. Figure 13.56 and Figure 13.57 depict the break flowrates and vessel water level in Case 3 . Reactor scram occurs at $0.8 \mathrm{~s}$ on the lower outer plenum flow. The primary pumps trip at $2.2 \mathrm{~s}$ on the LOCA signal and the valves at the outlets of the pumps close in three seconds. After closure of the valves coolant drains only from the coolant channels. The 
vessel water level reaches the top of the fuel elements at around $13 \mathrm{~s}$ and then stays at $1.92 \mathrm{~m}$. The upper fuel plate starts to be uncovered at $12.7 \mathrm{~s}$.

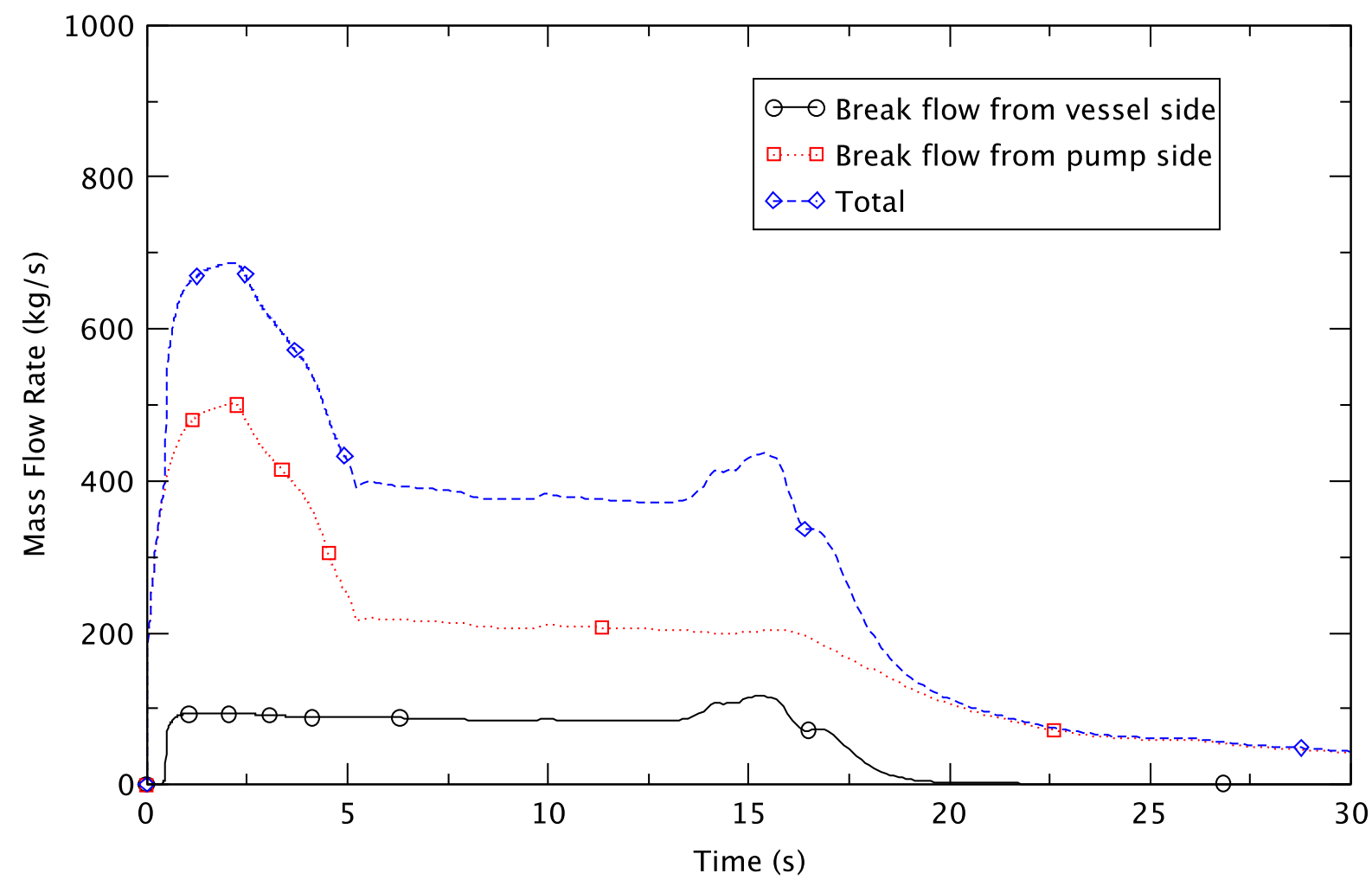

\section{Figure 13.56 Mass Flowrate at Guillotine Break Between Inner Plenum and Control Valve DWV-2}

The water level behavior in each section of fuel plates is shown in Figure 13.58 and the sequence of important events is given in Table 13.20. It takes $2.9 \mathrm{~s}$ to drain the upper fuel plates in this case whereas it takes $3.7 \mathrm{~s}$ in Case 2. This is contrary to what might be expected for a smaller break area. In Case 3 the vessel water level has reached the top of the fuel elements (about $13 \mathrm{~s}$ after the break) almost at the same time as the upper fuel plate starts to be uncovered (12.7 s after the break). A relatively large amount of water continues to flow into the flow channel from the vessel for an additional $1.4 \mathrm{~s}$ in Case 2 while only a small amount of water is supplied for $0.3 \mathrm{~s}$ in Case 3. This fact causes the flow channel to take more time to be completely drained in Case 2 than in Case 3. The end-state of water distribution inside the NBSR will be identical to that shown in Figure 13.55. 


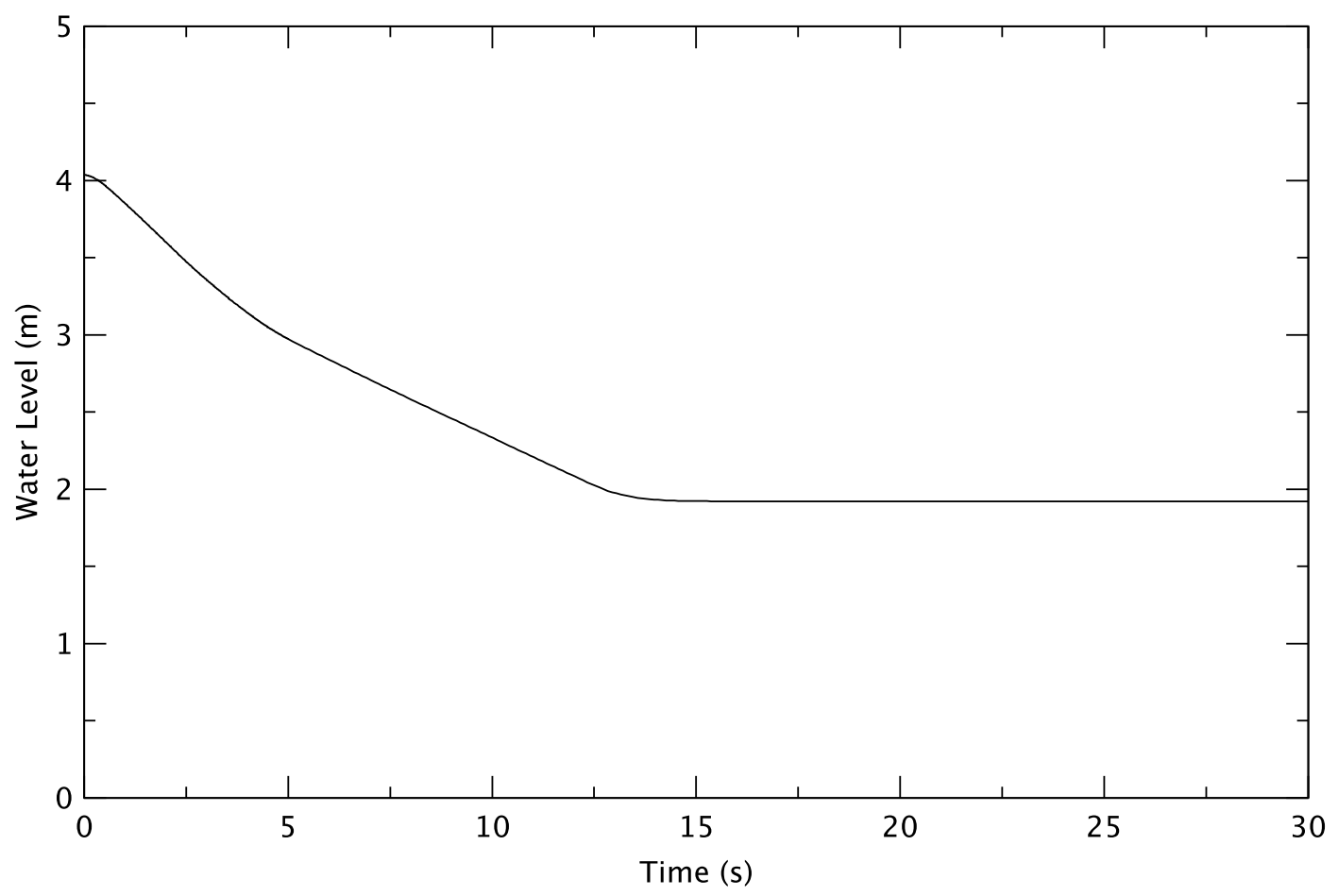

Figure 13.57 Vessel Water Level after Guillotine Break Between Inner Plenum and Control Valve DWV-2

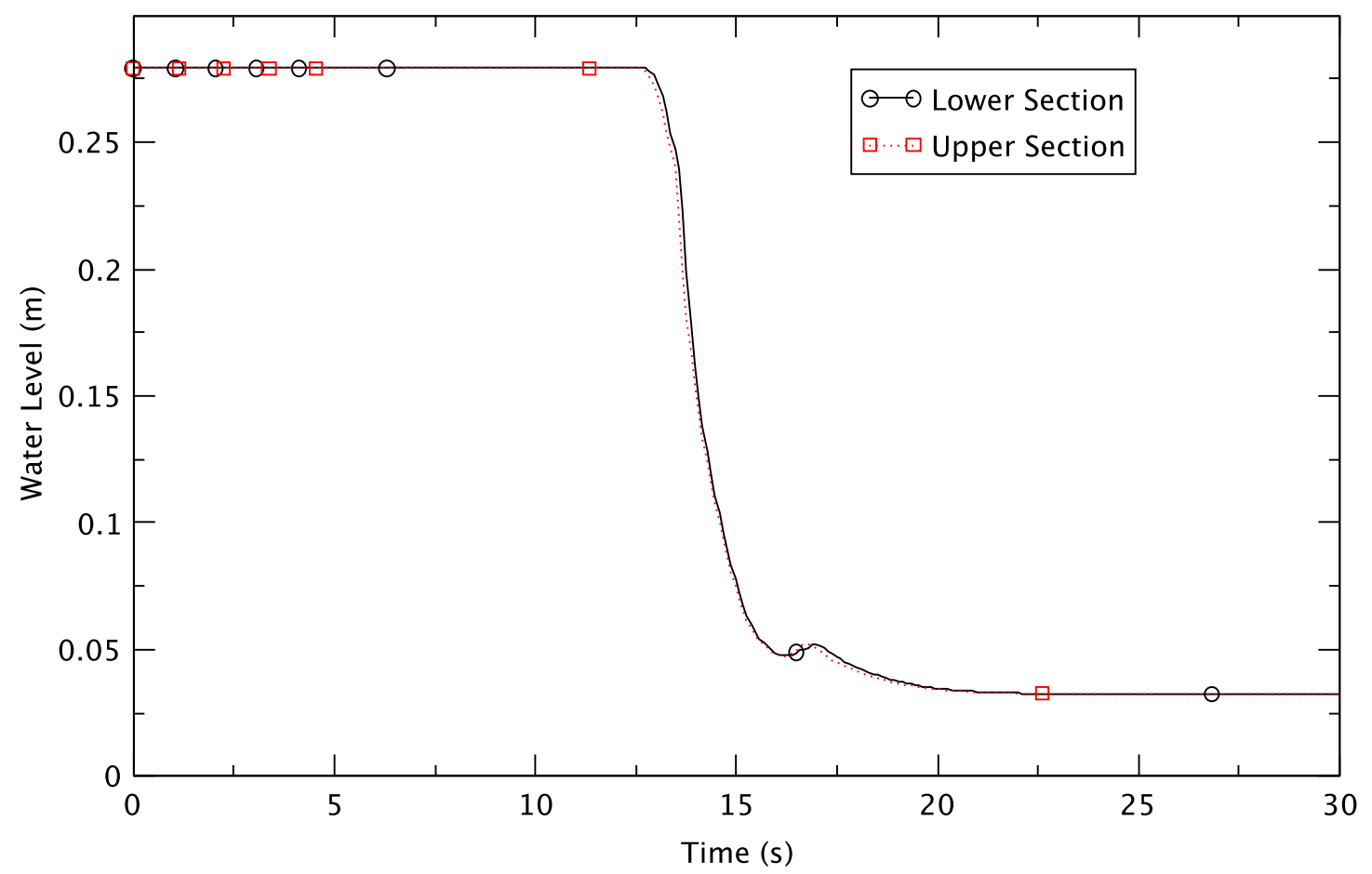

Figure 13.58 Water Level in Fuel Elements after Guillotine Break Between Inner Plenum and Control Valve DWV-2 
Table 13.20 Sequence of Events After Guillotine Break Between Inner Plenum and Control Valve DWV-2

\begin{tabular}{|c|c|}
\hline Time (s) & Event (Case 3) \\
\hline 0.0 & $\begin{array}{l}\text { - Guillotine break occurs at the 10-inch pipe between the control valve DWV-2 } \\
\text { and the inner plenum. } \\
\text { - Water level drops in the upper plenum. } \\
\text { - Water flows into the vessel from the IRT via the distribution pan. }\end{array}$ \\
\hline 0.4 & $\begin{array}{l}\text { - Flowrate at the outer plenum inlet pipe decreases to the setpoint of low outer } \\
\text { plenum flow }(\leq 4,700 \mathrm{gpm}) \text {. }\end{array}$ \\
\hline 0.8 & - First reactor scram signal is generated due to low outer plenum flow. \\
\hline 2.2 & $\begin{array}{l}\text { - LOCA signal is generated due to low level }(\leq 3.56 \mathrm{~m}) \text {. } \\
\text { - Main coolant pumps are tripped. }\end{array}$ \\
\hline 5.2 & - Valves at the main coolant pumps' outlets are completely closed. \\
\hline $12.7(10.5)^{1}$ & $\begin{array}{l}\text { - The fuel plate starts to be uncovered in the upper section of the FE (Node- } \\
\text { 407). }\end{array}$ \\
\hline $12.8(10.6)$ & $\begin{array}{l}\text { - The fuel plate starts to be uncovered in the lower section of the FE (Node- } \\
\text { 403). }\end{array}$ \\
\hline $\begin{array}{c}\sim 15.6 \\
(\sim 13.4)\end{array}$ & $\begin{array}{l}\text { - The fuel plate is completely uncovered in the upper section of the FE (Node- } \\
\text { 407). }\end{array}$ \\
\hline $\begin{array}{l}\sim 15.6 \\
(\sim 13.4)\end{array}$ & $\begin{array}{l}\text { - The fuel plate is completely uncovered in the lower section of the FE (Node- } \\
\text { 403). }\end{array}$ \\
\hline 30.0 & - Simulation ends. \\
\hline
\end{tabular}

\subsubsection{Small break LOCA}

$\underline{\text { Small Break at vessel outlet pipe (Case 4) }}$

SBLOCAs were considered for the same three locations addressed for GBLOCAs as shown in Table 13.17. The difference between an SBLOCA and GBLOCA is that the operator has time to take action. For the case with the break at the vessel outlet this makes no difference and the sequence of events proceeds as in the case with the GBLOCA (Case 1) except at a much slower rate. The end-state for the SBLOCA at the outlet pipe is as shown in Figure 13.51 with coolant water remaining in the fuel elements. As stated for Case 1, there is adequate cooling to keep the clad temperatures low and there is no need to do analysis with HEATING7.3. This is particularly true for this case since the reduction of vessel water level occurs much later than in the GBLOCA case and hence, decay heat levels are much lower.

$\underline{\text { Small break at outer plenum inlet pipe (Case 5) or at inner plenum inlet pipe (Case 6) }}$

A small break occurring between the control valve DWV-1 and the outer plenum is simulated by opening VALVE-12 at the outer plenum inlet pipe (flow area $=0.089 \mathrm{~m}^{2}$ ) while a small break assumed to occur between the control valve DWV-2 and the inner plenum is simulated by opening VALVE-33 at the inner plenum inlet pipe $\left(\right.$ flow area $=0.0509 \mathrm{~m}^{2}$ ). In both cases a 
break size of $0.76 \%\left(6.8 \mathrm{~cm}^{2}\right)$ is considered in the simulation. The simulations have some similarity to the GBLOCA Cases 2 and 3 in that because of the primary pumps' trip, the water in the vessel outside of the fuel elements cannot drain. However, in this case the slow evolution of the event means that operator actions can be effective. The operator shuts the control valves (DWV-1, DWV-2, and DWV-19) in the primary system and therefore, the water in the fuel elements fed by the inner plenum cannot drain when the break is at the outer plenum and similarly, the elements fed by the outer plenum cannot drain when the break is at the inner plenum. The final state for Case 5 is shown in Figure 13.59 and for Case 6 in Figure 13.60.

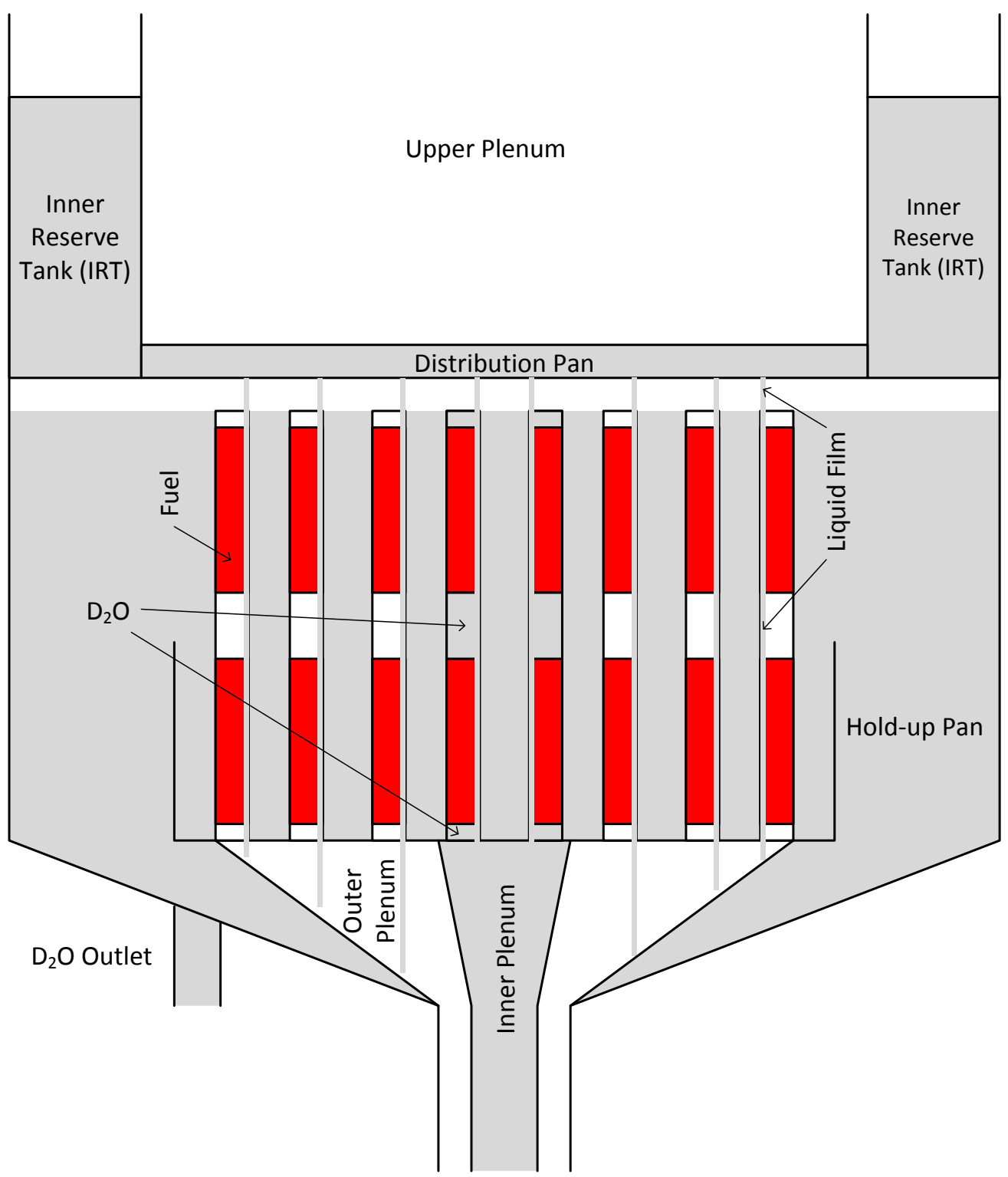

Figure 13.59 End-State of Coolant after SBLOCA at Inlet Pipe to Outer Plenum

The results are also used to see how much time it would take to drain the fuel elements in either case. The results (Baek, 2014a) for the $6.8 \mathrm{~cm}^{2}$ break show that in these cases the water level reaches the top of the fuel plates in $\sim 1700 \mathrm{~s}$. The fuel plates in either the top or bottom of the 
element take 5-18 seconds to drain depending on the location of the break. Larger breaks will of course drain sooner and smaller breaks later.

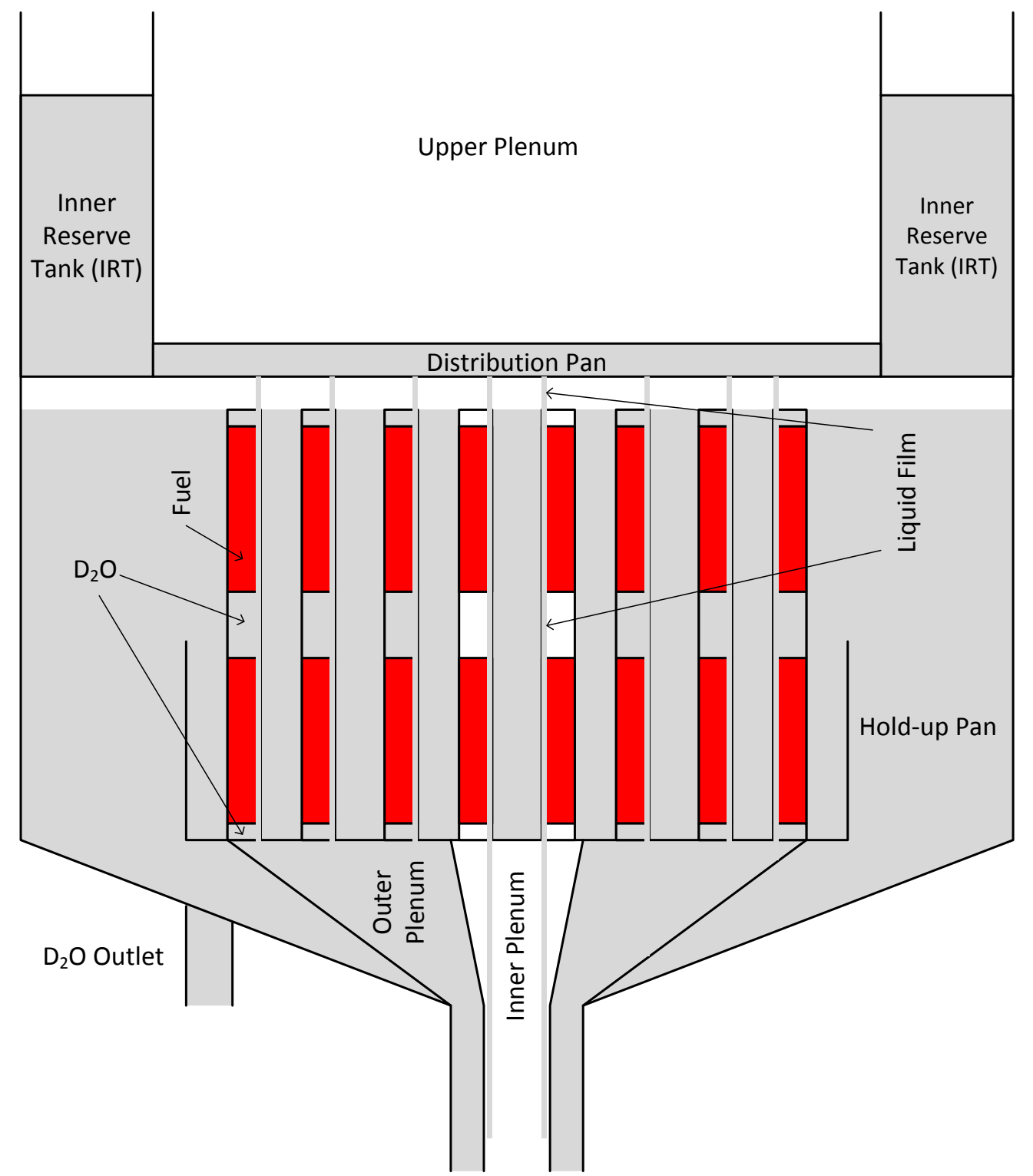

Figure 13.60 End-State of Coolant after SBLOCA at Inlet Pipe to Inner Plenum

\subsubsection{Analysis of Peak Clad Temperatures}

\subsubsection{Steady State Conditions}

HEATING7.3 transient runs begin when the upper or lower fuel plates have been uncovered and it is assumed that the temperatures in the fuel element have not changed from normal operating conditions. To obtain the steady state temperatures, HEATING7.3 has been run with a heat transfer coefficient (as a boundary condition) commensurate with the flowrate in a flow channel under normal operating conditions. The heat transfer coefficient of $2.0 \mathrm{~W} / \mathrm{cm}^{2}-{ }^{\circ} \mathrm{C}$ is applied to 
all outer surfaces of the mesh regions (see Figure 13.13). The hot spot is located in the bottom of the 17th fuel plate in the upper section (see Figure 4.25 and Figure 4.27). Reactor inlet and outlet temperatures are $38^{\circ} \mathrm{C}$ and $46^{\circ} \mathrm{C}$, respectively, during normal operation (NIST, 2010a).

The steady-state average temperatures are shown in Table 13.21 for both the HEU and LEU cores. $\Delta \mathrm{T}_{\mathrm{AVG}}$ is the difference between the material temperature and the reference bulk temperature, which is artificially taken to be zero in the HEATING7.3 calculations. Comparison of the steady-state results with the clad temperatures predicted by RELAP5 for non-LOCA analyses (Baek, 2014b) shows good agreement between them. The steady-state bulk (coolant) temperature varies between $38^{\circ} \mathrm{C}$ and $46^{\circ} \mathrm{C}$ and therefore, the highest initial average clad temperature (in plate 17 upper section) is less than $78^{\circ} \mathrm{C}\left(46^{\circ} \mathrm{C}+31.5^{\circ} \mathrm{C}\right)$ for the HEU fuel and $81^{\circ} \mathrm{C}$ for the LEU fuel.

Table 13.21 Steady-State Average Temperatures $\left(\Delta T_{A V G}\right.$ in $\left.{ }^{\circ} \mathrm{C}\right)$ in Upper Sections

\begin{tabular}{|c|c|c|c|c|c|c|c|}
\hline Plate & Name & HEU & LEU & Plate & Name & HEU & LEU \\
\hline \multirow[t]{3}{*}{ Outside } & Clad & 0.7 & 0.7 & \multirow[t]{3}{*}{$13^{\text {th }}$} & Clad & 23.5 & 23.9 \\
\hline & Fuel meat & NA & NA & & Fuel meat & 32.2 & 33.0 \\
\hline & Side plate & 5.1 & 4.9 & & Side plate & 8.6 & 8.1 \\
\hline \multirow[t]{3}{*}{$17^{\text {th }}$} & Clad & 31.5 & 34.2 & \multirow[t]{3}{*}{$12^{\text {th }}$} & Clad & 22.7 & 22.8 \\
\hline & Fuel meat & 44.1 & 48.0 & & Fuel meat & 31.1 & 31.4 \\
\hline & Side plate & 7.8 & 7.5 & & Side plate & 8.4 & 7.7 \\
\hline \multirow[t]{3}{*}{$16^{\text {th }}$} & Clad & 28.4 & 30.1 & \multirow[t]{3}{*}{$11^{\text {th }}$} & Clad & 22.0 & 22.3 \\
\hline & Fuel meat & 39.3 & 41.8 & & Fuel meat & 30.1 & 30.6 \\
\hline & Side plate & 9.0 & 8.7 & & Side plate & 8.1 & 7.5 \\
\hline \multirow[t]{3}{*}{$15^{\text {th }}$} & Clad & 26.4 & 27.4 & \multirow[t]{3}{*}{$10^{\text {th }}$} & Clad & 21.5 & 21.6 \\
\hline & Fuel meat & 36.3 & 37.8 & & Fuel meat & 29.4 & 29.7 \\
\hline & Side plate & 9.2 & 8.7 & & Side plate & 8.0 & 7.3 \\
\hline \multirow[t]{3}{*}{$14^{\text {th }}$} & Clad & 24.6 & 25.4 & \multirow[t]{3}{*}{$9^{\text {th }}$} & Clad & 21.3 & 21.4 \\
\hline & Fuel meat & 33.7 & 35.0 & & Fuel meat & 29.1 & 29.5 \\
\hline & Side plate & 8.9 & 8.4 & & Side plate & 7.9 & 7.3 \\
\hline \multirow{3}{*}{$\begin{array}{l}\text { Extended } \\
\text { lower } \\
\text { region }\end{array}$} & Clad & 0.1 & 0.1 & \multirow{3}{*}{$\begin{array}{l}\text { Extended } \\
\text { upper } \\
\text { region }\end{array}$} & Clad & 0.0 & 0.0 \\
\hline & Fuel meat & NA & NA & & Fuel meat & NA & NA \\
\hline & Side plate & 0.0 & 0.0 & & Side plate & 0.0 & 0.0 \\
\hline
\end{tabular}

\subsubsection{Guillotine Break LOCAs}

The GBLOCA quasi-equilibrium end-state of Figure 13.55 (Cases 2 and 3) is considered for the HEATING 7.3 simulations. The coolant channels have been drained and the outside of the fuel elements are submerged in the water that has not drained from the vessel. Two cases are considered with different assumptions about the falling liquid film.

As discussed in (Baek, 2014a) the thickness of the falling liquid film on the inside of one side plate depends on the coolant mass flowrate and its thermal properties and is expected to be 0.12 
$\mathrm{cm}$ if the flow is uniformly distributed across the side plate. Analysis has been conducted with a film thickness of $0.1 \mathrm{~cm}$ to conservatively represent the actual thickness (and with a thinner film as will be explained below).

The results for the peak clad temperature in the upper fuel section are shown in Figure 13.61. The ordinate represents the temperature difference between the clad surface and the falling liquid film and the abscissa is the time after the fuel plate is uncovered. The clad temperatures start increasing rapidly from time zero because the power is higher than the cooling capacity of the liquid film and the quiescent water outside the fuel elements and the rate of the temperature increase becomes smaller as the decay power decreases. The maximum temperature difference is $171^{\circ} \mathrm{C}$ at $23 \mathrm{~s}$ for the HEU fuel and $187^{\circ} \mathrm{C}$ at $25 \mathrm{~s}$ for the LEU fuel. These peak temperatures occur toward the bottom of the $17^{\text {th }}$ (end) fuel plate near the bottom where the decay heat is highest.

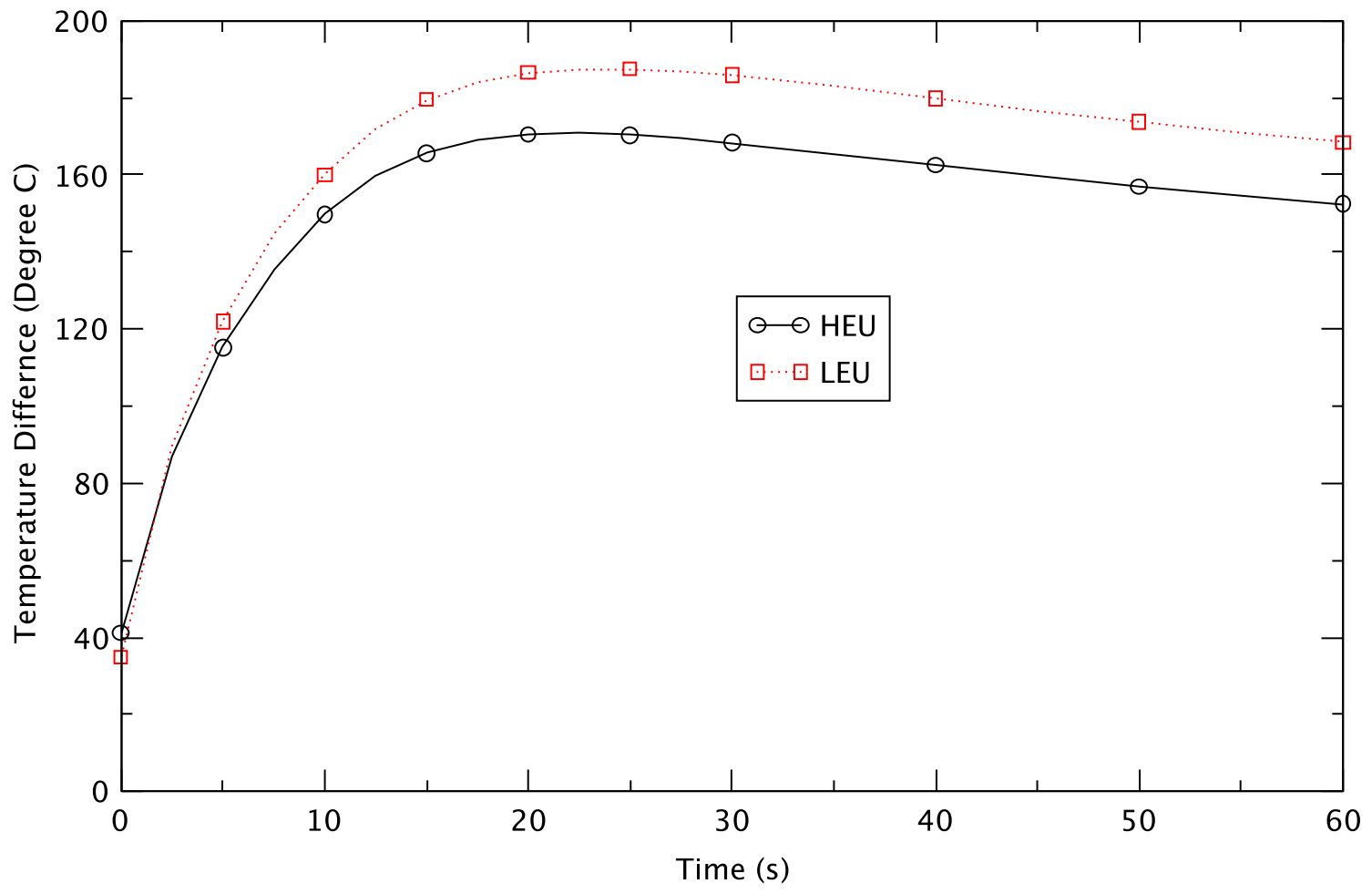

Figure 13.61 Peak Clad Temperature with Uniform Film Thickness $(0.1 \mathrm{~cm})$ after GBLOCA

The liquid temperature is discussed below. However, since the liquid temperature will be less than or equal to the saturation temperature of $101^{\circ} \mathrm{C}$ (and more than $\sim 41^{\circ} \mathrm{C}$, the temperature of water from the IRT), the maximum PCT is lower than $300^{\circ} \mathrm{C}$ in both cases and far below the threshold temperature for blistering for either $\mathrm{HEU}\left(450^{\circ} \mathrm{C}\right)$ or $\mathrm{LEU}\left(380^{\circ} \mathrm{C}\right)$ fuel. It can also be concluded, since the fuel plate with the highest power is in the upper section of the fuel element, there is no need to also do the analysis for a fuel plate in the lower section. 
Figure 13.62 shows the clad surface temperature difference where the film is located at the axial location of the hot spot for the $17^{\text {th }}$ plate with a thin film of $0.04 \mathrm{~cm}$ (discussed below) for LEU fuel. One curve is at the location where the clad meets the sideplate and one curve is at the location further away (by $0.04 \mathrm{~cm}$ in the $\mathrm{X}$ direction) where the film is assumed to end. Figure 13.11 and Figure 13.12 show the $\mathrm{X}, \mathrm{Y}$, and $\mathrm{Z}$ coordinates for HEU fuel that are close to those relevant to Figure 13.62 for LEU fuel. If the water temperature is assumed to be $41^{\circ} \mathrm{C}$ in the IRT, the surface temperature reaches the boiling temperature of $101^{\circ} \mathrm{C}$ at $\sim 25 \mathrm{~s}$ because the temperature difference becomes $\sim 60^{\circ} \mathrm{C}$ at $\mathrm{X}=3.08 \mathrm{~cm}$ at that time. (Actually it will happen earlier than $25 \mathrm{~s}$ because the film temperature will increase as it flows downward.) At that point subcooled boiling may occur on the surface. This result means that a film temperature of $101^{\circ} \mathrm{C}$ is a reasonable bound to use in determining the peak clad temperature. It also suggests that the heat transfer coefficient (the Wilke correlation for turbulent subcooled film flow) discussed in Section 13.3.2.2 needs to be reconsidered.

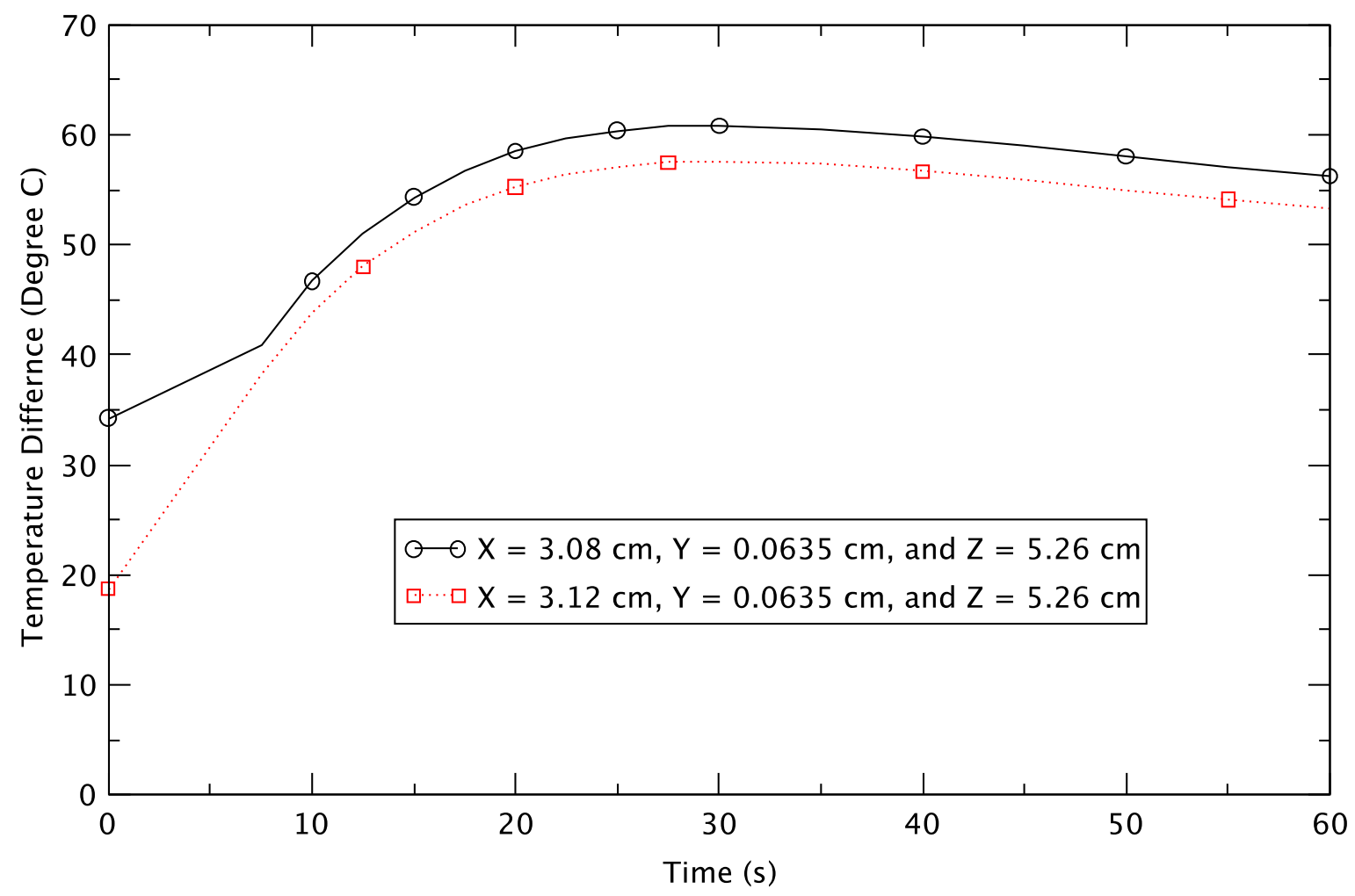

Figure 13.62 LEU Clad Temperature at Film after GBLOCA

Fujita and Ueda suggested a heat transfer coefficient for nucleate boiling in a falling film on a vertical plate (Fujita, 1978)

$$
h=0.006\left(\frac{\mu^{2}}{k^{3} \rho^{2} g}\right)^{-\frac{1}{3}}\left(\frac{4 \Gamma}{\mu}\right)^{0.4}
$$

where, $\mu, k, \rho, g$, and $\Gamma$ represent the dynamic viscosity, thermal conductivity, density, gravitational acceleration, and mass flowrate per length, respectively, of the fluid. The heat transfer coefficient with nucleate boiling for falling film in the NBSR coolant channel becomes 
$0.5617 \mathrm{~W} / \mathrm{cm}^{2}-{ }^{\circ} \mathrm{C}$ with the initial mass flowrate of $2.8 \mathrm{~kg} / \mathrm{s}$ from the IRT at the saturation temperature of $101^{\circ} \mathrm{C}$. This heat transfer coefficient for nucleate boiling is smaller than the one used in the simulation $\left(0.7041 \mathrm{~W} / \mathrm{cm}^{2}-{ }^{\circ} \mathrm{C}\right)$ by considering subcooled turbulent film flow without evaporation. This means that if nucleate boiling occurs in the falling film on the side plate, it will result in a higher PCT than the one in Figure 13.61. This would be a small effect as the change in heat transfer coefficient might only occur at the bottom of a fuel plate late in the event and most of the heat transfer is to the water on the outside of the fuel element.

In the HEATING7.3 simulations discussed above, it was assumed that the water is evenly distributed among the 18 coolant flow channels in a fuel element and the film thickness in each coolant channel is evaluated to be $0.12 \mathrm{~cm}$. Figure 13.10 shows the water impingement in the mockup of the upper portion of the fuel element, including the upper end adaptor. The distribution into coolant channels would be influenced by where the water impinges and the internal structures (the center metal bar, latch bars, and windows) that interrupt the spread of the liquid film. Based on the figure, the distribution would be skewed to the left side of the side plate. No measurements have been made of the liquid film thickness and mass flowrate in the partial mockup shown in the figure and no demonstration has been done with an entire fuel element. Hence, the film thickness in each of the 18 flow channels is estimated.

In the following it is assumed that the film mass flowrate is considerably smaller along one side of the side plate and that the nine fuel plates modeled in HEATING7.3 are located on the side away from where the water impinges. A liquid film mass flowrate of only $1 / 5(0.84 \mathrm{~g} / \mathrm{s}$ per fuel channel) of the average film flowrate is considered. The heat transfer coefficient of the film is evaluated (Baek, 2014a) to be $0.370 \mathrm{~W} / \mathrm{cm}^{2}-\mathrm{K}$ at $0.84 \mathrm{~g} / \mathrm{s}$ using Eq. (13-1). The evaluated film thickness is $0.04 \mathrm{~cm}$.

However, if a very thin film is assumed along the right side, it must be recognized that there is a significant amount of water dripping down vertically from the center bar which is parallel to the coolant channels and this water contacts some fuel plates directly. Hence, the assumption is also made that there is a film flowing with a flowrate of about $1 / 4$ of the total flow $(0.7 \mathrm{~kg} / \mathrm{s})$ which covers half of fuel plate no. 9 (the mesh region R-135 in Figure 13.13) from $0.0 \mathrm{~cm}$ to $3.2 \mathrm{~cm}$ in the $\mathrm{X}$-direction. For this liquid film due to the water dripping, the heat transfer coefficient is evaluated to be $0.494 \mathrm{~W} / \mathrm{cm}^{2}-\mathrm{K}$ using the Wilke correlation for turbulent subcooled film flow (Baek, 2014a).

Figure 13.63 shows that the effect of reducing the film thickness and adding cooling to a portion of plate no. 9 is to increase the peak clad temperature difference $\sim 10^{\circ} \mathrm{C}$. The maximum temperature difference becomes $180^{\circ} \mathrm{C}$ at $25 \mathrm{~s}$ for the HEU fuel and $196^{\circ} \mathrm{C}$ at $25 \mathrm{~s}$ for the LEU fuel. In reality, there are eight more fuel plates plus another outside plate that are present but not modeled in HEATING7.3 and they are cooled more effectively because more water is available for them than for the plates being modeled in the simulation. This fact will lead to a lower PCT than calculated and shown in Figure 13.63. Hence, again it can be concluded that the GBLOCA scenarios will not lead to any fuel damage. 


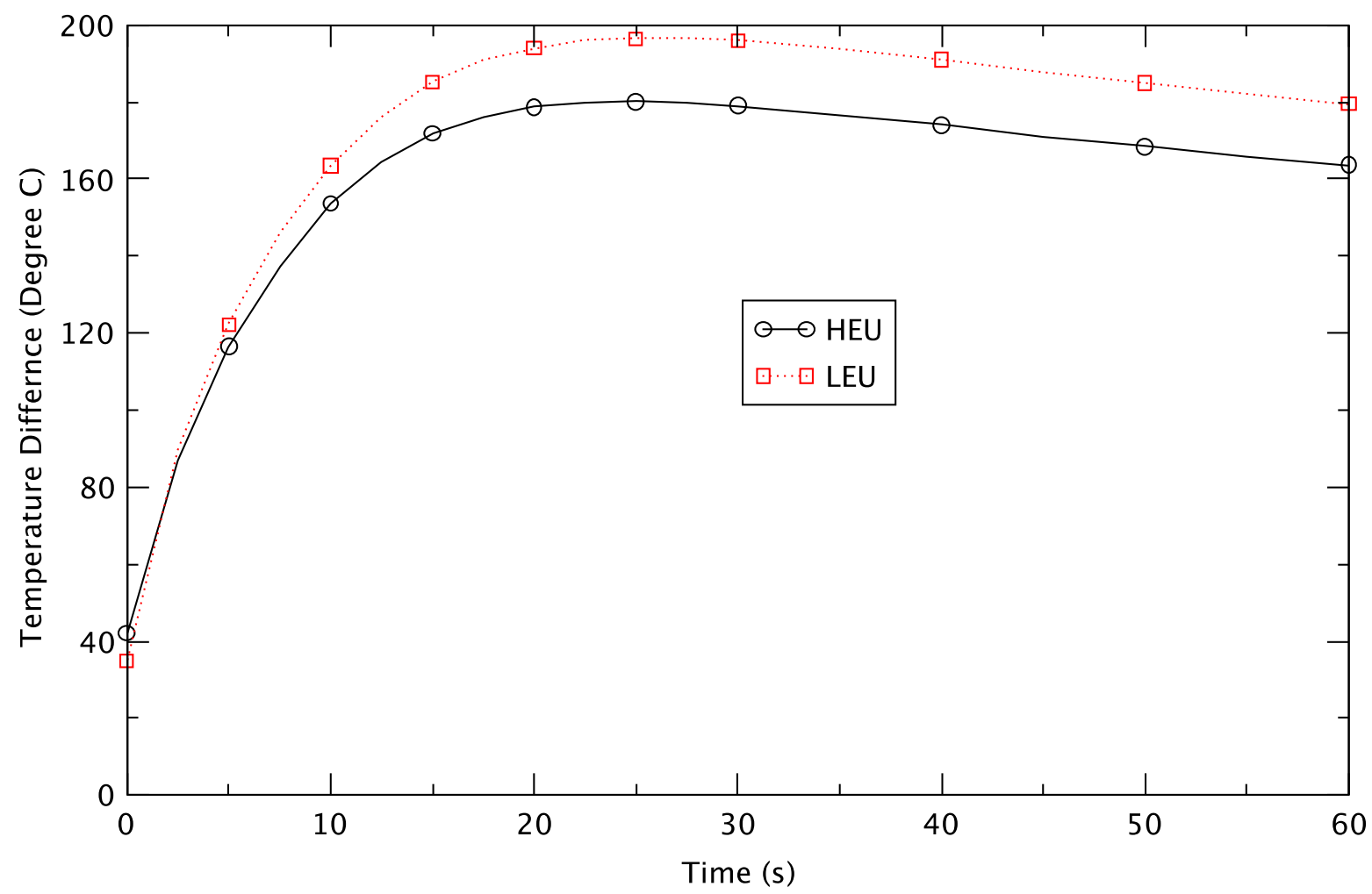

Figure 13.63 Peak Clad Temperature with Reduced Film $(0.04 \mathrm{~cm})$ on Side Plate and Partial Cooling of $9^{\text {th }}$ Plate

\subsubsection{Small Break LOCAs}

SBLOCAs at the outer and inner plenum inlet pipes will cause the NBSR to reach the conditions in which the outside of the side plates are in contact with the coolant in both the upper and lower sections of the fuel elements. The end-state will be similar to that for the GBLOCA in that some of the fuel elements will have drained (see Figure 13.59 and Figure 13.60). In the GBLOCA HEATING7.3 calculation began at the time the fuel elements were drained which was around seven seconds. Decay heat is high at this point but in the SBLOCA simulations the decay heat at the start of fuel element drainage would correspond to times on the order of $1700 \mathrm{~s}$ (see Section 13.6.2.2) after reactor trip. Hence, the SBLOCA, as with the GBLOCA, will not lead to any fuel damage.

\subsubsection{Radiological Impact of a LOCA}

It is assumed that a major pipe rupture drains the entire contents of the reactor vessel, approximately $11 \mathrm{~m}^{3}$ (3,000 gal), into the process room. The primary coolant is trapped there by a dam built for the purpose, resulting in a pool with a surface area of approximately $100 \mathrm{~m}^{2}$ $\left(1080 \mathrm{ft}^{2}\right)$. During the event, a system already in place can be started, and lost primary water 
would be pumped from the dammed area in the process room up to the $\mathrm{D}_{2} \mathrm{O}$ Emergency Cooling Tank, providing virtually unlimited cooling time. As discussed above, no fission products will be released during this accident for either HEU or LEU fuel. However, the primary water will contain tritium as a result of neutron capture in the heavy water, and the radiological consequences of this needs to be computed. The analysis is described in detail in (NIST, 2010a) and summarized herein.

For analysis purposes, the following conservative assumptions are made:

- The tritium concentration in the primary coolant is at the maximum level permitted by the Technical Specifications $(5,000 \mu \mathrm{Ci} / \mathrm{ml})$.

- After the break, emergency ventilation is immediately established.

- The process room is not isolated from the emergency ventilation system (ACV-10 is left open).

- The Emergency Ventilation System pulls the maximum design flow of $7.08 \times 10^{-3} \mathrm{~m}^{3} / \mathrm{s}(15$ $\mathrm{cfm}$ ) from this area.

- Equilibrium between the spilled heavy water at an assumed temperature of $42^{\circ} \mathrm{C}\left(108^{\circ} \mathrm{F}\right)$ and the air in the process room is established immediately.

With these assumptions, the rate of tritium release to the stack is $\mathrm{R}=\mathrm{F} \rho_{\mathrm{D} 2 \mathrm{O}} \mathrm{C}$, where:

$\mathrm{F}=$ flow rate $=7.08 \times 10^{-3} \mathrm{~m}^{3} / \mathrm{s}$,

$\rho_{\mathrm{D} 2 \mathrm{O}}=$ mass of $\mathrm{D}_{2} \mathrm{O}$ per $\mathrm{m}^{3}$ at saturated vapor pressure of $7.3 \mathrm{kPa}=55 \mathrm{~g} / \mathrm{m}^{3}$, and

$\mathrm{C}=$ tritium concentration $=5,000 \mu \mathrm{Ci} / \mathrm{ml}=4.5 \times 10^{-3} \mathrm{Ci} / \mathrm{g}$.

Equivalently, $\mathrm{R}=1.8 \times 10^{-3} \mathrm{Ci} / \mathrm{s}$.

Using this release rate, the effluent concentrations have been calculated for a variety of weather conditions, as explained in (NIST, 2010a) using three different codes with conservatisms built in. For all of the codes and weather conditions used, the effluent concentration at or beyond the $400 \mathrm{~m}$ boundary is less than $1000 \mathrm{nCi} / \mathrm{m}^{3}$. It should be noted that any release would be terminated within 24 hours, as remedial measures (pumping water into tanks, closing ACV-10, covering spilled water with plastic) would be taken immediately. Taking these time factors into account, no individual would receive as much as 0.2 mrem total dose even if they stood at the boundary throughout the release. If the entire inventory were to leak out in this manner, a person at the site boundary would receive less than 6.5 mrem or $6.5 \%$ of the permissible annual dose to the general public. This last calculation assumes average weather conditions over the year, and assumes the entire inventory in the vessel is released. Since this accident would not result in exposures approaching 10 CFR 20 limits, there are no serious off-site consequences.

The primary coolant is confined to the process room where the tritium levels are determined by the vapor pressure. For the conditions analyzed, this will result in a concentration approaching $1.25 \times 10^{-4} \mathrm{DAC}$. Access to this area is always strictly controlled. If prolonged access were required, special provisions would be implemented to control exposure to acceptable levels. 


\subsubsection{Summary for LOCA Events}

Guillotine break LOCAs and small break LOCAs were considered at three different limiting break locations: (1) the 18-inch pipe between the reactor vessel outlet and the control valve DWV-19; (2) the 14-inch pipe between the control valve DWV-1 and the outer plenum; and (3) the 10-inch pipe between the control valve DWV-2 and the inner plenum. TRACE has been run to investigate the hydrodynamic behavior, especially the water level inside and outside the fuel elements. For the break at the vessel outlet, because the primary pump valves close after a low level signal, the fuel elements do not drain. Cooling is through the boiling of coolant inside the coolant channels and this will continue indefinitely as emergency water is supplied by the inner reserve tank. Hence, no fuel damage is expected for either GBLOCAs or SBLOCAs at the vessel outlet.

For the breaks at the inlet pipe to either the inner or outer plenums, all of the fuel elements will drain but water will remain surrounding the outside of the elements for a GBLOCA.

HEATING7.3 has been used to examine the clad temperature in the fuel plates of the hottest fuel element given the coolant available (from the TRACE simulation) after the fuel elements drain during a GBLOCA. The coolant available is from the inner reserve tank and the quiescent water outside the elements. The results show that the peak clad temperature will remain well below the Safety Limit, which is the threshold for blistering, for either HEU or LEU fuel, and hence, fuel integrity can be assured.

The corresponding situation for a SBLOCA at either the inner or outer plenums is to have water surrounding the outside of the fuel elements but only some fuel elements drained. The fuel elements in the inner (outer) core are drained when the break is at the inner (outer) plenum. The reason that not all fuel elements are drained as in the GBLOCA is the operator actions that close valves that preclude the inner or outer plenum from draining. Since the fuel elements that do drain take a long time to drain, the decay heat levels are much less and since fuel integrity was shown to be maintained for the GBLOCA, it can also be assured for these SBLOCA scenarios.

The radiological consequences of a LOCA are independent of whether the fuel is HEU or LEU and only depend on the amount of tritium in the primary coolant. The resulting doses to the public or workers are within acceptable limits.

\subsection{Natural Circulation Cooling at Low Power Operation}

\subsubsection{Simulation of Event}

A RELAP5 calculation was performed to simulate operation at low power without forced-flow cooling. The Limiting Safety System Setting (LSSS) for reactor power with natural circulation cooling is that it shall not exceed $10 \mathrm{~kW}$ (NIST, 2010b). In order to demonstrate the conservatism in this Technical Specification, the analysis was done at a power level of $100 \mathrm{~kW}$. Since low power operation without forced flow is essentially a credible accident, no additional accident initiating events are assumed to occur (e.g., a reactivity initiated accident). 
The calculation starts with zero reactor power and zero primary flow in the system. The initial temperature of the primary coolant is set at $43.4^{\circ} \mathrm{C}$. The secondary flow in the primary heat exchanger is assumed to be at an arbitrarily low value of $1 \mathrm{~kg} / \mathrm{s}$. The reactor power is then ramped linearly from zero to $100 \mathrm{~kW}$ in 60 seconds. From that point on the reactor power is maintained constant till the end of the simulation at $500 \mathrm{~s}$.

Results for coolant velocities in the LEU core at EOC show quasi-steady state natural circulation flow from about $200 \mathrm{~s}$ in all cases as shown in Figure 13.64. The figure shows the coolant velocities at the inlets to the channels that contain the hottest node in the inner and outer core. As shown in the figure, however, the velocities are very small and this is due to the fact that there is no significant hydrostatic head because the elevation of the heat sink (the heat exchanger) is lower than that of the heat source (the reactor core). The small velocity seems to be developed as the density of the coolant decreases due to heat transfer in the core and it causes a small difference in the hydrostatic head between the core and the heat exchanger. The figure shows that the core liquid velocity starts increasing as the power is ramped linearly from zero to $100 \mathrm{~kW}$ in 60 seconds and then decreases after $\sim 160 \mathrm{~s}$.

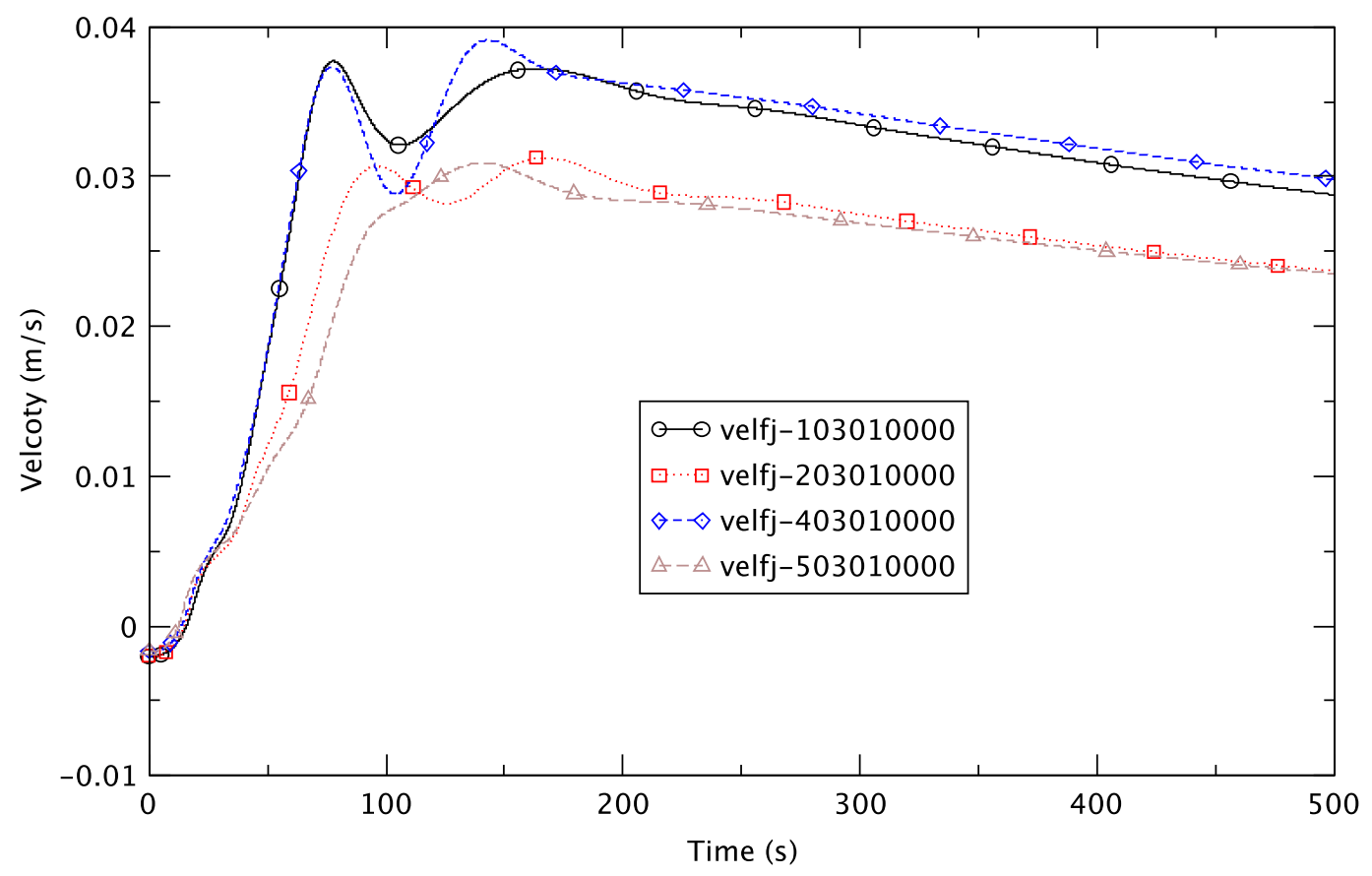

Figure 13.64 Natural Circulation Coolant Velocities inside Core at Low Power

\subsubsection{Limiting Parameters}

Figure 13.65 shows clad temperatures from zero to $500 \mathrm{~s}$ in the fuel element nodes corresponding to the highest PCT. Heat structure number 5000 in the legend indicates the fuel channel containing the hottest fuel cell (highest power cell) in the core with a mid-plane gap shared with 16 average fuel channels. The general behavior of the clad temperature with LEU fuel is similar to that with HEU fuel. The clad temperature starts increasing from time zero due to the increase of reactor power according to the event scenario. When the flow velocity 
increases from zero at time zero and colder coolant is flowing into the channels from the lower plenums, the rate of clad temperature increase reduces and a peak occurs between 60 and $70 \mathrm{~s}$. Then clad temperature starts decreasing slightly as the reactor power stays at $100 \mathrm{~kW}$ beyond 60 $\mathrm{s}$ and coolant flow into the channel shows an increase in velocity. The clad temperature continues increasing very slowly after $200 \mathrm{~s}$ and this is caused by the increase in coolant temperature owing to continuous heat transfer from fuel to coolant as the coolant stays in the heated channel for a long time because of its very small velocity. As shown in the figure, however, the temperature increase is almost negligible and there is ample time for the operators to take necessary actions to protect the reactor (e.g., reactor trip) before the clad temperature increases significantly.

The peak clad temperatures vary from $57^{\circ} \mathrm{C}$ to $64^{\circ} \mathrm{C}$ corresponding to less than a $20^{\circ} \mathrm{C}$ increase. Needless to say, no fuel plate damage is expected.

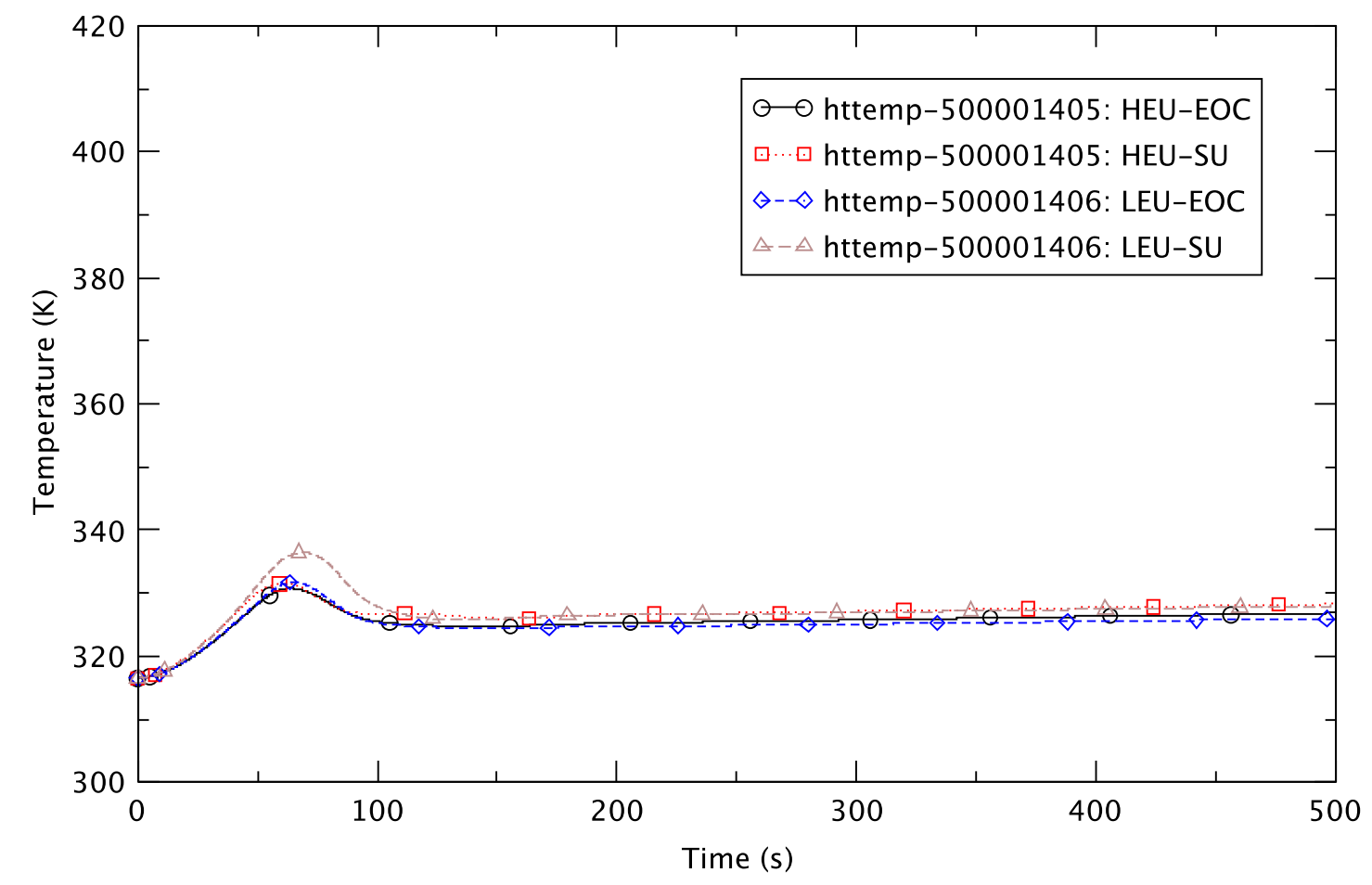

Figure 13.65 Clad Temperature for Natural Circulation Cooling at Low Power Operation

Critical-heat-flux ratios are shown in Figure 13.66. The hydraulic nodes in the figure are the ones where minimum CHFR takes place. When the CHFR is larger than 1,000, it is plotted as 1,000. The CHFR starts decreasing from time zero as the coolant begins flowing through the core and then remains higher than 28 after $60 \mathrm{~s}$ until the end of the simulation (500 s) in all cases. This means that fuel element damage is precluded in the HEU and LEU cores with a probability greater than $99.9 \%$.

Minimum OFIR is not evaluated for this natural circulation cooling event; if forced flow is not available in the core, a system is not subject to excursive instability. 


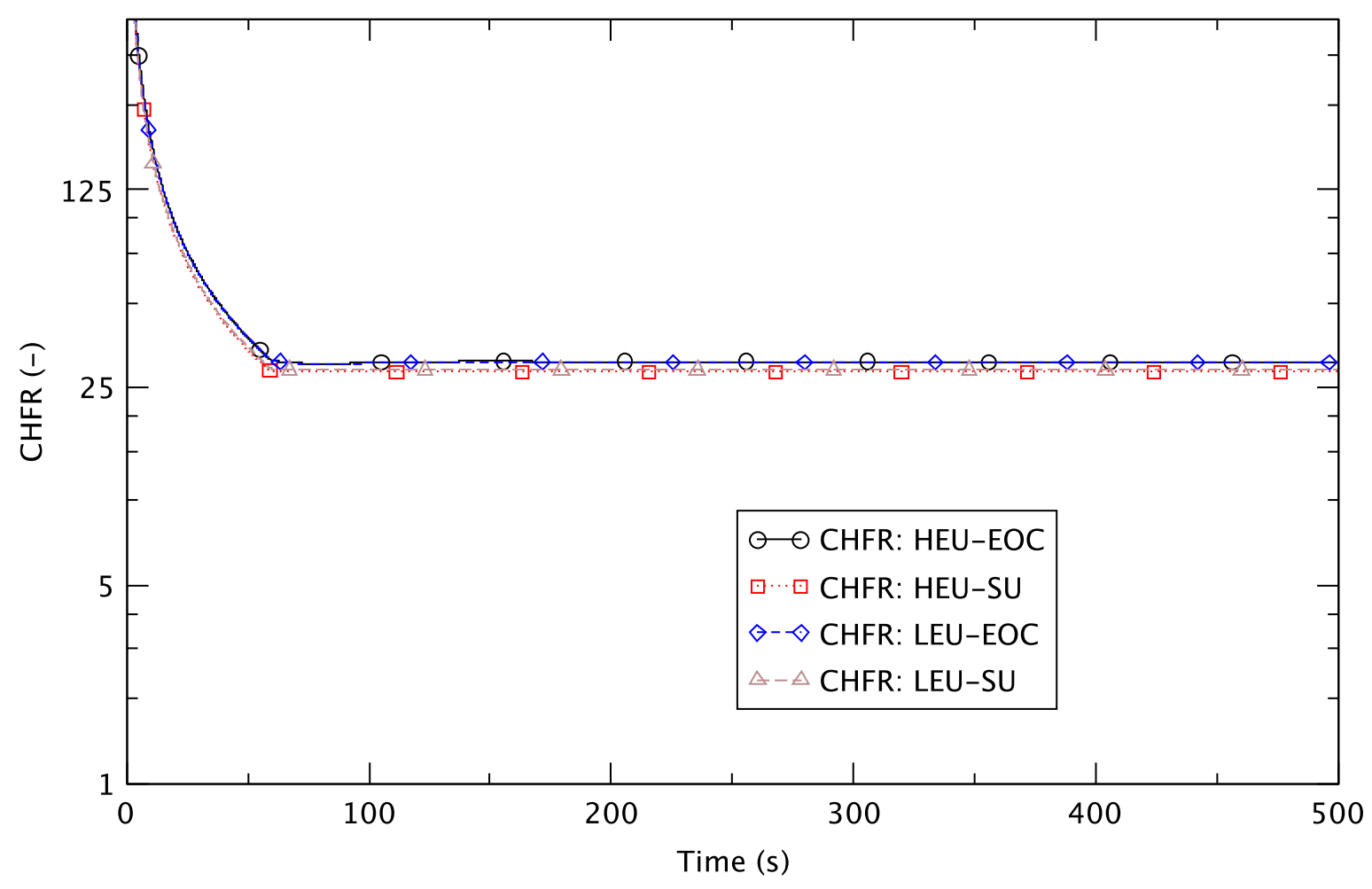

Figure 13.66 CHFR for Natural Circulation Cooling at Low Power

\subsubsection{Natural Circulation Cooling Under Different Conditions}

In the scenario discussed immediately above natural circulation cooling was assumed to occur in spite of normal procedures which would have the pumps operational. The RELAP5 analysis shows that even though significant natural circulation flow is not established in the primary system, the safety of the reactor core is maintained (witness peak clad temperature and CHFR) because of the large coolant inventory in the reactor vessel.

Fuel integrity in this stagnant condition can also be assured by the approach in Appendix E of (Cheng, 2004). Cheng et al. evaluated "flooding-limited critical power" for a heated channel with a blocked inlet by assuming that a critical power for the blocked channel is reached when the steam flow rate exceeds that of the liquid flow and this deficit in liquid flow would lead to the eventual dryout of the channel. The evaluated flooding-limited core critical power is 1.2 MW when the NBSR flow channel is filled with saturated liquid. This is consistent with the results which showed that dryout was precluded when the power was $100 \mathrm{~kW}$. Furthermore, it is noted that for a $20 \mathrm{MW}$ core, the decay power drops below $1.2 \mathrm{MW}$ in less than 10 seconds after reactor trip. Therefore, power transferred to the coolant channels in the NBSR core would be below the flooding-limited critical power shortly after reactor shutdown. Even without any forced flow, decay power can be removed from the NBSR core simply by boiling, as long as the core is covered with coolant. 


\subsection{Maximum Hypothetical Accident}

The maximum hypothetical accident (MHA) in the current SAR is postulated as due to a complete blockage of flow to one element, leading to complete melting of 34 fuel plates. Such blockage is very unlikely, (e.g., there is a 0.25 inch mesh screen upstream of the fuel element) but rather than try to identify the origin of the blockage, it is simply assumed. This event is analyzed for both the HEU and the LEU cores.

The event would proceed by first having boiling in the coolant channels. This results in a decrease in reactivity (see Section 4.5.2.5) and can also cause fluctuations in power, which are assumed to not cause a reactor trip. Therefore, the fuel element can heat up to the point at which the fuel plates melt releasing fission products to the water that is present outside of that one fuel element. At this point, the reactor would shut down since, as fuel plates melt and drop out of the core region, reactivity would decrease significantly. In addition, within two seconds, the sweep gas will reach the stack with gaseous fission products and initiate an immediate reactor trip.

The melting of fuel occurs far below $1000^{\circ} \mathrm{C}$, which is the temperature at which metal-water reactions need to be considered. If the fuel remains in a high flux region until reactor trip, the temperature could reach or exceed $1000^{\circ} \mathrm{C}$. However, as mentioned above, the decrease in reactivity due to slumping of the melt and/or reactor trip stops the heating rate. Hence, any increase in temperature will be followed by a cooling trend and any metal-water reaction would be of minor significance.

The assumed scenario for the MHA and the analysis of the consequences, in terms of radiation dose to the workers at the NBSR and the general public, are given in detail in (NIST, 2010a) and further explained in (NRC, 2009) for the existing HEU reactor. The analysis of the consequences with LEU fuel was done only slightly differently and with updated information on fission product concentrations. The HEU analysis was repeated with the same methodology and updated information on fission product concentrations. The new HEU results shown below are consistent with the results in the existing SAR.

Since the MHA does not involve the release of primary coolant, the important fission products are the noble gases and iodine (which may remain volatile at the temperatures that would be reached). Table 13.24 shows, for each fuel type, the isotopic iodine and noble gas fission product inventory in a half-element with maximum burnup after eight cycles. These bounding values (rather than say a core average) are used in the analyses for the full element. The values were generated with the CINDER code (Cowell, 2008) which calculates isotopic concentrations given a power density and fuel material. These isotopes are the ones that would contribute to the doses to individuals. The table also shows the change from an HEU to an LEU core. The three largest changes in activity are in I isotopes that contribute less than $0.1 \%$ to the total fission product activity. Hence, the changes are not significant relative to the safety margin that is available.

All of the noble gases are insoluble in water and quickly collect in the helium space at the top of the reactor vessel (with volume of $\sim 0.7 \mathrm{~m}^{3}$ ). The analysis done for the current SAR (NIST, 2010a) indicates that only $3 \%$ of the iodine in the form of $I_{2}$ makes its way to the helium space. 
The assumption is made that this is instantaneous although it is known that the contribution from radiolysis of CsI to create $\mathrm{I}_{2}$ takes place over a period of time. Furthermore, the fact that $\mathrm{I}_{2}$ is soluble in water up to $0.3 \mathrm{~g} /$ liter at $298 \mathrm{~K}$, and the fully diluted concentration is more than an order of magnitude smaller, is not taken into account. The partial pressure of $\mathrm{I}_{2}$ in the cover gas is less than $1.0 \times 10^{-9} \mathrm{~atm}$ and is assumed immediately available in the helium space.

Table 13.21 Activity of I, Kr, and Xe Isotopes in Half-Element

\begin{tabular}{|c|c|c|c|}
\hline Nuclide & HEU Fuel (Ci) & LEU Fuel (Ci) & $\begin{array}{c}\text { Change from } \\
\text { HEU, \% }\end{array}$ \\
\hline $\mathrm{I}-130$ & $5.05 \mathrm{E}+01$ & $7.24 \mathrm{E}+01$ & 30 \\
\hline I-130* & $3.75 \mathrm{E}+01$ & $5.35 \mathrm{E}+01$ & 30 \\
\hline I-131 & $8.30 \mathrm{E}+03$ & $8.68 \mathrm{E}+03$ & 4 \\
\hline $\mathrm{I}-132$ & $1.46 \mathrm{E}+04$ & $1.52 \mathrm{E}+04$ & 4 \\
\hline I-132* & $3.42 \mathrm{E}+01$ & $6.21 \mathrm{E}+01$ & 45 \\
\hline $\mathrm{I}-133$ & $2.36 \mathrm{E}+04$ & $2.44 \mathrm{E}+04$ & 3 \\
\hline I-133* & $1.54 \mathrm{E}+03$ & $1.67 \mathrm{E}+03$ & 8 \\
\hline $\mathrm{I}-134$ & $2.80 \mathrm{E}+04$ & $2.88 \mathrm{E}+04$ & 3 \\
\hline I-134* & $1.31 \mathrm{E}+03$ & $1.53 \mathrm{E}+03$ & 14 \\
\hline $\mathrm{I}-135$ & $2.25 \mathrm{E}+04$ & $2.32 \mathrm{E}+04$ & 3 \\
\hline Kr-83* & $1.94 \mathrm{E}+03$ & $1.93 \mathrm{E}+03$ & 0 \\
\hline Kr-85 & $2.42 \mathrm{E}+01$ & $3.12 \mathrm{E}+01$ & 22 \\
\hline $\mathrm{Kr}-85^{*}$ & $4.29 \mathrm{E}+03$ & $4.27 \mathrm{E}+03$ & -1 \\
\hline Kr-87 & $9.31 E+03$ & $9.20 \mathrm{E}+03$ & -1 \\
\hline Kr-88 & $1.25 \mathrm{E}+04$ & $1.23 \mathrm{E}+04$ & -1 \\
\hline Xe-131* & $2.27 \mathrm{E}+01$ & $2.42 \mathrm{E}+01$ & 6 \\
\hline Xe-133 & $1.82 \mathrm{E}+04$ & $1.88 \mathrm{E}+04$ & 3 \\
\hline Xe-133* & $4.73 \mathrm{E}+02$ & $4.93 \mathrm{E}+02$ & 4 \\
\hline Xe-134* & $1.79 \mathrm{E}+02$ & $2.24 \mathrm{E}+02$ & 20 \\
\hline Xe-135 & $1.82 \mathrm{E}+03$ & $1.82 \mathrm{E}+03$ & 0 \\
\hline Xe-135* & $4.17 \mathrm{E}+03$ & $4.43 E+03$ & 6 \\
\hline Xe-137 & $2.18 \mathrm{E}+04$ & $2.25 \mathrm{E}+04$ & 3 \\
\hline Xe-138 & $2.25 \mathrm{E}+04$ & $2.29 \mathrm{E}+04$ & 2 \\
\hline *Isomer & & & \\
\hline
\end{tabular}

The halogens and $\mathrm{I}_{2}$ will be released to the confinement building along with helium at a rate characteristic of the tightness of the primary system under emergency ventilation conditions (no normal building exhaust). These (measured) rates to the different areas within the confinement building are shown in Table 13.25 along with the rate of removal due to the emergency ventilation system which has been activated. The rates are assumed to be constant with time.

By procedure, the operators would evacuate the building of all non-essential personnel immediately upon seeing the high readings of stack monitor or fission product monitor. They would then proceed to place the reactor in a safe condition, and leave themselves. For purposes of dose estimation the complete evacuation is assumed to take 10 minutes although it could be done more quickly. The worker total effective dose equivalent (TEDE) is determined by 
converting the concentration of radioactivity (conservatively assumed to be uniform throughout the particular space), to dose taking into account immersion and inhalation. The analysis utilizes the radiation dosimetry Dose Conversion Factors from the Hotspot computer program (Homann, 2014). The results are given in Table 13.26. The annual occupational dose limit for workers is 5 rem (10 CFR 20.1201), which is considerably higher than the expected doses shown in the table.

Table 13.22 Leak Rates to Confinement and Release Rates to Stack

\begin{tabular}{|c|c|c|c|}
\hline Confinement Area & Volume $\left(\mathbf{m}^{3}\right)$ & $\begin{array}{c}\text { Leak Rate Into Floor } \\
\left(\mathrm{m}^{3} / \mathrm{s}\right)\end{array}$ & Removal Rate $\left(\mathrm{m}^{3} / \mathrm{s}\right)$ \\
\hline $\begin{array}{l}\text { Experimental Floor } \\
(\mathrm{C}-100)\end{array}$ & $4.5 \times 10^{3}$ & $1.2 \times 10^{-6}$ & $9.4 \times 10^{-3}$ \\
\hline $\begin{array}{l}\text { Operations Level } \\
(\mathrm{C}-200)\end{array}$ & $8.3 \times 10^{3}$ & $8.1 \times 10^{-6}$ & $1.9 \times 10^{-2}$ \\
\hline $\begin{array}{l}\text { Process Room } \\
\text { (Basement) }\end{array}$ & $2.0 \times 10^{3}$ & $2.3 \times 10^{-6}$ & $7.1 \times 10^{-3}$ \\
\hline
\end{tabular}

Table 13.23 Ten-Minute Dose (TEDE) to NBSR Staff after MHA

\begin{tabular}{|l|c|c|}
\hline \multicolumn{1}{|c|}{ Location } & $\begin{array}{c}\text { HEU Fuel: } \\
\text { Dose, rem }\end{array}$ & $\begin{array}{c}\text { LEU Fuel: } \\
\text { Dose, rem }\end{array}$ \\
\hline C-100 & 0.3 & 0.3 \\
\hline C-200 & 2.1 & 2.1 \\
\hline
\end{tabular}

The doses to the public are obtained using Hotspot (Homann, 2014) which calculates the atmospheric dispersion of a plume using a standard model considered to be conservative. The model includes: low wind speed, highly stable atmospheric conditions, and no change in wind direction. The conversion to dose at a particular location is done in Hotspot using the dosimetry methods of (ICRU. 1993) and (Eckerman, 2010). The assumption is made that for the two hour dose, the concentration of material is what is obtained at the end of two hours (i.e., the maximum during that time period) taking into account an average one-hour decay time. The instantaneous release for the $I_{2}$ is reduced by the factor of 0.999 to take into account the efficiency of the filters in the ventilation system (NIST, 2010a). Similarly, for the release used in Hotspot for the period 2-24 hours, the amount of instantaneously released material is that accumulated over the 22-hour period taking into account an average 11 hour decay. The approach for the 1-30 day dose is similar. In each case the material is released at the top of the $30 \mathrm{~m}$ high stack. Of the original inventory, more than $80 \%$ of the gaseous material will leak from the building within 30 days. For this analysis, 3\% of the iodine isotopes are assumed to be released into the reactor building, before the filters, and no credit is given for the partial pressure that would help keep the iodine isotopes in solution.

For an individual at the boundary of the NBSR 400 m exclusion zone, the results are given in Table 13.27 for both sources of exposure; namely the halogens and iodine. It is clear that the halogens are the more important component because the iodine has been removed by the filters. For research reactors the total dose to a member of the public that the NRC staff has generally found acceptable is less than 100 mrem (10 CFR 20.1301). The results given in the table in 
mrem show a very large margin to the limit. They also show that there is no need to calculate the total dose at any other location or for longer periods.

Table 13.24 Dose (TEDE) to an Individual at $400 \mathrm{~m}$ Exclusion Zone after MHA

\begin{tabular}{|c|c|c|c|c|c|c|c|c|}
\hline & \multicolumn{4}{|c|}{ HEU Fuel: Dose, mrem } & \multicolumn{4}{c|}{ LEU Fuel: Dose, mrem } \\
\hline & $\mathbf{0 - 2}$ hr & $\mathbf{2 - 2 4} \mathbf{~ h r}$ & $\begin{array}{c}\mathbf{1 - 3 0} \\
\text { days }\end{array}$ & Total & $\mathbf{0 - 2}$ hr & $\mathbf{2 - 2 4}$ hr & $\begin{array}{c}\mathbf{1 - 3 0} \\
\text { days }\end{array}$ & Total \\
\hline $\begin{array}{c}\text { Noble } \\
\text { Gases: }\end{array}$ & 0.4 & 2.7 & 2.8 & 5.9 & 0.4 & 2.7 & 3.0 & 6.1 \\
\hline Iodine: & $\sim 0.0$ & $\sim 0.0$ & 0.1 & $\sim 0.0$ & $\sim 0.0$ & $\sim 0.0$ & 0.1 & $\sim 0.0$ \\
\hline
\end{tabular}

\subsection{Mishandling, Malfunction, or Misloading of Fuel}

The fuel for the NBSR is subject to stringent quality control to ensure that there will be no "leaky" elements that could release fission products into the primary cooling system. In addition, if any element were to leak, the fission products would be detected immediately, and the faulty element would be identified and removed. This has only happened once in the operating history of the NBSR, and there were no releases to the atmosphere. The releases to the primary coolant were small, and the normal water treatment system quickly removed all traces of activity once the element was removed.

Four separate scenarios involving mishandling of fuel were extensively analyzed in (NBS, 1980) and shown to present no significant risks. These accidents were: a refueling accident involving a dropped element; dropping of a fuel element into the storage pool; dropping of a heavy object onto the fuel rack in the storage pool; and dropping of the spent fuel cask during a shipping operation. There has been no change in any of these accidents for the LEU-fuel and the previous analysis applies also to the LEU fuel.

The fuel misloading accident is analyzed assuming a fresh fuel element (FE) was inserted into an incorrect location. The power level in the misloaded element is analyzed to determine whether thermal limits would be exceeded. To perform this analysis, one fresh fuel element was placed in each position in the core and the fuel element that should have been placed in that location is placed in the A4 position (one of the four positions for fresh fuel elements). The radial power distributions were calculated at SU when fresh fuel is available and power peaking has its largest value.

The location and relative power of the half-element with maximum power are given in Table 13.28. The maximum relative power is always in the lower half-element. The first column is the location in which the fresh fuel element was placed, the second and fourth columns show the location which exhibited the highest relative power and the third and fifth columns show the relative power (unity represents the average half-element power, $20 \mathrm{MW}$ / 60 half-elements) in the location.

For both the HEU and LEU cores, the highest powers occur when the fresh fuel element is placed in the F3 or H3 locations. Figure 13.67 shows the radial power distribution for the fresh 
HEU fuel element placed in the F3 position and Figure 13.68 shows the radial power distribution for the fresh LEU fuel element placed in the H3 position.

The consequences of the worst misloaded fuel element in terms of CHFR and OFIR can be inferred by noting that for normal steady state conditions Table 4.22 shows that the minimum CHFR is $\sim 4.0$ for HEU fuel and 4.1 for LEU fuel. Values for the minimum OFIR are higher. A steady state power distribution with peaking factors increased (using the half-element peaking factors for HEU in Table 13.28 to approximate local peaking factors) by the factor 1.93/1.28 (an increase of 51\%) for HEU fuel or 1.83/1.35 (an increase of 36\%) for LEU fuel, would reduce MCHFR (and MOFIR) by no more than these amount. Hence, even with a misloaded fuel element, no thermal-hydraulic limits would be exceeded.

Table 13.25 Maximum Relative Power (RP) for a Misloaded FE

\begin{tabular}{|c|c|c|c|c|}
\hline & \multicolumn{2}{|l|}{ HEU } & \multicolumn{2}{|l|}{ LEU } \\
\hline & Max FE & Max RP & Max FE & Max RP \\
\hline Normal: & F3 & 1.28 & H3 & 1.35 \\
\hline \multicolumn{5}{|c|}{ Swap fresh FE with: } \\
\hline F1 & $\mathrm{I} 2$ & 1.29 & F3 & 1.35 \\
\hline B3 & B3 & 1.39 & H3 & 1.35 \\
\hline C6 & C6 & 1.34 & H3 & 1.34 \\
\hline E2 & E2 & 1.66 & E2 & 1.54 \\
\hline E6 & E6 & 1.56 & E6 & 1.48 \\
\hline E4 & E4 & 1.91 & E4 & 1.81 \\
\hline D7 & H3 & 1.27 & H3 & 1.35 \\
\hline $\mathrm{C} 2$ & $\mathrm{C} 2$ & 1.37 & F3 & 1.35 \\
\hline B5 & B5 & 1.43 & B5 & 1.36 \\
\hline F7 & F7 & 1.30 & H3 & 1.32 \\
\hline C4 & C4 & 1.68 & C4 & 1.56 \\
\hline F3 & F3 & 1.93 & F3 & 1.83 \\
\hline F5 & F5 & 1.87 & F5 & 1.80 \\
\hline H1 & $\mathrm{I} 2$ & 1.30 & H3 & 1.35 \\
\hline L3 & L3 & 1.38 & F3 & 1.36 \\
\hline K6 & K6 & 1.34 & H3 & 1.35 \\
\hline $\mathrm{I} 2$ & $\mathrm{I} 2$ & 1.66 & $\mathrm{I} 2$ & 1.54 \\
\hline I6 & I6 & 1.55 & I6 & 1.48 \\
\hline I4 & I4 & 1.89 & I4 & 1.79 \\
\hline J7 & H3 & 1.27 & F3 & 1.34 \\
\hline K2 & K2 & 1.39 & H3 & 1.35 \\
\hline L5 & L5 & 1.38 & H3 & 1.35 \\
\hline H7 & H7 & 1.33 & F3 & 1.33 \\
\hline K4 & K4 & 1.62 & K4 & 1.53 \\
\hline H3 & H3 & 1.92 & H3 & 1.83 \\
\hline H5 & H5 & 1.87 & H5 & 1.79 \\
\hline
\end{tabular}




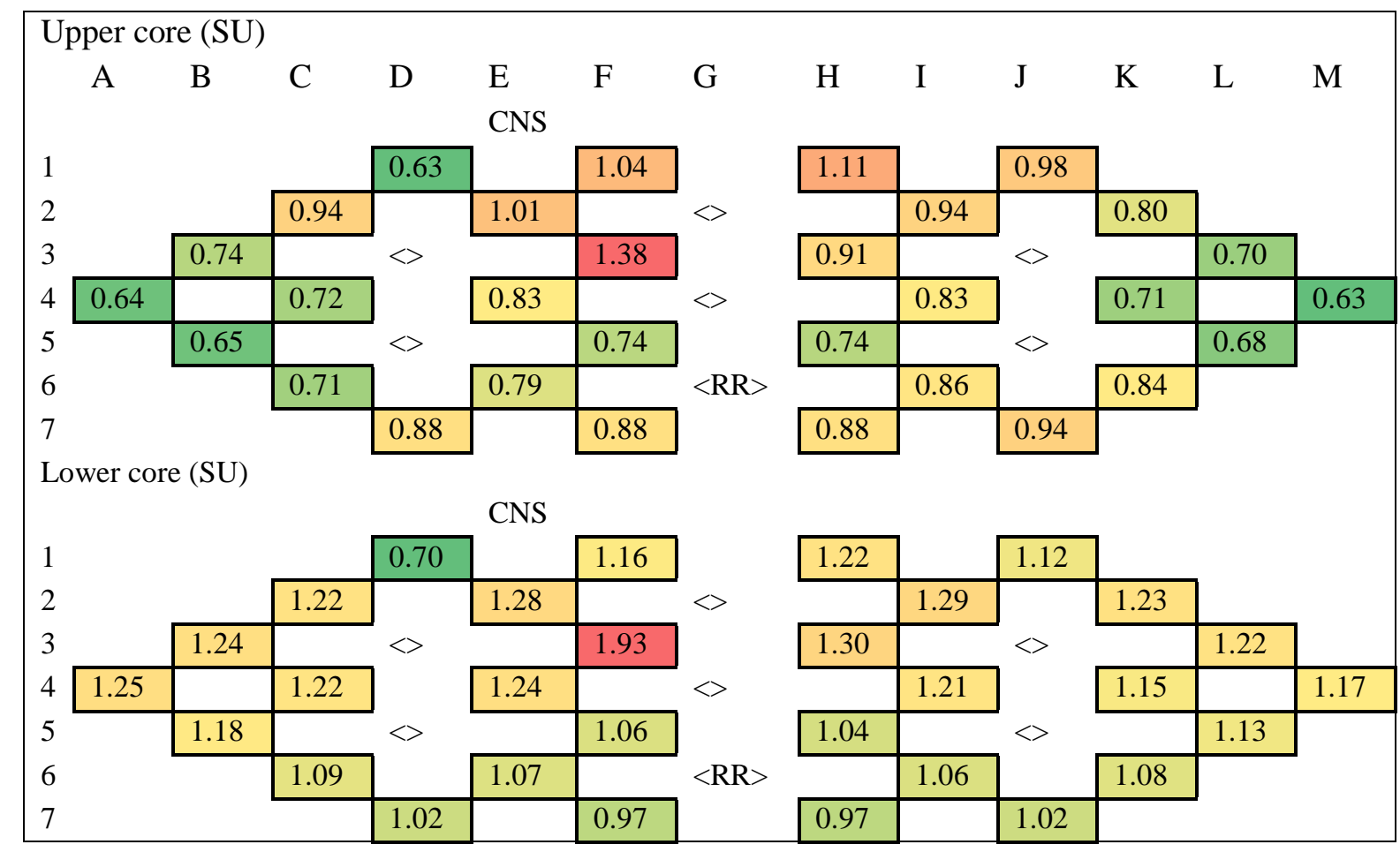

Figure 13.67 Radial Power Distribution with Fresh HEU FE in the F3 Position

\begin{tabular}{|c|c|c|c|c|c|c|c|c|c|c|c|c|c|}
\hline \multicolumn{14}{|c|}{ Upper core (SU) } \\
\hline & A & B & C & D & $\begin{array}{l}\mathrm{E} \\
\mathrm{CNS}\end{array}$ & $\mathrm{F}$ & G & $\mathrm{H}$ & I & $\mathrm{J}$ & $\mathrm{K}$ & $\mathrm{L}$ & $\mathrm{M}$ \\
\hline 1 & & & & 0.90 & & 0.99 & & 1.02 & & 0.66 & & & \\
\hline 2 & & & 0.92 & & 1.01 & & $<>$ & & 0.93 & & 0.76 & & \\
\hline 3 & & 0.72 & & $<>$ & & 0.98 & & 1.30 & & $<>$ & & 0.68 & \\
\hline 4 & 0.60 & & 0.73 & & 0.91 & & $<>$ & & 0.90 & & 0.73 & & 0.60 \\
\hline 5 & & 0.65 & & $<>$ & & 0.85 & & 0.85 & & $<>$ & & 0.68 & \\
\hline 6 & & & 0.71 & & 0.82 & & $<\mathrm{RR}>$ & & 0.89 & & 0.85 & & \\
\hline 7 & & & & 0.87 & & 0.91 & & 0.92 & & 0.93 & & & \\
\hline \multicolumn{14}{|c|}{ Lower core (SU) } \\
\hline & & & & & CNS & & & & & & & & \\
\hline 1 & & & & 0.98 & & 1.08 & & 1.14 & & 0.76 & & & \\
\hline 2 & & & 1.17 & & 1.27 & & $<>$ & & 1.27 & & 1.17 & & \\
\hline 3 & & 1.18 & & $<>$ & & 1.37 & & 1.83 & & $<>$ & & 1.17 & \\
\hline 4 & 1.14 & & 1.20 & & 1.32 & & $<>$ & & 1.34 & & 1.18 & & 1.13 \\
\hline 5 & & 1.15 & & $<>$ & & 1.18 & & 1.18 & & $<>$ & & 1.13 & \\
\hline 6 & & & 1.08 & & 1.12 & & $<\mathrm{RR}>$ & & 1.13 & & 1.09 & & \\
\hline 7 & & & & 1.00 & & 0.99 & & 1.00 & & 0.99 & & & \\
\hline
\end{tabular}

Figure 13.68 Radial Power Distribution with Fresh LEU FE in the H3 Position 


\subsection{Experiment Malfunction}

All experiments associated with the NBSR are carefully reviewed for hazards prior to being approved for construction and installation. Beam experiments external to the biological shield present a very small potential hazard to the reactor. Nevertheless, an experimental proposal must be prepared or amended before they can be installed or significantly modified. All proposals are reviewed in accordance with the Technical Specifications and Administrative Procedures. The Safety Evaluation Committee makes a recommendation to the Director of the NCNR, who has responsibility for final approval of any experiment. This includes all experiments involving explosive or corrosive materials. Quantities of explosives to be irradiated in the core are strictly limited to amounts for which any explosion can be totally contained within the experiment packaging.

The only scenario of concern is for an experiment internal to the reactor biological shield. Technical Specification 3.8, Experiments ((NIST, 2010b) covers allowable reactivity limits and materials. Thus, except for the reactivity issues addressed in Section 13.4.3, experiment malfunctions are not a credible threat to the core. Note too that this accident will also bound flooding of beam tubes.

The conversion of the fuel does not change the analysis of these events.

\subsection{Loss of Normal Power}

The bounding scenario of a loss of normal power is due to the resulting loss of flow because of the trip of the coolant pumps. This accident is addressed in Section 13.5.1

\subsection{External Events}

Damage to the core from external events, such as tornados, hurricanes, floods and earthquakes is not considered credible as a result of design features, administrative controls and the seismological and climatological characteristics of the site. Details are provided in (NIST, 2010a).

The NBSR is located in a zone of low seismic activity. The building and reactor systems have been analyzed and shown to be able to withstand the stresses generated by a $0.1 \mathrm{~g}$ earthquake loading (NBS, 1980). The probability of an earthquake resulting in accelerations larger than $0.08 \mathrm{~g}$ is less than $2 \%$ in 50 years.

The confinement building was designed to withstand the forces generated by winds of up to 100 mph, substantially faster than the largest wind ever recorded at Ronald Reagan Washington National Airport (76 mph during passage of Hurricane Hazel, October 1954).

The computed recurrence interval for a tornado at the NIST site is approximately 2,000 years. The NBSR is immediately shut down if NIST Security notifies the control room that a tornado or other major weather hazard is approaching the site. This action is specified in the Emergency 
Instructions Manual. Further, if a tornado is sighted on the NIST site, a Notification of Unusual Event is declared.

During unsettled weather conditions, control room personnel monitor all weather alerts. Therefore, none of these scenarios pose a significant threat to the reactor. Furthermore, it is difficult to envision any accident resulting from such a scenario that would have consequences exceeding those discussed in previous sections.

\subsection{Summary and Conclusions}

The analyses given in this chapter show that no credible reactor accident will lead to fuel damage. These analyses support the bases for the Technical Specifications as do the thermalhydraulic limits specified in Chapter 4. The Chapter 13 results show that the LSSS determined for routine operation are adequate to provide assurance that the Safety Limit will not be exceeded during any credible accident.

The MHA are those events that are not considered credible but would lead to fuel damage if they occurred. Nevertheless, the resultant consequences are well within the limits of 10 CFR 100, which applies to Test Reactors (and below 10 CFR 20 limits for workers). Therefore, operation of the NBSR will present no undue hazard to any member of the general public or to the NCNR staff.

Consideration has been given to external events, equipment malfunction, loss-of-normal power, and fuel mishandling misloading, or malfunction. These events do not challenge any safety criteria.

From the analysis results it can be concluded that the NBSR reactor with either HEU or LEU fuel is safe under postulated accident conditions and satisfies applicable thermal criteria to assure fuel element integrity.

\subsection{References}

ANS, “Decay Heat Power in Light Water Reactors,” American National Standard, ANSI/ANS5.1-1994, American Nuclear Society, August 1994

Baek, J.S., Cheng, L.-Y. and Diamond, D.J., “Analysis of Loss-of-Coolant Accidents in the NBSR,” BNL-105287-2014-IR, Brookhaven National Laboratory, Upton, N.Y., May 23, 2014a.

Baek, J.S., Cheng, L.-Y., Hanson, A.L., Cuadra, A., Brown, N.R., and Diamond, D.J., Accident Analysis for the NIST Research Reactor Before and After Fuel Conversion - Revision 2,” BNL98524-2014-IR-R2, Brookhaven National Laboratory, Upton, NY, July 22, 2014b.

Brown, N.R., Hanson, A.L., and Diamond, D.J., "Local Burn-up Effects in the NBSR Fuel Elements, BNL-99145-2013-IR, Brookhaven National Laboratory, Upton, N.Y., January 23, 2013. 
Brown, N.R. and Cuadra, A., “Calculation of Short-Time Decay Power in the NBSR,” BNL memorandum, Brookhaven National Laboratory, January 3, 2014 a.

Brown, N.R., Baek, J.S., Hanson, A.L., Cuadra, A., Cheng, L.-Y, and Diamond, D.J., “Irradiation Experiment Conceptual Design Parameters for NBSR Fuel Conversion,” BNL99897-2014-IR-R2, Brookhaven National Laboratory, Upton, N.Y., April 30, 2014b.

Cheng, L-Y. et al., "Physics and Safety Analysis for the NIST Research Reactor,” BNL-NIST0803, Rev. 1, Brookhaven National Laboratory, Upton, NY, April 2004.

Eckerman, K.F. and Leggett, R.W., "DCFPAK 2.2: Updated Dose and Risk Coefficient Database for Rapid Assessment of Radiation Doses, personal communication to Hotspot, 2010 (based on "DCFPAK: Dose Coefficient Data File Package for Sandia National Laboratory, ORNL/TM-13347, Oak Ridge National Laboratory, July 31, 1996).

Fujita, T. and Ueda, T., "Heat Transfer to Falling Liquid Films and Film Breakdown - II: Saturated Liquid Films with Nucleate Boiling,” International Journal of Heat and Mass Transfer, Vol. 21, pp. 109-118, 1978.

Hanson, A. and Diamond, D., "Energy Deposition in the NBSR,” BNL internal memo, Brookhaven National Laboratory, Upton, NY, February 2, 2005.

Homann, S.G. and Aluzzi, F., "HotSpot - Health Physics Codes, Version 3.0, User’s Guide," LLNL-SM-636474, Lawrence Livermore National Laboratory, August 27, 2014.

ICRU, “Quantities and Units in Radiation Protection Dosimetry,” ICRU Report 51, International Commission on Radiation Units and Measurements, 1993.

Incropera, F.P. and DeWitt, D.P., Fundamentals of Heat and Mass Transfer, Fourth Edition, John Wiley and Son, 1996.

INL, Discussions at the High Performance Research Reactor Working Group Meeting in Pasco, WA, Idaho National Laboratory (INL), July 2014.

ISL, “RELAP5/MOD3.3 Code Manual,” NUREG/CR-5535/Rev1, Information Systems Laboratories, Inc., Rockville, MD and Idaho Falls, ID, December 2001.

Kaminaga, M., Yamamoto, K., and Sudo, Y., "Improvement of Critical Heat Flux Correlation for Research Reactors using Plate-Type Fuel,” J. Nucl. Sci. Technol. 35[12], 943-951, 1998.

Mourgues, A., Hourtane, V., Muller, T., and Caron-Charles, M., “Boiling Behavior and Critical Heat Flux on a Horizontal and Vertical Plate in Saturated Pool Boiling with and without ZnO Nanofluid,” International Journal of Heat and Mass Transfer, Vol. 57, pp. 595 - 607, 2013.

NBS, "Supplement B of the Final Safety Analysis Report on the National Bureau of Standards Reactor,” NBSR-9B, National Bureau of Standards (NBS), December 1966 and “Addendum 1, 
Final Safety Analysis Report,” National Bureau of Standards (NBS) Research Reactor Radiation Division, November 1980.

NIST, "Safety Analysis Report (SAR) for License Renewal for the National Institute of Standards and Technology Reactor - NBSR; NBSR 14, Rev 4" National Institute of Standards and Technology (NIST), Gaithersburg, MD, 2010a.

NIST, “Technical Specifications for the NIST Test Reactor (NBSR),” Appendix A to License No. TR-5, National Institute of Standards and Technology (NIST), Gaithersburg, MD, 2010b.

NIST, "NBSR Annunciator Procedures,” National Institute of Standards and Technology (NIST), 2011.

NRC, "Guidelines for Preparing and Reviewing Applications for the Licensing of Non-Power Reactors; Format and Content,” NUREG/CR-1537, Part 1, U.S. Nuclear Regulatory Commission, February, 1996a.

NRC, "Guidelines for Preparing and Reviewing Applications for the Licensing of Non-Power Reactors; Standard Review Plan and Acceptance Criteria,” NUREG/CR-1537, Part 2, U.S. Nuclear Regulatory Commission, February, 1996b.

NRC, "Safety Evaluation Report Related to the Renewal of Facility Operating License No. TR-5 for the National Bureau of Standards Test Reactor, National Institute of Standards and Technology, U.S. Nuclear Regulatory Commission (NRC), June 2009.

NRC, “TRACE V5.0 Theory Manual,” U.S. Nuclear Regulatory Commission (NRC), June 4, 2010.

ORNL, "Multidimensional, Finite-Difference Heat Conduction Analysis Code System, Versions 7.2i and 7.3,” RSICC Code Package PSR-199, Oak Ridge National Laboratory, Oak ridge, TN, August 2007.

Saha, P., and Zuber, N., "Point of Net Vapor Generation and Vapor Void Fraction in Subcooled Boiling,“ Proc. $5^{\text {th }}$ Int. Heat Transfer Conf., Vol. IV, p. 175, Tokyo, Japan, September 3-7, 1974.

Sudo, Y. and Kaminaga, M., "A new CHF Correlation Scheme Proposed for Vertical Rectangular Channels Heated from Both Sides in Nuclear Research Reactors," Journal of Heat Transfer, Vol. 115, May 1993.

Williams, R., “Gamma Ray Heating in Fuel Element L-3,” NIST Center for Neutron Research, Gaithersburg, MD, March 11, 2014 and Williams, R., "Heat Distribution in LOCA Calculations Continued,” NIST Center for Neutron Research, Gaithersburg, MD, March 21, 2014.

Wolverine Tube Inc., “Wolverine Engineering Data Book II,” Chapter 5, 2001.

Wolverine Tube Inc., “Wolverine Engineering Data Book III,” Chapter 9, 2006. 


\section{TECHNICAL SPECIFICATIONS}

The changes in the technical specifications that are required by the conversion have been introduced in Chapter 4, Reactor Description. No other changes are anticipated at this time. The existing technical specifications that impact the safety analyses in Chapter 13 are all sufficient to assure that LEU fuel can be operated safely.

\subsection{Fuel Element Design}

There is one technical specification (NIST, 2009) concerning the fuel element design (as opposed to being related to operation). It is given below with the modifications (underlined or with strikeout) necessary to accommodate the LEU fuel. Note that the expectation is that the fuel will be qualified through a Nuclear Regulatory Commission review.

Technical Specification 5.3, Reactor Core and Fuel:

4. The $20 \mathrm{MW}$ reactor core may consist of $303.0 \times 3.3$ inch $(7.6 \times 8.4 \mathrm{~cm})$ MTR curved plate-type fuel elements. The NBSR MTR-type fuel elements shall be such that the central 7 inches of the fuel element contains no fuel. The middle 6 inches of the aluminum in the unfueled region of each plate shall have been removed.

5. The side plates, unfueled outer plates, and end adaptor castings of the fuel element shall be aluminum alloy.

6. The fuel plates shall be $\Theta_{3} \Theta_{8}$-dispersed in a matrix of aluminum uranium-molybdenum alloy foils clad with aluminum alloy with a zirconium interlayer between foil and clad.

Basis:

3. The neutronic and thermal hydraulic analysis was based on the use of 30 NBSR MTRtype thirty-four (34) plate fuel elements. The NBSR fuel element has a 7 inch centrally located unfueled area, in the open lattice array. The middle 6 inches of aluminum in the unfueled region has been removed. The analysis requires that the fuel be loaded in a specific pattern. Significant changes in core loading patterns would require a recalculation of the power distribution to ensure that the CHFR would be within acceptable limits.

4. and 3. The fuel element with aluminum alloy clad dispersion fuels used in the MTR fuel elements have a 50 year record of reliability at many researeh reactors. and uraniummolybdenum alloy foils have been qualified for use in the NBSR.

\subsection{Safety Limits and Limiting Conditions for Operation}

This section contains the safety limits and limiting conditions for operation (LCOs) (NIST, 2009) that are changed as a result of conversion; specifically with respect to nuclear design parameters.

To maintain the integrity of the fuel cladding and prevent the release of significant amounts of fission products, Technical Specification (TS) 2.1, Safety Limit, defines the limit based on the 
temperature at which blistering is first considered possible, which is $450^{\circ} \mathrm{C}\left(842^{\circ} \mathrm{F}\right)$ for the $\mathrm{HEU}$ fuel. According to (INL, 2014) this will change for the LEU fuel and TS 2.1 will need to be changed. Based on the information available, a conservative blister temperature of $380^{\circ} \mathrm{C}$ $\left(716^{\circ} \mathrm{F}\right)$ is used for LEU fuel. The change of TS 2.1 is given below and more information on why this blister temperature was chosen are found in Section 13.1.

\section{Specification:}

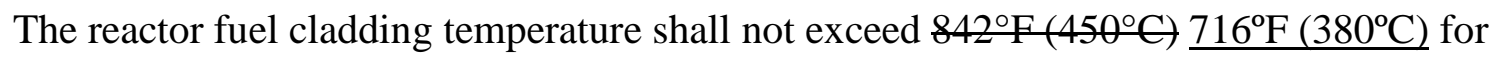
any operating conditions of power and flow.

The approach to protect against the safety limit remains as stated in the Basis for TS 2.1, namely:

Basis:

Maintaining the integrity of the fuel cladding requires that the cladding remain below its blistering temperature of $842^{\circ} \mathrm{F}\left(450^{\circ} \mathrm{C}\right) 716^{\circ} \mathrm{F}\left(380^{\circ} \mathrm{C}\right)$. For all reactor operating conditions that avoid either a departure from nucleate boiling (DNB), or exceeding the Critical Heat Flux (CHF), or the onset of flow instability (OFI), cladding temperatures remain substantially below the fuel blistering temperature. Conservative calculations have shown that limiting combinations of reactor power and reactor coolant system flow and temperature will prevent DNB and thus fuel blistering.

No substantive changes are required for either the limiting safety system settings (LSSSs) or LCOs. However, since the fuel has changed, minor modifications must be made to several LCOs.

LCO 3.1.2, Reactivity Limitations, must be modified to recognize that although the reactivity limits expressed in \% do not change, expressing them in dollars does change as the result of the change in delayed neutron fraction.

Specifications:

3. The maximum available excess reactivity for the reference core conditions shall not exceed 15\% $\Delta \rho$ (approximately $\$ 20 \underline{22}$ )

4. The reactor shall not be operated unless shutdown margin provided by the shim arm is greater than $0 . \underline{68757 \%} \% \rho(\$ 1.0)$ with:

c) The reactor in any core condition, and

d) All movable experiments in their most reactive condition.

LCO 3.1.4, Fuel Burnup, must be modified to account for the different fuel volume. At the time of the writing of this SAR no information was available on potential limits to the maximum fission density, which in turn might also impact the allowable average fission density. The following only addresses the different fuel volume. 


\section{Specification:}

The average fission density shall not exceed $\underline{4.5} 2 \times 10^{27} \underline{\text { fissions } / \mathrm{m}^{3}}$.

Basis:

Fuel elements in the NBSR are burned for seven or eight cycles. An eight cycle fuel element has an average fission density of approximately $4.11 .9 \times 10^{27}$ fissions $/ \mathrm{m}^{3}$ (Brown, 2014). Allowing for a $10 \%$ increase provides the specification. The $U_{3} \Theta_{8}-\mathrm{Al}$ dispersion MTR fuels have been in widespread use for over 40 years. Extensive testing of fuel plates has been performed to determine the limits on fission density as a function of fuel loading. Several measurements of swelling in fuel plates show that NBSR fuel, which is moderately loaded at $18 \%$ is well below the curve that represents the allowable limit of burnup.

\subsection{References}

Brown, N.R., Baek, J.S., Hanson, A.L., Cuadra, A., Cheng, L-Y. and Diamond, D.J., "Irradiation Experiment Conceptual Design Parameters for NBSR Fuel Conversion, Rev.2,” BNL-998972014-IR-R2, Brookhaven National Laboratory, Upton, NY, April 30, 2014.

INL, Discussions at the High Performance Research Reactor Working Group Meeting in Pasco, WA, Idaho National Laboratory (INL), July 2014.

NIST, "Technical Specifications for the NIST Test Reactor (NBSR)," Appendix A to License No. TR-5, National Institute of Standards and Technology (NIST), Gaithersburg, MD, 2009. 


\section{OTHER LICENSING CONSIDERATIONS}

There are no other licensing considerations. This chapter is not needed. 